UNIVERSIDADE DE SÃO PAULO

Escola de Engenharia de São Carlos

Departamento de Engenharia de Transportes

Programa de Pós-Graduação em Engenharia de Transportes

Luiz Henrique Castelo Branco

\title{
MANIAC: uma metodologia para o monitoramento automatizado das condições dos pavimentos utilizando VANTs
}



Luiz Henrique Castelo Branco

\title{
MANIAC: uma metodologia para o monitoramento automatizado das condições dos pavimentos utilizando VANTs
}

\author{
Tese de Doutorado submetida à Escola de Engenharia de \\ São Carlos, da Universidade de São Paulo, como parte \\ dos requisitos para a obtenção do título de Doutor em \\ Ciências, Programa de Pós-Graduação em Engenharia de \\ Transportes. Área de Concentração: Infraestrutura de \\ Transportes - Geomática
}

Orientador: Prof. Associado Paulo César Lima Segantine

São Carlos

2016 
AUTORIZO A REPRODUÇÃO TOTAL OU PARCIAL DESTE TRABALHO, POR QUALQUER MEIO CONVENCIONAL OU ELETRÔNICO, PARA FINS DE ESTUDO E PESQUISA, DESDE QUE CITADA A FONTE.

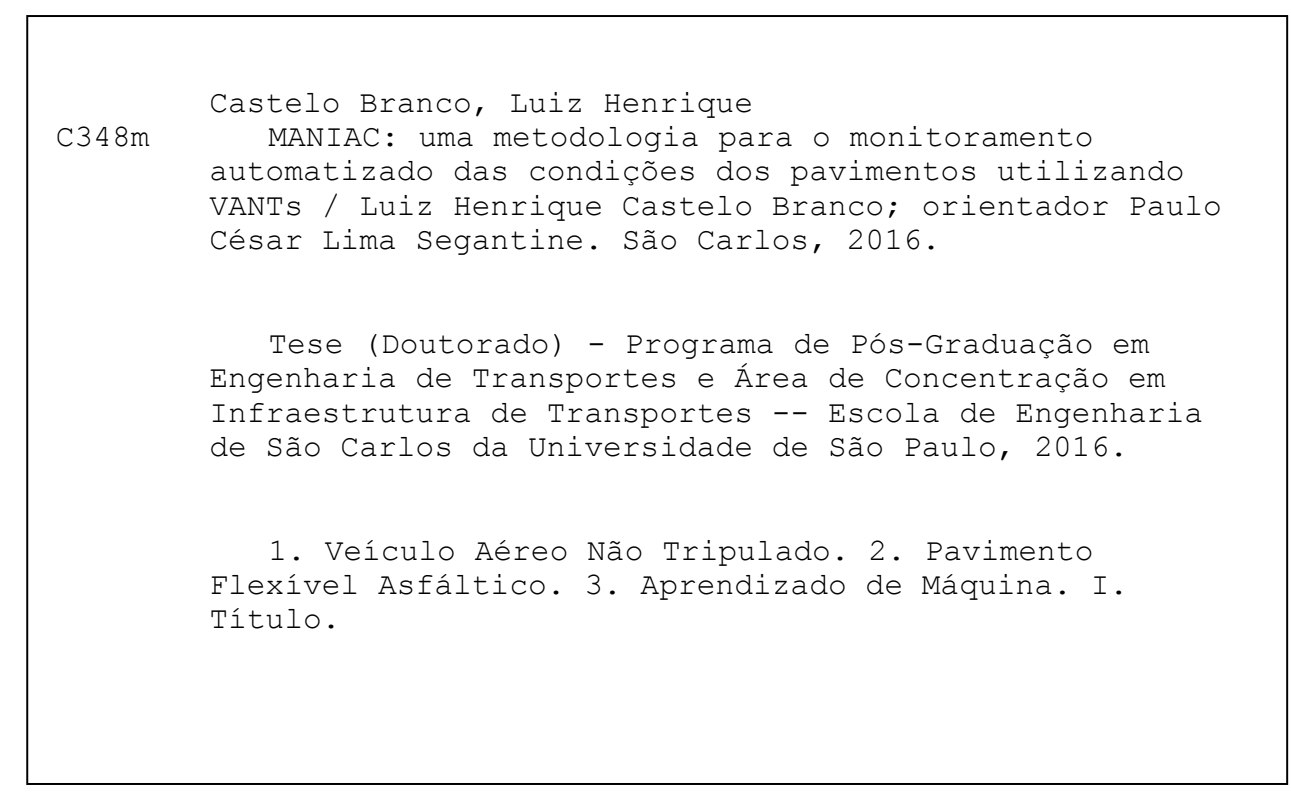




\section{FOLHA DE JULGAMENTO}

\section{Candidato: LUIZ HENRIQUE CASTELO BRANCO}

Título da tese: "MANIAC: uma metodologia para o monitoramento automatizado das condições dos pavimentos utilizando VANTs"

Data da defesa: 07.11.2016

\section{Comissão Julgadora:}

Prof. Associado Paulo Cesar Lima Segantine

(Orientador)

(Escola de Engenharia de São Carlos/EESC)

Profa. Titular Liedi Legi Bariani Bernucci

(Escola Politécnica/USP)

Prof. Dr. Fabio Tozeto Ramos

(University of Sydney/Austrália)

Profa. Dra. Célia Leiko Ogawa Kawabata (Instituto Federal de São Paulo/São Carlos)

Prof. Dr. Marcelo de Castro Takeda

(Universidade Federal de São Carlos/São Carlos)

\section{Resultado:}
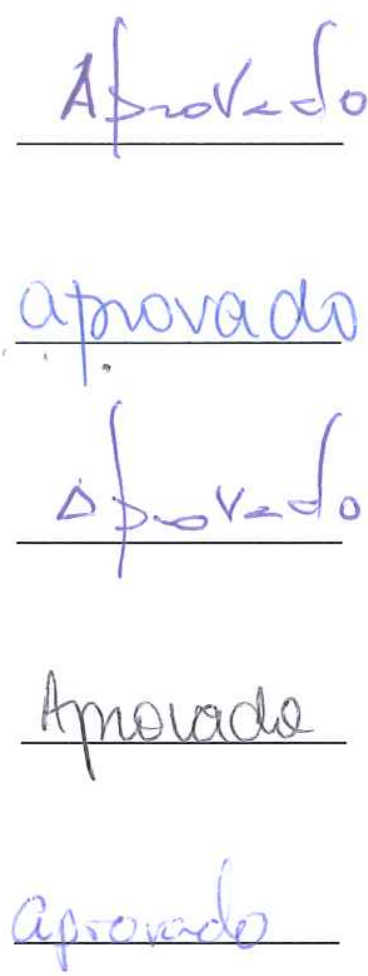

Coordenadora do Programa de Pós-Graduação em Engenharia de Transportes:

Profa. Associada Ana Paula Camargo Larocca

Presidente da Comissão de Pós-Graduação:

Prof. Associado Luís Fernando Costa Alberto 

À minha família pelo apoio incondicional, pela paciência e entendimento nos momentos em que estive ausente. Kali, Pi, Amo muito vocês. 



\section{Agradecimentos}

Agradeço a Deus em primeiro lugar.

Um agradecimento especial ao mais que professor, ao amigo Segantine pelos ensinamentos, pelo conhecimento compartilhado, pelas orientações sempre precisas e por toda a oportunidade a mim concedida, permitindo que mais essa conquista pudesse ser realizada.

A todos os professores do STT, as secretárias, técnicos, todos os funcionários, sem vocês certamente nenhum dos trabalhos seriam possíveis.

Aos colegas de laboratório (Rafael, Chico, Dinato e Marcela) meu muito obrigado pelo companheirismo e amizade.

Aos colegas do LSEC (Laboratório de Sistemas Embarcados Críticos), em especial Arthur Chaves Avelar, Rayner Pires de Melo e Adimara Colturato, que nos cederam a aeronave para que os voos pudessem ser realizados e acompanharam a realização das missões.

Ao supervisor no exterior, também um amigo, professor Dr. Fábio Ramos, obrigado por me receber em seu laboratório e compartilhar seu conhecimento. Aos amigos do ACFR (Australian Centre for Field Robotics) onde realizei meu estágio no exterior, Charika, Phillipe, Rafael e Lionel. Obrigado por compartilharem comigo desta que foi certamente uma experiência única.

Ao CNPq pelo apoio financeiro para a realização do estágio de pesquisa realizado no exterior.

Ao IFSP (Instituto Federal de São Paulo) pelo afastamento concedido das atividades de docência para a realização do doutoramento e do estágio de pesquisa no exterior. Aos colegas do IFSP por segurarem "a barra"durante o período que me ausentei para a finalização desta tese. Não mencionarei nomes porque certamente não conseguirei nominar todos, mas vocês sabem que fizeram parte desta conquista. Obrigado pessoal!!! 
À toda minha família, sem vocês certamente nada disso seria possível. Amo todos vocês do fundo do coração. Cada um sabe o quanto é importante para mim e como essa conquista dependeu do apoio incondicional de cada um de vocês direta ou indiretamente. 
"Você não pode voltar atrás e fazer um novo começo, mas pode começar agora a fazer um novo fim."

(Chico Xavier) 



\section{Resumo}

Branco, L. H. C. MANIAC: uma metodologia para o monitoramento automatizado das condições dos pavimentos utilizando VANTs. 191 p. Tese de Doutorado - Escola de Engenharia de São Carlos, Universidade de São Paulo, 2016.

Sistemas de Transportes Inteligentes (STIs) englobam um conjuntos de tecnologias (Sensoriamento Remoto, Tecnologia da Informação, Eletrônica, Sistemas de Comunicação de Dados entre outros) que visam oferecer serviços e gerenciamento de tráfego avançado para meios de transporte rodoviário, aéreo e outros. A obtenção de informações a respeito das características e das condições do pavimento das estradas constitui uma parte importante dentro do sensoriamento nesses STIs. Investigar novas técnicas, metodologias e meios de automatizar a obtenção dessas informações é parte deste trabalho. Uma vez que existem diferentes tipos de defeitos em vias pavimentadas, esta tese apresenta a proposta de uma metodologia que permite a obtenção, de forma automática, das condições dos pavimento asfálticos. A obtenção dos dados foi realizada por meio do Sensoriamento Remoto com uso de Veículos Aéreos Não Tripulados. A utilização de técnicas de Aprendizado de Máquina na detecção automática possibilitou alcançar uma acurácia de $99 \%$ na detecção de pavimentos asfálticos flexíveis e $92 \%$ na identificação de defeitos em alguns experimentos. Como resultado obteve-se o diagnóstico automático, não só das condições da via, mas de diferentes tipos de defeitos presentes em pavimentos.

Palavras-chave: Veículo Aéreo Não Tripulado. Pavimento Flexível Asfáltico. Aprendizado de Máquina. 



\section{Abstract}

Branco, L. H. C. MANIAC: a methodology for automated monitoring of the condition of pavements using UAVs. 191 p. Ph.D. Thesis - São Carlos School of Engineering, University of São Paulo, 2016.

Intelligent Transport Systems (ITS) is a set of integrated technologies (Remote Sensing, Information Technology, Electronics, Data Communication Systems among others) that aims to provide services and advanced traffic management for road, air, rail and others transportation systems. Obtaining information about characteristics and road pavement conditions is an important part within the sensing these ITS. Investigating new techniques, methods and means to optimize and automate obtaining these information are part of this work, since there are different types of defects on paved roads. Thus, this thesis proposes a methodology that allows automatically obtain information about the condition of the pavement. Data collection was performed with remote sensing technology using Unmanned Aerial Vehicles. Automatic detection was possible through the use of Machine Learning techniques with $99 \%$ of accuracy in pavements and $92 \%$ in distress identification. As a result we obtained the self-diagnosis, not just the pavement, but different types of distress present in the pavement.

Keywords: Unmanned aerial vehicles. UAVs. Flexible Pavement. Machine Learning. 



\section{Lista de ilustrações}

Figura 1.1 Desafios para a Gestão de Pavimentos. . . . . . . . . . . . . . . . . . 33

Figura 1.2 Etapas Envolvidas na Pesquisa. . . . . . . . . . . . . . . . . . 35

Figura 1.3 Mapa rodoviário do Estado de São Paulo - centro geográfico do Estado de São Paulo. . . . . . . . . . . . . . . . . . . . . . . . . . . . 37

Figura 1.4 eBee - VANT utilizado nesta pesquisa. . . . . . . . . . . . . . . . . . 38

Figura 1.5 Câmera Canon S110 utilizada para obter as imagens. . . . . . . . . . . . . . 40

Figura 2.1 Espectro eletromagnético. Adaptado de (GRIFFITHS, 1999) _ . . . . . . . . 56

Figura 2.2 Janelas atmosféricas. Adaptado de (SHORT, 2010) . . . . . . . . . . . . 57

Figura 2.3 Conceito de um SANT - Adaptado de (MICA; COSTELLO, 2008). . . . . . . . . 64

Figura $2.4 \quad$ Passos do Random Forest . . . . . . . . . . . . . . . . . . . . . . . . . 86

Figura 4.1 MANIAC - Macro visão. . . . . . . . . . . . . . . . . . . . . . . . . . . 109

Figura 4.2 Lançamento do VANT eBee para realização das missões para aquisição de imagens. . . . . . . . . . . . . . . . . . . 110

Figura 4.3 Acompanhamento da execução de uma missão na estação de base. . . . . . 111

Figura 4.4 Acompanhamento da execução de uma missão na estação de base - imageamento em progresso. . . . . . . . . . . . . . . . . . . 112

Figura 4.5 Imagem de uma área urbana com alta densidade populacional. . . . . . . . 113

Figura 4.6 Imagem de uma área urbana com baixa densidade populacional. . . . . . . . 113

Figura 4.7 Imagem de uma área urbana com alta densidade populacional. Mosaico com as fotos geradas com o VANT sobreposta a imagem do Google (mosaico georreferenciado). . . . . . . . . . . . . . . . . 114 
Figura 4.8 Imagem de uma área urbana com baixa densidade populacional. Mosaico com as fotos geradas com o VANT sobreposta a imagem do Google (mosaico georreferenciado). . . . . . . . . . . . . . . 114

Figura 4.9 Aproximações e ampliações de regiões com pavimento na região mais povoada. . . . . . . . . . . . . . . . . . . . . . . . . 115

Figura 4.10 Aproximações e ampliações de regiões com pavimento na região menos povoada.

Figura 4.11 Imagem obtida com a câmera NIR a partir do VANT eBee. . . . . . . . . 116

Figura 4.12 Detalhamento do processo Pré-Processar. . . . . . . . . . . . . 117

Figura 4.13 Pré-processamento da imagem para permitir realce das áreas de interesse. (a) Equalização do Histograma; (b) Método morfológico de Dilatação; (c) Método de Detecção de Borda. . . . . . . . . . . . . . . . . . . . . . . . . . 117

Figura 4.14 Testes de suavização. a) Imagem original. b) Filtro Gaussiano. c) Filtro Bilateral.

Figura 4.15 Testes de Histograma. a) Imagem original. b) Gaussiano. c) Bilateral. d) K-means (3 clusters) - imagem original. e) K-means Gaussiano. f) K-means Bilateral. . . . . . . . . . . . . . . . . . . . . . . . . 119

Figura 4.16 Detalhamento do processo Detectar asfalto. . . . . . . . . . . . . 120

Figura 4.17 Combinações dos pares de limiares. . . . . . . . . . . . . . . . . 121

Figura 4.18 Imagens segmentadas com combinação de pares de limiares: (a) Similaridade $=5$ e Área $=20$; (b) Similaridade $=15$ e Área $=50$; (c) Similaridade $=35$ e Área $=80 \ldots \ldots \ldots \ldots$. . . . . . . . . . . . . . . . . 122

Figura 4.19 Classificação pixel a pixel. (a) Método MAXVER - classificação supervisionada; (b) KMedias - classificação não-supervisionada. . . . . . . . . . . . 123

Figura 4.20 Classificação por região. (a) Método Bhattacharya - classificação supervisionada; (b) Isoseg - classificação não-supervisionada. . . . . . . . . . . . . 123

Figura 4.21 Fluxograma detalhado do processo Detectar asfalto. . . . . . . . . . . . . 124

Figura 4.22 Aplicação do algoritmo de superpixel na imagem aérea, a) imagem não segmentada. b) imagem segmentada com 3024 segmentos. . . . . . . . . . . . 125

Figura 4.23 Exemplo de imagem segmentada pelo algoritmo superpixel. . . . . . . . . . 125

Figura 4.24 Exemplo de listagem das features para treinamento. . . . . . . . . . . . . 126

Figura 4.25 Exemplo de imagem segmentada com o respectivo label. . . . . . . . . . . 126

Figura 4.26 Estratégia para a obtenção automática da geometria de ruas do GoogleMaps. 127

Figura 4.27 Exemplo de erro do posicionamento do label de ruas do GoogleMaps. a) imagem aérea VANT e imagem de satélite e mapa de ruas do (label GoogleMaps sobrepostas). b) imagem aérea VANT e imagem de ruas do GoogleMaps sobrepostas . . . . . . . . . . . . . . . . 128 
Figura 4.28 Exemplo segmentação de Ruas com sobreposição dos labels para treinamento. a) imagem aérea original. b) segmentação com os labels destacados. c) Label de ruas automáticamente obtido do GoogleMaps (cor verde) e label manual (cor azul) . . . . . . . . . . . . . . . . . . . 128

Figura 4.29 Exemplo do processo de conversão de sistema de coordenadas do Mosaico. 129

Figura 4.30 Mapa de ruas extraído do GoogleMaps da região mapeada pelo VANT. . . . 129

Figura 4.31 Mapa de ruas extraído do GoogleMaps. a) Formatação padrão. b) Formatação customizada para destacar a malha viária. . . . . . . . . . . . . 130

Figura 4.32 Exemplo de um conjunto de imagens particionadas do mosaico. . . . . . . 131

Figura 4.33 Resultado do processamento em uma imagem teste. a) imagem original. b) máscara de ruas do GoogleMaps para validação. c) máscara gerada automaticamente com as marcações de malha viária na cor branca. d) imagem final. . . . . . . . . . . . . . . . . .

Figura 4.34 Resultado do teste de processamento em 2 imagens novas. a) imagem original. b) imagem/máscara gerada automaticamente. c) imagem final com a aplicação da máscara de ruas na imagem original para deixar apenas a malha viária. . . . . . . . . . . . . . . . . . . 133

Figura 4.35 Processo Identificar defeitos. . . . . . . . . . . . . . . . . . 134

Figura 4.36 Detalhamento do processo Identificar defeitos. . . . . . . . . . . . . . 134

Figura 4.37 Aplicação do algorítmo superpixel na imagem. a) imagem não segmentada com o asfalto detectado. b) imagem segmentada. . . . . . . . . . . . . . . . 135

Figura 4.38 Features mais importantes para o treinamento. . . . . . . . . . . . . . 136

Figura 4.39 Resultado do processamento da classificação de defeitos no pavimento. a) imagem original b) máscara gerada automaticamente com os defeitos em branco. c) imagem com sobreposição destacando as áreas sem defeitos em azul. d) imagem final apenas com as regiões com defeitos detectadas. . . .

Figura 4.40 Exemplo de utilização da técnica de aproximação de polígono. (a) Imagem original. (b) Fator de aprox. $=0.05$. (c) Fator de aprox. $=0.01$ (contorno mais suave). (d) Fator de aprox. $=0.00001$ (muito parecido com a imagem original) 139

Figura 4.41 Exemplo da segmentação e aproximação dos polígonos da região com defeito. a) imagem segmentada. b) imagem com os polígonos dos defeitos da segmentação destacados em branco. c) imagem com os polígonos dos defeitos aproximados. . . . . . . . . . . . . . . . . . . . 139

Figura 4.42 Processamento dos tipos defeitos no pavimento. a) imagem classificada com os defeitos. b) imagem com os defeitos destacados em preto. c) imagem com os defeitos do tipo Fenda destacados em preto. d) imagem com os defeitos do tipo Remendo destacados em preto. e) defeitos do tipo Panela não foram encontrados nessa imagem. . . . . . . . . . . . . . . . . 140

Figura 4.43 Relatório de tipos de defeitos para cada imagem. . . . . . . . . . . . . . . . 141 
Figura 4.44 Relatório parcial de defeitos com os valores do IGI' e IGG' calculados a partir das imagens analisadas. . . . . . . . . . . . . . . . . . 141

Figura 4.45 Relatório parcial de defeitos com o valor do IGGE' calculado a partir das imagens analisadas. . . . . . . . . . . . . . . . . . . 14

Figura 5.1 Tela da execução da missão do Experimento 1. . . . . . . . . . . . . . . . 145

Figura 5.2 Mosaico gerado a partir da imagens obtidas pelo VANT sobreposto pela imagem de satélite do GoogleMaps - Experimento 1. . . . . . . . . . . . . . 145

Figura 5.3 Pré-processamento das imagens obtidos no Experimento 1 (E1). (a) Imagens originais; (b) Imagens pré-processadas com o filtro bilateral. . . . . . . . . 146

Figura 5.4 Particionamento do arquivo digital do mosaico do Experimento 1 (E1). . . . 147

Figura 5.5 Pavimento asfáltico detectado para o Experimento 1 (E1) . . . . . . . . . . . 147

Figura 5.6 Matriz de confusão e outras medidas de avaliação do algoritmo de AM aplicado ao Experimento 1 (E1) na detecção de pavimento. . . . . . . . . . 147

Figura 5.7 Resultados do processamento da classificação de defeitos em diferente trechos de pavimentos do E1. a) imagem original b) máscara gerada automaticamente com os defeitos em branco. c) imagem com sobreposição destacando as áreas sem defeitos em azul. d) imagem final apenas com as regiões com defeitos detectadas. . . . . . . . . . . . . . . . . . . . . . 148

Figura 5.8 Processamento dos tipos defeitos no pavimento das imagens obtidas no E1. a) imagem classificada com os defeitos. b) imagem com os defeitos destacados em preto. c) imagem com os defeitos do tipo Fenda destacados em preto. d) imagem com os defeitos do tipo Remendo destacados em preto. e) defeitos do tipo Panela não foram encontrados nessas imagens. . . . . . . . 149

Figura 5.9 Matriz de confusão e outras medidas de avaliação do algoritmo de AM aplicado ao Experimento 1 (E1) na detecção de defeito no pavimento. . . . . . 149

Figura 5.10 Listagem parcial do cálculo do IGI' e do IGG' a partir das imagens obtidas no E1. . . . . . . . . . . . . . . . . . . . . . . 150

Figura 5.11 Listagem parcial do cálculo do IGGE' a partir das imagens obtidas no E1. . 150

Figura 5.12 Tela da execução da missão do Experimento 2 (E2) . . . . . . . . . . . . . 151

Figura 5.13 Mosaico gerado a partir da imagens obtidas pelo VANT sobreposto pela imagem de satélite do GoogleMaps - Experimento 2 (E2). . . . . . . . . . . . 151

Figura 5.14 Pré-processamento das imagens obtidas para o Experimento 2 (E2). (a) Imagens originais; (b) Imagens pré-processadas fazendo uso do filtro bilateral. 152

Figura 5.15 Particionamento do arquivo digital do mosaico do Experimento 2 (E2). . . . 153

Figura 5.16 Pavimento asfáltico detectado para diferentes imagens obtidas no Experimento 2 (E2) . . . . . . . . . . . . . . . . . . . . . . . . . 154

Figura 5.17 Matriz de confusão e acurácia do Experimento 2 (E2) para a detecção de pavimento. . . . . . . . . . . . . . . . . . 154 
Figura 5.18 Resultados do processamento da classificação de defeitos em diferente trechos de pavimentos do E2. a) imagem original b) máscara gerada automaticamente com as partes com defeitos na cor branca. c) imagem com sobreposição destacando as áreas sem defeitos em azul. d) imagem final apenas com as regiões com defeitos detectadas. . . . . . . . . . . . . . . . 155

Figura 5.19 Processamento dos tipos defeitos no pavimento das imagens obtidas no E2. a) imagem classificada com os defeitos. b) imagem com os defeitos destacados em preto. c) imagem com os defeitos do tipo Fenda destacados em preto. d) imagem com os defeitos do tipo Remendo destacados em preto. e) defeitos do tipo Panela não foram encontrados nessas imagens. . . . . . . . .

Figura 5.20 Matriz de confusão e outras medidas de avaliação do algoritmo de AM aplicado ao Experimento 2 (E2) na detecção de defeito no pavimento.

Figura 5.21 Listagem parcial do cálculo do IGI' e do IGG' a partir das imagens obtidas no E2. . . . . . . . . . . . . . . . . . . . . . . 156

Figura 5.22 Listagem parcial do cálculo do IGGE' a partir das imagens obtidas no E2. 156 Figura 5.23 Mosaico gerado a partir da imagens obtidas pelo VANT - Experimento 3 (E3). 157 Figura 5.24 Pré-processamento das imagens obtidas para o Experimento 3 (E3). . . . . 158

Figura 5.25 Particionamento do arquivo digital do mosaico do Experimento 3 (E3). . . . 158

Figura 5.26 Pavimento asfáltico detectado para o Experimento 3 (E3) . . . . . . . . . . 159

Figura 5.27 Matriz de confusão e acurácia do Experimento 3 (E3) para a detecção de pavimento. . . . . . . . . . . . . . . . . . . . . 159

Figura 5.28 Resultados do processamento da classificação de defeitos em diferente trechos de pavimentos do E3. a) imagem original b) máscara gerada automaticamente com os defeitos em branco. c) imagem com sobreposição destacando as áreas sem defeitos em azul. d) imagem final apenas com as regiões com defeitos detectadas. . . . . . . . . . . . . . . . . . 160

Figura 5.29 Processamento dos tipos defeitos no pavimento das imagens obtidas no E3. a) imagem classificada com os defeitos. b) imagem com os defeitos destacados em preto. c) imagem com os defeitos do tipo Fenda destacados em preto. d) imagem com os defeitos do tipo Remendo não foram encontrados em nenhuma das imagens. e) defeitos do tipo Panela não foram encontrados em nenhuma das das imagens. . . . . . . . . . . . . . . . . . . 161

Figura 5.30 Matriz de confusão e outras medidas de avaliação do algoritmo de AM aplicado ao Experimento 3 (E3) na detecção de defeito no pavimento.

Figura 5.31 Listagem parcial do cálculo do IGI' e do IGG' a partir das imagens obtidas no E3. . . . . . . . . . . . . . . . . . . . . . . . . 161

Figura 5.32 Listagem parcial do cálculo do IGGE’ a partir das imagens obtidas no E3. 162

Figura A.1 Quantidade de artigos encontrados nas bases de dados para a primeira seleção. 190

Figura A.2 Quantidade de artigos aceitos e rejeitados durante a primeira seleção. . . . 190 
Figura A.3 Quantidade de artigos aceitos em cada base de dados após a leitura completa dos trabalhos. . . . . . . . . . . . . . . . . . . . . . . 191 


\section{Lista de tabelas}

Tabela 1.1 Especificação Técnica da Câmera Utilizada - Canon S110 . . . . . . . . . . . 39

Tabela 2.1 Classificação segundo a CAA, Reino Unido. Adaptado de (AUTHORITY, 2012). 67

Tabela 2.2 Classificação segundo o DoD, Estados Unidos. Adaptado de (DOD, 2013). . . 67

Tabela 2.3 Classificação segundo a UVS International, Europa, de VANTs pequenos e que estão em operação. Adaptado de (YEARBOOK, 2011). . . . . . . . . . . . 69

Tabela 2.4 Níveis de Serventia. Adaptado de (JR; IRICK, 1960). . . . . . . . . . . . . . . 73

Tabela 2.5 Valor do fator de ponderação dos tipos de ocorrência de defeito. Norma DNIT 006/2003 - PRO (IPR, 2003c). . . . . . . . . . . . . . . . 78

Tabela 2.6 Conceitos de Degradação do Pavimento em Função do IGG. Adaptado de (LIEDI et al., 2008). . . . . . . . . . . . . . . . . . . . . . . . 79

Tabela 2.7 Frequência de defeitos. Norma DNIT 008/2003 - PRO (IPR, 2003d). . . . . . 80

Tabela 2.8 Conceitos do ICPF. Norma DNIT 008/2003 - PRO (IPR, 2003d). . . . . . . . 80

Tabela 2.9 Pesos para cálculo do IGGE. Norma DNIT 008/2003 - PRO (IPR, 2003d). . . 81

Tabela 2.10 Índice do Estado da Superfície do pavimento. Norma DNIT 008/2003 - PRO

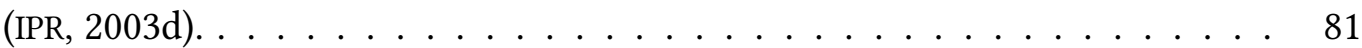

Tabela 4.1 Parametrização específica para obtenção das imagens. . . . . . . . . . . . . 111

Tabela 4.2 Exemplos de features utilizadas. . . . . . . . . . . . . . . . . . . . . 135

Tabela $4.3 \quad$ Features selecionadas para extrair da Imagem. . . . . . . . . . . . . . . 136

Tabela 4.4 Exemplo de listagem das features para treinamento. . . . . . . . . . . . . 136

Tabela 4.5 Intervalos utilizados nos parâmetros. . . . . . . . . . . . . . . 138

Tabela 4.6 Critério de classificação dos tipos de defeitos. . . . . . . . . . . . . . . . . 140 
Tabela 5.1 Projeto dos experimentos realizados. . . . . . . . . . . . . . . . 144 


\section{Lista de siglas}

ANAC Agência Nacional de Aviação Civil

AM Aprendizado de Máquina

AM/FM Automed Mapping/Falicity Managemen

CAD Computer Aided Design

DAC Departamento de Aviação Civil

FHWA Federal Highway Administration

HSV Hue, Saturation and Value

ICAO International Civil Aviation Organization

ITS Intelligent Transport Systems

NIR Near Infrared

NUV Near Ultraviolet

RBHA Regulamento Brasileiro de Homologação Aeronáutica

RGB Red, Green and Blue

SGBD Sistema Gerenciador de Banco de Dados

SIG Sistemas de Informações Geográficas 
SR Sensoriamento Remoto

STIs Sistemas de Transportes Inteligentes

SWIR Short Wave Infrared Region

VC Visão Computacional

YCrCb Component Luma, Red and Blue Difference

VANTs Veículos Aéreos Não Tripulados 


\section{Sumário}

1 Introdução $\quad 31$

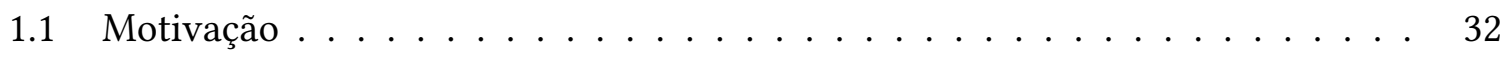

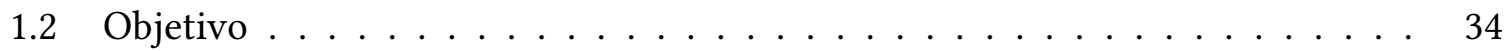

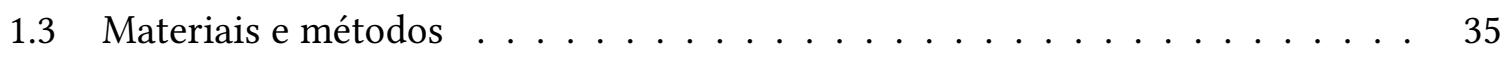

1.3.1 Área de estudo . . . . . . . . . . . . . . . . . . . 36

1.3.2 Aquisição das imagens . . . . . . . . . . . . . . . 37

1.3.3 Tipos de defeitos em superfícies asfálticas . . . . . . . . . . . . . 41

1.3.4 Ferramentas computacionais . . . . . . . . . . . . . . 41

1.4 Contribuições . . . . . . . . . . . . . . . . . . . 42

1.5 Estrutura da tese . . . . . . . . . . . . . . . . 42

2 Fundamentação teórica $\quad 45$

2.1 Considerações iniciais . . . . . . . . . . . . . . . . . . . 45

2.2 Sistemas de Informações Geográficas . . . . . . . . . . . . . . . . . . 46

$2.2 .1 \quad$ Arquitetura de SIG . . . . . . . . . . . . . . . . 48

2.2.2 Tipos de dados tratados em SIG . . . . . . . . . . . . . 48

$2.2 .3 \quad$ Mapas temáticos . . . . . . . . . . . . . . . . . . . . 49

2.3 Visão Computacional . . . . . . . . . . . . . . . . . . . . . . . 49 
2.3.1 O modelo de imagens digitais . . . . . . . . . . . . . 50

2.3.2 Operações com imagens digitais . . . . . . . . . . . . . 51

2.4 Sensoriamento Remoto . . . . . . . . . . . . . . . . . . . . . 54

2.4.1 O espectro eletromagnético . . . . . . . . . . . . 55

2.4.2 Resolução das imagens de Sensoriamento Remoto . . . . . . . . . . . 58

2.4.3 Processamento digital e análise de imagens . . . . . . . . . . 58

2.4.4 Aplicações de Sensoriamento Remoto . . . . . . . . . . . . . . . . . 60

2.4.5 Sensores e plataformas de Sensoriamento Remoto . . . . . . . . . . 61

2.5 Veículos Aéreos Não Tripulados . . . . . . . . . . . . . . . . . . 62

2.5.1 Sistemas embarcados críticos . . . . . . . . . . . . 63

2.5.2 Definições e características básicas de Veículos Aéreos Não Tripulados 64

2.5.3 Classificação dos VANTs . . . . . . . . . . . . . . . 65

2.5.4 Aplicações dos VANTs . . . . . . . . . . . . . . . . . 68

2.6 Conservação de rodovias - pavimentos asfaltados . . . . . . . . . . . . . 71

2.6.1 Conservação de rodovias . . . . . . . . . . . . . . 71

2.6.2 Tipos de pavimentos . . . . . . . . . . . . . . . 72

2.6.3 Defeitos de superfícies asfálticas . . . . . . . . . . . . 74

2.6.4 Tipos de defeitos em superfícies asfálticas . . . . . . . . . . . . 75

2.6.5 Avaliação de superfície pela determinação do $I G G$. . . . . . . . . . 77

2.6.6 Avaliação de superfície visual pela determinação do $I G G E$. . . . . . . 78

2.7 Aprendizado de Máquina $(\mathrm{AM}) \ldots \ldots \ldots \ldots \ldots$

2.7.1 Aprendizado supervisionado . . . . . . . . . . . . 83

2.7.2 Aprendizado não-supervisionado . . . . . . . . . . . . . . . 87

2.7.3 Avaliação dos métodos de Aprendizado de Máquina . . . . . . . . . . 91

2.8 Considerações finais . . . . . . . . . . . . . . . . . . . . 93

$\begin{array}{lll}3 & \text { Trabalhos Correlatos } & 95\end{array}$

3.1 Considerações iniciais . . . . . . . . . . . . . . . . . . . . 95

3.2 Estado da arte . . . . . . . . . . . . . . . . . . . . 96

3.2.1 Uso de veículos aéreos para detecção de defeitos em pavimentos asfálticos . . . . . . . . . . . . . . . . . 96 
3.2.2 Detecção de pavimentos asfálticos . . . . . . . . . . . . . . . . 99

3.2.3 Classificação automática de defeitos em pavimentos asfálticos . . . . 99

3.3 Considerações finais . . . . . . . . . . . . . . . . . . . 105

4 MANIAC 107

4.1 Considerações iniciais . . . . . . . . . . . . . . . . . . 108

4.2 MANIAC - Methodology for PAvemeNt AutomatIc CharACterization . . . . . 108

4.2 .1 Obtenção das imagens . . . . . . . . . . . . . . . . . . . . . . 109

4.2.2 Pré-Processar imagens . . . . . . . . . . . . . . . 116

4.2 .3 Detectar asfalto . . . . . . . . . . . . . . . . . . . 120

4.2 .4 Identificar defeitos . . . . . . . . . . . . . . . . . . . 133

4.2 .5 Considerações finais . . . . . . . . . . . . . . . . . . . . . . . . 142

$5 \quad$ Resultados Experimentais $\quad 143$

5.1 Considerações iniciais . . . . . . . . . . . . . . . . . . . . . 143

5.2 Experimento em área menos povoada . . . . . . . . . . . . . . . . . 144

5.2.1 A missão - obtenção das imagens . . . . . . . . . . . . . . . . . . . . . 144

$5.2 .2 \quad$ Pré-Processar . . . . . . . . . . . . . . . . . . . . . . 146

5.2 .3 Detectar asfalto . . . . . . . . . . . . . . . . 146

5.2 .4 Identificar defeitos . . . . . . . . . . . . . . . . . . 148

5.3 Experimento em área povoada . . . . . . . . . . . . . . . . . 150

5.3.1 A missão - obtenção das imagens . . . . . . . . . . . . . . . . 150

5.3.2 Pré-Processar . . . . . . . . . . . . . . . . . . . . . 152

5.3 .3 Detectar asfalto . . . . . . . . . . . . . . . . 152

5.3 .4 Identificar defeitos . . . . . . . . . . . . . . . . . . . 153

5.4 Experimento em rodovia . . . . . . . . . . . . . . . . 156

5.4.1 A missão - obtenção das imagens . . . . . . . . . . . . . . . . . . 156

5.4 Pré-Processar . . . . . . . . . . . . . . . . . . . 157

5.4 .3 Detectar asfalto . . . . . . . . . . . . . . 158

5.4 .4 Identificar defeitos . . . . . . . . . . . . . . . 160

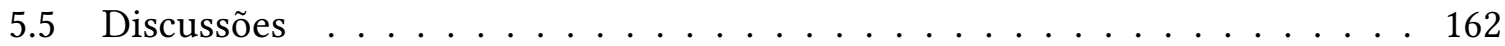

5.6 Considerações finais . . . . . . . . . . . . . . . . . . . . . . 164 
6.1 Principais resultados e contribuições . . . . . . . . . . . . . . . . 167

6.2 Limitações da abordagem . . . . . . . . . . . . . . . . . . . . 168

6.3 Dificuldades encontradas . . . . . . . . . . . . . . . . 168

6.4 Trabalhos futuros . . . . . . . . . . . . . . . . . . . . . . . 169

$\begin{array}{ll}\text { Referências } & 171\end{array}$

Anexos

$\begin{array}{lll}\text { ANEXO A Revisão Sistemática } & 183\end{array}$

A.1 Planejamento . . . . . . . . . . . . . . . . . . 183

A.1.1 Objetivos . . . . . . . . . . . . . . . . . 184

A.1.2 Questões . . . . . . . . . . . . . . . . . . . . 184

A.1.3 Seleção das fontes . . . . . . . . . . . . . . . . . . . . 185

A.1.4 Seleção dos estudos . . . . . . . . . . . . . . . . . . . 186

A.2 Execução . . . . . . . . . . . . . . . . . . . 187

A.2.1 Construção da string de busca . . . . . . . . . . . . . . . . . 187

A.3 Seleção de estudos . . . . . . . . . . . . . . . . . . . . . . . . . . . 189 
!TEX encoding = ISO-8859-1 


\section{Capítulo}

\section{Introdução}

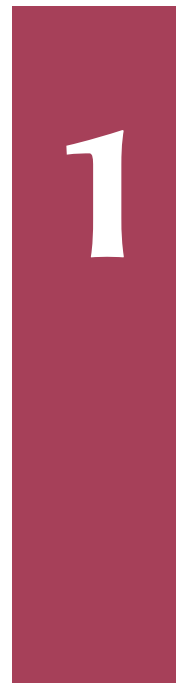

Devido ao uso constante, manutenção de estradas é uma tarefa essencial para garantir o desempenho efetivo do pavimento ${ }^{1}$. Examinar as condições da superfície do pavimento é um papel importante na análise de avaliação da qualidade estrutural e funcional do mesmo, influenciando a adoção de políticas adequadas de gestão de manutenção, reabilitação, entre outras. Periodicamente, os dados sobre danos ou defeitos em superfícies asfálticas são coletados e esse processo é realizado normalmente por um operador humano durante as sessões de inspeção visual, para identificar a extensão e gravidade dos diferentes tipos de defeitos do pavimento.

Segundo estatísticas publicadas pelo Federal Highway Administration (FHWA), a manutenção e reabilitação de pavimentos rodoviários nos Estados Unidos requer mais de US\$ 17 bilhões por ano. Análise de defeitos em pavimentos fazendo uso de abordagens convencionais, visual e manual, em que os inspetores atravessam as estradas para medir o desgaste e defeitos, são muito caras, demoradas, perigosas, e de trabalho intensivo e tedioso, além de muitas vezes resultarem em análises subjetivas, podendo ainda apresentar alto grau de variabilidade, e não permitindo assim obter informações significativamente quantitativas Cheng e Miyojim (1998). Isto leva, muitas vezes, à inconsistências na caracterização dos tipos de defeitos, na sua localização e em todo o processo de obtenção das informações, mesmo que vários países tenham produzido catálogos ilustrando situações padrões de defeitos de pavimento, a fim de ajudar o operador humano a produzir definições mais corretas sobre as classes de defeitos observadas em cada caso, e introduzir terminologias padronizadas para tal tarefa Campoverde e Cobos (2002), SIFFERT et al. (1998), Miller e Bellinger (2014) são alguns exemplos desse tipo de catálogo.

\footnotetext{
${ }^{1}$ Nesta tese de doutorado o pavimento que se investiga é o pavimento asfáltico flexível, que será tratado a partir de agora simplesmente como pavimento
} 
Informações sobre certas áreas da superfície terrestre podem ser obtidas diretamente em campo ou indiretamente por meio de produtos do Sensoriamento Remoto (SR). Por meio desta geotecnologia podem-se obter informações novas, assemelhando-se ao levantamento diretamente em campo, por outro lado tem-se a possibilidade de se obter amostras de áreas mais rapidamente.

A distância do sensor que fará o sensoriamento em relação à superfície da Terra é variável e pode ser classificada em 3 níveis de altitude: orbital (a bordo de satélites artificiais ou balões meteorológicos), semi-orbital (a bordo de aeronaves ou radares) e o terrestre (implantados em estruturas terrestres) (FLORENZANO, 2002).

Ozz Sensoriamento Remoto, independente do nível de altitude utilizado, tem sido uma ferramenta bastante útil na obtenção de informações para diferentes tipos de aplicações e áreas, como por exemplo, para obtenção de informações sobre avalanches McCormack e Stimberis (2010), sobre problemas em estradas Ishikawa e Silva (2007), entre outras.

Nesta tese, o Sensoriamento Remoto empregado é o do tipo semi-orbital, focado principalmente no uso de Aeronaves não tripuladas (VANTs - Veículos Aéreos Não Tripulados) ou UAV (Unmanned Aerial Vehicle) Aldridge e Stenbit (2002) que permitiu a obtenção de imagens para possibilitar a elaboração de análises a respeito do pavimento asfáltico, permitindo a identificação de defeitos de forma automatizada a partir de uma plataforma de monitoramento aérea de baixo custo.

$\mathrm{Z}$

\subsection{Motivação}

Ao longo das últimas décadas, as agências de transporte têm presenciado grandes mudanças na forma como os negócios são conduzidos. Por exemplo, desde a construção do sistema de rodovias interestaduais, tem havido uma maior ênfase no monitoramento do desempenho e da utilização de dados de gerenciamento de pavimentos para ajudar no planejamento e programação para atividades de manutenção e melhorias. Além disso, os métodos utilizados para avaliar a condição do pavimento evoluíram em conjunto com outros avanços tecnológicos de modo que os procedimentos automatizados são mais amplamente utilizados do que no passado.

Os avanços na capacidade e disponibilidade da computação permitem uma infinidade de novas ferramentas para a concepção, análise e gestão de pavimentos, e além dessas mudanças tecnológicas, as agências de transporte têm feito ajustes na forma como as decisões são tomadas.

A disponibilidade de dados de qualidade tem apresentado impacto sobre a capacidade de uma agência em comparar diferentes opções de investimentos e tomar decisões de negócios, de modo que seja possível considerar tanto os fatores econômicos quanto os operacionais (ou de engenharia). Como resultado, muitas agências de transporte estão mudando suas prioridades 
de foco, que era na ampliação do sistema, para um foco crescente na preservação do sistema. De fato, um número de agências reconheceram a relação custo-benefício associado à utilização de tratamentos de manutenção preventiva para diminuir a taxa de deterioração e para evitar a necessidade de estratégias de recuperação mais dispendiosas.

A FHWA patrocinou o desenvolvimento de um Roadmap de gerência de pavimentos para ajudar a identificar os passos necessários para atacar os desafios e as lacunas existentes na gerência de pavimentos e estabelecer iniciativas e prioridades de pesquisa e desenvolvimento (ZIMMERMAN; PIERCE; KRSTULOVICH, 2010).

Com base na análise desse Roadmap foi possível identificar uma lista de desafios relacionados à manutenção de pavimentos que ainda não foram solucionados (Figura 1.1). Segundo o Roadmap existem desafios elencados cuja intensão é a solução dos mesmos a curto prazo, enquanto outros a longo prazo.

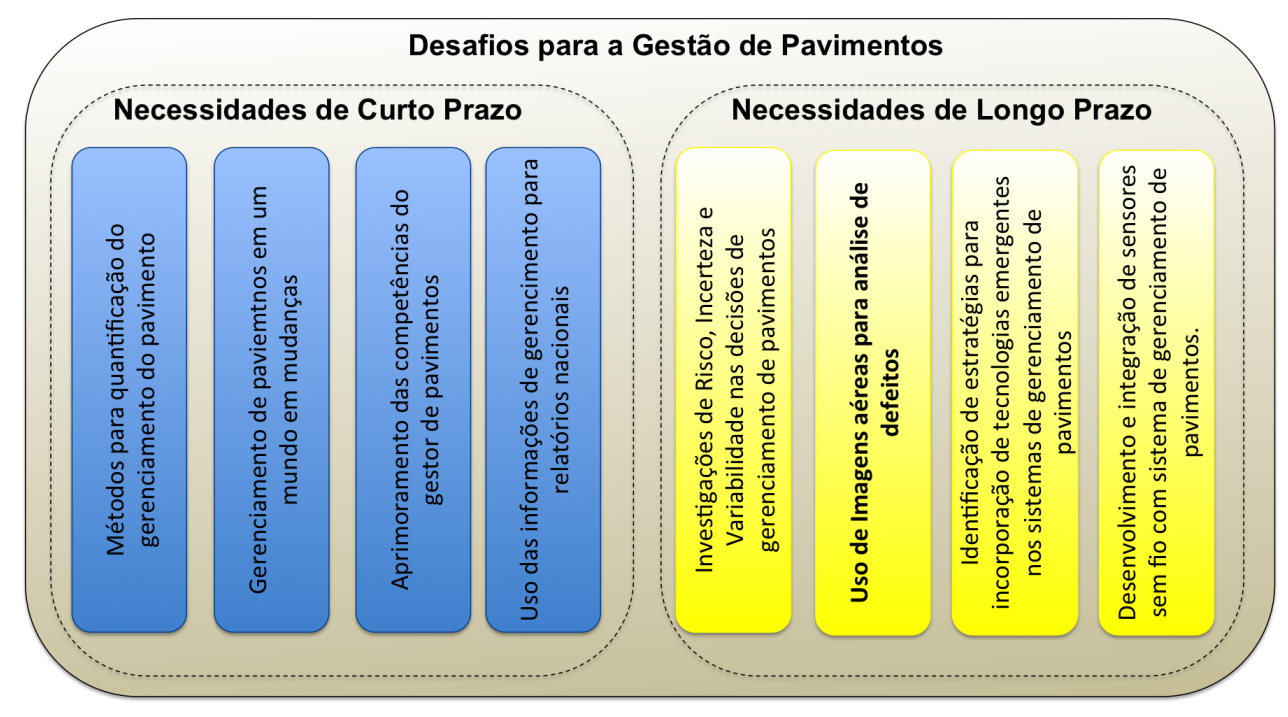

Figura 1.1 - Desafios para a Gestão de Pavimentos.

Esse Roadmap tem sido utilizado como orientação para a comunidade, não somente órgãos públicos, mas também a comunidade científica em geral, como um meio de orientação para novas oportunidade de pesquisa, desenvolvimento e transferência de tecnologia, visando assim melhorar e auxiliar as práticas atuais por meio da identificação de lacunas e necessidades existentes na gestão de pavimentos.

Pode-se inferir a partir do explanado que a preservação e o monitoramento de rodovias é algo de grande importância principalmente quando se fala em um país de grande extensão geográfica como o Brasil. Estradas estão, cada vez mais, apresentando situações emergenciais de manutenção, principalmente, em regiões de difícil acesso e em locais distantes. Sendo assim, um dos focos de pesquisa dessa tese é o Uso de imagens aéreas para análise de defeitos nos pavimentos asfálticos, destacado na Figura 1.1.

Do ponto de vista do usuário, o estado da superfície do pavimento é o mais importante, 
pois os defeitos ou irregularidades nessa superfície são percebidos uma vez que afetam tanto a segurança e o conforto do usuário, quanto eleva seus custos operacionais relacionados às peças de manutenção dos veículos, ao consumo de combustível, de pneus e entre outros. Além disso, as condições precárias de uma rodovia podem implicar em acidentes, colocando em risco a vida de seres humanos.

A utilização de técnicas tradicionais de trabalho em campo, ou até mesmo de veículos terrestres para a detecção da qualidade das rodovias é algo que demanda muito tempo e alto custo. Desse modo, o uso de tecnologias modernas que permitam monitorar as condições dessas rodovias e atuar/auxiliar de forma mais eficiente na recuperação dessas rodovias constitui tarefa importante.

A área de transporte tem apresentado um crescente interesse pela tecnologia de VANTs. O workshop de 2003 do Departamento de Transportes (DoT - Departament of Transportation) dos Estados Unidos, foi reconhecido o potencial desta tecnologia para transporte, mas também foram destacadas uma série de barreiras, incluindo a necessidade de certificação da FAA (Federation Avition Administration) Brecher, Noronha e Herold (2003). Um levantamento apresentado em 2005 nas referências para vigilância de tráfego, listou um conjunto de aplicações reais e potenciais para esta tecnologia Puri (2005). Por exemplo, uma série de voos (missões) realizados na Ohio State University testou com sucesso VANTs para monitoramento de Infraestrutura de Transporte e Operações McCormack e Stimberis (2010), Weiser (2003). O Departamento de Transporte da Flórida financiou um projeto de pesquisa para investigar o uso de VANTs para o tráfego e gestão de emergência e realizou vários voos bem sucedidos Farradine (2005). No Brasil a ANAC (Agência Nacional de Aviação Civil) tem apresentado restrições relativas ao uso de VANTs no espaço aéreo brasileiro, entretanto, normas para uso desses veículos tem sido consideradas e devem ser regulamentas em curto prazo de tempo. Independente dessa aprovação, o uso de veículos experimentais para comprovação da efetividade do uso dessa tecnologia em diversas áreas do conhecimento estão constantemente sendo realizados.

\subsection{Objetivo}

A eficiência dos VANTs, aliada aos desafios e lacunas apresentadas no Roadmap é possível tecer a hipótese:

É possível a detecção eficiente de defeitos em pavimentos flexíveis asfálticos a partir do uso de imagens aéreas obtidos por meio de Veículos Aéreos Não Tripulados de pequeno porte? Esse processo auxilia a análise de detecção de defeitos? É possível a obtenção dessas informações de modo automático?

Partindo-se da realidade que se vivencia nos dias de hoje, o objetivo deste trabalho é especificar e desenvolver uma metodologia eficaz e de baixo custo para auxiliar a gestão do monitoramento de pavimentos por meio de um processo automático de detecção de defeitos 
fazendo uso de Veículos Aéreos Não Tripulados.

Considera-se que o uso de VANTs pode diminuir os custos operacionais, auxiliar e agilizar o processo de monitoramento e ser utilizado inclusive em situações em que uma inspeção tradicional não seja possível, por exemplo por dificuldades de acesso ou situações de risco de morte da equipe técnica.

Tudo isso parece um tanto simples, mas é, na verdade, muito complexo quando considerada a especificação e implementação propriamente ditas. O aspecto mais difícil a ser contemplado é a integração das técnicas e das especificidades dos algoritmos de processamento de imagens (mais especificamente com o uso de abordagem de extração de características utilizadas em Aprendizado de Máquina) de modo que as as eventuais necessidades de manutenção/reabilitação no pavimento possam ser detectadas ou classificadas automaticamente pelo processamento das informações obtidas das imagens aéreas.

\subsection{Materiais e métodos}

Para verificar a real possibilidade de aplicações utilizando VANTs para obtenção de imagens que possam ser utilizadas como parâmetros de entrada para a classificação e determinação automática dos principais defeitos dos pavimentos, foram realizados voos em áreas com diferentes tipos de defeitos. Além disso, foram utilizados Sistema de Informações Geográfica e algoritmos de Aprendizado de Máquina para auxiliar no processo automático de detecção de defeitos. Dessa forma, as etapas envolvidas na pesquisa são ilustradas na Figura 1.2.

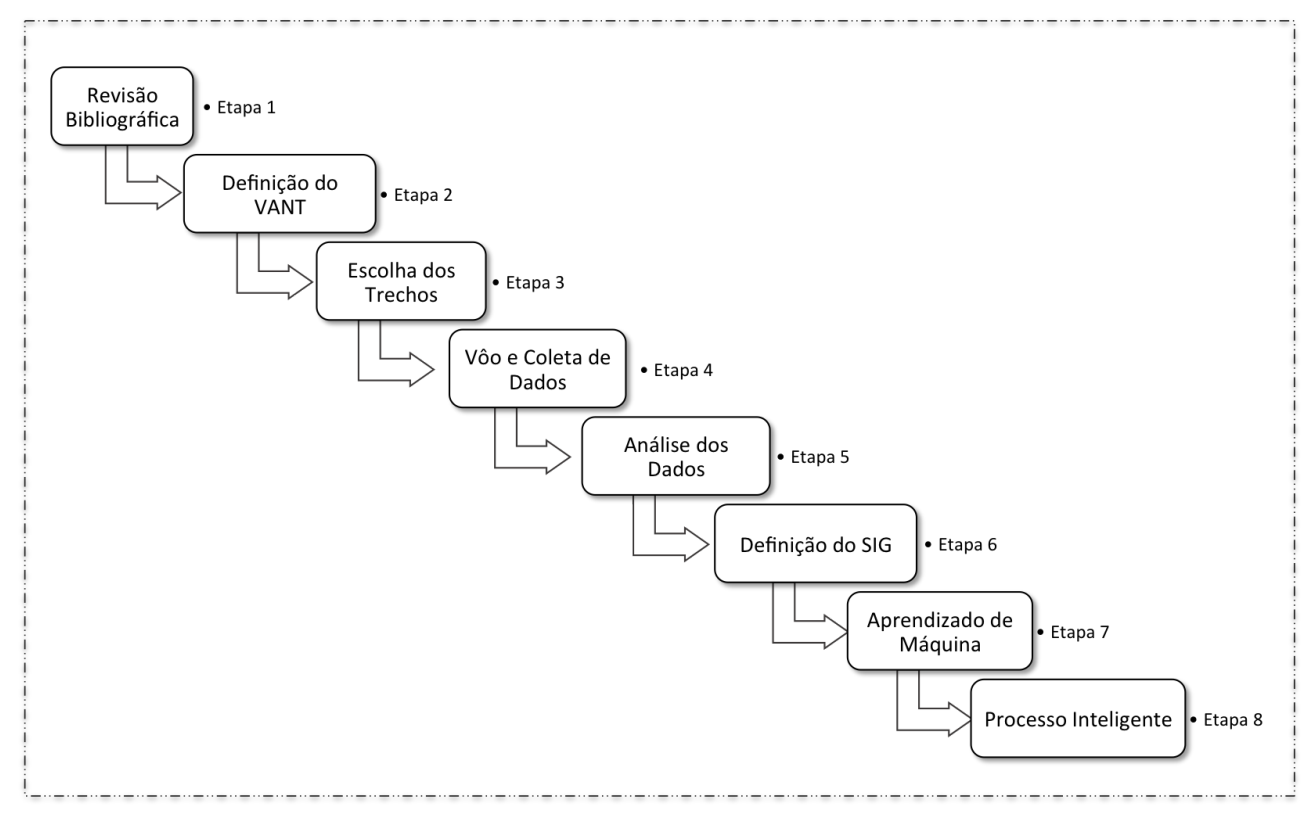

Figura 1.2 - Etapas Envolvidas na Pesquisa.

Na Etapa 1, buscou-se o conhecimento necessário para iniciar a pesquisa, ou seja, identificar, avaliar e interpretar o estado da arte nas questões relacionadas a métodos e metodologias que 
envolvam a utilização de VANTs para a auxiliar na tarefa de levantamento das informações sobre os defeitos no pavimento. O que se pretende é averiguar se há uma forma automática e inteligente de se obter os defeitos existentes em um pavimento.

A Etapa 2 constitui a escolha e determinação do tipo mais apropriado de VANT a ser utilizado para esse tipo de avaliação. Estudos de diferentes tipos de Veículos Aéreos Não Tripulados foram avaliados, tanto de asa fixa quanto de asa rotativa, optando-se pelo de asa fixa em detrimento ao de asa rotativa em função das características que vêm ao encontro das necessidades da missão de levantamento das condições de conservação das rodovias. Para a realização deste trabalho o veículo de asa fixa permite uma maior autonomia de voo para a realização das missões.

A Etapa 3 consistiu na determinação das áreas e dos trechos pavimentados que foram monitoradas para a realização das missões de voos. Para a validação das próximas etapas, foram selecionadas áreas (amostras) com essas principais características: utilização do pavimento em diferentes cenários e maior quantidade e heterogeneidade de defeitos possíveis na camada de rolamento. A Etapa 4 contemplou a realização de diversos voos em diferentes altitudes e velocidades a fim de determinar os parâmetros necessários da missão para a obtenção de informações relevantes que pudessem ser tratadas neste trabalho.

Na Etapa 5 buscou-se realizar uma análise dos dados obtidos a fim de se obter informações que pudessem ser utilizadas na Etapa 6. Essa etapa teve por objetivo a definição e escolha de um Sistema de Informações Geográfica de modo que se possa produzir o mosaico das imagens com o seu devido georreferenciamento.

Na Etapa 7 serão especificados os modelos de Aprendizado de Máquina utilizados para a obtenção e extração das características específicas sobre os defeitos em pavimentos. Por fim, na Etapa 8 foram especificados os algoritmos inteligentes que proverão respostas automáticas que possibilitem a detecção dos defeitos do pavimentos analisados.

\subsection{1 Área de estudo}

Diversas são as rodovias que apresentam problemas e defeitos no pavimento no contexto do território brasileiro. Frente a essa realidade, diversas são as áreas que podem ser sobrevoadas a fim de se obter informações que permitam que sejam averiguados os métodos propostos. Para tanto foi definido como área de estudo o município de São Carlos que está situado no centro geográfico do Estado de São Paulo.

De acordo com o IBGE (Instituto Brasileiro de Geografia e Estatística), segundo os dados divulgados em julho de 2012, o Brasil tem 193.946.886 milhões de habitantes, sendo que desses, o Estado de São Paulo é o mais populoso com 41.901.219 milhões de habitantes, destes, 11.376.685 milhões estão concentrados na cidade de São Paulo. O município de São Carlos conta com 226.322 mil habitantes, passando por esse município importantes rodovias em di- 
versas e diferentes condições de pavimentação que irão auxiliar a aplicação das técnicas e métodos propostos neste trabalho. Na Figura 1.3 é ilustrada a localização da cidade de São Carlos.

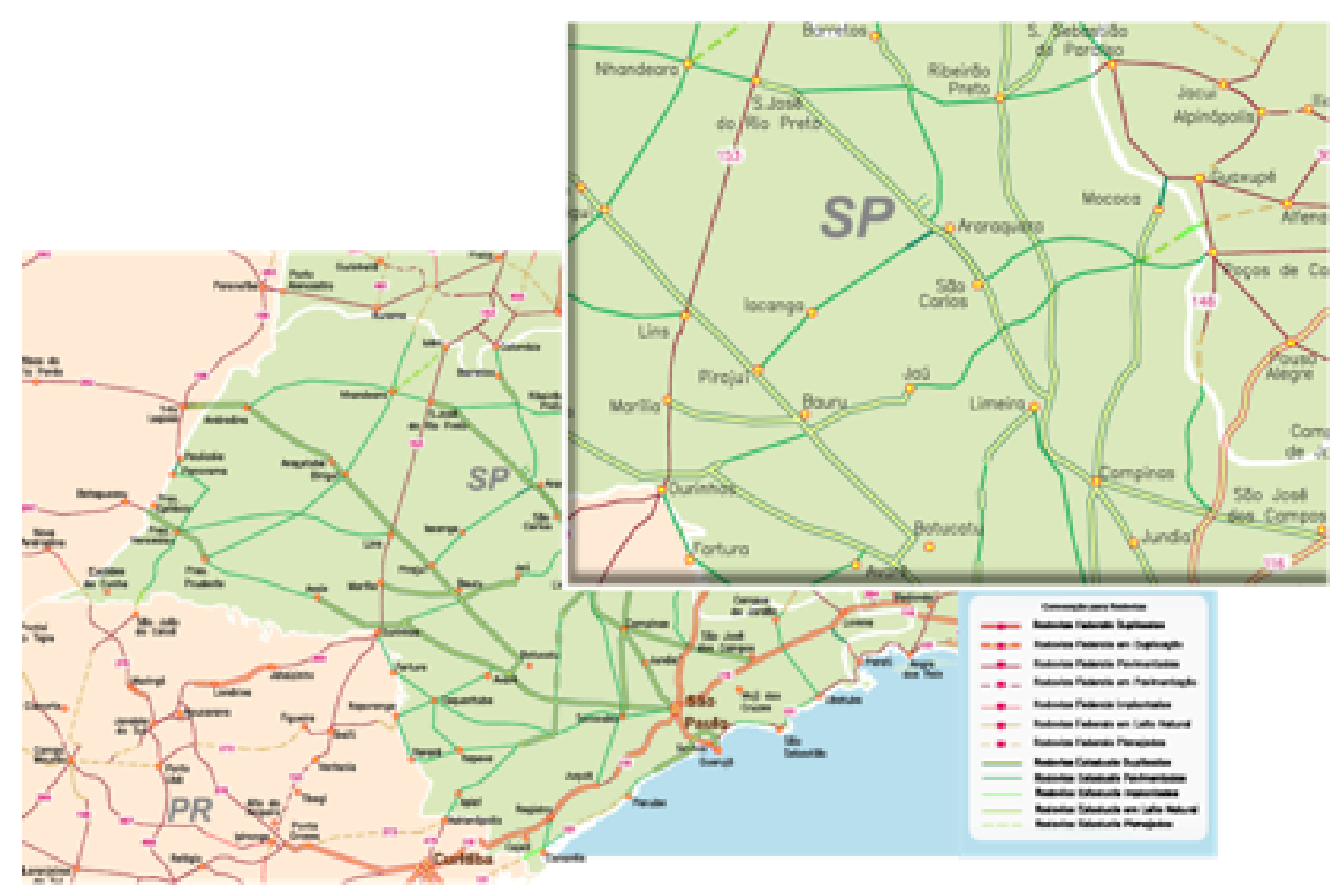

Figura 1.3 - Mapa rodoviário do Estado de São Paulo - centro geográfico do Estado de São Paulo.

\subsubsection{Aquisição das imagens}

Mesmo que se possa adquirir imagens com boa resolução espacial e grande riqueza de detalhes, os olhos humanos ainda não são capazes de ver boa parte daquilo que a tecnologia é capaz de capturar. Desse modo, existe um campo da ciência que estuda o espectro de frequência permitindo que a aplicação da tecnologia possibilite que se veja o que os olhos não veem.

Os espectros são a gama de cores que o olho humano pode e não pode ver e são medidos em nanômetros. Os olhos humanos só são capazes de ver o vermelho, verde e azul seguido de muitas cores que podem ser obtidas a partir da mistura desses três componentes. O espectro é dividido em quatro categorias principais chamadas wavebands, que são classificados em diversos tipos, tais como ondas: near, mid e short. O espectro consiste do ultravioleta Near Ultraviolet (NUV) entre 300-400nm , o visível entre 400-750nm , o infravermelho próximo - Near Infrared (NIR) entre 750-1100nm e ondas curtas Infrared - Short Wave Infrared Region (SWIR) com bandas de frequências entre 1100-3000 (RICHARDS, 2001).

O espectro não-visível consiste dos espectros infravermelho próximo, ultravioleta e o SWIR. Os produtos químicos existentes em nossos olhos contraem a visão de cores, permitindo que o ser humano possa ver apenas espectro denominado visível. Os fótons em NIR, por exemplo não são capazes de estimular os olhos humanos devido a uma falta de energia. As lentes nos olhos 
bloqueiam a luz ultravioleta, sendo assim, o ser humano também não é capaz de ver essa cor. $\mathrm{O}$ vidro e o filme fotográfico, feito especificamente para as câmeras, estão nas faixas de ondas NIR e p NUV e possem propriedades ópticas que são semelhantes o suficiente para a banda visível. Então, usando filtros especiais é possível gerar imagens nos espectros não-visíveis ao olho humano.

Raios X e raios gama ficam no lado oposto do espectro e têm esses comprimentos de onda curta fazendo com que eles interajam de forma muito diferente em comparação com as ondas mais longas. Com a sua capacidade de atravessar matéria sólida são frequentemente utilizados em estudos de várias ciências como na Arqueologia e Sensoriamento Remoto. Eles são considerados perigosos devido à sua capacidade de iniciar mudanças químicas permanentes no corpo humano, mas a probabilidade disso ocorrer é baixa.

A visão humana apresenta cortes de cerca de $400 \mathrm{~nm}$ na escala de espectro, sendo assim, para que se possa visualizar o que não é possível com a visão humana, tem-se as câmeras e sensores apropriados. Todas as câmeras têm a capacidade de tirar fotos em UV, enquanto que o infravermelho tem de ser obtido a partir do uso de filtros especiais (RICHARDS, 2001).

O processo de aquisição de imagens digitais é a primeira etapa do processo fotogramétrico uma vez que, nas plataformas aéreas, as câmeras digitais são eletronicamente conectadas ao computador e sincronizadas com a estação de controle em solo.

A aquisição das imagens aéreas dessa pesquisa foram obtidas utilizando-se o VANT eBee ${ }^{2}$ (Figura 1.4). O eBee é um VANT elétrico, de pequeno porte, tendo como principais características técnicas:

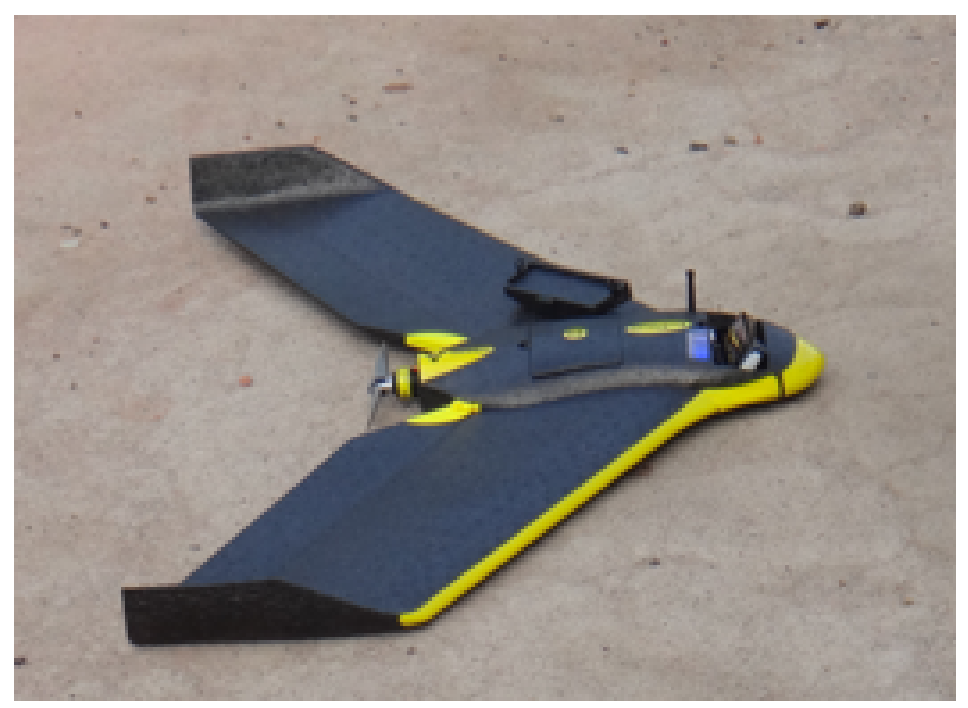

Figura 1.4 - eBee - VANT utilizado nesta pesquisa.

- $96 \mathrm{~cm}$ de envergadura;

\footnotetext{
${ }^{2}$ https://www.sensefly.com/drones/ebee.html
} 
- Raio de alcance de 3 a 5 km;

- Câmera Red, Green and Blue (RGB) ou NIR de 16 MP, eletronicamente integrada e controlada automaticamente;

- Resolução espacial de 3 a 30 centímetros por pixel;

- Autonomia de 45 minutos de voo;

- Bateria de Lithium Polímero;

- Velocidade de cruzeiro de $36-57 \mathrm{~km} / \mathrm{h}(10-16 \mathrm{~m} / \mathrm{s})$;

- Resistência a ventos de até $45 \mathrm{~km} / \mathrm{h}(12 \mathrm{~m} / \mathrm{s})$;

- $630 \mathrm{~g}(1,5 \mathrm{lbs})$ quando pronto para decolagem;

- Sensor de altura e reverso para pousos lineares;

- Software de controle.

Uma característica importante desse equipamento é que ele é lançado a mão e faz o pouso automaticamente, sem auxílio de um piloto em solo.

O piloto automático permite conduzir o VANT sobre uma determinada trajetória pré-definida, permitindo desta forma capturar as imagens, e ainda assim gerenciar a câmera fotográfica embarcada remotamente. O VANT foi equipado com uma câmera digital CANON S110 e as especificações técnicas dessa câmera são apresentadas da Tabela 1.1.

Tabela 1.1 - Especificação Técnica da Câmera Utilizada - Canon S110.

\begin{tabular}{|l|l|}
\hline \multicolumn{2}{|c|}{ Características Técnicas - Canon S110 } \\
\hline Resolução & $16 \mathrm{MP}$ \\
\hline Lente focal equivalente a 35mm & $24 \mathrm{~mm}$ \\
\hline Altitude de voo (4cm/px GSD) & $115 \mathrm{~m}$ \\
\hline Sensor de tamanho & $7,44 \times 5,58 \mathrm{~mm}$ \\
\hline Formato da imagem & JPEG e RAW \\
\hline Configuração & Totalmente Configurável \\
\hline Tempo de voo & 40 minutos \\
\hline Modelos disponíveis & RGB e NIR \\
\hline Aplicações & $\begin{array}{l}\text { Todas as aplicações, até as com baixa } \\
\text { luminosidade ou com ventos. }\end{array}$ \\
\hline
\end{tabular}

A câmera fotográfica corresponde a um dos principais dispositivos no campo da fotogrametria. As câmeras podem ser divididas em métricas e não métricas do ponto de vista da geometria. As câmeras métricas são compostas por lentes métricas de alta qualidade e são utilizadas para fins de mapeamento, já as não métricas têm sido usadas mais frequentemente em projetos fotogramétricos. As câmeras não métricas proporcionam algumas vantagens tais 
como: baixo preço quando comparadas com as métricas, tamanho pequeno, leve e de fácil manuseio. Neste trabalho, a aquisição das imagens no VANT eBee foi feita por uma câmera a ele integrada, sendo esta de pequeno formato conforme ilustrado na Figura 1.5, automática, denominada Canon S110, não métrica, com auto-focagem e ajuste de abertura de velocidade, que é desligado durante a decolagem e o pouso para proteção da câmera.

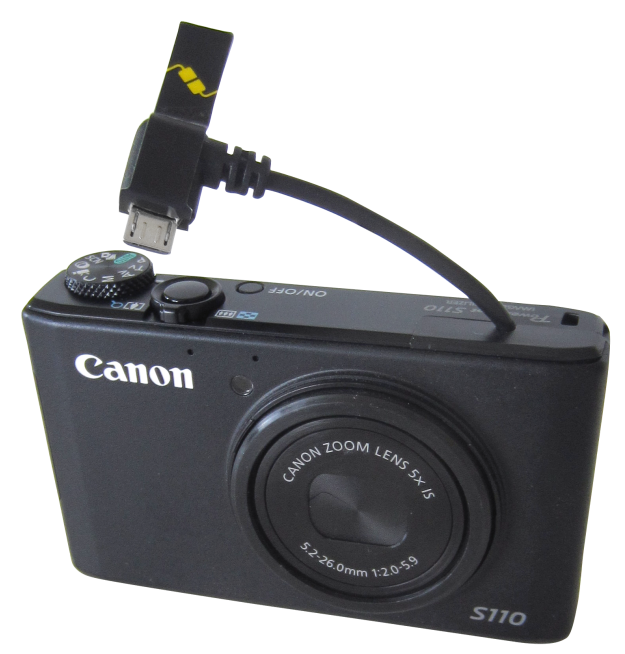

Figura 1.5 - Câmera Canon S110 utilizada para obter as imagens.

O processo de aquisição das imagens engloba um conjunto de ações pré-programadas de maneira à diminuir o risco das imagens saírem desfocadas devido a vibração e turbulência ou ainda fatores relacionados com o clima. Em relação a missão foram definidos alguns parâmetros iniciais para aquisição das imagens, tais como:

- Distância focal 6mm;

- Sobreposição vertical 60\%;

- Sobreposição horizontal 70\%;

- Tipo de área: Polygonal;

- Tipo de missão: Mosaico;

- Resolução espacial: $4 \mathrm{~cm}$ por pixel;

- Altitude de Voo: 130m;

- Velocidade: $10 \mathrm{~m} / \mathrm{s}$;

- Tempo de aquisição: 7,5s.

- Dimensões de cobertura de cada imagem: 184,3 x 135,9 m. 
Nesta pesquisa, foram feitas várias missões com o VANT na tentativa de obter os melhores parâmetros para a realização de missões de levantamento de informações sobre defeitos no pavimento. Sendo assim, os melhores parâmetros de vôo para esse tipo de missão foram apresentados anteriormente. Esses parâmetros serão constantemente revisados, avaliados e validados durante todas as etapas do trabalho visando determinar o intervalo de valores mais confiáveis para que seja possível detectar os defeitos nos pavimentos a partir das imagens obtidas pelo VANT da maneira cada vez mais precisa, otimizada e principalmente, com um melhor desempenho computacional em toda a execução do processo.

\subsubsection{Tipos de defeitos em superfícies asfálticas}

A norma DNIT 005/2003 - TER IPR (2003b): Defeitos nos pavimentos flexíveis e semirrígidos: terminologia, é utilizada para classificar os defeitos as superfícies. Os defeitos catalogados segundo a norma brasileira e considerados para cálculo de indicador de qualidade da superfície do pavimento (índice de Gravidade Global - IGG) constituem: fendas (F); afundamentos (A); corrugação e ondulações transversais (O); exsudação (EX); desgaste ou desagregação (D); panela ou buraco $(\mathrm{P})$; e remendos $(\mathrm{R})$. Esses defeitos são detalhados na Seção 2.6.4

A maioria desses defeitos pode ser observada de forma fácil em imagens obtidas com câmeras convencionais a uma pequena distância. Entretanto, constitui um desafio diagnosticar esses defeitos fazendo uso de ferramentas como os Veículos Aéreos Não Tripulados e do Sensoriamento Remoto para obtenção dessas informações.

Os principais defeitos com potencial de serem detectados nas imagens disponíveis para a pesquisa serão os remendos, as panelas e as fendas.

Os trechos escolhidos para a inspeção realizados na fase de definição da área de estudo levaram em conta os diferentes tipos de defeitos de pavimentos existentes, buscando assim, apresentar uma metodologia mais robusta na detecção dos defeitos observados.

\subsubsection{Ferramentas computacionais}

Para realização do processamento de imagens e extração de características existem diversas

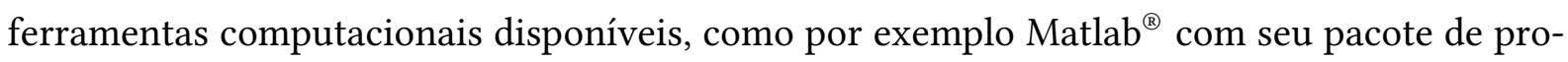
cessamento de imagens (IPT - Image Processing Toolkit). Nesta pesquisa foi utilizada a linguagem de programação Python versão 2.7.11+ em conjunto com a biblioteca scikit-image ${ }^{3}$ versão 0.12.3., que é uma biblioteca de funções de Visão Computacional. Para o realização do Aprendizado de Máquina foi utilizada a biblioteca scikit-learn ${ }^{4}$ versão 0.17.1.

\footnotetext{
${ }^{3}$ http://scikit-image.org/)

${ }^{4}$ http://scikit-learn.org/
} 


\subsection{Contribuições}

Nesta tese, os desafios apresentados na seção anterior são tratados de modo a ter as seguintes contribuições:

- Recomendações - recomendações sobre parâmetros para execução de missões de monitoramento para detecção de defeitos em pavimentos asfálticos fazendo uso de VANTs de pequeno porte;

- Detecção automática de Desgastes de Pavimentos - detecção automática de desgastes de pavimentos flexíveis asfálticos por meio do uso de equalização de histograma, permitindo assim que medidas preventivas possam ser tomadas para que não ocorram maiores danos ocasionando maiores gastos com consertos nas áreas detectadas;

- Geração automática de label - a geração do label a partir do mapa de ruas do GoogleMaps que permite o processo de verificação automática do label de referência e, permitindo assim, que o tempo e o custo sejam minimizados;

- MANIAC - especificação e desenvolvimento de uma Metodologia para Monitoramento de Pavimentos Asfálticos com uso de VANTs para Detecção Automática de Defeitos. Essa metodologia permite que ocorra uma diminuição no tempo e custo para o diagnóstico de rodovias pavimentadas, além de permitir que medidas preventivas possam também ser tomadas (BRANCO; SEGANTINE, 2015).

\subsection{Estrutura da tese}

Esta tese de doutorado está organizada da seguinte forma:

- No Capítulo 2 é apresentada a Fundamentação Teórica, apresentando os conceitos necessários para o entendimento da pesquisa desenvolvida nesta tese de doutorado. Por se tratar de uma pesquisa multidisciplinar os conceitos abordados incluem informações que vão desde Sensoriamento Remoto, passando pela ferramenta de Sensoriamento Remoto utilizada (Veículos Aéreos Não Tripulados), e chegando até os conceitos relacionados a técnicas e algoritmos de Aprendizado de Máquina.

- No Capítulo 3 são apresentados os trabalhos correlatos ao trabalho aqui desenvolvido. É apresentado o resultado final do processo de revisão sistemática que busca então apresentar a revisão bibliográfica que permitiu efetuar um levantamento do estado da arte do problema apresentado.

- No Capítulo 4 é apresentada a Metodologia MANIAC (Methodology for PAvemeNt AutomatIc CharACterization) especificada, implementada e avaliada neste trabalho. A MANIAC constitui uma metodologia que permite a identificação de defeitos em pavimentos 
asfálticos flexíveis a partir de imagens oriundas de um Veículo Aéreo Não Tripulado. Todo o detalhamento e a especificação da metodologia são apresentados neste capítulo.

- No Capítulo 5 são apresentados os resultados experimentais que corroboram com a hipótese desta tese de que é possível a concepção de uma metodologia que permita a detecção automática de defeitos em pavimentos asfálticos a partir de imagens de Veículos Aéreos Não Tripulados de pequeno porte.

- Por fim, no Capítulo 6 são destacadas as conclusões obtidas nesta pesquisa, bem como as dificuldades encontradas, as contribuições, as limitações e os trabalhos futuros. 


\section{Capítulo}

\section{Fundamentação teórica}

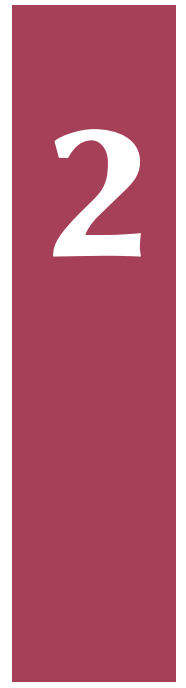

Neste capítulo é descrita a fundamentação teórica necessária para o entendimento desta tese de doutorado. É possível observar que, por essa tese tratar de um tema multidisciplinar, esse capítulo apresenta uma diversidade de informações de diferentes áreas de pesquisa. As considerações iniciais são tecidas na seção 2.1. Na Seção 2.3 são apresentados os conceitos básicos de Sensoriamento Remoto, Sistemas de Informações Geográficas, Processamento de Imagens e Visão Computacional bem como informações básicas sobre imagem, necessárias para o entendimento do trabalho aqui desenvolvido. Na Seção 2.5 são apresentados os conceitos fundamentais de Veículos Aéreos Não Tripulados, suas classificações e os principais tipos de aplicações em que são utilizados. Esses conceitos fazem-se necessários uma vez que essa plataforma é a plataforma de Sensoriamento Remoto que foi utilizada. Na Seção 2.6 são apresentados os principais tipos de classificações de defeitos em pavimentos flexíveis asfálticos, de modo a permitir o conhecimento dos defeitos existentes e como são classificados pelos órgãos responsáveis. Uma vez que o trabalho desenvolvido neste doutorado utiliza os conceitos de Aprendizado de Máquina, na Seção 2.7 são descritos as principais características e o funcionamento dos algoritmos supervisionados e não supervisionados utilizados nesta tese de doutorado, bem como os métodos de avaliação do desempenho desses algoritmos. O capítulo é finalizado na Seção 2.8 com as considerações finais.

\subsection{Considerações iniciais}

Sensoriamento Remoto (SR), Visão Computacional (VC), Veículos Aéreos Não Tripulados (VANTs), pavimentos asfálticos, Sistemas de Informações Geográficas (SIG) e Aprendizado de Máquina (AM), são por si só áreas de estudo que apresentam ainda vários desafios a serem resolvidos. 
Quando se pensa em unir essas áreas em prol de um benefício para uma ou mais áreas o trabalho torna-se ainda mais desafiador. O objetivo desse capítulo não é estressar todos os conceitos envolvidos nessas diversas áreas, mas sim apresentar uma fundamentação teórica básica para que contribua no entendimento da pesquisa desenvolvida nessa tese de doutorado.

O SIG, SR e VC estão cada vez mais entrelaçados. A velocidade e a dinâmica da mistura desses universos, antes essencialmente separados, aumentaram consideravelmente nos últimos anos. Para tanto, a integração cada vez mais intensa de dados de SR e SIG, fazendo uso da VC, tem desempenhado um papel importante. O desenvolvimento mais atual iniciado é a rápida mudança de processamento de imagens, até então orientado fortemente ao pixel como o menor elemento e portador exclusivo de informações, isso do ponto de vista metodológico. Desse modo, os conceitos básicos, as características, a arquitetura, os tipos de dados e os demais conteúdos necessários para o entendimento dessas áreas de pesquisa são apresentados nesse capítulo.

O Sensoriamento Remoto foi executado com objetivo de obter imagens aéreas de áreas pavimentadas, fazendo uso de um Veículo Aéreo Não Tripulado, cuja câmera permite a obtenção de imagens de alta resolução espacial. A obtenção das imagens fizeram-se necessárias para que se pudesse detectar possíveis defeitos em pavimentos asfálticos. Para a obtenção automática desses defeitos, foram utilizadas técnicas de Visão Computacional, como a extração de características, fazendo-se uso de uma especificamente, o Aprendizado de Máquina.

Desse modo, esse capítulo apresenta os conceitos fundamentais para o entendimento dos assuntos aqui abordados.

\subsection{Sistemas de Informações Geográficas}

Com o advento da tecnologia digital os mapas, antes analógicos, passaram a ser produzidos de forma digital. Os sistemas computacionais responsáveis inicialmente por este processo, chamados de Computer Aided Design (CAD), somente reproduzem, na forma digital, o desenho original. Neste sentido, um CADnada mais é do que um conjunto de ferramentas para entrada de dados gráficos, edição e geração de desenhos por meio de dispositivos de saída. Manipulações avançadas como, por exemplo, mudanças de projeções, associação com banco de dados estão fora do escopo destes tipos de sistemas.

Os sistemas de Mapeamento Automático e Gerência de Facilidades, também conhecido como Automed Mapping/Falicity Managemen (AM/FM) se desenvolveram a partir da proliferação dos sistemas CAD. Tanto os sistemas CAD quanto os AM/FM apresentam boas características para análise de dados de mapas.

Sendo assim, os sistemas computacionais evoluíram, cada qual especializando-se em áreas determinadas. Como consequência desta evolução surgiram os Sistemas de Informação Geográfica SIG. 
Um SIG é um sistema de informação baseado em computador que permite capturar, modelar, manipular, recuperar, consultar, analisar e apresentar dados geograficamente referenciados Skidmore (2003). O uso de SIG permite obter enormes benefícios devido à sua capacidade de manipular infomações espaciais (ou seja, georeferenciadas, referenciado a uma região do espaço geográfico) de forma precisa, rápida e de certo modo sofisticada (SKIDMORE, 2003).

Na década de 80, o uso de SIG tornou-se comum em empresas, universidades e agências governamentais, e atualmente é utilizado por diversos profissionais nas mais variadas aplicações. Diversas são as definições de SIG, cabendo destacar:

- "conjunto poderoso de ferramentas para coletar, armazenar, recuperar, transformar e visualizar dados sobre o mundo real" (BURROUGH, 1986);

- "um banco de dados indexados espacialmente, sobre o qual opera um conjunto de procedimentos para responder a consultas sobre entidades espaciais” (SMITH et al., 1987);

- "um sistema de suporte à decisão que integra dados referenciados espacialmente num ambiente de respostas a problemas" (COWEN, 1988); e

- "um conjunto manual ou computacional de procedimentos utilizados para armazenar e manipular dados geo-referenciados" (ARONOFF, 1989).

Essas definições refletem, cada uma à sua maneira, a multiplicidade de usos e visões possíveis desta tecnologia, apontando para uma perspectiva inter e multidisciplinar de sua utilização. Algumas de suas aplicações incluem: agricultura, floresta, cartografia, geologia, cadastro urbano, redes de concessionárias (água, energia e telefonia), entre outras. Segundo Segantine (2001) "o SIG pode ser visto como uma inovação tecnológica, que permite aos usuários a organização de tarefas, a resolução e a tomada de decisões de vários tipos de problemas e forma inovadora", já que cada uma das definições individuais de SIG refletem a multiplicidade de usos e visões possíveis desta tecnologia, demonstrando sua interdisciplinaridade. Sendo assim, o significado de SIG pode ser visto de forma mais ampla como Sistema: Tecnologia da computação; Informação: Dados e seus significados e; Geográfica: Realidades espaciais do mundo real.

Cabe ainda diferenciar os sistemas CAD, AM/FM e SIG. A maneira pela qual se modela o meio a ser analisado é uma das diferenças básicas entre SIG e AM/FM, já que o primeiro, por tratar melhor as relações espaciais, usam células ou polígonos ao invés de relações de redes, técnica utilizada pelo segundo. Já o que difere um SIG de um CAD é o volume e a diversidade dos dados de entrada e a natureza especializada dos métodos de análise utilizados, que no primeiro é bem mais abrangente e completo que no segundo (SEGANTINE, 2001).

Apesar do uso do SIG ter se popularizado na década de 80 e por consequência diversas serem as aplicações e as definições a ele dada, a anteriormente apresentada é a que será assumida nesta tese de doutorado. 


\subsubsection{Arquitetura de SIG}

De modo geral, um SIG pode ser dividida nos seguintes módulos (BURROUGH, 1986):

- interface com o usuário;

- entrada de dados e verificação;

- armazenagem de dados e gerenciamento do banco de dados geográfico;

- funções para a manipulação e análise dos dados; e

- saída de dados: visualização e impressão.

Por se tratar de um sistema que lida com uma ampla variedade de informações, o módulo de entrada de dados deve ser robusto a ponto de não restringir o formato do dado a ser tratado. Um SIG deve tratar dados provenientes de sensores, de mapas analógicos, de arquivos digitais, e de interação direta.

O módulo de armazenagem de dados e gerenciamento do banco de dados geográfico é considerado o coração do SIG. Depois de ajustes, os dados são armazenados de modo a preservar a topologia, a localização geográfica de acordo com a projeção geométrica adotada e atributos descritivos dos objetos geográficos. De modo geral o banco é gerenciado por um programa denominado Sistema Gerenciador de Banco de Dados (SGBD). Sobre este banco de dados serão executadas consultas específicas, recuperação de dados, atualizações de dados transformados, e suporte aos mecanismos de análise de informações espaciais, característica principal de um SIG.

Já o módulo sobre funções e manipulações dos dados é o componente que distingue o SIG da cartografia automatizada. É um módulo provedor de mecanismos de questionamento aos dados armazenados, de forma a analisá-los, manipulá-los, e apresentá-los de uma maneira diferente da original. O último módulo trata a saída de dados por meio da visualização de mapas, tabelas de banco de dados, figuras, entre outros. Esta saída pode ser expressa por uma plotter, impressora, tela da estação de trabalho, ou por meio magnético.

Sendo assim, segundo Segantine (2001) o SIG é um sistema computacional que permite armazenar virtualmente qualquer tipo de informação desde que seja possível que a mesma possa ser colocada em um mapa na forma de papel, sendo mais útil que um mapa tradicional.

\subsubsection{Tipos de dados tratados em SIG}

O aspecto mais fundamental dos dados tratados em um SIG é a natureza dual da informação: um dado espacial ou dado geográfico possui localização expressa como coordenadas de um mapa e atributos descritivos representados num banco de dados convencional (SKIDMORE, 2003). 
Além disso, outro aspecto é o fato dos dados geográficos não existirem sozinhos no espaço: tão importante quanto localizá-los é descobrir e representar as relações entre os diversos dados. Segundo Goodchild (1992), as aplicações de geoprocessamento lidam com dois tipos de dados espaciais:

- geo-campos: variações espaciais contínuas, usadas para grandezas distribuídas espacialmente, tais como tipo de solo, topografia e teor de minerais. Na prática correspondem a dados temáticos, imagens, mapas temáticos e modelos numéricos de terreno; e

- objetos geográficos (ou geo-objetos): individualizáveis e que possuem identificação. Este tipo de dado tem atributos não espaciais, armazenados em um banco de dados convencional, podendo estar associado a várias representações gráficas. Exemplos: escolas, municípios e fazendas.

\subsubsection{Mapas temáticos}

Mapas temáticos são dados do tipo geo-campo e caracterizam-se por conter regiões definidas por um ou mais polígonos. Este tipo de dado é armazenado na forma de arcos (limites entre regiões), incluindo os nós (pontos de interseções entre arcos) para montar uma representação topológica. A topologia construída é do tipo arco-nó-região: arcos se conectam entre si por meio de nós (ponto inicial e final) e arcos que circundam uma área definem um polígono (região) Burrough (1986). De modo análogo, os mapas temáticos podem ser armazenados sob a forma matricial (raster). A área correspondente ao mapa é dividida em células de tamanho fixo e cada célula tem um valor correspondente ao tema mais frequente naquela localização espacial.

\subsection{Visão Computacional}

Quando se fala em imagem não há como não se preocupar com o processamento das mesmas. Nesse sentido, faz-se necessário abordar o conceito de Processamento de Imagem, ou mais especificamente o de Visão Computacional. A delimitação da fronteira entre essas duas áreas não é algo trivial, mas pode-se, de modo mais simples definir que: Processamento de Imagem compreende o processo onde ocorre a entrada de uma imagem e a saída de um conjunto de valores numéricos que podem ou não compor outra imagem, enquanto que Visão Computacional compreende o processo em que há a entrada de uma imagem e a saída é constituída pela interpretação desta imagem Gonzalez, Woods e Eddind (2004). Esse é o conceito adotado nesta tese de doutorado, o de Visão Computacional.

Sendo assim, a Visão Computacional tenta simular a visão natural do ser humano, que a faz de forma rápida e eficaz, ao passo que os algoritmos de Visão Computacional são ainda precários quando comparados à visão humana. Entretanto, apesar de não atingirem os mesmos resultados dos obtidos naturalmente, os algoritmos de Visão Computacional têm evoluído e 
permitido que novas pesquisas sejam realizadas e resultados satisfatórios sejam obtidos, principalmente quando são feitos comparativos de custo. A redução de preço e melhoria da definição dos dispositivos de captura de informação (câmeras de alta definição), o desenvolvimento de novas tecnologias (como os Veículos Aéreos não Tripulados - VANTs), e o aumento da potência computacional dos computadores (além da sua redução em tamanho e custo), tem permitido um desenvolvimento rápido da Visão Computacional nos últimos anos.

\subsubsection{O modelo de imagens digitais}

Uma imagem digital pode ser monocromática ou colorida. A primeira é uma função bidimensional contínua $f(x, y)$, onde $x$ e $y$ são coordenadas espaciais e o valor de $f$ em qualquer ponto $(x, y)$ é proporcional a intensidade de brilho (ou nível de cinza) Gonzalez e Woods (2007); já na segunda, se considerado o sistema RGB (Red, Green e Blue), um pixel pode ser visto como um vetor cujas correspondentes representam as intensidades das cores (vermelho, verde e azul), podendo ser considerada como uma composição de três imagens monocromáticas.

O pixel ou elemento de imagem constitui cada ponto na grade bidimensional que representa a imagem digital. Isso se deve ao fato dos computadores não serem capazes de processar imagens contínuas, fazendo-se necessário que as imagens sejam representadas por meio de vetores bidimencionais de pontos (matrizes).

A intensidade luminosa no ponto $(x, y)$ pode ser decomposta em componente de iluminação e componente de reflectância. A primeira está associada à quantidade de luz que incide sobre o ponto e é representada por $i(x, y)$, enquanto que a segunda está associada à quantidade de luz refletida pelo ponto, e é representada por $r(x, y)$. Sendo assim, tem-se a Equação (2.1).

$$
f(x, y)=i(x, y) \cdot r(x, y)
$$

sendo que $0<i(x, y)<\infty$ e $0<r(x, y)<1$, e $i(x, y)$ dependente das características da fonte de iluminação e $r(x, y)$ das características das superfícies do objeto.

De modo análogo, a equação para a imagem colorida é dada pela Equação (2.2)

$$
f(x, y)=f_{R}(x, y)+f_{G}(x, y)+f_{B}(x, y)
$$

sendo que $f_{R}(x, y), f_{G}(x, y)$ e $f_{B}(x, y)$ representam as intensidades liminosas das componentes vermelho, verde de azul respectivamente (GONZALEZ; WOODS, 2007).

\subsubsection{Amostragem e quantização}

Para que uma imagem possa ser armazenada computacionalmente faz-se necessário sua discretização tanto em nível de coordenadas espaciais quanto em valores de brilho. Essa digitalização das coordenadas espaciais em valores discretos inteiros e positivos constitui a amostragem. Já 
a discretização dos valores de brilho (ou a digitalização da amplitude - escala de variação da intensidade luminosa), constitui a quantização.

A amostragem está relacionada ao tamanho da imagem nos eixos $x$ e $y$ (representado por linhas e colunas da matriz que compõe a imagem), e a quantização está relacionada ao espaço de memória de armazenamento da imagem (que assume potências inteiras de dois).

Sendo assim, para uma imagem monocromática com resolução de 8 bits fornece $2^{8}$ ou 256 níveis de cinza, enquanto que uma com resolução de 2 bits fornece $2^{2}$ ou 4 níveis de cinza diferentes. Cabe ressaltar que costuma-se associar o limite inferior 0 da faixa de níveis de cinza de um pixel à cor preta, e ao limite superior $(L-1)$ à cor branca.

Já para imagens coloridas, cada pixel armazena três valores de intensidade de luz (R, G e B), de modo que uma imagem com 24 bits possui três planos de 8 bits, perfazendo um total de 16 milhões de cores diferentes.

Uma vez que a amostragem e a quantização implicam na supressão de informações de uma imagem analógica, seu equivalente digital é uma aproximação, cuja qualidade depende dos valores da quantidade de linhas e colunas da matriz, bem como da resolução. Sendo assim, quanto melhores (maiores) forem esses valores, melhor é a qualidade da imagem, e consequentemente maior será o número de bits necessários para armazená-la.

Nesta tese estão sendo utilizadas imagens digitais, coloridas e de alta resolução, o que implica em um grande volume de dados a ser manipulado.

\subsubsection{Operações com imagens digitais}

Uma vez que as imagens digitais são representadas por meio de matrizes, as operações matriciais são válidas, assim como os operadores lógicos e os aritméticos. Algumas das operações mais frequentes realizadas com imagens são:

- Espaço de Cores - descritores de cores na análise e processamento automático de imagens é considerado um descritor poderoso que permite simplificar diversos processos de identificação de elementos. A especificação das cores em um determinado padrão resulta na definição de espaços de cores. Os espaços de cores mais comuns são: RGB, Hue, Saturation and Value (HSV) e Component Luma, Red and Blue Difference (YCrCb). Os espaço de cores nada mais são que modelos matemáticos utilizados para descrever cada cor a partir de fórmulas, uma vez que a cor pode ser expressa pelas características de brilho (intensidade de luz), matiz (cor dominante) e saturação (quantidade de luz branca misturada a matiz). O espaço de cor utilizado nas imagens aéreas que serão utilizadas nesta tese é o RGB. Neste modelo, cada cor é derivada da combinação de seus componentes espectrais primários: vermelho, verde e azul, sendo baseado no sistema de coordenadas cartesianas (cubo RGB). Nos vértices do cubo encontram-se as cores primárias e as cores 
secundárias (ciano, magenta e amarelo). A cor preta localiza-se na origem e a cor branca na extremidade oposta, e a diagonal a escala de cinza.

- Histograma de Cores - O histograma traduz a distribuição estatística dos níveis de cinza de uma imagem monocromática ou, a distribuição de frequências das intensidades luminosas. O histograma facilita o entendimento da imagem, permitindo que parâmetros como contraste e luminosidade possam ser modificados e ajustados (reduzidos, realçados entre outros). Entretanto, esse processo não traz informações sobre posição dos pixels na imagem, o que pode ser muitas vezes desejado e desse modo ser considerado um aspecto negativo dessa técnica.

- Filtragem Espacial - de modo análogo às técnicas de contraste, as técnicas de filtragem implicam em transformações pixel a pixel. Entretanto, ao contrário das dessas técnicas, onde cada pixel é tratado individualmente, sendo que as alterações efetuadas dependem apenas do nível de cinza do pixel corrente, a filtragem espacial considera também a vizinhança do pixel, agregando informações importantes dos seus vizinhos. Desse modo, a filtragem espacial baseia-se na operação de convolução de máscaras (janelas, templates, ou filtros, entre outros). Essa máscara é um arranjo bidimensional (matriz), geralmente de dimensões inferiores às da imagem original, cujos valores são definidos como fatores de ponderação a serem aplicados sobre os pixels da imagem. A equação matemática para a filtragem espacial de uma imagem $f(x, y)$ de dimensões $M x N$ com filtro $w(u, v)$ de dimensões $M x N$ é dada pela Equação (2.3).

$$
g(x, y)=\sum_{u=0}^{m-1} \sum_{v=0}^{n-1} w(u, v) \cdot f\left(x+u-\frac{m}{2}, y+v-\frac{n}{2}\right)
$$

Desse modo, um novo pixel é gerado com coordenadas iguais às do pixel original, cujo valor é resultante do somatório da região da imagem original com a máscara definida. Essa operação é denominada filtragem espacial linear desde que a operação realizada sobre os pixels da imagem seja linear, caso contrário é denominada de filtragem espacial não linear. O desafio está na definição da máscara. Essas máscaras servem para realizar a suavização (filtros de passa baixa) ou o aguçamento (filtros de passa alta) (GONZALEZ; WOODS, 2007).

- Morfologia Matemática - é um campo de estudo que soma conhecimentos de basicamente dois subconjuntos da matemática: geometria diferencial e probabilidade geométrica junto com algumas outras áreas relacionadas como análises harmônicas, processos estocásticos e topologia algébrica Serra (1982). A morfologia é uma modelagem destinada à descrição da forma de um objeto digital. A morfologia matemática trata as imagens como conjuntos de pontos em um espaço, no sentido matemático. As operações básicas da morfologia matemática são a erosão e dilatação. A primeira remove da 
imagem os pixels que não atendem a um dado padrão (dada por $Y=X \ominus \check{B}$ - a erosão $Y$ do conjunto $X$ pelo conjunto $B$ é definida como a subtração $X \ominus \check{B}$ de forma similar a clássica subtração de Minkowsk da geometria diferencial definida por $X \ominus B=\underset{b \in B}{\cap} X_{b}$ ), enquanto que a segunda faz com que uma pequena área relacionada a um pixel seja alterada para um dado padrão (dada por $Y=X \oplus \check{B}=\underset{b \in \check{B}}{\cup} X_{b}$ ) (DOUGHERTY; LOTUFO; SPIE, 2003).

- Segmentação - técnica que consiste na subdivisão da imagem em partes. Os algoritmos de segmentação permitem a identificação de diferenças entre objetos, discriminando-os em partes.

- Limiarização (Thresholding) - É um operador fundamental na identificação de objetos. Essa abordagem de segmentação está fundamentada na similaridade de níveis de cinza, de modo a extrair objetos de interesse mediante a definição de um limiar $\tau$ que separa os agrupamentos de níveis de cinza. Onde: $T(x, y)=$ $\left\{\begin{array}{lll}0, & \text { se } & f(x, y)<\tau) \\ 1, & \text { se } & f(x, y) \geq \tau)\end{array}\right.$. Nesse caso, cada pixel é comparado com o valor limiar e, em sendo menor que o limiar a imagem resultante $T(x, y)$ é rotulada como zero (preto), caso contrário com um (branco). A dificuldade reside em encontrar um limiar adequado. Por meio da análise do histograma da imagem é possível estabelecer um valor para o limiar na região situada entre picos que caracterizam regiões de interesse na imagem.

- Segmentação Orientada a Regiões - Essa técnica baseia-se na similaridade dos níveis de cinza da imagem. O crescimento de região agrupa um conjunto de pixels em regiões maiores, enquanto que a agregação de pixels fundamenta-se na definição de uma semente (ou um conjunto de pontos similares) a partir do qual a região cresce com a agregação de cada pixel à semente.

- Segmentação Baseada em Bordas - Várias são as técnicas de segmentação que baseiam-se na detecção de bordas por meio do uso de operadores de gradiente (tais como Sobel, Roberts, Laplaciano) seguidos por um processo de limiarização. A detecção de bordas permite a análise de descontinuidade nos níveis de cinza que são úteis para segmentação.

- Extração de Características - as técnicas de extração de características, ou de reconhecimento de padrões podem ser classificadas em aprendizagem supervisionada e nãosupervisionada. A aprendizagem supervisionada divide-se em paramétrica e não-paramétrica. $\mathrm{Na}$ abordagem paramétrica o classificador é treinado com uma grande quantidade de amostras rotuladas para que possa então estimar os parâmetros estatísticos de cada classe de padrão (média, variância). Exemplo são os classificadores de distância mínima e de máxima verossimilhança. No caso da abordagem não-paramétrica os parâmetros 
estimados do conjunto de treinamento não são levados em consideração. Exemplo de classificador não-paramétrico é o K-vizinhos mais próximos. Já na classificação não supervisionada, os dados de entrada são particionados a partir de um critério de similaridade, resultando em conjunto de clusters normalmente associados a uma classe. Neste campo destacam-se os algoritmos e técnicas baseadas em redes neurais (com variantes para classificação supervisionada e não supervisionada), técnicas de Machine Learning (que serão detalhadas na Seção 2.7), e os classificadores bayesianos.

Nesta tese de doutorado são utilizadas mais frequentemente as operações de segmentação e a extração de características.

\subsection{Sensoriamento Remoto}

Juntamente com a invenção da câmera fotográfica pode-se dizer que teve o início do Sensoriamento Remoto, uma vez que esse foi o primeiro instrumento utilizado e até os dias atuais, é ainda utilizado para a tomada de fotos aéreas. Não diferente das demais tecnologias, o SR teve suas origens nas aplicações militares. Entretanto, a grande revolução do SR, principalmente no Brasil, aconteceu no início da década de 70, com o lançamento dos satélites de recursos naturais terrestres.

Quatro foram os segmentos tecnológicos que determinaram o processo evolutivo do SR por satélite:

1. Sensores - que constituem os instrumentos que compõem o sistema de captação de dados e imagens, cuja evolução tem contribuído para a coleta de imagens de melhor qualidade e de melhor definição.

2. Sistema de telemetria - sistema de transmissão de dados e imagens dos satélites para estações terrestres, e tem evoluído no sentido de aumentar a capacidade de transmissão dos grandes volumes de dados (imagens).

3. Sistemas de processamento - consistem dos equipamentos computacionais e softwares destinados ao armazenamento e processamento dos dados do SR, que tem incrementado a capacidade de manutenção de acervos e as potencialidades do tratamento digital das imagens.

4. Lançadores - consistem das bases de lançamento e foguetes que transportam e colocam em órbitas os satélites mais pesados, com maior quantidade de instrumentos, e consequentemente, com mais recursos tecnológicos.

Na verdade a evolução do SR é fruto de um esforço multidisciplinar que envolveu e envolve avanços na física, na físico-química, na química, nas biociências e geociências, na computação, na mecânica, entre outros. 
O conceito de Sensoriamento Remoto varia ligeiramente de autor para autor na literatura aberta. Segundo o Canada Centre for Remote Sensing - CCRS, Evelyn Pruitt do United States Office of Naval Research cunhou o termo em 1958 para englobar fotografia aérea, imagem baseada em satélite e outras formas de coletar dados remotamente. A partir de então, o termo tem sido empregado amplamente e sendo definido e redefinido por alguns autores. Para o CCRS "Sensoriamento Remoto é a ciência (e, em certa medida, a arte) de aquisição de informações sobre a superfície da Terra sem realmente estar em contato com ela. Isto é feito por sensores e gravação da energia refletida ou emitida, processamento, análise e aplicação dessa informação", restringindo-se somente ao monitoramento da superfície da Terra, no entanto, a mesma tecnologia é utilizada na astronomia para a observação e estudo de outros planetas.

Sensoriamento Remoto pode ser visto também como "a arte ou a ciência de dizer alguma coisa sobre um objeto sem tocá-lo"Fischer, Hemphill e Kover (1976). Ou ainda, "Sensoriamento Remoto é a ciência e a arte de obter informações sobre objetos, áreas ou fenômeno através da análise de dados obtidos por um dispositivo que não está em contato direto com o objeto, área ou fenômeno sob investigação" Lillesand, Kiefer e Chipman (2014). Em suma, o ponto comum entre as definições de Sensoriamento Remoto está em adquirir informações sem contato físico com o objeto ou fenômeno de interesse.

Como o trabalho desenvolvido neste doutorado faz uso, principalmente, de imagens para o monitoramento da condição de uso de pavimentos, será dado enfoque nos sensores de energia eletromagnética para formação de imagens, que atualmente tem sido operado principalmente por aeronaves e satélites. No caso específico deste trabalho, como já mencionado anteriormente, as imagens foram obtidas a partir de aeronaves não tripuladas.

\subsubsection{O espectro eletromagnético}

Para se obter estas informações, usa-se um meio que, neste caso, é a radiação eletromagnética das imagens, supondo que esta possa chegar diretamente ao sensor de captura. Isto, no entanto, não é possível em todas partes do espectro eletromagnético, porque a transmissividade atmosférica é variável para os diversos comprimentos de onda. As ondas eletromagnéticas, também chamadas de radiação eletromagnética (REM), podem ser consideradas como termômetrosmensageiros do SR. Elas não apenas captam as informações pertinentes às principais características das feições terrestres, como também as levam até os satélites ou até as aeronaves. A radiação eletromagnética pode ser definida como sendo uma propagação de energia, por meio de variação temporal dos campos elétrico e magnético, da onda portadora.

A radiação eletromagnética propaga-se, no vácuo, a uma velocidade aproximada de $300.000 \mathrm{~km} / \mathrm{s}$. A intensidade da radiação varia senoidalmente e está correlacionada diretamente com o comprimento de onda e a frequência. O comprimento de onda $(\lambda)$ é definido pela distância média entre dois pontos semelhantes da onda, como, por exemplo, dois mínimos ou dois máximos. A frequência $(f)$ é o valor recíproco do período das ondulações, ou seja, do intervalo de tempo 
entre dois pontos consecutivos de mesma intensidade. A fonte principal de radiação natural é o Sol, que emite, a uma temperatura de cerca de $6.000^{\circ} \mathrm{K}$, grandes quantidades de energia em um espectro contínuo.

A faixa completa de comprimentos de onda e de frequência da REM é chamada de espectro eletromagnético. Este espectro varia desde as radiações gama com comprimentos de onda da ordem de $10^{-6} \mu \mathrm{m}$, até as ondas de rádio da ordem de $100 \mathrm{~m}$. No que se refere às técnicas de Sensoriamento Remoto por sistemas passivos, a faixa do espectro mais utilizada estende-se do ultravioleta (UV) até o infravermelho afastado (FIR - far infra red). O espectro eletromagnético pode ser observado por meio da Figura 2.1.

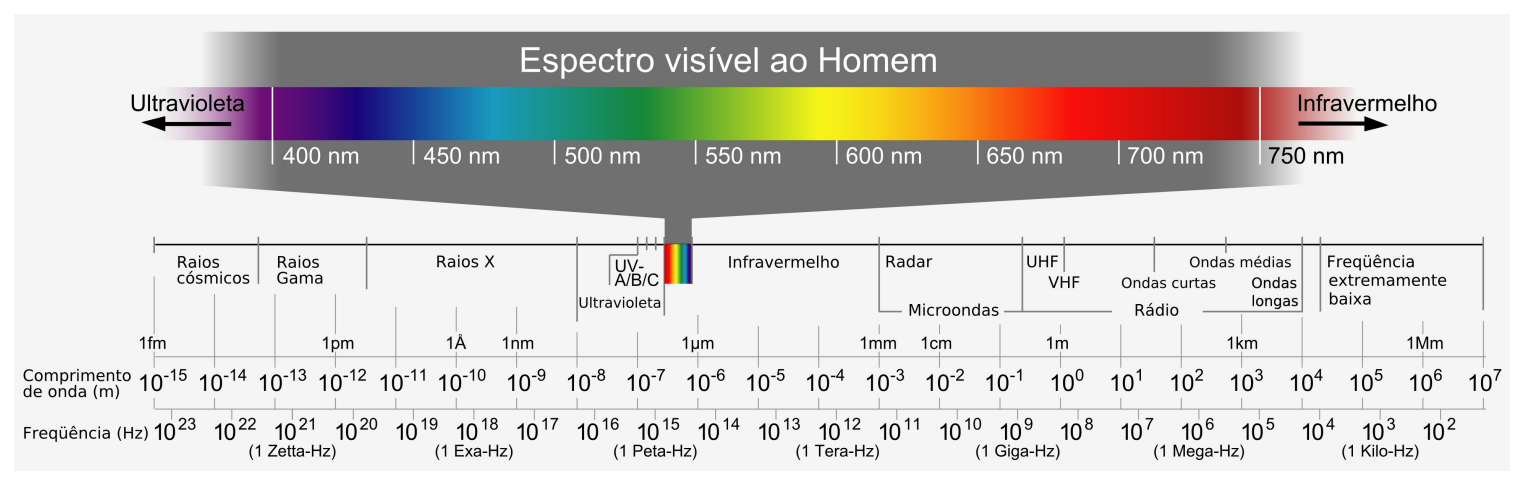

Figura 2.1 - Espectro eletromagnético. Adaptado de (GRIFFITHS, 1999)

A radiação eletromagnética sofre interferência ao atravessar a atmosfera terrestre. Isso se deve ao fato da radiação solar ser atenuada pelos gases e aerossóis presentes na atmosfera terrestre. Alguns gases (oxigênio, ozônio, vapor d'água, gás carbônico) absorvem a energia eletromagnética em determinadas bandas do espectro, de maneira que a atmosfera é intransmissível à radiação nestas bandas. Independentemente do tipo do sensor, sempre há uma distância entre a fonte emissora de energia e o sensor de detecção.

O trajeto entre a fonte de energia e o sensor é dependente do tipo de Sensoriamento Remoto que é realizado. Um satélite que capta a radiação eletromagnética refletida da superfície terrestre sofre duas vezes a influência da atmosfera terrestre. A primeira quando a energia do sol atravessa a atmosfera até chegar a superfície terrestre e a segunda quando a energia refletida pela superfície atravessa a atmosfera até chegar de volta ao satélite que está em órbita ou até uma plataforma de imageamento.

No caso de Sensoriamento Remoto por plataformas aéreas, a distância até o alvo, quando comparada com satélites, é significante menor, ou seja, quanto menor for a distância no trajeto da fonte de energia até o alvo de interesse e depois até o sensor, menor será a interferência da atmosfera na propagação da radiação eletromagnética. Esse já é um dos fatores de vantagem do uso de aeronaves na obtenção das informações.

A determinação da natureza dos alvos pelos métodos de Sensoriamento Remoto é baseada no fato de que diferentes materiais são caracterizados por refletâncias próprias em cada banda 
do espectro. A refletância, ou fator de reflexão, é proporcional à razão da radiação refletida pela radiação incidente. Quando as respostas espectrais de vários materiais são conhecidas, as propriedades de alvos desconhecidos podem ser determinadas pela comparação das respostas espectrais desses alvos com os dados de referência.

As janelas atmosféricas ${ }^{1}$ são limitantes ao emprego do Sensoriamento Remoto para certos comprimentos de onda, principalmente quando se faz uso de satélites. Antes da aplicação do Sensoriamento Remoto para identificação de determinada característica do objeto pesquisado faz-se necessário analisar o comportamento espectral do objeto frente às janelas atmosféricas. Muitas vezes, o comportamento espectral desejado do objeto não coincide com as janelas atmosféricas impedindo o desenvolvimento dos estudos, pesquisa e até mesmo do monitoramento. As janelas influenciam também na determinação do tipo de sensor que será utilizado no Sensoriamento Remoto (Figura 2.2).

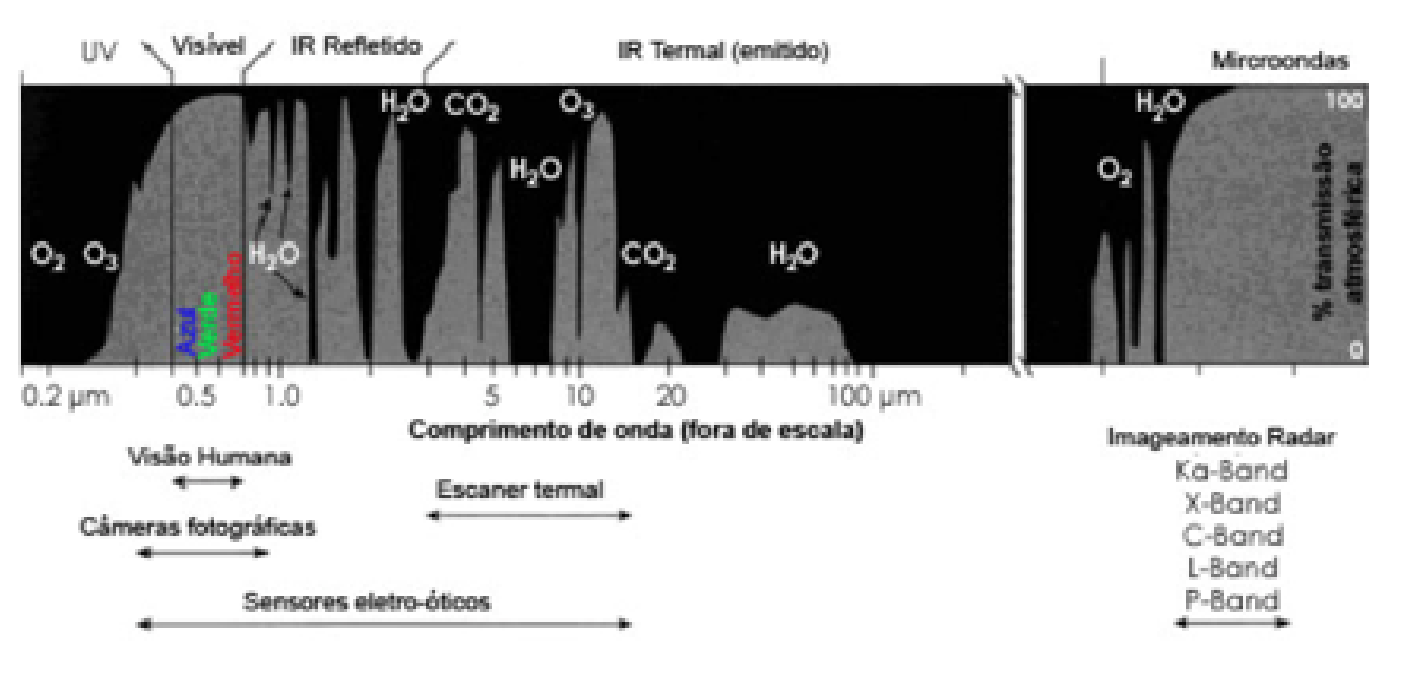

Figura 2.2 - Janelas atmosféricas. Adaptado de (SHORT, 2010)

A energia eletromagnética ao chegar à superfície terrestre interage com os objetos e elementos que a compõe. Essa interação com a superfície terrestre depende basicamente do tipo, forma e da condição do material. Existem três formas de interação da energia com a superfície terrestre: reflexão, absorção e transmissão. Com base no principio da conservação de energia, pode-se dizer que a energia incidente sobre um objeto é igual a soma das energias refletida, absorvida e transmitida conforme pode ser observado na Equação (2.4)

$$
E_{I}(\lambda)=E_{R}(\lambda)+E_{A}(\lambda)+E_{T}(\lambda)
$$

Sendo: $E_{I}=$ energia incidente; $E_{R}=$ energia refletida; $E_{A}=$ energia absorvida; $E_{T}=$ energia transmitida.

\footnotetext{
${ }^{1}$ Os gases absorvem a radiação em determinadas partes do espectro e produzem faixas onde a radiação consegue alcançar a superfície terrestre, a estas faixas dá-se o nome de janelas atmosféricas.
} 
Como já mencionado anteriormente, cada objeto possui sua própria refletância. Sendo assim, as áreas urbanas também são caracterizadas por uma aparência heterogênea, causada pelo fato da variação interna dessas áreas ser muito grande, devido à sua própria natureza. As áreas residenciais, por exemplo, são formadas por materiais variados, tais como concreto, asfalto, vidro, ferro e vegetação. Há que se considerar, ainda, a influência das sombras.

Deste modo, é possível construir um gráfico da refletância espectral de um objeto em função do comprimento de onda. Este gráfico é conhecido como sendo a curva espectral do objeto, ou também como a assinatura espectral do objeto. O conhecimento antecipado desta curva para os diferentes tipos de materiais observados no Sensoriamento Remoto permite reconhecer e analisar os objetos em uma imagem. Com isso é possível separar o asfalto, no caso específico deste trabalho, dos demais elementos presentes na imagem.

\subsubsection{Resolução das imagens de Sensoriamento Remoto}

Em Sensoriamento Remoto o termo resolução divide-se em três categorias:

- Resolução Espacial - este tipo de resolução é determinado pela capacidade do detector em distinguir objetos na superfície terrestre. A resolução espacial de um detector, geralmente, é expressa em termos do seu campo instantâneo de visada ou IFOV (Instantaneous Field of View). O IFOV define a área do terreno focalizada pelo sensor a uma dada altitude, ou seja, o IFOV representa o tamanho do pixel. A resolução geométrica de um detector é determinada pela resolução do ângulo sólido do IFOV, em mrad (milirad), e pela altitude do sistema sensor que é expressa em metros na superfície terreno.

- Resolução Espectral - é um conceito inerente às imagens multiespectrais de Sensoriamento Remoto. É definida pelo número de bandas espectrais de um sistema sensor e pela amplitude do intervalo de comprimento de onda de cada banda. A quantização das medidas radiométricas torna-se possível quando o sensor carrega dados de referência internos e calibrados.

- Resolução Radiométrica - é dada pelo número de valores digitais representando níveis de cinza, usados para expressar os dados coletados pelo sensor. Quanto maior o número de valores, maior é a resolução radiométrica. O número de níveis de cinza é normalmente expresso em função do número de dígitos binários (bits) necessários para armazenar, em forma digital, o valor do nível máximo. O valor em bits é sempre uma potência de 2 .

\subsubsection{Processamento digital e análise de imagens}

Outra etapa no processo de Sensoriamento Remoto é a de processamento e análise das imagens coletadas pelos sensores. Na etapa de processamento e análise é o momento em que o fotointérprete extrai as informações das imagens coletadas. 
Diversos são os desafios desde a captura das imagens até o processamento das mesmas, uma vez que a área de interesse pode estar coberta por nuvens, o que não permite identificar o objeto alvo de interesse, dificultando o trabalho de classificação. Quando a área monitorada possui grandes dimensões, tais como: área de um estado ou grandes reservas, o trabalho de fotointerpretação se torna extremamente oneroso e demorado, fazendo com que surjam técnicas e metodologias que procurem minimizar o esforço necessário para processar e analisar as imagens de Sensoriamento Remoto.

Essas metodologias devem permitir que os esforços sejam efetivamente minimizados. Antes de iniciar a etapa de análise das imagens, em alguns casos se faz necessária uma etapa de préprocessamento ou adaptação das imagens.

Nesta etapa de pré-processamento, as imagens são convertidas para formatos legíveis dos softwares especialistas, uma vez que, quando obtidas as mesmas encontram-se em formato bruto. São feitos dois tipos de correções nas imagens: as correções radiométricas e as correções geométricas.

Correções radiométrica são efetuadas nas imagens em função da característica específica do sensor utilizado, como por exemplo, ruídos eletrônicos, erros de quantização quando da transformação do sinal analógico para digital, defeitos do sensor entre outros. Essa correção destina-se a no mínimo reduzir as degradações radiométricas que ocorrem devido aos desajustes na calibração dos detectores e erros esporádicos na transmissão dos dados. As principais correções radiométricas são:

- stripping aplicado ao longo das linhas com base em padrão sucessivo, que aparecem na imagem em decorrência da diferença ou desajuste de calibração dos detectores; e

- droped lines, aplicado entre linhas com base em padrão anômalo na imagem, que ocorre pela perda de informações na gravação ou na transmissão dos dados.

Já as correções geométricas fazem-se necessárias para que a imagem possa ser utilizada e que medidas possam ser retiradas das mesmas. Esse tipo de correção retira as possíveis distorções das imagens oriundas da posição do sensor em relação a terra no momento da captura da imagem, ou seja, está relacionado diretamente ligada a atitude do sensor. Estas distorções podem ser corrigidas, pelo menos parcialmente, por meio de modelos matemáticos que descrevem as distorções existentes. Atualmente, para sensores digitais modernos, esse processamento atribui os valores de coordenada geográfica para cada pixel da imagem automaticamente, permitindo, desta forma, medir, comparar e sobrepor diferentes imagens de uma mesma região.

Analisar imagens implica em atuar e trabalhar com a semântica da imagem. Em alguns casos, a semântica das imagens encontra-se nos pixels, e na maioria dos casos essa importante informação semântica não está representada em pixels individuais, mas em objetos de imagem significativos e suas relações mútuas (BAATZ; SCHÄPE, 2000). 
Desse modo, na maioria dos casos, não é utilizado o pixel, mas um novo conceito, a Análise de Imagens Baseada em Objetos (OBIA) como meio de se obter informações mais detalhadas em termos de semântica quando se faz uso do Sensoriamento Remoto. A classificação, em Sensoriamento Remoto, significa a associação de pontos de uma imagem a uma classe ou grupo de classes. Estas classes representam as feições e alvos terrestres. Essa classificação de imagens é um processo de reconhecimento de classes ou grupos cujos membros exibem características comuns. Quando se classifica uma imagem, assume-se que objetos diferentes apresentam propriedades espectrais diferentes e que cada ponto pertence a uma única classe.

Essa classificação pode ser dividida em:

- Supervisionada - utilizada quando se tem algum conhecimento prévio sobre as classes na imagem permitindo, ao analista, definir sobre a mesma, áreas amostrais das classes. Estas áreas são utilizadas pelos algoritmos de classificação para identificar na imagem os pontos representativos das classes;

- Não supervisionada - útil quando não se tem informações relativas às classes de interesse na área imageada. Neste caso, as classes são definidas automaticamente pelo próprio algoritmo da classificação;

- Determinística (ou geométrica) - pressupõe-se que os níveis de cinza de uma imagem podem ser descritos por funções que assumem valores definidos de acordo com a classe;

- Estatística - assume-se que os níveis de cinza são variáveis aleatórias z.

Essas técnicas de classificação de imagens baseiam-se na abordagem pixel a pixel. Isso significa que cada pixel da imagem é analisado para saber se ele pertence ou não a uma determinada classe de interesse. Desse modo, a resposta espectral é que é utilizada para classificar o pixel. Esta técnica depende da quantidade de bandas espectrais que o sensor é capaz de capturar no momento da aquisição das imagens, de modo que quanto maior for a quantidade de bandas capturadas para o mesmo pixel, melhor será a discriminação do pixel no momento da classificação. A esse tipo de característica dá-se o nome de resolução espectral do sensor. Alguns sensores modernos chegam até 300 bandas, ou seja, para a mesma cena são capturadas 300 imagens. O processamento de imagens é utilizado neste doutorado para detectar e identificar de forma automática as regiões asfálticas nas imagens aéreas.

\subsubsection{Aplicações de Sensoriamento Remoto}

Diferentes são as áreas do conhecimento em que o Sensoriamento Remoto tem sido aplicado atualmente. As aplicações estendem-se desde a área ambiental, geologia, agricultura, engenharia florestal, meteorologia, hidrologia, uso e cobertura da terra (rural e urbana), oceanologia, engenharia de transporte entre muitas outras. Não diferente das outras áreas, na área de 
transportes o Sensoriamento Remoto por meio de imagens tem crescido nas últimas décadas. Destacam-se na literatura as seguintes aplicações:

- Uso de imagens de satélite como ferramenta de auxílio ao planejamento urbano;

- Detecção de arruamentos em áreas de ocupação urbana irregular com imagens do satélite;

- Determinação do índice de acessibilidade de uma região ou município por meio do uso de imagens de alta resolução espacial;

- Uso de imagens de alta resolução espectral e espacial na detecção de ruas asfaltadas;

- Monitoramento da condição da infraestrutura rodoviária;

- Uso de imagens SAR para o monitoramento de embarcações;

- Uso de imagens UV (ultravioleta) e IR (infravermelhos) na localização e rastreamento de derramamentos de óleo nos oceanos ou em transporte fluvial;

- Uso de imagens SAR (interferometria) e LIDAR para levantamento topográfico e planejamento da malha viária;

- Uso de imagens hiper-espectrais na detecção do envelhecimento do asfalto;

- Previsão da demanda de tráfego a partir da detecção de mudanças em áreas ocupadas por meio de imagens.

Dentre essas aplicações, o monitoramento da condição da infraestrutura viária é a aplicação foco deste trabalho.

\subsubsection{Sensores e plataformas de Sensoriamento Remoto}

Um sensor nada mais é que um dispositivo que responde a um estímulo físico/químico de maneira específica e mensurável analogicamente. No caso específico deste trabalho, os sensores correspondem às máquinas fotográficas que constituem o payload do VANT. Esses sensores têm por finalidade captar a radiação eletromagnética (REM) proveniente da superfície terrestre, e transformar a energia conduzida pela onda em pulso eletrônico ou valor digital proporcional à intensidade desta energia. Os sensores podem ser classificados como ativos e passivos de acordo com a fonte da onda eletromagnética.

Sensores passivos utilizam apenas a REM natural refletida ou emitida a partir da superfície terrestre. A luz solar é a principal fonte de REM dos sensores passivos. Nesta categoria estão, principalmente, os sensores da faixa do espectro visível e infravermelho, o Enhanced Thematic Mapper Plus (ETM+) e o Multispectral Scanner System (MSS) ambos do satélite americano 
Landsat, o Imageador de Amplo Campo de Visada (Wide Field Imager - WFI) e o Imageador por Varredura de Média Resolução (IRMSS - Infrared Multispectral Scanner System) do satélite China-Brazil Earth Resources Satellite (CBERS) e o sensor Compact Airborne Spectrographic Imager (CASI). Esses tipos de sensores, passivos, são os utilizados neste trabalho.

Já os sensores ativos utilizam a REM artificial, produzida por radares instalados nos próprios satélites. Estas ondas atingem a superfície terrestre onde interagem com os alvos, sendo refletidas de volta ao satélite. Como exemplo de sensores ativos temos: radares de abertura sintética (SAR - Sinthetic Aperture Radar), radares meteorológicos, Light Detection and Ranging (LIDAR), dentre outros. A grande vantagem dos sensores ativos está no fato de não dependerem das fontes de energia naturais, o sol ou a energia emitida dos objetos (termal). Por essa razão, os sensores ativos podem ser utilizados durante o dia ou noite. No caso dos sensores SAR, é possível adquirir imagens de uma região independente das condições meteorológicas. Outra vantagem dos sensores ativos é que as ondas produzidas pelos radares atravessam as nuvens, podendo ser operados sob qualquer condição atmosférica. Uma desvantagem é que o processo de interação com os alvos não capta, tão detalhadamente quanto os sensores passivos, informações sobre as características físicas e químicas das feições terrestres.

As plataformas de SR podem ser terrestres (fixas ou móveis), aéreas ou espaciais. Uma torre de vigilância contra incêndios florestais com sensores óticos e termais é um exemplo de uma plataforma terrestre fixa. Atualmente tem sido utilizados para obtenção de informações de filogenia. Já um veículo dotado de um perfilador laser e câmeras de imageamento para o monitoramento de pavimentos é um exemplo de plataforma terrestre móvel. Há um grande número de plataformas aéreas de sensoriamento, tais como: balões, aeronaves de pequeno, médio e grande porte, e também os veículos aéreos não tripulados (que graças ao avanço da tecnologia podem ser adquiridos e serem utilizados a baixos custos). As plataformas espaciais podem ser orbitais ou geoestacionárias. Os satélites Landsat e CBERS são exemplos de plataformas orbitais, já os satélites meteorológicos METEOSAT e o Geostationary Operational Environmental Satellites (GOES) são exemplos de plataformas espaciais geoestacionárias.

Nesta tese de doutorado, como mencionado anteriormente, é utilizado como plataforma de Sensoriamento Remoto os Veículos Aéreos Não Tripulados (VANTs).

\subsection{Veículos Aéreos Não Tripulados}

Esta seção apresenta os principais conceitos relacionais aos Veículos Aéreos Não Tripulados, um tipo de sistema embarcado crítico que vem ganhando espaço nos últimos tempos e que é apontado como um tema promissor para os próximos anos. Este capítulo introduz os conceitos fundamentais para o domínio do assunto em questão como definições, caracterização dos principais subsistemas que compõem um sistema de aeronaves não tripuladas, as classificações presentes em alguns países e as principais aplicações que podem ser realizadas com a 
utilização dessa plataforma.

\subsubsection{Sistemas embarcados críticos}

Diversas são as definições encontradas na literatura para sistemas embarcados. Segundo Barr (1999), um sistema embarcado (do inglês, embedded system) é uma combinação de software e hardware projetada para desempenhar uma tarefa específica, ou seja, um sistema baseado em microprocessador que opera embutido como subsistema de um determinado sistema maior, seja ele computacional ou não. Berger (2001) apresenta uma visão focada em hardware, definindo sistemas embarcados como compostos, normalmente, por uma unidade de processamento, a qual consiste em um circuito integrado fixado a um circuito impresso. Os autores de Bloomfield et al. (2005) definiram sistemas embarcados como ubíquos, pois podem ser encontrados em uma vasta quantidade de produtos, caros e possuidores de um vasto mercado, apresentando, desta forma, visão mais voltada para o mercado.

Por concenso geral, sistemas embarcados são uma combinação de hardware e software, e possivelmente mais algumas peças mecânicas, destinadas a executar uma função específica. Em alguns casos, são parte de um sistema ou produto.

Sistemas embarcados críticos são sistemas que podem, em casos de falhas, ocasionar sérios danos físicos a indivíduos, perdas de vidas humanas, prejuízos significativos por danos materiais, danos ao meio ambiente e colocar em risco instalações de alto custo ((KNIGHT, 2002); (DUNN, 2003); (YI; CAI; YUE, 2008); (ARMOUSH; BECKSCHULZE; KOWALEWSKI, 2009); (MEDIKONDA; PANCHUMARTHY, 2009); (JR et al., 2009); (BRANCO, 2012)).

Estes sistemas estão inseridos, geralmente, em um sistema mais amplo, como é o caso de um refrigerador, onde existe um sistema de refrigeração, composto de um motor e uma serpentina, mas existe um sistema embarcado que recebe comandos de ajustes de temperatura e monitora o funcionamento do motor de refrigeração, ligando-o e desligando-o ao atingir temperaturas pré-programadas. Existem muitos exemplos da utilização dessa classe de sistemas, tais como: aplicações médicas, indústria automotiva, aeronaves, sistemas de controle de veículos, robótica, sistemas de energia, usinas nucleares e inúmeras outras aplicações comerciais e industriais.

Em algumas aplicações, como na aviação, os sistemas embarcados críticos devem apresentar baixas taxas de falhas, como uma falha grave a cada período de $10^{5}$ a $10^{9}$ horas de operação (BRANCO, 2012). Os domínios de aviônicos e automotivos são exemplos clássicos de sistemas embarcados críticos. Desse modo, custos, ciclos de produção curtos e requisitos que visam rentabilidade, robustez, segurança, controle de emissão de poluentes e demandas específicas de cada cenário são fatores determinantes nesse tipo de sistema Januzaj et al. (2010). Devido ao alto investimento em pesquisas nesta área, a perda de um produto destes acarreta em perdas financeiras consideravelmente altas. Este doutorado está particularmente interessado nos VANTs (Veículos Aéreos Não Tripulados), os quais são considerados uma aplicação típica de 
sistemas embarcados críticos e serão abordados na próxima sub-seção.

\subsubsection{Definições e características básicas de Veículos Aéreos Não Tripulados}

Segundo o relatório do DoD (Departamento de Defesa dos EUA) denominado Unmanned Aerial Vehicle Roadmap 2002 - 2027 Aldridge e Stenbit (2002), que é um dos principais e mais completos documentos sobre o estado da arte da tecnologia, VANT, de modo geral, pode ser definido como uma aeronave capaz de voar sem a presença de um piloto humano a bordo.

Formalmente, VANTs são definidos como: "Veículos aéreos que não carregam operador humano, utilizam forças aerodinâmicas para se elevar, podem voar autonomamente ou ser pilotados remotamente, podem ser descartáveis ou recuperáveis e podem transportar cargas bélicas ou não bélicas. Excluem-se desta definição, veículos balísticos e semi-balísticos como mísseis de cruzeiro, e projéteis." (ARMY, 2010).

O conceito de construir aeronaves não tripuladas para aplicações diversas surgiu, inicialmente, de necessidades militares, visando a execução de missões aéreas que ofereciam risco à vida humana.

O termo robô aéreo, cunhado em 1990, descreve uma classe de máquinas voadoras pequenas e altamente inteligentes, não impondo nenhuma restrição de autonomia, podendo ser autônomos ou controlados a distância por operadores humanos. As aeronaves mais utilizadas são os aviões, helicópteros e dirigíveis.

Um VANT é um robô aéreo que faz parte de um SANT (Sistema de Aeronave Não Tripulada). Esse termo é utilizado pelo DoD para refletir que esses sistemas complexos incluem não somente a aeronave, mas também as estações de solo, o payload e outros elementos conforme exemplificado na Figura 2.3, que são descritos em detalhes:

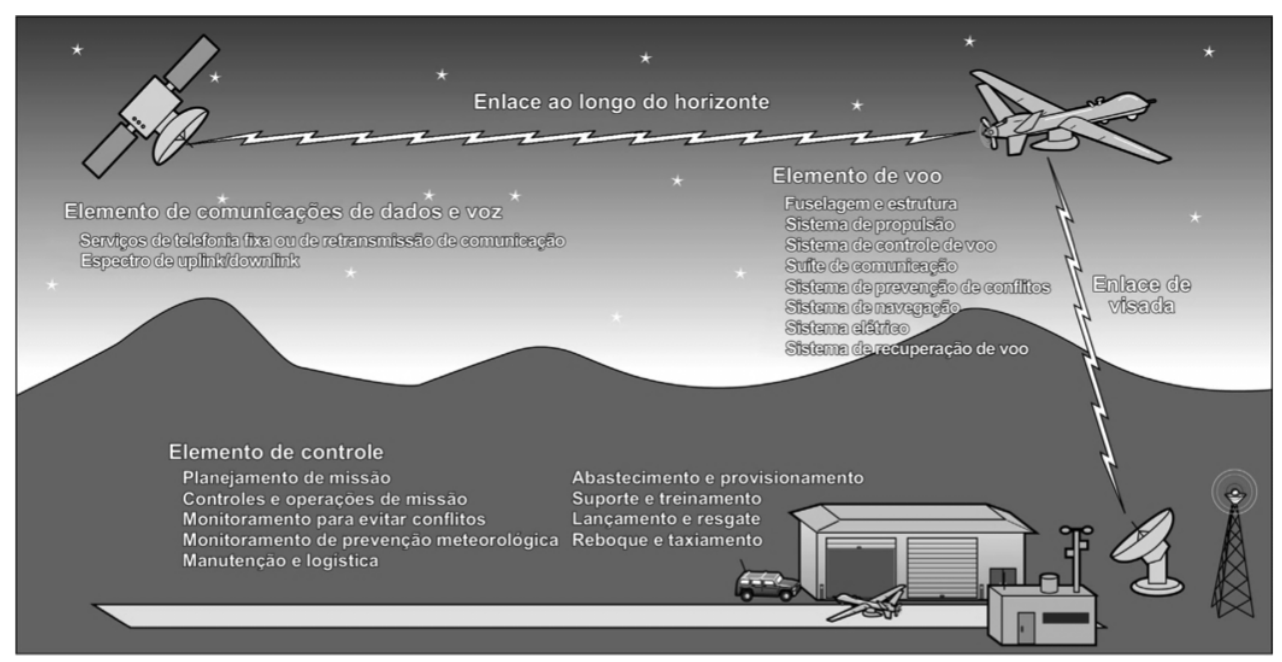

Figura 2.3 - Conceito de um SANT - Adaptado de (MICA; COSTELLO, 2008). 
- A aeronave, dotada de processadores de missão, sistemas de navegação e sensores tais como câmeras de vídeo, termais e radares, o chamado payload;

- Estação de Controle Terrestre, conhecida também como estação base, constitui o centro de controle operacional de todo o sistema. É a partir dela que se pode controlar desde o lançamento, passando pelo voo ou operação propriamente dita até chegar a recuperação do VANT. Fica a cargo dela também receber e processar os dados dos sensores que compõem o payload, controlar o seu funcionamento (geralmente em tempo real) e fornecer uma interface entre o sistema e o mundo exterior. Ela é um sistema de computador projetado para acompanhar o desenvolvimento da missão e, eventualmente, operar o VANT e seu payload (PASTOR; LOPEZ; ROYO, 2007);

- Payload, normalmente sensores, e equipamentos adicionados com a finalidade de realizar uma missão. O payload pode também englobar armamentos e outros dispositivos, excluindo-se aviônicos (eletrônicos da aviação), links de comunicação e combustível (PASTOR; LOPEZ; ROYO, 2007);

- Links de Comunicação de Dados, uma combinação de mecanismos de comunicação (rádio, satélites, dentre outros) que deve garantir conexão contínua entre o VANT e a estação de controle terrestre (PASTOR; LÓPEZ; ROYO, 2006). Compõem a parte do link o hardware necessário para a comunicação, as Antenas de Comunicação, normalmente com opção de rastreamento da aeronave para aumento de alcance e largura da banda de comunicação;

- Sistemas de suporte, o que incluem sistemas de manutenção, lançamento, pouso e transporte da aeronave (AUSTIN, 2011).

O VANT pode ser pilotado a distância por meio de uma estação de controle terrestre ou realizar missões pré-programadas de forma autônoma (OLIVEIRA, 2009), (JR et al., 2002), (TRINDADE et al., 2010) e (AUSTIN, 2011).

\subsubsection{Classificação dos VANTs}

De acordo com a Federal Aviation Administration (FAA), por exemplo, um VANT pode ter diversas formas, tamanhos e propósitos. Pode ser tão pequeno quanto um modelo rádio controlado ou possuir uma envergadura tão grande quanto um Boeing 737.

A Portaria Normativa número 606 do Ministério da Defesa, publicada no Diário Oficial da União número 112 em 14 de junho de 2004, estabelece, no Brasil, que o VANT é uma plataforma aérea de baixo custo operacional, a qual pode ser operada via controle remoto ou executar voos de forma autônoma. Adicionalmente, VANTs podem ser utilizados para: transportar cargas convencionais, tais como sensores e equipamentos de comunicação; servir como alvo aéreo; e levar designador de alvo e cargas letais, quando empregados para fins bélicos. 
Os VANTs podem ser aeronaves das mais diversas formas, tais como: asas fixas (aviões), asas rotativas (helicópteros), balões dirigíveis e variantes de todos estes, além de utilizar o mais diversos meios de propulsão: combustão interna, turbinas, motores elétricos, gases mais leves que o ar, entre outros. Seu emprego, para fins militares, pode variar desde um alvo móvel para treinamento de artilharia antiaérea, vigilância, reconhecimento, monitoramento e as versões mais avançadas como aeronaves armadas para ataque. As versões civis são utilizadas para fotografia aérea, filmagem, busca e salvamento, monitoramento ambiental e recreação. Desse modo, classificar os VANTs tem sido considerada uma das dificuldades relacionadas ao assunto, devido principalmente à falta de padronização de uma metodologia na classificação desse tipo de aeronave.

Essa ausência, tanto de normas nacionais quanto internacionalmente aceitas para a classificação, permite que cada país desenvolva suas próprias regras para categorizar os VANTs. Nas seções a seguir são apresentadas as classificações mais usuais e que mais aparecem na literatura, que são adotadas pelo Reino Unido, Estados Unidos, Europa em geral e Brasil.

Uma das classificações mais comuns existentes na literatura é a baseada no tamanho e autonomia da aeronave, sendo apresentada da seguinte maneira (AUSTIN, 2011):

- HALE: do inglês High Altitude Long Endurance, são aeronaves que voam acima dos 15000 $\mathrm{m}$ de altitude e possuem uma autonomia maior do que 24 horas. Usadas geralmente por forças aéreas para missões de reconhecimento e vigilância de áreas muito extensas;

- MALE: do inglês Medium Altitude Long Endurance, são aeronaves que voam acima de 1500 e até $5000 \mathrm{~m}$ de altitude e possuem uma autonomia de aproximadamente 24 horas. Usadas para as mesmas aplicações que as HALE, para distâncias menores mas ainda superiores a $500 \mathrm{~km}$;

- TUAV: do inglês Tactical UAV, são aeronaves de médio alcance, entre 100 e $300 \mathrm{~km}$. São menores do que as HALE e MALE, mas usadas para as mesmas missões, com menor alcance;

- Close-Range: são aeronaves com alcance de aproximadamente $100 \mathrm{~km}$ e são usadas em diversas missões, como de reconhecimento, de designação de alvos, de monitoramento de produtos nocivos, entre outras;

- MUAV: do inglês Mini UAV, são aeronaves de pequeno porte, com aproximadamente 20 $\mathrm{kg}$, e com alcance de $30 \mathrm{~km}$. Usadas para as mais diversas aplicações, como as CloseRange;

- MAV: do inglês Micro UAV, são aeronaves ainda menores, usadas em ambientes urbanos. Geralmente voam em baixas velocidades e possuem a capacidade de pairar no ar e/ou de se fixar em uma parede. Devido a esses requisitos, algumas pesquisas são realizadas utilizando a configuração de batedores de asas; 
- NAV: do inglês Nano Air Vehicle, são aeronaves menores do que a palma de uma mão e são usadas em enxames para missões como a confusão de radares ou a vigilância de curtíssimo alcance.

A Civil Aviation Authority (CAA) do Reino Unido utiliza uma orientação provisória de acordo com o peso da aeronave (AUTHORITY, 2012) (Tabela 2.1).

Tabela 2.1 - Classificação segundo a CAA, Reino Unido. Adaptado de (AUTHORITY, 2012).

\begin{tabular}{|c|c|c|c|c|}
\hline $\begin{array}{c}\text { Classificação } \\
\text { por Peso }\end{array}$ & Categoria Civil & Peso (kg) & Equivalente Militar & $\begin{array}{c}\text { Regulamentação } \\
\text { Civil }\end{array}$ \\
\hline 1 & $\begin{array}{c}\text { Aeronave não } \\
\text { tripulada } \\
\text { pequena }\end{array}$ & $0-20$ & $\begin{array}{c}\text { Micro (até 5kg) e } \\
\text { Mini (até 30kg) }\end{array}$ & Nacional \\
\hline 2 & $\begin{array}{c}\text { Aeronave não } \\
\text { tripulada } \\
\text { Leve }\end{array}$ & $21-150$ & Tático & Nacional \\
\hline 3 & $\begin{array}{c}\text { Aeronave não } \\
\text { tripulada }\end{array}$ & $>150$ & $\begin{array}{c}\text { MALE } \\
\text { HALE }\end{array}$ & $\begin{array}{c}\text { European Aviation } \\
\text { Safety } \\
\text { Agency (EASA) }\end{array}$ \\
\hline
\end{tabular}

Por outro lado, a classificação nos Estados Unidos, feita pelo DoD baseia-se no peso máximo de decolagem, na altitude (dada em relação ao nível do chão) e na velocidade do voo (Tabela 2.2) (CLAPPER et al., ), (DOD, 2013).

Tabela 2.2 - Classificação segundo o DoD, Estados Unidos. Adaptado de (DOD, 2013).

\begin{tabular}{|c|c|c|c|}
\hline Grupo & $\begin{array}{c}\text { Máximo peso de } \\
\text { decolagem } \mathbf{( k g})\end{array}$ & Altitude de voo $\mathbf{( m )}$ & Velocidade $\mathbf{( m / s )}$ \\
\hline 1 & Até 9,1 & Até 365,80 & Até 51,40 \\
\hline 2 & De 9,5 até 25 & Até 1066,80 & Até 128,60 \\
\hline 3 & Até 598,70 & Até 5486,40 & Até 128,60 \\
\hline 4 & Maior que 598,70 & Até 5484,40 & Variada \\
\hline 5 & Maior que 598,70 & Maior que 5484,40 & Variada \\
\hline
\end{tabular}

No Brasil não existe uma classificação oficial dos VANTs, porém se reconhece o seu desenvolvimento e diferencia-se aeronaves remotamente pilotadas como uma subcategoria de VANTs. É possível também obter um certificado de autorização de voo experimental, sendo cada caso analisado especificamente pela Agência Nacional de Aviação Civil (ANAC).

Isso se deve ao fato de que em 2004, o hoje extinto Departamento de Aviação Civil (DAC), atual ANAC, propôs o Regulamento Brasileiro de Homologação Aeronáutica (RBHA) número 100. Esse novo regulamento seria aplicado especificamente aos VANTs. Porém, a proposta do RBHA 100 foi retirada do DAC por não atender as normas da International Civil Aviation Organization (ICAO) Oliveira (2009). De qualquer forma, o RBHA 100 classificava os VANTs em três tipos: 
- Tipo 1: peso máximo de decolagem igual ou inferior a $20 \mathrm{~kg}$, operado por controle remoto;

- Tipo 2: peso máximo de decolagem superior a $20 \mathrm{~kg}$, operado por controle remoto;

- Tipo 3: qualquer peso máximo de decolagem, operado por controle autônomo.

A partir de 2016 a ANAC passou a alinhar-se com a FAA no sentido de regulamentar o uso de aeronaves de pequeno porte. As informações mais recentes podem ser obtidas na ANAC ${ }^{2}$.

A classificação Européia é definida pela UVS International e baseia em VANTs pequenos aplicados para missões civis. Essa classificação foi realizada com dados de uma pesquisa em 2009 obtidos com organizações de 27 países, e divide os VANTs de acordo com as suas aplicações, alcance, altitude de voo, duração do voo e peso máximo de decolagem, como pode ser visto na Tabela 2.3 (BLYENBURGH, 2006), (ENTERPRISE et al., 2013), (YEARBOOK, 2011).

Essa classificação foi adotada nesse trabalho por considerar mais parâmetros e, portanto, ser mais completa, desse modo a aeronave utilizada neste doutorado é considerado um Micro VANT por possuir um peso máximo de decolagem menor do que $5 \mathrm{~kg}$ e um alcance de aproximadamente $10 \mathrm{~km}$.

As classificações, como já mencionadas, surgiram devido ao grande número de VANTs sendo desenvolvidos para as mais diferentes missões. Com o objetivo de exemplificar e justificar tal uso, algumas aplicações são relatadas na próxima sub-seção.

\subsubsection{Aplicações dos VANTs}

Os VANTS foram concebidos inicialmente para aplicações militares, entretanto, vêm sendo empregados de forma crescente em diversos tipos de aplicações e serviços civis, aproveitando um grande mercado emergente. Especificamente, os VANTs podem ser aplicados em missões do tipo D-cube (Dangerous-Dirty-Dull), ou seja, missões consideradas perigosas, sujas, ou enfadonhas (FURTADO et al., 2008); (CHAO; CAO; CHEN, 2010).

$\mathrm{Na}$ literatura, foram encontradas várias referências sobre aplicações de Veículos Aéreos Não Tripulados para realizar diferentes tarefas. A maioria das aplicações encontradas Jacques (2002), Cooper e Goodrich (2008), Pitre, Li e DelBalzo (2009), George, Sujit e Sousa (2011), Willigen et al. (2011) se concentram em tarefas relacionadas à missões militares como busca, detecção, reconhecimento, rastreamento e ataque a alvos móveis e realocáveis, e utilizam sensores como câmeras fotográficas, de vídeo e de infravermelho, sensores de temperatura, ultravioleta, laser e detectores de reagentes químicos. Entretanto, como pode ser observado na classificação da UVS International, graças ao avanço tecnológico nos setores de processamento de dados e a miniaturização de componentes eletrônicos ocorridos nas últimas duas décadas,

\footnotetext{
${ }^{2} \mathrm{http}: / /$ www2.anac.gov.br/transparencia/audienciasPublicas.asp
} 
Tabela 2.3 - Classificação segundo a UVS International, Europa, de VANTs pequenos e que estão em operação. Adaptado de (YEARBOOK, 2011).

\begin{tabular}{|c|c|c|c|c|c|}
\hline Aplicação & Grupo & $\begin{array}{c}\text { Máximo } \\
\text { peso de } \\
\text { decolagem } \\
\text { (kg) }\end{array}$ & $\begin{array}{l}\text { Altitude de } \\
\text { voo }(\mathrm{m})\end{array}$ & $\begin{array}{c}\text { Duração } \\
\text { (horas) }\end{array}$ & $\begin{array}{c}\text { Alcance } \\
(\mathrm{km})\end{array}$ \\
\hline \multirow[t]{10}{*}{ Tática } & Nano & Até 0,025 & 100 & Até 1 & Até 1 \\
\hline & Micro & Até 5 & 250 & 1 & Até 10 \\
\hline & Mini & Até 30 & $\begin{array}{c}\text { De } 150 \text { até } \\
300\end{array}$ & Até 2 & Até 10 \\
\hline & $\begin{array}{c}\text { Próximo } \\
\text { alcance }\end{array}$ & 150 & 3000 & De 2 até 4 & $\begin{array}{c}\text { De } 10 \text { até } \\
30\end{array}$ \\
\hline & $\begin{array}{l}\text { Curto } \\
\text { alcance }\end{array}$ & 200 & 3000 & De 3 até 6 & $\begin{array}{c}\text { De } 30 \text { até } \\
60\end{array}$ \\
\hline & $\begin{array}{l}\text { Médio } \\
\text { alcance }\end{array}$ & 1250 & 5000 & De 6 até 10 & $\begin{array}{c}\text { De } 70 \text { até } \\
200\end{array}$ \\
\hline & $\begin{array}{l}\text { Médio } \\
\text { alcance e } \\
\text { duração }\end{array}$ & 1250 & 8000 & $\begin{array}{c}\text { De } 10 \text { até } \\
18\end{array}$ & $\begin{array}{c}\text { Maior do } \\
\text { que } 500\end{array}$ \\
\hline & $\begin{array}{c}\text { Baixa } \\
\text { altitude }\end{array}$ & 350 & $\begin{array}{c}\text { De } 50 \text { até } \\
9000\end{array}$ & De 0,5 até 1 & $\begin{array}{c}\text { Maior do } \\
\text { que } 250\end{array}$ \\
\hline & $\begin{array}{c}\text { Baixa } \\
\text { altitude e } \\
\text { longa } \\
\text { duração }\end{array}$ & Até 30 & 3000 & $\begin{array}{c}\text { Maior do } \\
\text { que } 24\end{array}$ & $\begin{array}{c}\text { Maior do } \\
\text { que } 500\end{array}$ \\
\hline & $\begin{array}{c}\text { Média } \\
\text { altitude e } \\
\text { longa } \\
\text { duração }\end{array}$ & 1500 & 14000 & $\begin{array}{c}\text { De } 24 \text { até } \\
48\end{array}$ & $\begin{array}{c}\text { Maior do } \\
\text { que } 500\end{array}$ \\
\hline Estratégica & $\begin{array}{c}\text { Alta altitude } \\
\text { e longa } \\
\text { duração }\end{array}$ & $\begin{array}{c}\text { De } 4500 \mathrm{a} \\
12000\end{array}$ & 20000 & De 24 até 48 & $\begin{array}{l}\text { Maior do } \\
\text { que } 2000\end{array}$ \\
\hline \multirow[t]{4}{*}{$\begin{array}{c}\text { Propósito } \\
\text { Especial }\end{array}$} & $\begin{array}{l}\text { VANT de } \\
\text { combate }\end{array}$ & 10000 & 10000 & 2 & 1500 \\
\hline & Letal & 250 & 4000 & De 3 a 4 & 300 \\
\hline & Isca & 250 & 5000 & Até 4 & $\begin{array}{c}\text { De } 0 \text { até } \\
500\end{array}$ \\
\hline & Estratosférico & Até 5 & 250 & 1 & Até 10 \\
\hline
\end{tabular}

os VANTs de pequeno porte podem ser utilizados para diversas aplicações, não só na área militar, mas também no âmbito civil. Alguns exemplos de aplicações são listadas por (MERINO et al., 2006), (AUSTIN, 2011), (BEKMEZCI; SAHINGOZ; TEMEL, 2013):

- Aquisição de dados e imagens de alvos em áreas inacessíveis por meios terrestres;

- Localização de alvos; 
- Rastreamento;

- Mapeamento de vias e construções;

- Cenários de desastres causados pelo homem ou pela natureza;

- Busca e resgate;

- Reforço na aplicação da lei;

- Vigilância e monitoramento de tráfego;

- Identificação de rodovias;

- Inspeção de linhas de transmissão de energia;

- Medições;

- Transporte de carga;

- Cinematografia;

- Sensoriamento Remoto.

Atualmente também há a utilização de VANTs na agricultura de precisão, buscando melhorar a produtividade e a qualidade das plantações. Nesse caso em particular, o uso de VANT como ferramenta de mapeamento e monitoramento de plantações é muito apropriado, pois permite a aquisição de imagens com uma alta resolução espacial, na ordem de centímetros, com custos operacionais relativamente baixos e com disponibilidade rápida, em questão de horas Xiang e Tian (2011); Hardin e Hardin (2010). Essas aplicações são realizadas com sucesso (ZHANG; KOVACS, 2012).

Esse crescente uso dos VANTS deve permitir que os mesmos se tornem algo comum, de modo que passem a ser comercializados de forma mais ampla garantindo uma disseminação cada vez maior. Um dos objetivos desse doutorado é o monitoramento das condições da pavimentação de rodovias por meio do uso de VANTs. Embora ocorra aumento do número de projetos de VANTs voltados para aplicação civil, esta ainda pode ser considerada recente e incipiente, principalmente no cenário brasileiro. Deste modo, há carência de estudos que apresentem o estágio atual do desenvolvimento do Sensoriamento Remoto por VANTs. As principais vantagens do Sensoriamento Remoto por VANTs, em relação ao aerotransportado por aeronaves tripuladas e ao orbital, podem ser: a redução dos custos de obtenção de imagens/fotografias/visões aéreas; a maior flexibilidade de resolução temporal para aquisição de imagens de alta resolução espacial; possibilidade de execução de missões em condições adversas sem o risco de vida para o piloto e operador da câmara aerofotogramétrica; menor necessidade de gastos de treinamento de pilotos e; a maior facilidade e velocidade de incorporação de novas tecnologias. Cabe ressaltar: a detecção, monitoramento, caracterização e 
mapeamento de eventos, processos e alterações de rápido desenvolvimento, como é o caso da detecção de pavimentação e sinalização horizontal precárias, que necessitam de manutenção tanto corretiva quanto preventiva, em rodovias.

\subsection{Conservação de rodovias - pavimentos asfaltados}

Esta seção tem por objetivo apresentar conceitos básicos sobre a conservação de rodovias, e dessa forma, apresenta os conceitos básicos de avaliação funcional, bem como os tipos de defeitos básicos encontrados nos pavimentos asfálticos. Dessa forma, conhecendo os principais tipos de defeitos, é possível desenvolver técnicas e mecanismos automatizados que permitam que esses defeitos possam ser detectados a partir da utilização de VANTs.

\subsubsection{Conservação de rodovias}

A conservação da malha viária compreende o conjunto de operações rotineiras, periódicas e normalmente de emergência realizadas com o objetivo de preservar as características técnicas e físico-operacionais do sistema rodoviário e das instalações fixas, dentro de padrões de serviço estabelecidos, sejam eles por Normas ou regras pelas agências reguladoras.

Os serviços de conservação das rodovias fazem parte do conjunto de funções e atividades destinadas a proporcionar conforto e segurança aos usuários.

Neste contexto, a estrutura dos serviços de conservação deverá estar direcionada para os aspectos físicos do sistema rodoviário, ou seja, aqueles relacionados às condições da pista, em termos de pavimentação, drenagem, dispositivos de segurança, sinalização horizontal, vertical e aérea, obras-de-arte especiais, entre outros.

As tarefas de conservação propriamente dita podem ser enfocadas em função de sua natureza e finalidade específica. Dividem-se basicamente em 5 grupos que constituem Macroatividades que comportam, segundo a terminologia oficial do DNIT, as definições que seguem:

- Conservação Corretiva Rotineira - conjunto de operações de conservação que tem como objetivo reparar ou sanar um defeito e restabelecer o funcionamento dos componentes da rodovia, propiciando conforto e segurança aos usuários;

- Conservação Preventiva Periódica - conjunto de operações de conservação, realizadas periodicamente com o objetivo de evitar surgimento ou agravamento de defeitos; Tratase de tarefas requeridas durante o ano, mas cuja frequência de execução depende do trânsito, topografia e clima;

- Conservação de Emergência - conjunto de operações, que com o serviço ou obras necessárias para reparar, repor, reconstruir ou restaurar trechos ou estrutura da rodovia, que tenham sido seccionados, obstruídos ou danificados por um evento extraordinário, catastrófico, ocasionando à interrupção do tráfego da rodovia; 
- Restauração - conjunto de operações destinado a restabelecer o perfeito funcionamento de um bem determinado ou avariado, e restabelecer, na íntegra, suas características técnicas originais. Envolve, portanto um conjunto de medidas destinadas a adaptar a rodovia, de uma forma permanente, às condições de tráfego atuais e futuras, prolongando seu período de vida;

- Melhoramentos da Rodovia - conjunto de operações que acrescentam à rodovia existente, características novas, ou modificam as características existentes.

\subsubsection{Tipos de pavimentos}

Os pavimentos que serão foco deste trabalho são as vias com pavimento asfáltico.

O pavimento é uma estrutura de múltiplas camadas de espessuras finitas construída sobre a superfície final de terraplenagem. Essa estrutura é destinada, técnica e economicamente, a resistir aos esforços oriundos do tráfego de veículos e do clima, e a propiciar aos usuários melhoria nas condições de utilização das mesmas, provendo conforto, economia e segurança.

O pavimento rodoviário se classifica, tradicionalmente, em dois tipos: rígidos e flexíveis. Entretanto, recentemente há a tendência de usar a nomenclatura pavimentos de concreto de cimento Portland (ou concreto-cimento) e pavimentos asfálticos, respectivamente, para indicar o tipo de revestimento do pavimento.

- Concreto - cimento - aqueles em que o revestimento é uma placa de concreto de cimento Portland. Neles a espessura é fixada em função da resistência à flexão das placas de concreto e das resistências das camadas subjacentes;

- Asfálticos - aqueles em que o revestimento é composto por uma mistura constituída basicamente de agregados e ligantes asfálticos. É formado por quatro camadas principais: revestimento asfáltico, base, sub-base e reforço do subleito. O revestimento asfáltico pode ser composto por camada de rolamento - em contato direto com as rodas dos veículos e por camadas intermediárias ou de ligação denominadas binder.

O revestimento asfáltico é a camada superior destinada a resistir diretamente às ações do tráfego e atenuar o impacto quando transmitidos às camadas inferiores, impermeabilizar o pavimento, além de melhorar as condições de conforto e segurança dos usuários.

Tensões e deformações induzidas na camada asfáltica pelas cargas do tráfego estão associadas à formação das trincas por fadiga dessa camada. Essa camada pode ainda apresentar trincas por envelhecimento do ligante asfáltico, ação climática entre outros. Parte de problemas relacionados à deformação permanente e outros defeitos pode ser atribuída ao revestimento asfáltico. 
Propor alternativas para a restauração do pavimento asfáltico exige o estudo da condição do pavimento existente, estudo este que deve ser precedido por avaliação funcional e estrutural. Essas avaliações proveem dados tanto para análise da condição da superfície do pavimento e de sua estrutura, quanto para a definição das alternativas de restauração apropriadas.

Na primeira avaliação, a funcional, verifica-se a condição da superfície do pavimento, por meio do levantamento e análise de defeitos superficiais, e da condição de irregularidade longitudinal. Os principais defeitos averiguados na avaliação funcional são: área trincada e severidade das trincas, deformações permanentes e irregularidade longitudinal.

Já na avaliação estrutural verifica-se a condição da estrutura do pavimento de suportar cargas, por meio de levantamentos não-destrutivos pela determinação da deflexão superficial resultante da aplicação de uma carga conhecida.

A avaliação funcional de um pavimento relaciona-se à apreciação da superfície dos pavimentos e a influência deste no conforto do usuário. Para isso existem alguns métodos sistemáticos para a avaliação funcional: Serventia é a forma mais comum. Concebida por Carey e Irick Jr e Irick (1960), corresponde uma atribuição numérica compreendida em uma escala de 0 a 5 (conforme Tabela 2.4), dada pela média de notas de avaliadores para o conforto ao rolamento de um veículo trafegando em um determinado trecho, em um dado momento da vida do pavimento.

Tabela 2.4 - Níveis de Serventia. Adaptado de (JR; IRICK, 1960).

\begin{tabular}{|l|c|}
\hline Padrão de conforto & Faixa de notas \\
\hline Excelente & 4 a 5 \\
\hline Bom & 3 a 4 \\
\hline Regular & 2 a 3 \\
\hline Ruim & 1 a 2 \\
\hline Péssimo & 0 a 1 \\
\hline
\end{tabular}

Levantamentos recorrentes da Confederação Nacional do Transporte (CNT) têm considerado a grande maioria dos pavimentos do Brasil de baixo conforto e segurança e, observado que a malha rodoviária brasileira encontra-se em condições insatisfatórias aos usuários também com relação ao desempenho e à economia, uma vez que as estradas, principal quando considerada meio de escoamento da produção nacional, encontram-se em um estado que não são capazes de atender as necessidades de transporte de carga nacionais. Essa realidade torna o Brasil pouco competitivo no mercado exterior criando uma situação econômica nacional ruim.

O estado da superfície do pavimento é o mais importante, principalmente do ponto de vista do usuário, pois os defeitos ou irregularidades nessa superfície são percebidos por afetarem o conforto do motorista. Além do conforto, o veículo propriamente dito também sofre as consequências desses defeitos.

Isto leva a maiores custos operacionais que estão diretamente relacionados a maiores gastos com peças de manutenção dos veículos, com consumo de combustível e de pneus, com o tempo 
de viagem, entre outros. Diagnosticar e promover as medidas de correção e manutenção destas rodovias permite uma economia nos custos do transporte.

Neste trabalho, o que se pretende é fazer uma avaliação funcional, detectando as condições das superfícies asfálticas.

\subsubsection{Defeitos de superfícies asfálticas}

Os defeitos na superfície podem aparecer precocemente ou a médio e longo prazo. Os defeitos precoces ocorrem devido a erros ou inadequações, enquanto os de médio ou longo prazo ocorrem normalmente devido à utilização pelo tráfego e efeitos das intempéries. Segundo LIEDI et al. (2008) os defeitos de pavimentos asfálticos decorrem principalmente dos seguintes fatores:

- Erros de projeto - decorrem de diferentes fatores como aqueles relacionados à dificuldade de prever o tráfego real que atuará no período de projeto, problemas no dimensionamento estrutural, especificação de materiais inexistente ou de difícil disponibilidade no local, problemas com o aprisionamento de água;

- Erros ou inadequações na seleção de materiais ou na dosagem de materiais - esses erros decorrem da seleção incorreta de solo para reforço de subleito, seleção imprópria de agregados e de graduação para compor bases e sub-bases, além da seleção imprópria do tipo de solo ou dosagem inadequada para solo-brita, dosagem de materiais estabilizados com cimento ou cal, entre outros;

- Erros ou inadequações construtivas - esses erros por sua vez decorrem da falta de compactação apropriada das camadas, técnica de compactação inadequada, compactação de misturas asfálticas em temperaturas inadequadas, erros nas taxas do impermeabilizante ou ligante;

- Erros ou inadequações nas alternativas de conservação e manutenção - esses erros decorrem do reforço de revestimento asfáltico delgado e rígido sobre pavimento muito trincado, uso de tratamentos superficiais delgados para redução de irregularidade, uso de revestimento asfálticos permeáveis sobre pavimento trincado sem tratamento de impermeabilização.

Esses erros podem agir separadamente ou em conjunto e desse modo causar defeitos maiores ou menores. Entretanto, antes da adoção de qualquer alternativa de restauração para que possa haver a conservação, um bom diagnóstico geral dos defeitos de superfície é imprescindível. Desse modo, conhecer os defeitos é fator primordial para permitir a melhor forma de se prover a restauração. 


\subsubsection{Tipos de defeitos em superfícies asfálticas}

A norma DNIT 005/2003 - TER IPR (2003b): Defeitos nos pavimentos flexíveis e semirrígidos: terminologia, é utilizada para classificar os defeitos as superfícies. Os defeitos catalogados segundo a norma brasileira que são considerados para cálculo de indicador de qualidade da superfície do pavimento (Índice de Gravidade Global - IGG) constituem: fendas (F); afundamentos (A); corrugação e ondulações transversais (O); exsudação (EX); desgaste ou desagregação (D); panela ou buraco (P); e remendos (R).

1. Fenda (F) - são aberturas na superfície asfáltica. Essas aberturas são classificadas como fissuras quando é perceptível a olho nu apenas à distância inferior a 1,5m. Por outro lado, são classificadas como trincas quando superior à da fissura. As fendas representam os defeitos mais significativos dos pavimentos asfálticos e são classificadas dependendo da tipologia e da gravidade. A gravidade é dividida em classe 1, classe 2 e classe 3 . Na primeira a abertura é não superior a $1 \mathrm{~mm}$, já a classe 2 apresenta fendas com aberturas superior a $1 \mathrm{~mm}$, e a classe $3 \mathrm{com}$ aberturas superiores a $1 \mathrm{~mm}$ e com degradações nas bordas. Quanto à tipologia as fendas são subdivididas em trincas isoladas e trincas interligadas. As trincas isoladas podem ser transversais curtas (TTC) ou longas (TTL), longitudinais curtas (TLC) ou longas (TLL), ou ainda de retração (TRR). Já as trincas interligadas subdividem-se em: trincas de bloco (TB) quando tendem a uma regularidade geométrica, ou (TBE) quando apresentam complementarmente erosão junto às suas bordas; ou trincas tipo couro de jacaré (J) quando não seguem um padrão de reflexão geométrico sendo comumente derivadas da fadiga do revestimento asfáltico, ou (JE) quando apresentam complementarmente erosão junto às suas bordas.;

2. Afundamento (A) - são deformações permanentes caracterizada por depressão da superfície do pavimento ou de camadas subjacentes, acompanhada, ou não de solevamento. Os afundamentos classificam-se em:

a) afundamento por consolidação (AC) - neste caso as depressões ocorrem por densificação diferencial. Além disso esses afundamentos podem ser:

i. localizado (ALC) quando a extensão não supera 6m;

ii. longitudinal nas trilhas de roda (ATC) - quando exceda $6 \mathrm{~m}$ de extensão.

b) afundamentos plásticos (AP) - quando as depressões são decorrentes principalmente da fluência do revestimento asfáltico. Os afundamentos plásticos podem ser:

i. localizado (ALP);

ii. longitudinal nas trilhas de roda (ATP) - neste tipo há certa compensação volumétrica, com solevamento da massa asfáltica junto às bordas do afundamento. 
3. Corrugação (ou Ondulação) (O) - são deformações caracterizadas por ondulações ou corrugações transversais na superfície do pavimento, ou seja, deformações transversais ao eixo da pista que podem ser compensatórias, com depressões intercaladas de elevações com comprimento de onda entre duas cristas de alguns centímetros ou dezenas de centímetros, ou decorrentes da consolidação diferencial do subleito, diferenciadas da corrugação pelo comprimento de onda entre duas cristas da ordem de metros;

4. Escorregamento (E) - Deslocamento do revestimento em relação à camada subjacente do pavimento, com aparecimento de fendas em forma de meia-lua, sendo decorrente de fluência do revestimento asfáltico;

5. Desgaste (D) - decorrente do desprendimento de agregados da superfície ou da perda de mástique junto aos agregados. Constitui o efeito da retirada progressivo do agregado do pavimento fazendo com que o mesmo apresente uma característica de aspereza superficial do revestimento provocado por esforços tangenciais causados pelo tráfego;

6. Exsudação (EX) - caracterizada pelo surgimento de ligante em abundância na superfície (manchas escurecidas) decorrente em geral do excesso deste ligante betuminoso na massa asfáltica (migração do ligante por meio do revestimento);

7. Panela (P) - conhecido popularmente como buraco, é uma cavidade no revestimento asfáltico, que pode ou não atingir camadas subjacentes provocando a desagregação dessas camadas;

8. Remendo (R) - defeito caracterizado pelo preenchimento de panelas ou de qualquer outro orifício, buraco ou depressão com massa asfáltica. Esse procedimento, quando utilizado para recuperação ou manutenção é chamado de operação "tapa-buraco". O remendo pode ser subdivido em :

a) remendo profundo - aquele em que há substituição do revestimento e, eventualmente, de uma ou mais camadas inferiores do pavimento, apresentando, geralmente, uma forma retangular, e;

b) remendo superficial - correção, em área localizada, da superfície do revestimento, pela aplicação de uma camada betuminosa.

Existem ainda outros defeitos que não acarretam prejuízo nos indicadores do tipo do $I G G$ (Índice de Gravidade Global), IGGE (Índice de Gravidade Global Expedito) e IES (Índice de Estado de Superfície do Pavimento) que são importantes a serem levados em consideração para uma análise da solução de restauração: escorregamento do revestimento asfáltico, polimento de agregados, bombeamento de finos, trincas distintas das anteriores como trincas de borda próximas aos acostamentos e parabólicas, falhas do bico espargidor, desnível entre pista e acostamento, marcas impressas na superfície - marcas de pneus, empolamento ou elevações por expansão ou raízes de árvores, entre outros. 


\subsubsection{Avaliação de superfície pela determinação do $I G G$}

Como já mencionado anteriormente, o IGG constitui um indicador de qualidade da superfície do pavimento. Desse modo, o DNIT 006/2003 - PRO IPR (2003c) estabelece um método de levantamento de defeitos e de atribuição do IGG. O IGG não é determinado para toda a área da pista, ele é obtido a partir de uma amostra. As áreas e distanciamento entre cada uma das amostras é prefixada pela especificação do DNIT.

As estações são inventariadas nas rodovias de pista simples a cada $20 \mathrm{~m}$, alternados entre faixas, significando que em cada a amostragem é feita a cada $40 \mathrm{~m}$. Nas rodovias de pista dupla, essas áreas são feitas a cada $20 \mathrm{~m}$, na faixa mais solicitada pelo tráfego, em cada uma das pistas. A superfície de avaliação corresponde a $3 \mathrm{~m}$ antes e $3 \mathrm{~m}$ depois de cada uma das estacas demarcadas. Isso totaliza, em cada estação, uma área correspondente a $6 \mathrm{~m}$ de extensão e largura igual a da faixa avaliada.

Uma vez que se obtêm os dados procede-se a uma análise prévia de forma a subdividir a via em segmentos que possuam as mesmas características ou defeitos. Assim, método contabiliza as frequências absolutas $\left(f_{a}\right)$ de cada um dos tipos de defeitos (somatório da quantidade de estações que apresentam aquele tipo de defeito) e uma frequência $\left(f_{r}\right)$, relativa ao conjunto das estações de um dado segmento.

Desse modo, tem-se a frequência absoluta multiplicada pela porcentagem de estações onde ocorre este determinado tipo de defeito, sendo que $100 \%$ corresponde à totalidade das estações de um dado segmento. Cabe ressaltar que a norma estabelece um fator de ponderação prefixado para os defeitos, ou seja, confere a gravidade daquele tipo de defeito sobre os demais, ou seja, o defeito mais grave prevalece sobre o de menor gravidade.

Assim, a frequência absoluta $\left(f_{a}\right)$ corresponde ao número de vezes em que a ocorrência foi verificada. A frequência relativa $\left(f_{r}\right)$ é obtida conforme Equação (2.5).

$$
f_{r}=\frac{\left(f_{a} \times 100\right)}{n}
$$

Sendo:

- $f_{r}$ - frequência relativa;

- $f_{a}$ - frequência absoluta;

- $n$ - número de inspeções realizadas.

O cálculo do Índice de Gravidade Individual (IGI) é expresso pela Equação (2.6).

$$
I G I=f_{r} \times f_{p}
$$


Sendo:

- $f_{r}$ - frequência relativa;

- $f_{p}$ - fator de ponderação (obtido de acordo com a Tabela 2.5);

- IGI - Índice de Gravidade Individual.

Tabela 2.5 - Valor do fator de ponderação dos tipos de ocorrência de defeito. Norma DNIT 006/2003 - PRO (IPR, 2003c).

\begin{tabular}{|c|l|c}
\hline $\begin{array}{c}\text { Ocorrência } \\
\text { Tipo }\end{array}$ & \multicolumn{1}{|c|}{$\begin{array}{c}\text { Codificação de ocorrências de acordo com a Norma DNIT 005/2002-TER “Defeitos nos pavimentos } \\
\text { flexiveis e semi-rígidos }\end{array}$} & $\begin{array}{c}\text { Fator de } \\
\text { Ponderação fp }\end{array}$ \\
\hline 1 & Fissuras e Trincas Isoladas (FI, TTC, TTL, TLC, TLL e TRR) & 0,2 \\
\hline 2 & FC-2 (J e TB) & 0,5 \\
\hline 3 & $\begin{array}{l}\text { FC-3 (JE e TBE) } \\
\text { NOTA:Para efeito de ponderação quando em uma mesma estação forem constatadas ocorrências tipos 1, } \\
2 \text { e 3, só considerar as do tipo 3 para o cálculo da freqüência relativa em percentagem (fr) e Índice de } \\
\text { Gravidade Individual (IGI); do mesmo modo, quando forem verificadas ocorrências tipos 1 e 2 em uma } \\
\text { mesma estação, só considerar as do tipo 2. }\end{array}$ & 0,8 \\
\hline 4 & ALP, ATP e ALC, ATC & 0,9 \\
\hline 5 & O,P, E & 1,0 \\
\hline 6 & EX & 0,5 \\
\hline 7 & D & 0,3 \\
\hline 8 & R & 0,6 \\
\hline
\end{tabular}

NOTA 1: Classe das trincas isoladas

FC-1: são trincas com abertura superior à das fissuras e menores que $1,0 \mathrm{~mm}$.

FC-2: são trincas com abertura superior a 1,0mm e sem erosão nas bordas.

FC-3: são trincas com abertura superior a 1,0mm e com erosão nas bordas.

NOTA 2: Classe das trincas interligadas

As trincas interligadas são classificadas como FC-3 e FC-2 caso apresentem ou não erosão nas

bordas.

E deste modo, o IGG pode ser obtido a partir da Equação (2.7).

$$
I G G=\sum I G I
$$

Sendo:

- IGI - Índice de Gravidade Individual;

- IGG - Índice de Gravidade Global.

Com o IGG calculado é possível conferir ao pavimento inventariado um conceito que retrate o grau de degradação atingido, conforme ilustrado na Tabela 2.6.

\subsubsection{Avaliação de superfície visual pela determinação do $I G G E$}

O Índice de Gravidade Global Expedito (IGGE) é um outro um indicador de qualidade da superfície do pavimento definido pela Norma DNIT 008/2003 - PRO IPR (2003d). A Norma estabelece um método de avaliação das condições do pavimento pelo processo de Levantamento 
Tabela 2.6 - Conceitos de Degradação do Pavimento em Função do IGG. Adaptado de (LIEDI et al., 2008).

\begin{tabular}{|l|l|}
\hline \multicolumn{2}{|c|}{ Norma DNIT 06/2003 } \\
\hline Conceito & Limites \\
\hline Ótimo & $0<\mathrm{IGG} \leq 20$ \\
\hline Bom & $20<\mathrm{IGG} \leq 40$ \\
\hline Regular & $40<\mathrm{IGG} \leq 80$ \\
\hline Ruim & $80<\mathrm{IGG} \leq 160$ \\
\hline Péssimo & $\mathrm{IGG}>160$ \\
\hline
\end{tabular}

Visual Contínuo (LVC), sendo assim, permite determinar o cálculo do Índice de Condição de Pavimentos Flexíveis (ICPF). O cálculo do ICPF considera todos os defeitos detectados durante o processo de LVC, enquanto o cálculo do IGGE considera somente os defeitos 'trincas', 'deformações permanentes', 'panelas' e 'remendos'. A partir desses índices é possível determinar o Índice do Estado de Superfície do Pavimento (IES) para cada trecho analisado.

Para a realização do LVC deve-se garantir as várias condições, como por exemplo:

- veículo equipado com velocímetro/odômetro calibrado para aferição da velocidade de operação e das distâncias percorridas;

- evitar dias chuvosos, com neblina ou com pouca luz natural (início ou final de dia);

- dois técnicos (no mínimo, além do motorista);

- velocidade média de trabalho igual a $40 \mathrm{~km} / \mathrm{h}$;

- dividir o pavimento que será analisado em trechos de no mínimo 1 km e no máximo 6 $\mathrm{km}$.

- dividir os trechos a serem avaliados de maneira a preservarem alguma homogeneidade.

O preenchimento dos formulários definidos na Norma para o registro do levantamento são obrigatórios. Com relação aos defeitos observados em cada trecho avaliado o avaliador faz o registro utilizando um código de letras: "A", "M"ou "B"de acordo a Tabela 2.7.

Baseado na avaliação visual do pavimento, o ICPF de cada trecho avaliado é anotado de acordo com a Tabela 2.8. O ICPF final é calculado a partir da média dos valores anotados de todos os trechos.

Por meio do levantamento da frequência dos defeitos e dos seus respectivos pesos de acordo com a Tabela 2.9, o IGGE é calculado de acordo com a Equação (2.8). 
Tabela 2.7 - Frequência de defeitos. Norma DNIT 008/2003 - PRO (IPR, 2003d).

\begin{tabular}{|c|c|c|}
\hline \multicolumn{3}{|c|}{ Panelas (P) e Remendos (R) } \\
\hline Código & Frequência & Quant./km \\
\hline A & Alta & $\geq 5$ \\
\hline M & Média & $2-5$ \\
\hline B & Baixa & $\leq 2$ \\
\hline \multicolumn{3}{|c|}{ Demais defeitos } \\
\hline Código & Frequência & $\%$ por km \\
\hline A & Alta & $\geq 50$ \\
\hline M & Média & $50-10$ \\
\hline B & Baixa & $\leq 10$ \\
\hline
\end{tabular}

Tabela 2.8 - Conceitos do ICPF. Norma DNIT 008/2003 - PRO (IPR, 2003d).

\begin{tabular}{|c|l|c|}
\hline Conceito & \multicolumn{1}{|c|}{ Descrição } & ICPF \\
\hline Otimo & NECESSITA APENAS DE CONSERVAÇÃO ROTINEIRA & $5-4$ \\
\hline Bom & $\begin{array}{l}\text { APLICAÇÃO DE LAMA ASFÁLTICA - Desgaste superficial, trincas } \\
\text { não muito severas em áreas não muito extensas }\end{array}$ & $4-3$ \\
\hline Regular & $\begin{array}{l}\text { CORREÇÃO DE PONTOS LOCALIZADOS OU RECAPEAMENTO - } \\
\text { pavimento trincado, com “panelas” e remendos pouco } \\
\text { freqüentes e com irregularidade longitudinal ou transversal. }\end{array}$ & $3-2$ \\
\hline Ruim & $\begin{array}{l}\text { RECAPEAMENTO COM CORREÇÕES PRÉVIAS - defeitos } \\
\text { generalizados com correções prévias em áreas localizadas - } \\
\text { remendos superficiais ou profundos. }\end{array}$ & $2-1$ \\
\hline Péssimo & $\begin{array}{l}\text { RECONSTRUÇÃO - defeitos generalizados com correções } \\
\text { prévias em toda a extensão. Degradação do revestimento e } \\
\text { das demais camadas - infiltração de água e descompactação } \\
\text { da base. }\end{array}$ & $1-0$ \\
\hline
\end{tabular}

$$
I G G E=\left(P_{t} \times F_{t}\right)+\left(P_{\text {oap }} \times F_{\text {oap }}\right)+\left(P_{p r} \times F_{p r}\right)
$$

Sendo:

- IGGE - Índice de Gravidade Global Expedito;

- $P_{t}, F_{t}$ - Freqüência e Peso do conjunto de trincas $t$;

- $P_{\text {oap }}, F_{\text {oap }}$ - Freqüência e Peso do conjunto de deformações;

- $P_{p r}, F_{p r}$ - Freqüência (quantidade por $\mathrm{km}$ ) e Peso do conjunto de panelas e remendos.

A partir dos índices ICPF e IGGE, calcula-se o IES de acordo com a Tabela 2.10.

Esse índice é o que será utilizado pela MANIAC para a geração dos relatórios e detecção e identificação dos defeitos no pavimento. 
Tabela 2.9 - Pesos para cálculo do IGGE. Norma DNIT 008/2003 - PRO (IPR, 2003d).

\begin{tabular}{|c|c|c|c|c|}
\hline \multicolumn{3}{|c|}{ Panelas (P) e Remendos (R) } & \multicolumn{1}{c}{} \\
\cline { 1 - 2 } Código & Frequência & Quant./km & Gravidade & Ppr \\
\hline A & Alta & $\geq 5$ & 3 & 1,00 \\
\hline M & Média & $2-5$ & 2 & 0,80 \\
\hline B & Baixa & $\leq 2$ & 1 & 0,70 \\
\hline
\end{tabular}

\begin{tabular}{|c|c|c|c|c|}
\hline \multicolumn{3}{|c|}{ Demais defeitos (trincas) } & \multicolumn{2}{c}{} \\
\hline Código & Frequência & \% por km & Gravidade & Pt \\
\hline A & Alta & $\geq 50$ & 3 & 0,65 \\
\hline M & Média & $50-10$ & 2 & 0,45 \\
\hline B & Baixa & $\leq 10$ & 1 & 0,30 \\
\hline
\end{tabular}

\begin{tabular}{|c|c|c|c|c|}
\hline \multicolumn{3}{|c|}{ Demais defeitos (deformações) } & \multicolumn{2}{|}{} \\
\cline { 1 - 2 } Código & Frequência & \% por km & Gravidade & Poap \\
\hline A & Alta & $\geq 50$ & 3 & 1,00 \\
\hline M & Média & $50-10$ & 2 & 0,70 \\
\hline B & Baixa & $\leq 10$ & 1 & 0,60 \\
\hline
\end{tabular}

Tabela 2.10 - Índice do Estado da Superfície do pavimento. Norma DNIT 008/2003 - PRO (IPR, 2003d).

\begin{tabular}{|c|c|c|c|}
\hline DESCRIÇÃO & IES & CóDIGO & CONCEITO \\
\hline IGGE $\leq 20$ e ICPF $>3,5$ & 0 & A & ÓTIMO \\
\hline IGGE $\leq 20$ e ICPF $\leq 3,5$ & 1 & \multirow{2}{*}{ B } & \multirow{2}{*}{ BOM } \\
\hline $20 \leq \mathrm{IGGE} \leq 40$ e ICPF $>3,5$ & 2 & & \\
\hline $20 \leq \mathrm{IGGE} \leq 40$ e ICPF $\leq 3,5$ & 3 & \multirow{2}{*}{ C } & \multirow{2}{*}{ REGULAR } \\
\hline $40 \leq \mathrm{IGGE} \leq 60$ e ICPF $>2,5$ & 4 & & \\
\hline $40 \leq \mathrm{IGGE} \leq 60$ e ICPF $\leq 2,5$ & 5 & \multirow{2}{*}{ D } & \multirow{2}{*}{ RUIM } \\
\hline $60 \leq \mathrm{IGGE} \leq 90$ e ICPF $>2,5$ & 7 & & \\
\hline $60 \leq \mathrm{IGGE} \leq 90$ e ICPF $\leq 2,5$ & 8 & \multirow{2}{*}{$E$} & \multirow{2}{*}{ PÉSSIMO } \\
\hline IGGE > 90 & 10 & & \\
\hline
\end{tabular}

\subsection{Aprendizado de Máquina (AM)}

Uma vez definidos os conceitos de Sensoriamento Remoto, VANTs, Tipos de Pavimentos Asfálticos, cabe ainda a definição e explanação sobre Aprendizado de Máquina (AM), técnica que será utilizada para obtenção da classificação das imagens obtidas por meio do Sensoriamento Remoto feito por Veículos Aéreos Não Tripulados para detecção de defeitos em superfícies asfálticas. 
A grande quantidade de dados, estruturados ou não, é um recurso em abundância na era da tecnologia. O AM evoluiu como um subcampo da inteligência artificial, principalmente a partir da segunda metade do Século XX, onde foi possível observar a evolução e o desenvolvimento de algoritmos de auto-aprendizagem para adquirir conhecimento a partir desses dados, principalmente com o objetivo de fazer previsões. Pode-se dizer que o AM estuda o desenvolvimento de métodos computacionais capazes de extrair conceitos, conhecimentos, habilidades e meios de organizar o conhecimento existente nas amostras de dados Raschka (2015), Murphy (2012). Em vez de exigir seres humanos para derivar regras manualmente e construir modelos de análise de grandes quantidades de dados, o aprendizado de máquina oferece uma alternativa mais eficiente para capturar o conhecimento a partir dos dados para melhorar gradualmente o desempenho de modelos preditivos e tomar decisões baseadas nesses dados. Sendo assim, o Aprendizado de Máquina tem se tornado cada vez mais importante na pesquisa científica, mas também tem desempenhado um papel relevante na vida cotidiana. De modo geral, os diferentes algoritmos de AM são utilizados de forma a gerar classificadores para um conjunto de exemplos. Entende-se por um processo de atribuir a uma determinada informação o rótulo da classe a qual ela pertence (RUSSELL; NORVIG, 2002).

As técnicas de AM são empregadas por indução, ou seja, a partir de um conjunto de treinamento, de um classificador, que por sua vez deve ser capaz de prever a classe de instâncias do domínio em que foi treinado.

A estrutura básica de um sistema de AM é formada por quatro campos:

- Environment: Ambiente do sistema. É a parte que porporciona informações para a parte de aprendizado do sistema;

- Learning: Aprendizado. Responsável por revisar a base de conhecimento fazendo uso de informações do ambiente;

- Knowledge Base: Base de conhecimento. Vetor de características, sentenças lógicas, regras de modelo de produção, redes semânticas, entre outros.

- Execution: Constitui o núcleo de todo o sistema, sendo a parte operativa, cujo foco está no aperfeiçoamento das ações de aprendizagem.

Exitem três tipos diferentes de técnicas aprendizado de máquina, ou paradigmas que podem ser utilizados na geração de um preditor por meio de técnicas de AM: aprendizado supervisionado, aprendizado não-supervisionado e aprendizado por reforço (RASCHKA, 2015).

A maneira como o algoritmo de AM se relaciona com seu meio ambiente (como ocorrerá o aprendizado) é determinada por meio da escolha do paradigma de aprendizado.

Entende-se pelos paradigmas: 
- Supervisionado - aquele onde tem-se a figura do "professor externo", o qual representa o conhecimento do ambiente representado por conjuntos de exemplos na forma entradasaída. Sendo assim, o algoritmo de AM é treinado a partir de conjuntos de exemplos rotulados da função a ser aprendida. O algoritmo aprende a representar ou agrupar as entradas submetidas segundo uma medida de qualidade.

- Não-supervisionado - aquele onde não há presença de um "professor". Neste caso não existem instâncias rotuladas da função a ser aprendida. O algoritmo aprende a agrupar as entradas segundo uma medida de qualidade.

- Por Reforço - é aquele em que o aprendizado se dá por meio de recompensas ou não ao indutor, o que vai depender do seu desempenho em aproximar a função desejada.

Nesta tese de doutorado foram utilizados dois dos paradigmas de Aprendizado de Máquina: o supervisionado e o não-supervisionado. Esses paradigmas foram utilizados em etapas distintas que serão detalhadas nas Seções 2.7.1 e 2.7.2.

\subsubsection{Aprendizado supervisionado}

Como anteriormente mencionado, o aprendizado supervisionado baseia-se em um conjunto de exemplos de treinamento de modo que as respostas ou saídas corretas (ou desejadas) são fornecidas. Baseados no conjunto de treinamento, os algoritmos normalmente generalizam para fornecerem uma resposta correta a todas as possíveis entradas.

Sendo o aprendizado supervisionado, dado um conjunto de exemplos rotulados na forma $\left(x_{i}, y_{i}\right)$, em que $x_{i}$ representa um exemplo e $y_{i}$ denota o seu rótulo, deve-se produzir um classificador (ou modelo, preditor), capaz de predizer precisamente o rótulo de novos dados. $\mathrm{O}$ processo de indução de um classificador a partir de uma amostra é denominado treinamento. Sendo assim, o classificador obtido por ser visto como uma função $f$ que recebe um dado $x$ e fornece uma predição $y$. Os rótulos constituem o fenômeno de interesse sobre o qual se deseja fazer a previsão.

Existem diversas técnicas de aprendizado supervisionado, por exemplo, Árvores de Decisão, Máquinas de Vetores de Suporte, Redes Bayesianas, entre outras. Nesta seção, serão abordadas as técnicas com aprendizado supervisionado utilizadas para o desenvolvimento desta tese de doutorado. Maiores detalhes sobre técnicas de aprendizado de máquina podem ser obtidos em (WITTEN; FRANK; HALL, 2011), (MURPHY, 2012), (RASCHKA, 2015).

\subsubsection{Máquinas de Vetor de Suporte}

As Máquinas de Vetor de Suporte (Support Vector Machines - SVMs) constituem uma técnica de aprendizado de máquina fundamentada em Teorias Estatísticas. De modo simplificado, podese dizer que a Teoria de Aprendizado Estatístico, na qual se baseia o SVM, estabelece condições 
matemáticas que auxiliam na escolha de um classificador particular a partir de um conjunto de dados de treinamento. Essas condições matemáticas levam em conta o desempenho do classificador no conjunto de treinamento e sua complexidade, objetivando obter também um bom desempenho para novos dados do mesmo domínio.

Uma das características interessantes das SVMs é a sua capacidade de generalização (classificadores alcançam bons resultados de generalização - evita-se o overfitting). Além da generalização, outras características tornam as SVMs atrativas: robustez em grandes dimensões (robustas diante de objetos de grandes dimensões como imagens); convexidade da função objetivo (otimização da função quadrática que possui apenas um mínimo local) e; teoria bem definida (fundamentada dentro da Matemática e Estatística).

Os SVMs podem ser classificados em lineares e não-lineares. Os SVMs lineares são eficazes na classificação de conjuntos de dados linearmente separáveis, ou que possuam uma distribuição aproximadamente linear. Dentre os SVMs lineares encontram-se os com Margens Rígidas e os com Margens Suaves. Os primeiros se aplicam a conjuntos com dados linearmente separáveis (o que é difícil de se encontrar em situações reais). Já os com Margens Suaves toleram a presença de alguns ruídos e outliers. Entretanto, apesar dos últimos tolerarem ruídos e absorverem algumas classes de problemas que não sejam lineares, há ainda muitos casos em que não é possível dividir satisfatoriamente os dados de treinamento em um hiperplano.

Quando isso ocorre, deve-se fazer uso dos SVMs não lineares, que lidam com problemas não lineares mapeando o conjunto de treinamento de seu espaço original (entradas), para um novo espaço de maior dimensão (espaço de características - feature space) onde eles se tornam linearmente separáveis Raschka (2015). Esse é o caso do problema abordado nesta tese de doutorado.

Um problema com essa abordagem é que a construção de novas características é computacionalmente caro, especialmente quando lida-se com dados de grandes dimensões. Para solucionar esse problema utiliza-se o "kernel". Não é o objetivo aqui detalhar a resolução da programação quadrática envolvida no treinamento de um SVM, entretanto, o que se precisa saber para utilizá-la é substituir o produto escalar $x^{(i) T} x^{(j)}$ por $\phi\left(x^{(i) T}\right) \phi\left(x^{(j)}\right)$. Desse modo pode-se definir a função kernel como $k\left(x^{(i)}, x^{(j)}\right)=\phi\left(x^{(i) T}\right) \phi\left(x^{(j)}\right)$.

Uma das funções de kernel mais amplamente utilizado é o RBF kernel (Radial Basis Function Kernel) ou Gaussian Kernel apresentado na Equação (2.9) e sua otimização na Equação (2.10).

$$
\begin{gathered}
k\left(x^{(i)}, x^{(j)}\right)=\exp \left(-\frac{\left\|x^{(i)}-x^{(j)}\right\|^{2}}{2 \sigma^{2}}\right) \\
k\left(x^{(i)}, x^{(j)}\right)=\exp \left(-\gamma\left\|x^{(i)}-x^{(j)}\right\|^{2}\right)
\end{gathered}
$$

De um modo simplificado, o termo kernel pode ser interpretado como uma função de simi- 
laridade entre um par de amostras. O sinal negativo inverte a medida de distância em uma pontuação de semelhança e, devido ao termo exponencial, a pontuação de semelhança resultante vai cair em um intervalo entre 1 (para amostras exatamente semelhantes) e 0 (para amostras muito diferentes).

Um requisito importante para as técnicas de AM é que elas sejam capazes de lidar com dados imperfeitos, denominados ruídos. Muitos conjuntos de dados apresentam essa característica, sendo alguns erros comuns a presença de ruídos e/ou atributos incorretos. Assim, a técnica de AM deve ser, idealmente, robusta a ruídos presentes nos dados, procurando não fixar a obtenção dos classificadores sobre esse tipo de caso. Deve-se também minimizar a influência dos outliers ${ }^{3}$ no processo de indução. Nesta tese fez-se uso, como anteriormente mencionado, do SVM não linear fazendo uso do kernel RBF.

\subsubsection{Floresta aleatória}

Um dos classificadores utilizados nesta tese foi a floresta aleatória (Random Forest Breiman (2001)). Esse método pode ser entendido como uma extensão de árvores de decisão, pois trata de um procedimento que faz uso de métodos de reamostragem tais como bootstrapping com objetivo de melhorar a precisão dos modelos construídos. De modo geral, esse método gera muitos classificadores (múltiplas árvores de decisão ${ }^{4}$ ) e agrega o seu resultado. A ideia por trás deste método está na combinação do aprendizado fraco para construir o aprendizado robusto, que possui menor erro e que seja menos suscetível a overfitting.

O algoritmo do Random Forest pode ser sumarizado em quatro passos simples (RASCHKA, 2015):

1. Desenhar uma amostra de inicialização aleatória de tamanho n (aleatoriamente escolher $\mathrm{N}$ amostras do conjunto de treinamento com substituição).

2. Cresça uma árvore de decisão a partir da amostra de inicialização. Em cada nó:

a) Selecione aleatoriamente $d$ características sem substituição.

b) Divida o nó usando o recurso que fornece a melhor separação de acordo com a função objetivo, por exemplo, por meio da maximização do ganho de informação.

3. Repita os passos 1 e $2 \mathrm{k}$ vezes.

4. Agregue a previsão de cada árvore para atribuir o rótulo de classe por maioria de votos.

\footnotetext{
${ }^{3}$ Outliers são exemplos muito distintos dos demais presentes no conjunto de dados, podendo ser ruídos ou casos muito particulares

${ }^{4}$ Arvores de Decisão utilizam a estratégia de dividir para conquistar. A ideia central é encontrar a solução para um problema a partir de sua sucessiva decomposição em subproblemas menores.
} 
Uma ilustração do algoritmo é dada na Figura 2.4. $D$ representa o conjunto de dados originais de treinamento, $D_{1} . . D_{t}$ os dados aleatórios para geração das árvores independentes, $T_{1} . . T_{t}$ as árvores e $T^{*}$ as árvores combinadas.

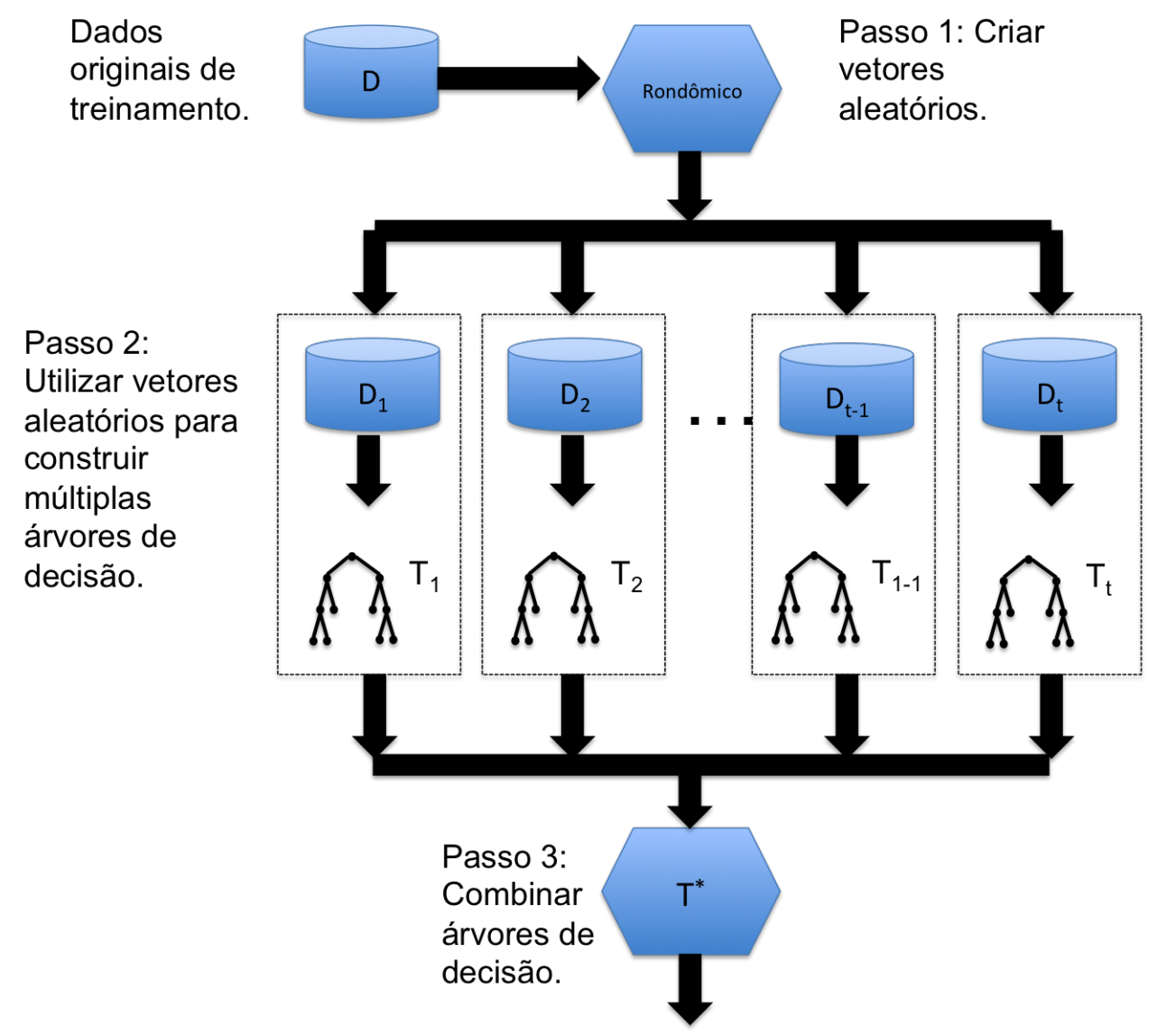

Figura 2.4 - Passos do Random Forest

Há uma ligeira modificação no passo 2 quando se está treinando as árvores de decisão individualmente: em vez de avaliar todos os recursos para determinar a melhor divisão em cada nó, considera-se apenas um subconjunto aleatório desses.

Embora o método Random Forest não ofereça o mesmo nível de interpretabilidade que as árvores de decisão, uma grande vantagem do mesmo é não precisar se preocupar tanto sobre a escolha de bons valores dos hiper-parâmetro. Normalmente não é preciso podar a Random Forest, uma vez que o modelo de conjunto é bastante robusto ao ruído das árvores de decisão individuais. O único parâmetro com o qual é necessário se preocupar é o número de árvores k (etapa 3) que é escolhido aleatoriamente para a Random Forest. Tipicamente, quanto maior for o número de árvores, melhor o desempenho do classificador, obviamente às custas de um aumento do custo computacional.

Outros hiper-parâmetros que podem ser otimizados neste método são o tamanho da amostra de inicialização $\mathrm{n}$ e o número de características d. Via o tamanho da amostra n é possível controlar a troca bias-variância. Sendo assim, um valor maior para n diminui a aleatoriedade, deixando o método mais suscetível a overfits. Por outro lado, é possível reduzir o grau de 
superajuste escolhendo menores valores para $\mathrm{n}$ em detrimento ao desempenho do modelo (geralmente a amostra de inicialização é escolhida de modo a ser igual ao número de amostras no conjunto de treino original, o que oferece uma boa troca bias-variância).

Já para o número de características, o que se deseja é escolher um valor que seja menor do que o número total de recursos no conjunto de treinamento. Um padrão razoável a ser utilizado é $\mathrm{d}=\mathrm{m}$, onde $\mathrm{m}$ é o número de recursos no conjunto de treinamento.

Dentre as técnicas avaliadas neste doutorado, a escolhida por prover melhores resultados foi esta. Random Forest têm sido amplamente utilizada em aplicações de AM por apresentar um bom desempenho na classificação, escalabilidade e ser de fácil utilização.

\subsubsection{Aprendizado não-supervisionado}

No aprendizado supervisionado foram discutidos algoritmos para classificação que aprendem a partir de dados treinados e rotulados. Sendo assim, somente as entradas são fornecidas $T\left(x_{i}\right) 1 \leq i \leq n$, e o objetivo é buscar por "padrões interessantes"no conjunto de dados, tarefa essa conhecida como descoberta de conhecimento. Diferentemente do supervisionado, no aprendizado não-supervisionado, o algoritmo de aprendizado simplesmente analisa os exemplos fornecidos e tenta determinar se alguns deles podem ser agrupados de alguma maneira, formando agrupamentos ou clusters. Após a determinação dos agrupamentos, em geral, fazse necessária uma análise para determinar o que cada agrupamento significa no contexto do problema que está sendo analisado. Pode-se dizer nesse caso que o algoritmo aprende por si só, uma vez que o objetivo do aprendizado não-supervisionado é o de encontrar estruturas e padrões escondidos em conjuntos de dados de treinamento não rotulados.

Desse modo, pode-se definir clusterização (ou Cluster) como a forma de aprendizado nãosupervisionado utilizada para encontrar grupos de observações similares sem um conjunto rotulado de dados.

As etapas do processo de aprendizagem não-supervisionado podem ser assim resumidas:

- Seleção de atributos - os atributos devem ser adequadamente selecionados de forma a codificar a maior quantidade possível de informações relacionada à tarefa de interesse; Devem ter também uma redundância mínima entre eles;

- Medida de proximidade - medida para quantificar quão similar ou dissimilar são os vetores de atributos. O ideal é que todos os atributos contribuam de maneira igual no cálculo da medida de proximidade (um atributo não deve ser dominante sobre outro, de modo que os dados devem ser normalizados);

- Critério de agrupamento - Esse critério depende da interpretação que o especialista dá para o termo sensível com base no tipo do cluster que são esperados; 
- Algoritmos de agrupamento - deve-se escolher um algoritmo de clusterização que revele a estrutura agrupada do conjunto;

- Verificação dos resultados - Uma vez obtidos os resultados do algoritmo, deve-se verificar se o resultado está correto por meio da execução de testes apropriados;

- Interpretação dos resultados - Os resultados da clusterização devem ser integrados com outras evidências experimentais e análises para se chegar às conclusões corretas.

Como exemplos de algoritmos utilizados em aprendizado não-supervisionado tem-se: $K$ means, Expectation-Maximization (EM) e Mean shift.

\subsubsection{K-means}

O K-means é a técnica de aprendizagem não-supervisionada mais simples, e consiste em fixar $k$ centroides (de maneira aleatória), sendo um para cada cluster. O algoritmo básico do K-means pode ser observado no Algoritmo 1.

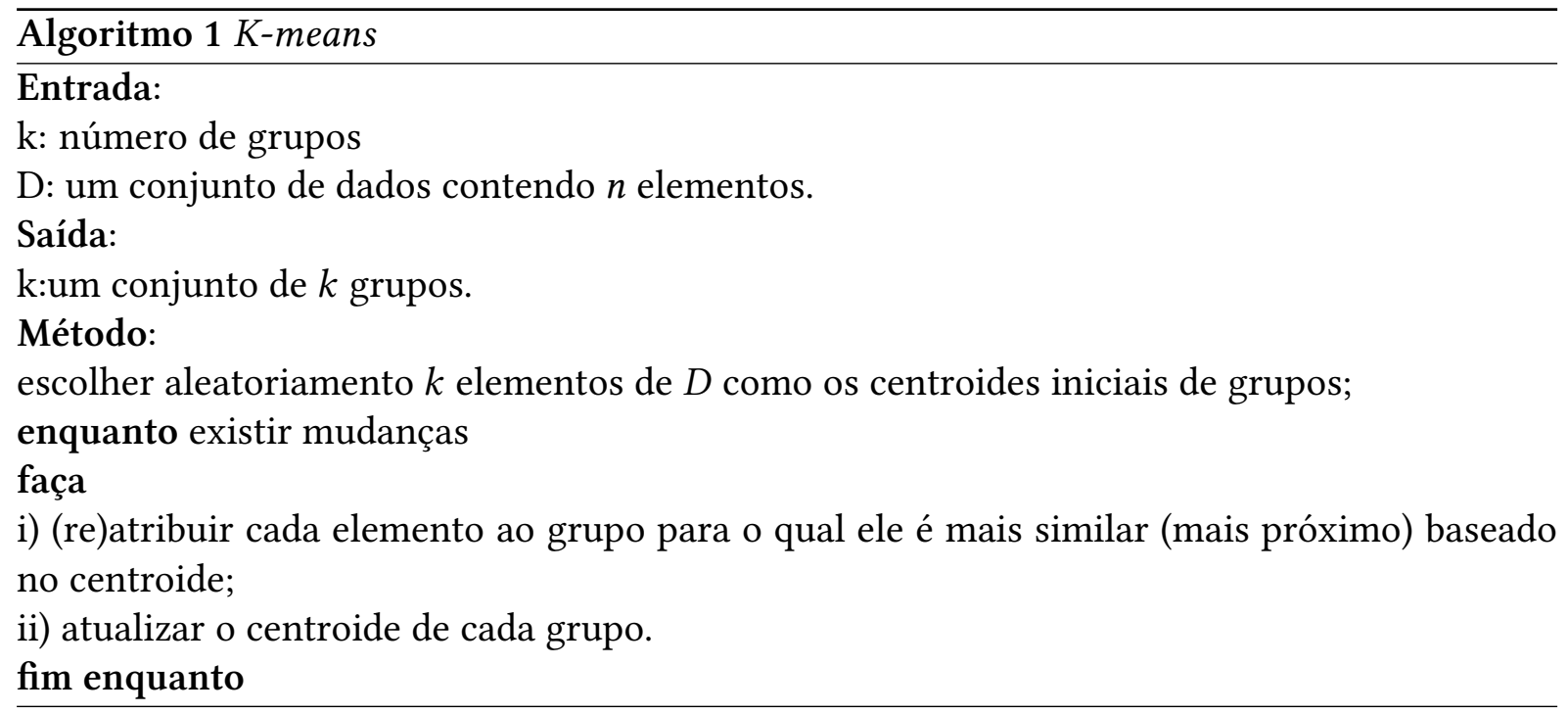

$\mathrm{O}$ algoritmo de agrupamento não supervisionado utilizado nesta tese de doutorado foi o K-means.

\subsubsection{Detecção de anomalias}

Um problema sério com qualquer forma de detecção automática de dados aparentemente incorreta é a perda de informações importantes ou significativas sem ser percebidas. A não ser consultando um especialista (humano), não há outra maneira de dizer se uma instância particular é realmente um erro ou se simplesmente não se encaixa no tipo de modelo que está sendo aplicado. Sendo assim, em regressão estatística, visualizações ajudam, pois valores discrepantes podem ser facilmente visualizados. 
Entretanto, na maioria dos problemas de classificação essas discrepâncias não podem ser tão facilmente visualizadas: a noção de "qual é o modelo"é mais sutil do que uma linha de regressão e, embora se saiba que bons resultados são obtidos na maioria dos conjuntos de dados padrão, descartando casos que não se encaixam, por exemplo, em um modelo de árvore de decisão, isso não é necessariamente de grande conforto quando se lida com um novo conjunto particular de dados.

Uma solução que tem sido experimentada é fazer uso de vários esquemas de aprendizagem diferentes (por exemplo, uma árvore de decisão, um nearest-neighbor, e uma função discriminante linear) para filtrar os dados. Treina-se os três e vota-se no melhor. No entanto, existe o perigo no uso de técnicas de voto, uma vez que existem algoritmos de aprendizagem mais adequados para certos tipos de dados do que outros, e o esquema mais apropriado pode simplesmente ser eliminado pelo voto. O uso de filtragem também pode trazer problemas, sacrificando instâncias de uma classe particular para melhorar a precisão nas demais classes.

Sendo assim, é apresentada na literatura a Detecção de Anomalias. Uma anomalia é um exemplo ou grupo de exemplos discrepantes ou inconsistentes ao conjunto de dados do qual fazem parte Bamnett e Lewis (1994), Witten, Frank e Hall (2011). Objetos anômalos podem surgir por diversos motivos, entretanto devem ser identificados e analisados pois podem conter informações importantes sobre o porque foram gerados.

Os desafios da deteção de anomalias podem ser sumarizados em:

1. definição do comportamento normal e formalização do modelo para o comportamento;

2. alteração do comportamento normal com o passar do tempo;

3. camuflagem das anomalias juntamente aos resultados normais;

4. ausência de dados anormais para realizar treinamento e validação do classificador;

5. presença de ruídos nos dados normais que se assemelham a anomalias;

Em problemas de aprendizado de máquina trabalha-se com dois espaços: o espaço de entrada (características), e o espaço de saída (rótulos ou classes). Na detecção de anomalias isso não é diferente, tem-se também um espaço de entradas e um de saídas.

A maioria dos métodos de detecção de anomalias recebem uma observação e separam as saídas em uma classe normal e uma anormal, sendo que na maioria das aplicações em que são executados, o conjunto maior de amostras é incluído na classe normal, enquanto o menor conjunto fica na classe anormal. Sendo então uma tarefa desafiadora a detecção de anomalias, uma série de métodos específicos foram desenvolvidos ou adaptados para o tratamento desse problema. 
Para a escolha da melhor técnica de detecção de anomalias deve-se analisar a natureza dos dados (binários, categóricos, contínuos). As saídas geradas pelas técnicas de detecção de anomalias são: na forma de rótulos binários, indicando a qual classe pertence qual amostra, ou; por meio de pontuações que indicam quão anômalas são as amostras do conjunto, permitindo assim um ranqueamento.

Os métodos estatísticos e os baseados em teoria da informação constituem os métodos mais utilizados para detecção de anomalias, uma vez que, a maioria dos métodos de classificação existentes não são adequados para detectá-las.

Técnicas de classificação (baseadas em redes neurais, redes Bayesianas e Support Vector Machines (SVMs)) bem como técnicas de agrupamentos, técnicas estatísticas e métodos baseados em vizinhos mais próximos, foram adaptados e/ou utilizados como base para o desenvolvimento de métodos para realização a detecção de anomalias.

A detecção de anomalias baseada em agrupamentos tem por objetivo reunir dados similares em um mesmo grupo, assumindo que os dados normais se reúnam e os demais fiquem dispersos. Desse modo, as anomalias podem: pertencer a nenhum grupo; encontrarem-se na periferia dos grupos, distantes dos centros e; estarem presentes em pequenos grupos ou esparsos. Essa técnica é vantajosa pois permite que o aprendizado a ser realizado seja o não-supervisionado.

O método de detecção de anomalias adotado nesta tese de doutorado é o não-supervisionado, apesar do mesmo poder ser utilizado de forma supervisionada. Uma distinção clara deve ser feita entre os métodos para "limpeza"de dados reais: Novelty detection - no qual o conjunto de treinamento de dados não é poluídos por outliers, e está-se interessado em detectar anomalias em novas observações e; Outliers detection - o qual o conjunto de dados contém outliers, e necessita-se ajustar o modo central dos dados de formação, ignorando as observações desviantes.

\subsubsection{Envelope elíptico (Elliptic Envelope)}

Uma maneira comum de executar a detecção de outlier é assumir que os dados regulares são provenientes de uma distribuição conhecida (como por exemplo, uma distribuição Gaussiana). A partir deste pressuposto, tenta-se definir a "forma"dos dados, e pode-se definir observações periféricas como observações que ficam longe o suficiente da "forma". Esse método aprende em forma de elipse, o que permite que a distribuição dos inliers seja feita de forma mais eficiente quando os dados seguem uma distribuição.

No caso desta tese de doutorado utilizou-se uma função Gaussiana. Nesse caso, os parâmetros da distribuição são estimados para o caso normal a partir de um conjunto de treinamento, e por meio de um conjunto de validação encontra-se um limiar experimental $T$, que estipula a probabilidade mínima que uma nova amostra deve ter para que seja considerada como da mesma origem. O limiar $T$ também pode ser definido como a região contendo uma porcenta- 
gem dos dados.

Os modelos Gaussianos possíveis de serem utilizados são os uni e multivariados. No primeiro caso, não existe relação entre os atributos de um único objeto (média e variâncias calculadas a partir do atributo das amostras da base de treinamento). A probabilidade final de cada amostra é dada pela multiplicação das probabilidades calculadas para cada atributo. A função de densidade do modelo univariado é dado pela Equação (2.11). No caso do modelo multivariado, a função de densidade é dada pela Equação (2.12), e é possível considerar relações entre atributos do mesmo objeto.

$$
\begin{gathered}
f(x)=\frac{1}{\sigma \sqrt{2 \pi}} e^{\frac{(x-\mu)^{2}}{2 \sigma^{2}}} \\
f(x)=\frac{1}{\sqrt{(2 \pi)^{M}\left|\sum\right|}} e^{-\frac{(x-\mu)^{T} \Sigma^{-1}(x-\mu)}{2}}
\end{gathered}
$$

onde a variância $\sigma$ é substituída pela matriz de covariância $\sum$.

\subsubsection{Avaliação dos métodos de Aprendizado de Máquina}

Uma vez aplicados os métodos de Aprendizado de Máquina faz-se necessária a avaliação dos mesmos. Para que se possa fazer a correta avaliação dos métodos fazem-se necessárias algumas definições como:

- Classe de interesse - são os resultados que fazem parte do que deve ser classificado como de interesse para o algoritmo, e é definido como classe positiva.

- Demais classes - classes que são geradas com elementos que não deveriam fazer parte do objeto de interesse do algoritmo, e são definidas como classes negativas.

- Classificação correta - quando os elementos que deveriam estar nas classes de interesse assim o são. É denominado verdadeiro.

- Classificação incorreta - quando os elementos que deveriam estar nas classes de interesse são alocados nas demais classes ou, quando elementos que deveriam estar alocados nas demais classes acabam sendo alocados na classe de interesse. É denominado falso.

Além disso, o Verdadeiro Positivo (TP) constitui o caso corretamente classificado como pertencente à classe de interesse, já o Verdadeiro Negativo (TN) constitui o caso corretamente classificado como não pertencente à classe de interesse. De modo análoco, tem-se o Falso Positivo (FP) que consiste no caso incorretamente classificado como pertencente à classe de interesse, e o Falso Negativo (FN) que constitui do caso incorretamente classificado como não pertencente à classe de interesse. 
Com base nessas definições, tem-se na literatura diversas medidas que podem ser utilizadas para avaliar os resultados apresentados pelos algoritmos de Aprendizado de Máquina. Dentre eles destacam-se: Matriz de Confusão, Acurácia e Taxa de Erro, Sensibilidade e Especificidade, Precisão e Recall, FMeasure e Curvas ROC (Receiver Operating Characteristic).

A matriz de confusão apresenta as classificações obtidas a partir de um modelo preditivo, e é composta pelo mesmo número de linhas e colunas, sendo ambos iguais ao número de classes a serem detectadas pelo algoritmo. As linhas da matriz correspondem à classe real, enquanto que as colunas correspondem às classificações obtidas a partir do modelo.

Por meio dos valores presentes na matriz de confusão é possível calcular várias medidas de desempenho como o TP, TN, FP e FN.

A acurácia constitui a medida que considera a quantidade de acertos sobre o total de amostras, ou seja, ela fornece o percentual de classificações verdadeiras (acertos), conforme pode ser observado na Equação (2.13). A taxa de erro, por sua vez fornece o percentual de classificações falsas (erros), e pode ser observada na Equação (2.14).

$$
\begin{gathered}
\text { acurácia }=\frac{T P+T N}{T P+T N+F P+F N} \\
\text { taxa de erro }=\frac{F P+F N}{T P+T N+F P+F N}=1-\text { acurácia }
\end{gathered}
$$

A taxa de verdadeiros positivos (TVP) ou sensibilidade mede a proporção de amostras positivas classificadas corretamente, mostrando dessa forma qual a porcentagem de acerto do algoritmo (Equação (2.15), enquanto a especificidade, mede a proporção de amostras negativas classificadas corretamente, ou seja, mostra qual a porcentagem de acerto do algoritmo, mas com relação aos casos negativos (Equação (2.16).

$$
\begin{aligned}
& \text { sensibilidade }=\frac{T P}{T P+F N} \\
& \text { especificidade }=\frac{T N}{T N+F P}
\end{aligned}
$$

A taxa de falsos positivos (TFP) mostra a relação entre a quantidade de amostras de classe positiva classificadas erroneamente e o número total de amostras classificadas de forma errada (Equação (2.17).

$$
T F P=\frac{F P}{F P+T N}
$$


A precisão ilustra a frequência com que um modelo classifica uma amostra como positiva uma amostra (que seja mesmo positiva) (Equação (2.18)), já o recall ilustra o qual completos ou abrangentes estão os resultados.

$$
\begin{gathered}
\text { precisão }=\frac{T P}{T P+F P} \\
\text { recall }=\frac{T P}{T P+F N}
\end{gathered}
$$

F-Measure aglutina o desempenho do modelo em um única medida, entretanto atribui pesos iguais aos erros de diferentes tipos (Equação (2.20).

$$
F-\text { Measure }=\frac{2 \times \text { precisão } \times \text { recall }}{\text { recall }+ \text { precisão }}=\frac{2 \times T P}{(2 \times T P)+F P+F N}
$$

E por fim, as curvas $R O C$, onde o $R O C$ foi desenvolvido durante a $2^{a}$ Guerra por engenheiros para discriminar sinais de rádio/radar verdadeiros de falsos positivos. Os gráficos de ROC constituem uma alternativa à avaliação utilizando medidas. Por ele é possível analisar o compromisso entre a detecção de verdadeiros positivos (a partir da sensibilidade) e a rejeição de falsos positivos $(1-$ especificidade).

As medidas utilizadas nesta tese de doutorado para avaliação dos métodos de aprendizado de máquina foram a matriz de confusão, a acurácia, o recall e o F-Measure.

\subsection{Considerações finais}

Este capítulo apresentou os principais conceitos necessários para o entendimento das áreas abordadas durante o desenvolvimento deste doutorado. Foram apresentados os conceitos de Sistemas de Informações Geográficas, Sensoriamento Remoto e Visão Computação, áreas complexas e indispensáveis para que a obtenção e o tratamento das imagens digitais fossem feitos de forma correta apropriada. Foram também apresentados os conceitos relacionados aos VANTs, provendo informações que vão desde os conceitos básicos, definições e características, passando pela apresentação das classificações existentes em alguns países, até chegar às principais missões militares e civis nas quais os VANTs podem ser empregados. VANTS, como mencionado anteriormente, são sistemas complexos que realizam missões complexas. O uso dessas aeronaves pode e deverá proporcionar o monitoramento e a detecção de problemas em pavimentos de rodovias. O uso dessa ferramenta resultou em uma melhoria no processo de monitoramento e deve reduzir, na prática, a quantidade de horas de trabalho quanto de mão de obra necessária para levantamento desse tipo de informações em um Sistema de Gerência de Pavimento. O processamento de imagens feito a posteriori permitiu a extração de dados em maior quantidade do que aqueles obtidos por amostragem terrestre, normalmente restrita a um porcentual pequeno da área total sob análise. 
Foram também apresentados os conceitos básicos sobre a classificação dos defeitos existentes em vias pavimentadas. Pode-se observar que existem diversos defeitos, e que nem todos são utilizados para efetuar o cálculo do $I G G$, um dos índices que classificam a qualidade do pavimento flexível asfáltico.

A partir do conhecimento dos defeitos e das regras de formas de classificação dos mesmos foi possível determinar um processo automático que permitiu tanto a classificação quanto a determinação do tipo do defeito e o índice de qualidade do pavimento. Isso permitiu que o monitoramento das condições do pavimento pudesse ser feito de maneira automatizada com o uso de imagens obtidas por meio de Veículos Aéreos Não Tripulados de pequeno porte.

Sendo assim, o próximo capítulo apresenta os trabalhos encontrados na literatura aberta que são relacionados a essa tese de doutorado, de modo a permitir delimitar e demonstrar o gap existente na área em que se insere esse trabalho. 


\section{Capítulo}

\section{Trabalhos Correlatos}

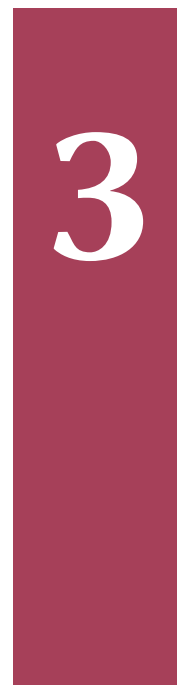

Diversos trabalhos podem ser encontrados na literatura na área de Gerencia de Pavimento, Sistemas de Informações Geográficas, Veículos Aéreos Não Tripulados, Sensoriamento Remoto, Visão Computacional e alguns com a junção e integração dessas áreas. Esse capítulo apresenta o resultado da síntese da revisão sistemática realizada que busca encontrar trabalhos que tenham característica muito similares à esta tese. Entretanto, como nenhum trabalho exatamente igual ao aqui apresentado foi encontrado, esta revisão sistemática apresenta artigos importantes para cada um dos tópicos de pesquisa desta tese. Esta seção apresenta a síntese dos resultados obtidos a partir dos trabalhos selecionados na última fase da revisão sistemática.

Este capítulo está estruturado da seguinte forma: na Seção 3.1 são apresentadas as considerações iniciais. Na seção 3.2 os trabalhos resultantes da última etapa da revisão sistemática são apresentados. A revisão sistemática realizada neste trabalho permitiu caracterizar o estado da arte na área de monitoramento de pavimentos asfálticos flexíveis, permitindo além disso a identificação de trabalhos relacionados à esta tese de doutorado. Na Seção 3.3 são listadas as limitações desses trabalhos e discutidas as motivações para o desenvolvimento da metodologia MANIAC.

\subsection{Considerações iniciais}

Uma vez que o objetivo principal da pavimentação é a garantia da trafegabilidade em qualquer condição climática em qualquer época do ano, além da segurança e do conforto do usuário quando utilizando as rodovias, efetuar um monitoramento nas rodovias pavimentadas tornase uma questão imprescindível quando é observado um aumento elevado tanto na quantidade e extensão dessas rodovias quanto no número de veículos que nelas trafegam. Desse modo, faz- 
se necessário efetuar um levantamento do estado-da-arte para descobrir trabalhos que apresentem esforços específicos em torno destes requisitos para identificar as melhores técnicas aplicadas na solução dos problemas e poder compor uma metodologia ou um processo que permita um monitoramento mais eficiente e efetivo a um custo mais acessível. Uma revisão sistemática foi realizada para identificar o estado-da-arte da área deste doutorado (essa revisão é apresentada em detalhes no Anexo A). Nesse capítulo é apresentada a síntese dos resultados obtida com a revisão sistemática no tocante aos artigos selecionados que melhor se relacionam com esta tese de doutorado.

\subsection{Estado da arte}

A revisão sistemática realizada buscou encontrar trabalhos que tenham características muito similares à proposta de doutorado apresentada nesta tese. Entretanto, como nenhum trabalho exatamente igual a esta proposta foi encontrado, esta revisão sistemática apresenta artigos publicados que têm contribuições importantes para cada um dos tópicos de pesquisa deste doutorado. Esta seção apresenta uma síntese dos resultados obtidos a partir dos trabalhos selecionados na última fase da revisão sistemática.

\subsubsection{Uso de veículos aéreos para detecção de defeitos em pavimentos asfálticos}

O estudo apresentado em Herold et al. (2004) aborda o uso da espectrometria de campo em rodovias combinado ao sensoriamento remoto hiperespectral para explorar o potencial em condições de estrada. O envelhecimento e degradação dos pavimentos são representados por características espectrais distintas. Este estudo utilizou índices de imagem e as medidas de variância espacial para relacionar o sinal de sensoriamento remoto aos índices de condição do pavimento. As relações das imagens apresentaram melhor correlação com o PCI Geomática OrthoEngine, e a variância correlacionada com um índice que descreve danos estruturais na estrada (por exemplo, rachaduras). Essencial para o mapeamento de deterioração das estradas são as resoluções dos sensores espaciais. O GIFOV deve ser, pelo menos, na ordem de $0,5 \mathrm{~m}$, para observações detalhadas de condições de estrada. Os mapeamentos são mais precisos para as estradas em boas condições. Estradas mais velhas são mais complexas e sua avaliação de condição é mais incerta. Existem algumas limitações para este estudo. A investigação só está focado em uma pequena área de estudo e em pisos de asfalto. Houve alguns problemas com a calibração espectral da alta resolução. Em resumo, os autores demonstraram que a avaliação de condição de estradas com câmeras hiperespectrais tem algum potencial. Segundo os autores não se pode substituir essa técnica pela feita em campo. Os próprios autores ilustram a necessidade de um refinamento das análises e do desenvolvimento de estratégias de mapeamento baseados na tecnologia existente em comparação ao uso de VANTs, e essa é a proposta deste trabalho, incluindo-se uma metodologia que permita a reprodução. 
De modo análogo, os mesmos autores continuam o estudo que é apresentado em Herold e Roberts (2005), Herold e Roberts (2005) e em Herold et al. (2008). Nesses estudos os autores mais uma vez salientam que os VANTs constituem uma tecnologia emergente no contexto de transporte. Segundo os autores, sensores embarcados em VANTs constituem uma nova e econômica fonte de informações para o sensoriamento remoto. Embora os esforços de mapeamento são até hoje pouco desenvolvidos, existe um grande potencial de desenvolvimento para apoiar pesquisas de Infraestrutura de Transporte em muitas circunstâncias. Desse modo, esta tecnologia pode apoiar, por exemplo os esforços de manutenção da estrada. Na época os estudos pararam pelo fato de haver uma grande barreira para o uso desses veículos no espaço aéreo dos Estados Unidos. Os autores sugerem que o uso de diferentes câmeras, como NIR (Near Infra Red), a videografia digital, entre outras, são sugestões de novas pesquisas, e que os estudos deveriam ser feitos sem a necessidade de um espectômetro de imagem. Nesse sentido, o trabalho de doutorado aqui proposto foca justamente nessa lacuna apresentada na literatura aberta.

Em Rathinam, Kim e Sengupta (2006), os autores investigam a inspeção e monitoramento de dutos de petróleo e gás fazendo uso de Veículos Aéreos Não Tripulados e de técnicas de processamento de imagens. Os autores apresentam características como diminuição do custo operacional, agilização no processo de monitoramento e utilização em ambientes onde o uso de veículos tripulados é impeditivo como argumentos para a utilização de VANTs. Os autores demonstram ainda a viabilidade de utilização de alguns algoritmos de processamento de imagem, tanto online como offlines para a realização da supervisão. $\mathrm{O}$ artigo vem ao encontro dos objetivos do trabalho aqui realizado, uma vez que demonstra a viabilidade de VANTs de pequeno custo para a aquisição de imagens visando ao monitoramento. As características do pavimento, bem como a detecção do mesmo e o estudo e determinação dos defeitos não é foco do artigo.

Vários são os trabalhos que buscam analisar algoritmos para classificação de imagens no intuito de extrair os diferentes tipos de cobertura do solo. Na maioria dos trabalhos as áreas levantadas são também vegetação, pavimentos, telhado, concreto, sombra, entre outros Leonardi et al. (2009). Na maioria desses trabalhos, os resultados ainda não garantem $100 \%$ de certeza com relação as partes observadas. Também as regiões de concreto e telhado acabam sendo confundidas com as regiões de asfalto.

Segundo estudos efetuados e apresentados em McCormack e Stimberis (2010), a Área de Transporte tem avaliado desde 2003 o uso da tecnologia de VANTs em diferentes frentes. Nesse estudo, os autores avaliam a efetividade do uso de VANTs no controle de avalanches e de neve nas estradas. Foi possível avaliar, com o uso dos VANTs, detectar áreas com possibilidade de avalanches e também a presença ou não de pessoas nessas áreas. Avaliaram também a possibilidade de transportar pequenas quantidades de explosivos para áreas de difícil acesso. É importante notar que não foram utilizadas técnicas inteligentes, os veículos foram 
simplesmente utilizados como extensão da visão dos analistas. Nenhum controle automático foi implementado para detectar regiões ou até mesmo para detectar pessoas. Por meio do trabalho realizado pelos pesquisadores, os mesmos chegaram a conclusão de veículos de asas fixas constituem veículos mais interessantes para esse uso. Mas uma vez fica evidente que não se pretendia ter maior autonomia, e sim ter a possibilidade de um manuseio melhor e que o veículo pudesse pairar sobre uma determinada área, não tomando nenhum decisão ou realizando nenhum processamento inteligente e automático, o mesmo simplesmente transmite imagens de vídeo para que as decisões possam ser tomadas pelos analistas em solo.

Há muitas aplicações de SIG que são utilizadas por profissionais no mundo todo: urbanistas utilizam o SIG para desenvolver e acompanhar os planos urbanos; analistas de mercado aplicam SIG para prever e planejar o crescimento do negócio; e os cientistas utilizam imagens de Sensoriamento Remoto que ajudam o reconhecimento da cobertura da terra Codella et al. (2011). Os autores ilustram a necessidade em se prover classificação de imagens (vistas como informações) de forma automática, uma vez que, geralmente, a quantidade de imagens oriundas de satélites e de VANTs é grande. No artigo os autores apresentam um framework que classifica de forma automática as imagens de satélite em regiões específicas como Vegetação, Construção e Pavimentos. O software utilizado é proprietário da IBM (International Business Machines Corporation) e os resultados apresentados demonstram a dificultada na caracterização do pavimento, que de modo geral se confunde com a construção, não sendo identificado com precisão. Esse trabalho será utilizado como base, e outros algoritmos serão analisados para a extração mais adequada do pavimento, que é um dos alvos desta pesquisa.

O trabalho de Resende et al. (2012) é o que mais se aproxima do trabalho aqui proposto. Neste os autores propõem o estudo supervisionado das condições asfálticas (pavimentos asfálticos flexíveis). Os autores propõem o uso de técnicas de classificação baseada em pixel e fazendo uso de sensores hiper-espectrais. Entretanto, os resultados obtidos não foram satisfatórios. A metodologia proposta não define os parâmetros necessários para que o uso de imagens aéreas possa ser feito de forma a produzir resultados satisfatórios. Também não foram utilizadas técnicas modernas como Machine Learning que permitem um melhor aprendizado e uma melhor caracterização das informações (layers) obtidas. Ademais, as imagens aéreas utilizadas foram de baixa resolução espacial e portanto não permitiram a geração de dados consistentes sobre os índices de qualidade do pavimento. Desse modo, nessa pesquisa, obteve-se com o uso de técnicas modernas de inteligência artificial (como é o caso de Machine Learning, associada ao processamento de imagens e aos SIGs uma metodologia específica para a classificação automática dos defeitos das superfícies dos pavimentos asfálticos.

Vários são os algoritmos propostos para detecção de pavimentos Birdal e Erçil (2007), Assidiq et al. (2008), Yenikaya, Yenikaya e Düven (2013), Fernando et al. (2014), Yinka et al. (2014), entretanto, a maior parte dos algoritmos encontrados está focada na localização do pavimento a partir de lasers ou imagens obtidas a partir de câmeras instaladas em veículos terrestres, mais 
especificamente, para o uso em veículos terrestres autônomos. Esses algoritmos não funcionam quando se tem imagens obtidas a partir de veículos aéreos, uma vez que as informações da trajetória e dos ângulos utilizados não serem os mesmos. Entretanto, esses diferente algoritmos são levados em consideração para a obtenção de um algoritmo que permita somente a detecção do pavimento como instrumento de auxílio para a obtenção dos defeitos, realizado a posteriori.

\subsubsection{Detecção de pavimentos asfálticos}

Maser Maser (1987) usando equalização de histograma para melhorar o contraste das imagens propôs uma segmentação baseada em limite. Li Li et al. (1991) usou os detectores de borda de Sobel e modificou o método automático de determinação de limite sugerido por Kittler e Illingworth, de modo a ligar os segmentos de fenda para formar um conjunto contínuo de pixel do objeto. Eles basearam-se no pressuposto que os aglomerados de ruído tinham um perímetro menor do que um número pré-especificado de pixels.

Houve uma quantidade significativa de pesquisas durante as últimas duas décadas no desenvolvimento de inspeção automatizada de pavimento. Em Xu e Huang (2003) os autores desenvolveram um algoritmo de processamento de imagem personalizado para a inspeção do pavimento rachado, no qual uma imagem é dividida em pequenas células e uma célula é classificada como fendas ou não com base nas suas características locais. Após a verificação, um conjunto de sementes é identificado como uma rachadura verdadeira.

Em Ishikawa e Silva (2007), os autores aplicam uma rotina para detecção de rodovias por meio das ferramentas de morfologia matemática em imagens de alta resolução. A teoria da Morfologia Matemática consiste em descrever as estruturas geométricas presentes quantitativamente na imagem. Uma vez que os autores sugerem o uso de imagens de alta resolução, a maior dificuldade está no processo de detecção das rodovias, uma vez que existe a presença de árvores e automóveis. Segundo os resultados apresentados pelos autores, os bons resultados se dão por meio da escolha de elementos estruturantes adequados para serem utilizados nas funções. Sendo assim, por meio da escolha adequada dos operadores morfológicos e elementos estruturantes, foi possível detectar as faixas de rodovias. Essa detecção, apesar de contribuir em aplicações cartográficas e também para a definição das técnicas a serem utilizadas na extração do pavimento das imagens aéreas, não se adequa ao estudo aqui proposto, uma vez que não preserva as características da imagens e agrega um tempo de processamento muito grande, o que não permite a obtenção e detecção dos defeitos de maneira eficaz.

\subsubsection{Classificação automática de defeitos em pavimentos asfálticos}

No artigo proposto por Kaseko e Ritchie (1993), os autores propõem uma metodologia para detecção e classificação de defeitos de pavimentos. É feito uso da segmentação de imagens, extração das características, decomposição das imagens pela severidade do defeito, classifica- 
ção da imagens e distribuição das mesmas entre os graus de severidade para cada imagem. Segundo os autores, os resultados obtidos foram bons, entretanto há necessidade de melhoria nos processos de segmentação, tendo em vista que os defeitos pequenos não foram classificados apropriadamente. Para classificação foi utilizada uma rede do tipo Multi-layer feed-forward network (MLF). Não for abordado o processo de obtenção das imagens.

Koutsopoulos Koutsopoulos e Downey (1993) propôs um método de compensação da variação de luminosidade por meio da subtração de uma média de algumas imagens sem problemas da mesma série. Para segmentação, em vez de usar a segmentação binário comum que atribui um valor de 1 a pixels de objeto e um valor de 0 para pixels de fundo, o que resulta numa imagem binária, uma abordagem diferente é sugerida, e atribui valores de 0 a 3 para cada $p i-$ $x e l$, com base na probabilidade de ser um pixel do objeto. Pixels de fundo são desenhados a partir da distribuição de Gauss. Pixels de objeto são desenhados a partir de uma distribuição semelhante, com uma média mais baixa e uma maior variância. Um limite que satisfaz vários critérios pode ser obtido a partir destas duas distribuições.

No artigo apresentado por Koutsopoulos, Kapotis e Downey (1994) métodos para classificação automática de imagens de defeitos de pavimentos são examinados e comparados. A proposta constitui na divisão das imagens em regiões e em um processo de classificação em duas fases: primeiramente as regiões são classificadas de acordo com primitivas (simples, longitudinal, transversal, diagonal, ou conjuntas), que são os blocos de construção que caracterizam as várias classes de defeitos; posteriormente, os resultados da classificação regionais são agregados e usados como entrada para a classificação de toda a imagem a uma das classes de interesse (normal, longitudinal, transversal, bloquear ou jacaré). Foi feito uso de um grande número de características (features) fazendo uso de análise discriminante, k-vizinhos mais próximos, e modelos de escolha discreta. Foi possível observar que poucos são os descritores que sejam adequados para a classificação global. O estudo apresentado nesse artigo está mais relacionado aos descritores e aos métodos de validação.

Em Kaseko, Lo e Ritchie (1994) é feita uma comparação entre o classificadores tradicionais e os fazendo uso de redes neurais para a classificação de defeitos de pavimentos. Os autores compararam basicamente o K-NN com o multilayer feed-forward (MFL). Como resultados os autores obtiveram que os classificadores baseados em redes neurais obtiveram resultados ligeiramente superiores aos apresentados pelos classificadores tradicionais. Já em Cheng e Miyojim (1998) os autores apresentam novos algoritmos capazes de melhorar as imagens de defeitos de pavimentos, o que possibilita classificar as imagens de defeitos por meio da análise dos esqueletos de tais imagens. Neste artigo, assim como em Kaseko, Lo e Ritchie (1994) a obtenção das imagens é feita por meio de filmagem e posteriormente a partir das imagens das fitas são obtidas imagens congeladas (fotos) para que a análise pudesse ser efetuada. Como a qualidade das imagens era baixa, fazia-se necessário a melhoria das imagens para que a detecção pudesse ser realizada. Não foram feitas diferenciações entre os defeitos, apenas o reconhecimento em 
ter ou não defeito no pavimento.

Chou et al Chou, O’Neill e Cheng (1994) utilizam momentos invariantes de diferentes tipos de problemas de pavimentos para obter os diferentes tipos de problemas, e então utiliza uma rede neural back-propagation para classificá-los, entretanto as imagens são obtidas em solo. Georgopoulos et al Georgopoulos, Loizos e Flouda (1995) propuseram um método em que a deterioração pode ser representada por um conjunto de vetores, aproximando as rachaduras que compõem o problema. Os vetores de direção são então agrupados em duas categorias: horizontais e verticais, levando à classificação das fissuras.

Cheng et al. Cheng et al. (1999) propuseram uma abordagem baseada na teoria dos conjuntos fuzzy. Em primeiro lugar, o método proposto compara a escuridão dos pixels e seus vizinhos para decidir a função de pertinência de brilho para os níveis de cinza na imagem. A imagem "fuzificada" é mapeada para o domínio da rachadura, encontrando os valores de adesão de rachadura dos pixels. Finalmente, a conectividade dos pixels escuros é verificada para eliminar os pixels que não possuem a propriedade de conectividade. Um algoritmo de projeção de imagem é utilizado para classificar as rachaduras.

Uma abordagem considerada inovadora na época em que foi proposta, para a detecção de pavimento foi a apresentada em Paquis, Legeay e Konik (2000). O artigo apresenta uma abordagem para a classificação de texturas de superfícies asfálticas baseada em um sistema de visão automático. Uma vez que a superfície da estrada é composta por agregados com uma determinada distribuição de tamanho de grão e a matriz de argamassa, do ponto de vista da visão computacional, as imagens da superfície da estrada podem ser descritas como um conjunto de objetos de altas intensidades colocados sobre um fundo uniforme de baixa intensidade. Em processamento de imagens, morfologia matemática fornece um conjunto de ferramentas utilizadas para comparar partes de uma imagem com elementos estruturantes de vários tamanhos e formas. Desse modo, o objetivo dos autores era o de caracterizar texturas de superfície de estrada com diferentes tamanhos e distribuições de forma. Apesar de utilizar técnicas baseadas em morfologias matemáticas as características apresentadas pelas imagens utilizadas nesta tese diferem das propostas neste artigo. Apesar de constituírem imagens de alta resolução, não é objetivo caracterizar e diferenciar a textura da superfície, e sim diferenciar o que é asfalto dos demais componentes da imagem e posteriormente detectar e classificar os principais tipos de defeitos encontrados no pavimento.

Os métodos fornecidos por Fukuhara Fukuhara et al. (1990) e Li Li et al. (2009) só podia julgar se uma rachadura existiu e os resultados não foram bons o suficiente. $O$ trabalho apresentado por Liu et al. (2002) também determina a presença de rachaduras a partir do uso de redes neurais, mas com informações de sensores ultrasônicos. Apesar do uso de redes neurais, o sensor utilizado neste artigo difere bastante do sensor utilizado nesta tese. Cabe ressaltar, que as imagens apresentadas para o classificador já constituem os defeitos propriamente, tendo sido previamente tratadas para isso. As imagens abordadas nesta tese leva em consideração 
imagens de VANTs e consequentemente necessita que haja uma extração da superfície asfáltica previamente, para que posteriormente ocorra a detecção e a classificação dos defeitos.

Javidi et al. Javidi et al. (2003) definem duas pequenas wavelets que são, respectivamente, as derivadas parciais ao longo de $\mathrm{x}$ e y da suavização bidimensional da função cúbica wavelet spline. Ao medir a evolução por meio de escalas da transformada wavelet máxima, o ruído de fundo pode ser separada da rachadura. As imagens de rachaduras são projetadas no domínio da transformada Hough para quantificar o número de fissuras dominantes em uma determinada imagem. O uso de uma transformada wavelet discreta (DWT - Discrete Wavelet Transform), também tem sido explorada para análise de imagens de rachadura. Usando uma transformada rápida de wavelet, uma imagem de pavimento pode ser decomposta em diferentes sub-bandas de frequência. A grandeza dos coeficientes de wavelet representa o nível de rachadura (ZHOU; HUANG; CHIANG, 2005), (ZHOU; HUANG; CHIANG, 2006).

Rachadura de vedação é uma operação de rotina e necessária para a manutenção do pavimento. Técnicas tradicionais de observações subjetivas de superfícies de estrada tem sido o método mais comum para avaliar as rachaduras da superfície da estrada em todo o mundo. No entanto, é difícil avaliar objetivamente e com precisão as rachaduras da estrada com base na percepção visual humana. Desse modo, em Kim et al. (2006) os autores propuseram um estudo para avaliar as características de rachaduras de vedação em rodovias de forma automatizada. Foram utilizados neste trabalho imagens de vídeo, a fim de se obter informações mais precisas que as imagens visuais humanas. Os autores propuseram uma metodologia simples, que faz uso de um conjunto de algoritmos de processamento de imagens para detectar o desgaste do pavimento em caso de rachaduras de vedação. Apesar de os autores mencionarem que os resultados da metodologia proposta serem promissores, os resultados ilustrados nas figuras não dizem o mesmo. Além disso, somente um tipo de defeito é tratado, e imagens específicas são utilizadas, diferenciando do trabalho aqui realizado.

Em Oliveira e Correia (2008) e Oliveira e Correia (2009) os autores propõem um framework para a detecção e classificação automática de trincas fazendo uso de imagens adquiridas durante o monitoramento de rodovias. Os autores fizeram uso de filtros morfológicos para redução da variância da intensidade de pixel. É feito uso de um limitante dinâmico para identificação de pixels escuros nas imagens, uma vez que correspondem aos pixels de fissura. O sistema proposto foi o aprendizado não supervisionado dividindo os dados em várias classes. Os resultados apresentados pelos autores demonstram que técnicas não-supervisionadas apresentam bons resultados para a classificação das trincas. O estudo apresentado nesse artigo permitiu averiguar que algoritmos não-supervisionados mostram-se promissores para detecção de defeitos. Entretanto, é importante salientar que as imagens obtidas neste artigo diferem muito da imagens obtidas nesta tese de doutorado, de modo que os algoritmos utilizados, bem como as técnicas de avaliação são diferentes.

Apesar de tentativas Meignen, Bernadet e Briand (1997), Cheng e Miyojim (1998), Wang e 
Gong (2002), Salari et al. (2010) feitas para coletar automaticamente os dados de fissuras em pavimento, devido ao efeito de iluminação não uniforme e irregularidades da superfície do pavimento, pequeno sucesso foi alcançado em detectar com precisão rachaduras e classificar seus diferentes tipos. Além disso, a maioria dos sistemas existentes requer algoritmos complexos, com altos níveis de poder de computação, assim, melhores abordagens ainda são necessários para otimizar o processo.

Com objetivo de resolver o problema de acidentes de tráfego rodoviário de rápida e com alta precisão, em Qingwu e Haiying (2011) os autores propõem um framework baseado no uso de um GPS (Global Positioning System) VRS (Vertical Speed Required), um banco de dados geográfico e uma câmera de visão. A técnica de GPS-VRS é adotada para determinar o local inicial do acidente de trânsito, que é usado para consultar o roteiro do acidente de trânsito a partir de banco de dados da estrada. Posteriormente, o GPS-VRS é usado para examinar ainda mais o mapa quadro a quadro da cena do acidente de trânsito com o apoio do mapa da estrada. Um sistema de visão estéreo binocular é utilizado para coletar a imagem estéreo no local do acidente, de modo que a cena que pode ser usada para completar a cena do acidente. Por fim, um sistema de gestão local do acidente o tráfego foi concebido para gerir o mapa de tráfego, com imagens estéreos, relatórios do acidente com imagens georreferenciadas (utilizando SIG), que podem ser inclusive utilizadas como provas de tribunal, além da análise estatística de acidentes, das causas de acidente de trânsito e segurança rodoviária. Este trabalho permite averiguar que o uso de SIG tem sido de vital importância para a concepção de banco de dados georreferenciados, permitindo que as informações nele armazenadas possam ser utilizadas formalmente, até mesmo como provas em tribunais. Isso permite inferir que o uso de SIG neste trabalho vem ao encontro do apresentado no artigo, pois é de vital importância que as informações relacionadas a conservação das rodovias (do pavimento) possa ser georreferenciado com precisão.

Em Koch e Brilakis (2011) os autores fazem a detecção de buracos. Na metodologia por eles proposta, uma imagem é primeiro segmentada em regiões de defeito e não-defeitos com base em forma de histograma. Com base nas propriedades geométricas de uma região com defeito a forma potencial buraco é feita por aproximações morfológicas e regressões elípticas. Subsequentemente, a textura dentro de uma forma potencial de defeito é extraída e em comparação com a textura que rodeia o pavimento sem defeito, a fim de determinar se a região de interesse representa um buraco real.

A análise multi-resolução, como decomposições wavelet fornece boas ferramentas analíticas para diferentes escalas de análise e classificação de pavimentos. Em Nejad e Zakeri (2011) é proposto um sistema especialista para a classificação do pavimento. Uma rede neural de radon, baseada em sistemas especialistas de transformada wavelet é utilizado para aumentar a eficácia do algoritmo de extração de características invariante a escala. O módulo wavelet é calculado e a transformada radon é então aplicada ao módulo wavelet. As características e os parâmetros dos picos são então usados para treinamento e teste da rede neural. Os resultados experi- 
mentais demonstram que o sistema especialista proposto constitui um método eficaz para a classificação de defeitos de pavimentos. Os testes apresentados pelos autores demonstram as vantagens do sistema, sendo ele rápido, fácil de operar. Entretanto, faz-se necessário o uso de um equipamento específico que é levado para a área onde existem defeitos para que seja feita a sua caracterização. Esse procedimento é custoso e leva muito tempo, pois o equipamento deve ser manejado por uma pessoa que o desliza pela rodovia.

Um processo baseado nas propriedades de textura e cor de diferentes regiões de imagens foi usada em conjunto com o mapa de Kohonen em Mathavan, Rahman e Kamal (2012). Neste trabalho a precisão da segmentação foi de $89,7 \%$ com o mapa de Kohonen. Com o adicionamento do preenchimento vazio e a eliminação de detecções falsas, a precisão geral de classificação foi aumentada de $97,7 \%$. Cabe destacar aqui que as imagens foram obtidas em solo (diretamente das câmeras feitas in-loco) e que somente a presença de defeitos foi detectada, sem definição de qual especificamente.

Detecção de buracos é uma das tarefas importantes para o planejamento adequado de reparos e reabilitação dos pavimentos asfálticos. Reparação desses buracos são necessárias nas situações onde os mesmos comprometem a segurança e a capacidade de passeio do pavimento. Métodos para detecção e estimativa de buracos existentes geralmente usam equipamentos sofisticados e impõe tarefas de computação intensiva. Em Buza, Omanovic e Huseinovic (2013) os autores apresentam um novo método baseado em visão sem supervisão, que não exige equipamentos caros, filtragem adicional e fase de treinamento. O método proposto emprega processamento de imagem e de agrupamento espectral para identificação e estimativa aproximada de buracos. Agrupamento espectral é usado para identificação de regiões com dados baseados em histograma de imagem em escala de cinza. Com base nesses resultados, foi possível identificar buracos e estimar sua superfície. Foram feitos testes com diferentes imagens e diferentes formas de buracos e os resultados mostram que o método estima buracos, mas que a precisão não é muito boa. Além disso, a maior parte das imagens não é obtida de cima, mas sim com a imagem do buraco na diagonal.

Uma nova abordagem para distinguir automaticamente rachaduras no pavimento em imagens digitais foi proposto por Salman et al. (2013). A função (ou filtro) de Gabor Jain e Farrokhnia (1990) foi comprovado ser uma técnica com grande potencial para a detecção de fissuras multidirecional. Análise de imagens utilizando a função Gabor está diretamente relacionada com a percepção visual dos mamíferos, essa foi a razão pela qual os autores escolheram esse método para detecção de rachaduras. Foram obtidos como resultados da aplicação dessa função em imagens de pavimentos asfálticos (obtidas a partir do solo) uma precisão de detecção inicial de até $95 \%$. Mais uma vez as imagens foram obtidas de forma diferente da obtenção realizada nesta tese de doutorado. A função de Gabor é recomendada quando se objetiva diferenciar texturas, o que não é o caso apresentado nesta tese.

Já em Li et al. (2014) os autores fazem uso de redes neurais do tipo back propagation para 
o reconhecimento de trincas em pavimentos. Os autores propõem ainda um framework completo de processamento de imagens, incluindo o pré-processamento das imagens bem como a extração de informações sobre as trincas. Neste trabalho as imagens foram obtidas a partir de imagens automáticas de rodovias, classificando defeitos como "jacaré " e trincas transversais e longitudinais. Segundo os experimentos realizados pelos autores as taxas de classificações corretas foram de $97,5 \%, 100 \%$ e $88 \%$. É ainda feita nesse artigo uma comparação dos métodos utilizados para realização de detecção de alguns tipos de defeitos Fukuhara et al. (1990), Koutsopoulos e Sanhouri (1991), Lee e Oshima (1994), Lee (2001), Zhou (2004), Li et al. (2009). Os métodos em estudos anteriores têm diferentes graus de inconvenientes, e as desvantagens dos mesmos podem ser resumidas como segue: - O método é específico e apenas funciona para alguns tipo de rachadura; demasiado complexo para operar computação rápida e de alto poder computacional é necessário; o resultado da classificação é muito simples de usar na prática ou as amostras de imagem são muito pequenas.

\subsection{Considerações finais}

Este capítulo apresentou uma revisão bibliográfica sobre monitoramento das condições de pavimentos de rodovias. O objetivo principal era a identificação de trabalhos iguais ou muito similares ao desenvolvido nesta tese de doutorado. Como nenhum trabalho exatamente igual foi encontrado, a síntese de resultados apresentada elencou os principais trabalhos e propostas relacionados às partes mais fundamentais deste doutorado.

Com base no estado-da-arte apresentado por meio da fundamentação teórica, é possível especificar a MANIAC, desenvolvida e implementada nesta tese de doutorado. 


\section{Capítulo}

\section{MANIAC}

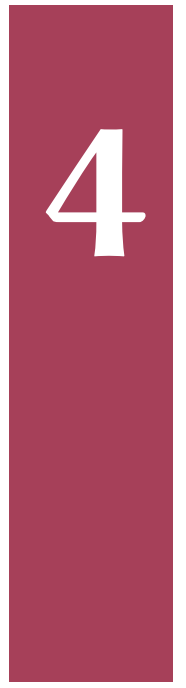

Diversos trabalhos são encontrados na literatura na área cujo objetivo é a detecção de defeitos em pavimentos asfálticos a partir de imagens aéreas obtidas por VANTs, sejam utilizando redes neurais, técnicas relacionadas a textura, e até mesmo alguns que fazem uso de técnicas mais modernas como Aprendizado de Máquina. No entanto, dentre esses trabalhos, como pode ser observado no capítulo anterior, poucos enfocam o uso de Veículos Aéreos Não Tripulados para a coleta das imagens a serem avaliadas, e, principalmente, a classificação automática das imagens permitindo a identificação, não apenas, do pavimento asfáltico, mas também a detecção e a identificação dos diferentes tipos de defeitos encontrados nesse tipo de pavimento. Este capítulo tem então como objetivo a apresentação da metodologia MANIAC, cujo objetivo é a especificação e definição dos parâmetros necessários para a adequada realização não só da coleta das imagens pelo VANT, mas de todos os requisitos para que possa ser realizada a detecção e classificação correta dos defeitos em pavimentos asfálticos utilizando técnicas de AM.

Este capítulo está estruturado da seguinte forma: na Seção 4.1 são apresentadas as considerações iniciais. Na seção 4.2 é apresentada a metodologia MANIAC, onde são detalhadas todas as etapas que constituem a metodologia. Na Seção 4.2.2 é detalhado o processo PréProcessar de modo a evidenciar a real necessidade de algoritmos que permitem a melhora nas imagens que compõem a entrada da MANIAC. A Seção 4.2.3 detalha os algoritmos e as técnicas utilizadas para que a malha viária possa ser automaticamente detectada refletindo o processo Detectar asfalto, permitindo assim que o pavimento com e sem defeito possam ser identificados corretamente, o que é apresentado na Seção 4.2.4 (processo Identificar defeitos). A especificação de cada processo da metodologia é feita em detalhes de modo a permitir o en- 
tendimento da mesma. O capítulo é encerrado com as considerações finais sendo apresentadas na Seção 4.2.5.

\subsection{Considerações iniciais}

O primeiro passo para que se possa utilizar um conjunto de imagens de alta resolução espacial para auxiliar na identificação automática de defeitos em pavimentos, sejam eles asfálticos ou não, é a especificação de etapas bem definidas, que contemplam a definição e recomendação de parâmetros para que essas etapas possam ser executadas de modo eficiente. Uma vez que são necessárias as definições de etapas a serem seguidas para a realização de um processo, especifica-se neste capítulo uma metodologia, denominada MANIAC (Methodology for PAvemeNt AutomatIc CharACterization), cujo objetivo é permitir que o processo de identificação de vias pavimentadas com defeitos seja realizado de modo estruturado e claro.

\subsection{MANIAC - Methodology for PAvemeNt Automatlc CharACterization}

Como já mencionado anteriormente, a análise do desgaste e de defeitos em pavimento asfálticos por meio de abordagens convencionais, visual e manual, requerem que os inspetores atravessem as estradas para medir o objeto de defeito ou desgastes quando são encontrados. Essa é uma atividade muito cara, demorada, perigosa, de trabalho intensivo, tedioso e com conclusões, que muitas vezes podem ser subjetivas, com alto grau de variabilidade, e quase sempre levando a inconsistências no detalhe do desgaste e/ou defeito.

Sendo assim, nesta tese foi desenvolvida e implementada a metodologia MANIAC que permite que sejam definidos todos os procedimentos necessários para que se possa realizar o monitoramento de rodovias que possuem pavimentos asfálticos a fim de detectar e classificar os defeitos por meio de imagens obtidas via Sensoriamento Remoto (mais especificamente fazendo uso de VANTs). Essa metodologia possui etapas bem definidas para que a detecção e classificação dos defeitos possam ser realizados de forma automática. Na Figura 4.1 é ilustrada a macro visão da MANIAC.

Como pode ser observado, a metodologia divide-se basicamente em três processos: PréProcessar, Detectar asfalto e, Identificar defeitos. Como entrada tem-se as imagens obtidas por VANTs e como saída o relatório dos defeitos encontrados com base na norma DNIT 008/2003 - TER (IPR, 2003d).

Inicialmente o processo de Pré-Processar refere-se ao processamento inicial dos dados brutos que permite a calibração radiométrica da imagem, a correção de distorções geométricas e a remoção de ruído. Com esse pré-processamento objetiva-se melhorar a qualidade da imagem, permitindo que os objetos presentes na imagem sejam melhor discriminados para a segmentação. Um detalhamento deste processo é apresentado na Seção 4.2.2. Cabe ressaltar que antes do processo Pré-Processar, as imagens são obtidas fazendo uso de VANTs, e os ajustes e as ca- 


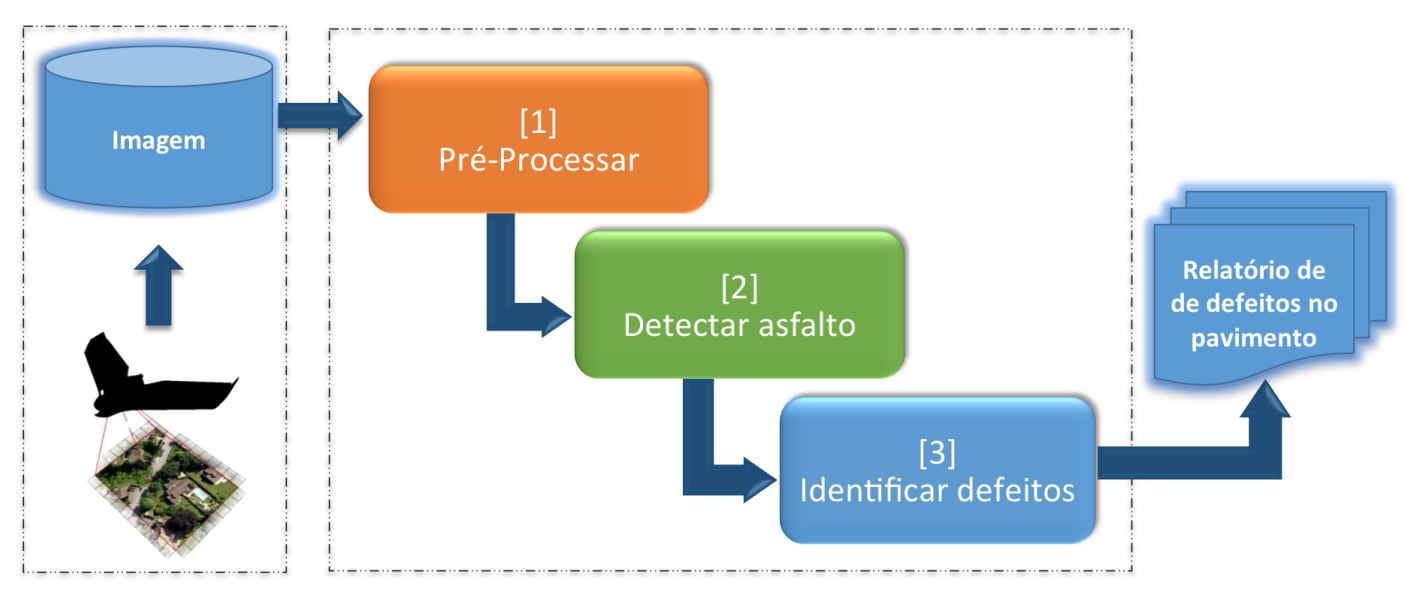

Figura 4.1 - MANIAC - Macro visão.

racterísticas das missões executadas fazem parte da metodologia. Sendo assim, esse processo será detalhado na Seção 4.2.1.

O segundo processo, Detectar asfalto, tem como objetivo a classificação das imagens obtidas. Essa classificação é feita por meio de SIGs e também por meio de técnicas de Aprendizado de Máquina. Nesse SIG são testados métodos de classificação automática que representem com maior fidedignidade os ambientes diversificados (classes de uso) que são visualmente detectados nas fotografias aéreas (rodovias e não-rodovias). Entretanto, a melhor forma encontrada para se obter a detecção de pavimentos asfálticos foi com o uso de Aprendizado de Máquina.

Para haver uma referência de uma classificação considerada ideal, as fotos aéreas também são classificadas por foto-interpretação. Esse processo é detalhado na Seção 4.2.3.

O resultado de saída deste processo são as imagens classificadas. Esse conjunto de imagens foram, então, organizados a fim de fazer uso de Machine Learning para a identificação automática dos defeitos encontrados nas imagens. Desse modo, o processo Identificar defeitos faz uso de dois conjuntos de dados: uma parte das imagens faz parte do conjunto de treinamento, e a partir dos resultados obtidos as demais imagens, de um outro conjunto utilizado para teste. A partir de então obtém-se o relatório com os defeitos identificados nas imagens informadas. O detalhamento do processo de Identificar defeitos é apresentado na Seção 4.2.4.

\subsubsection{Obtenção das imagens}

Este estudo apresenta possibilidades de uso de aviões não tripulados no campo do Sensoriamento Remoto voltado para detecção de defeitos em pavimentos.

Uma questão que sobressai é o por que utilizar um robô aéreo em detrimento aos satélites, capazes de proezas semelhantes. As principais razões por optar por VANTs são por causa das limitações dos satélites e da tecnologia fotométrica que eles usam.

Um robô aéreo é portátil e pode ser utilizado sempre que o utilizador quiser, em contraste 
com a aquisição de dados por meio de um satélite, que depende da órbita do mesmo, uma vez que tem que estar dentro do alcance do local desejado para ser capaz de fotografar e, normalmente possuem custo mais elevado tanto no aspecto financeiro quanto no computacional.

O VANT é capaz de tirar fotografias aéreas do local usando diferentes tipos de câmeras, permitindo a escolha da mais adequada para o tipo de inspeção ou missão que se deseja fazer. A qualidade desejada é sempre uma questão de custo quando se trata de tecnologia; o resultado desejado é, como tal, dependente dos recursos disponíveis. Todos os tipos de fotografia aérea são ferramentas de pesquisa não-destrutiva, pois não irão alterar o pavimento e nenhuma outra condição quando da sua realização.

Sendo assim, são de grande valia quando se associa o baixo custo dessas aeronaves frente ao custo do elevado número de pessoas necessárias para realizar o mesmo levantamento na mesma quantidade de tempo, quando da inspeção em solo, e também quando comparado o custo de imagens obtidas por satélite.

Resumidamente, a escolha pela utilização de VANTs se dá pelo fato das imagens obtidas serem mais ácuras e possíveis de serem obtidas a qualquer momento, inclusive serem feitas mais de uma vez no mesmo dia, diferentemente das obtidas por satélites.

\subsubsection{Características das imagens obtidas}

As imagens foram obtidas na região de São Carlos na Área II do Campus de São Carlos da USP e na cidade de Pardinho. A resolução da câmera utilizada foi de 16 megapixel enquanto que a altitude do voo foi de $130 \mathrm{~m}$ a qual permitiu uma resolução espacial de 4,0 cm/pixel. Vários voos foram realizado e o VANT é lançado a mão conforme ilustrado na Figura 4.2.

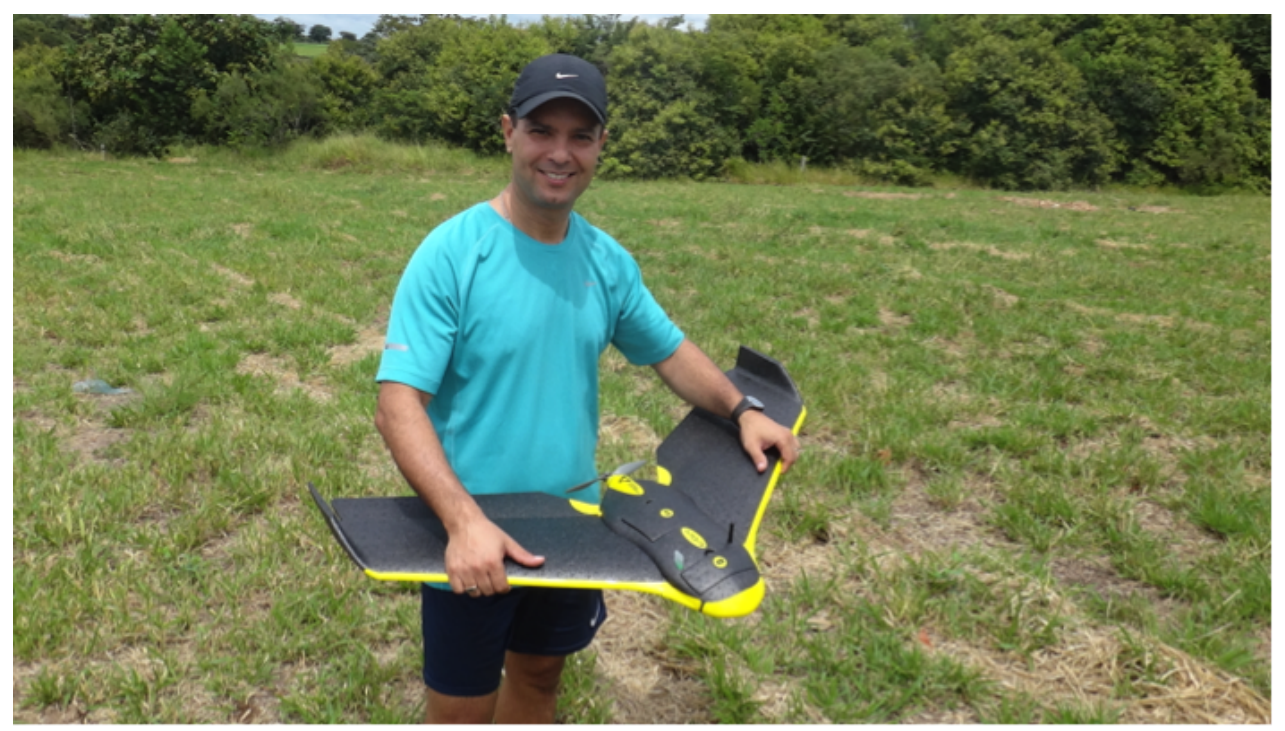

Figura 4.2 - Lançamento do VANT eBee para realização das missões para aquisição de imagens.

Os ajustes para os parâmetros recomendados de voo e da missão foram obtidos após a realização de diversas missões de testes. Recomenda-se, a partir dos experimentos realizados, 
que os parâmetros a serem configurados na aeronave e na câmera sejam os especificados na Tabela 4.1.

Tabela 4.1 - Parametrização específica para obtenção das imagens.

\begin{tabular}{|l|c|}
\hline \multicolumn{1}{c|}{ Parâmetros } & Valores Atribuídos \\
\hline Resolução Espacial da Imagem & $4.0 \mathrm{~cm} / \mathrm{px}$ \\
\hline Recobrimento Lateral & $60 \%$ \\
\hline Recobrimento Longitudinal & $70 \%$ \\
\hline Velocidade de Cruzeiro & $80 \mathrm{~km} / \mathrm{hora}$ \\
\hline Altitude de Voo & 130 metros \\
\hline
\end{tabular}

Os ajustes de voo são realizados diretamente no software de controle do VANT denominado eMotion. Toda a missão é mapeada e o mapa da região a ser sobrevoada pode ser observado durante a programação da missão.

No caso de missões para monitoramento de pavimentos asfálticos as missões foram planejadas por meio de polígonos para permitir que possam ser delimitadas as áreas a serem inspecionadas. A altitude de voo e a sobreposição das imagens que serão obtidas também são definidas durante a programação da missão. Isso significa que os parâmetros sugeridos e obtidos a partir dos experimentos realizados devem ser então inseridos previamente para garantir a execução desse tipo de missão.

As telas nas Figuras 4.3 e 4.4 ilustram como é feito o acompanhamento em solo, na estação de base, da missão que se está executando.

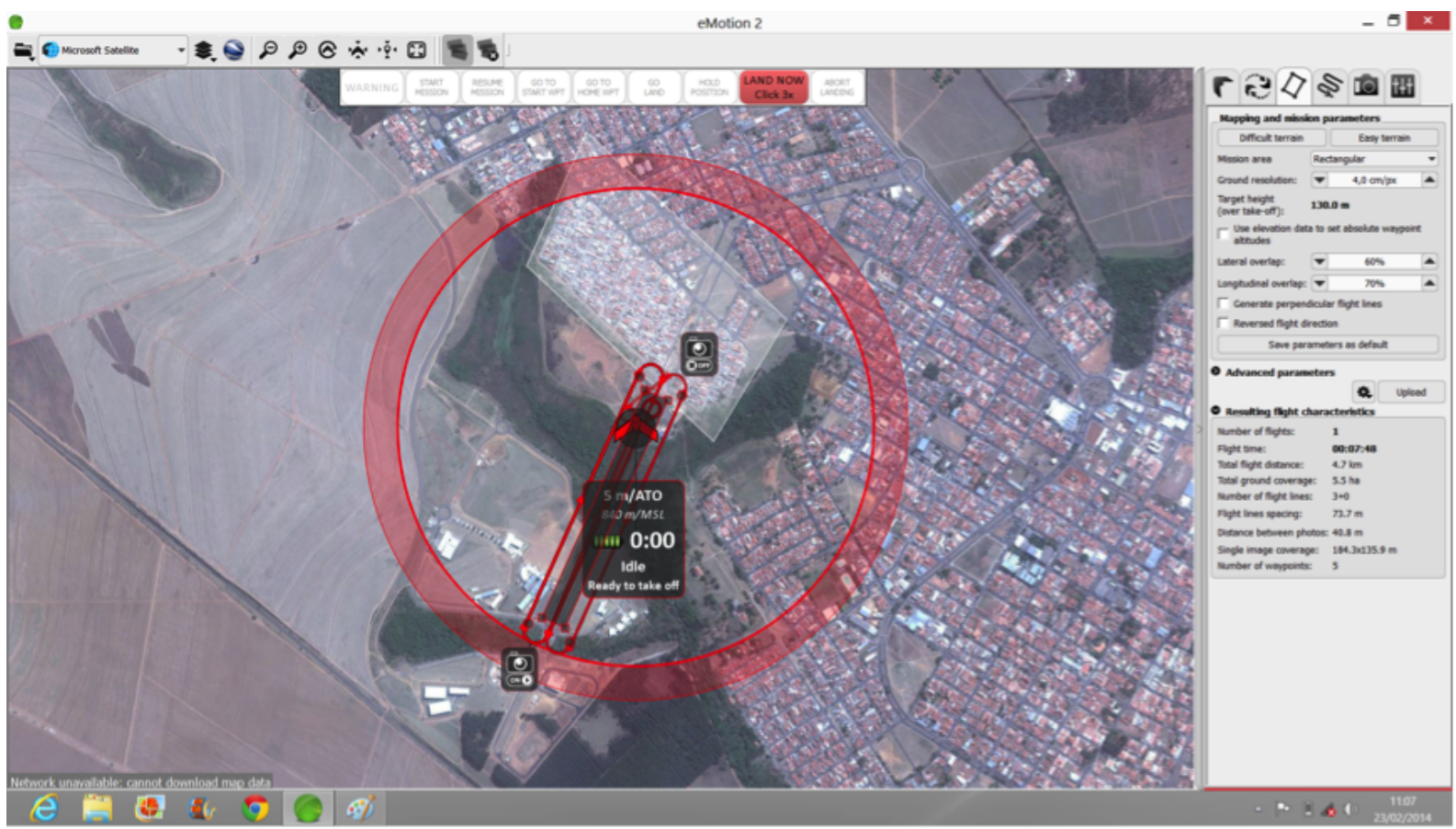

Figura 4.3 - Acompanhamento da execução de uma missão na estação de base. 
Na Figura 4.3 é possível observar a região delimitada pelo círculo que informa a área na qual o VANT pode voar. É a delimitação da fronteira de voo. Isso significa que mesmo que algo errado aconteça e ele seja impulsionado a ser levado para fora dessa área, ele não vai ultrapassar essa fronteira, pois um comando automático será ativado e ele retornará a base e pousará.

É possível observar também que há uma mensagem informando que ele está pronto para efetuar a decolagem. A rota de voo é delimitada pelas linhas vermelhas mais finas. Todas as informações de tempo/duração do voo, altitude da aeronave, área de cobertura, sobreposição lateral e longitudinal ficam também descritas na tela da missão.

Na Figura 4.4 é ilustrada uma missão em andamento. As áreas já fotografadas dentro do círculo vermelho ficam acinzentadas, e informações como a velocidade, altitude, direção do vento e quantidade de fotos já obtidas também são atualizadas em tempo real durante a execução da missão.

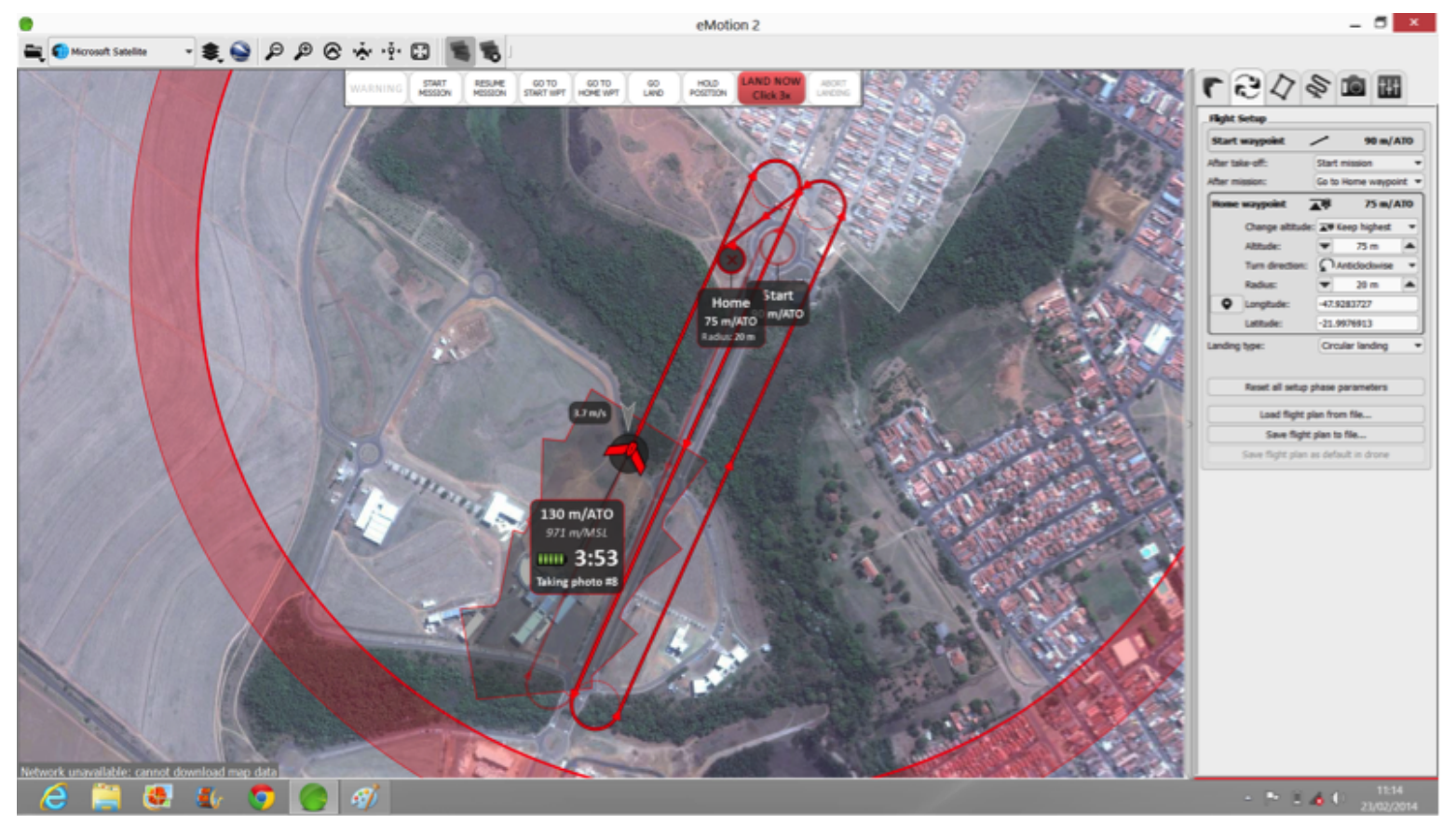

Figura 4.4 - Acompanhamento da execução de uma missão na estação de base - imageamento em progresso.

As coordenadas espaciais obtidas pela atual localização do VANT são marcadas para cada imagem no momento da aquisição possibilitando, dessa forma, que as imagens obtidas tenham a sua latitude e longitude definidas. Essas informações ficam armazenadas em um arquivo na aeronave. Quando as imagens são descarregas para o computador para o pós-processamento na geração do mosaico, há um arquivo de dados que permite georreferenciar as fotos obtidas durante a realização da missão, pois esse arquivo que fica armazenado no VANT contém as informações espaciais para cada imagem durante a realização das missões.

As localização das áreas onde as imagens são obtidas faz diferença nesse tipo de missão. A densidade populacional, bem como a presença de diferentes objetos na imagem agregam desa- 
fios ainda maiores no processo de detecção automática de defeitos em pavimentos asfálticos.

Nas Figuras 4.5 e 4.6 são ilustradas imagens obtidas em áreas de maior e menor densidade populacional, respectivamente. É possível observar que na área com maior densidade populacional a identificação do pavimento apresenta um desafio maior quando comparada a imagem com menor densidade. Isso se deve ao fato da presença não só de vegetação mas também de construções nessa área por se tratar de uma área urbana. Desse modo há muito concreto entre outros materiais, o que impõe um desafio maior no processo de caracterização dos objetos presentes na imagem.

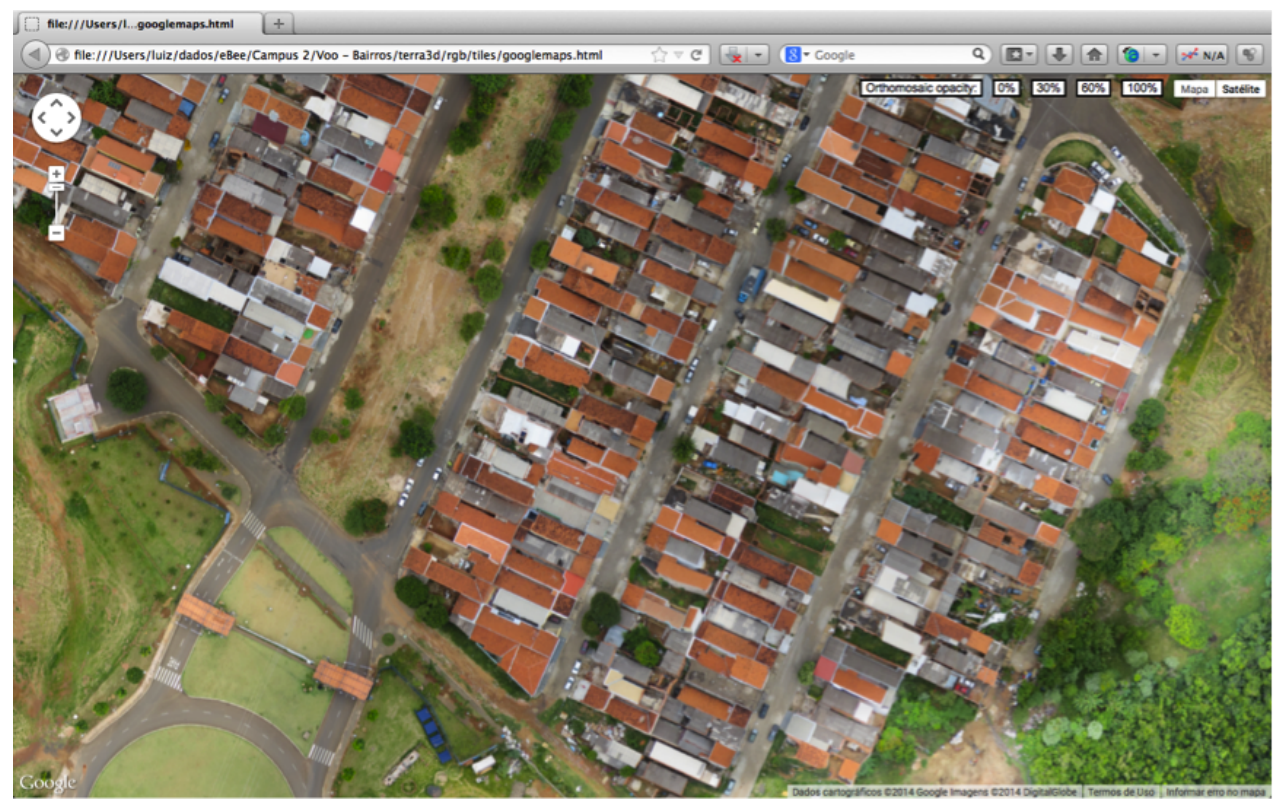

Figura 4.5 - Imagem de uma área urbana com alta densidade populacional.

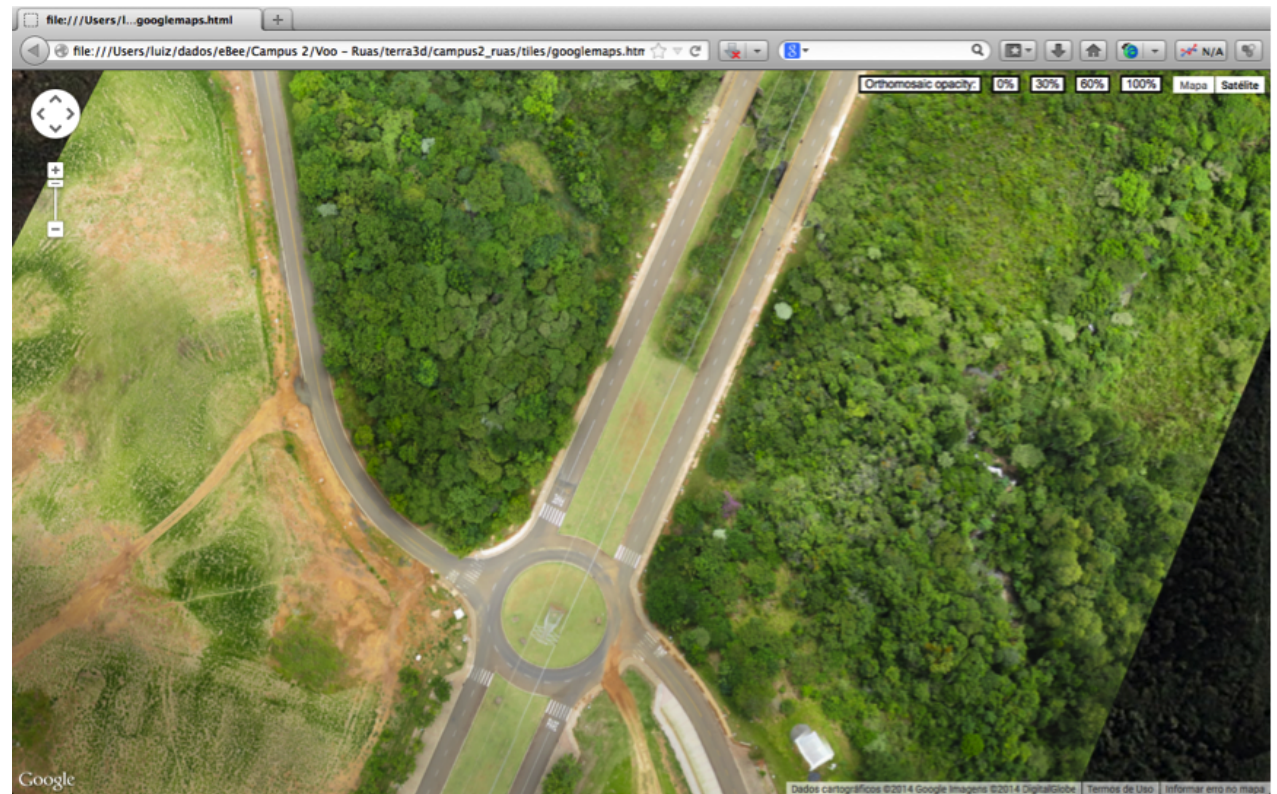

Figura 4.6 - Imagem de uma área urbana com baixa densidade populacional. 
A partir do conjunto de imagens com as suas respectivas informações espaciais de localização, foram produzidos, por meio de um processo de pós-processamento desses dados, o mosaico de cada missão. Nas Figuras 4.7 e 4.8 são ilustrados os mosaicos obtidos a partir das missões executadas nas áreas de maior e menor densidade populacional.

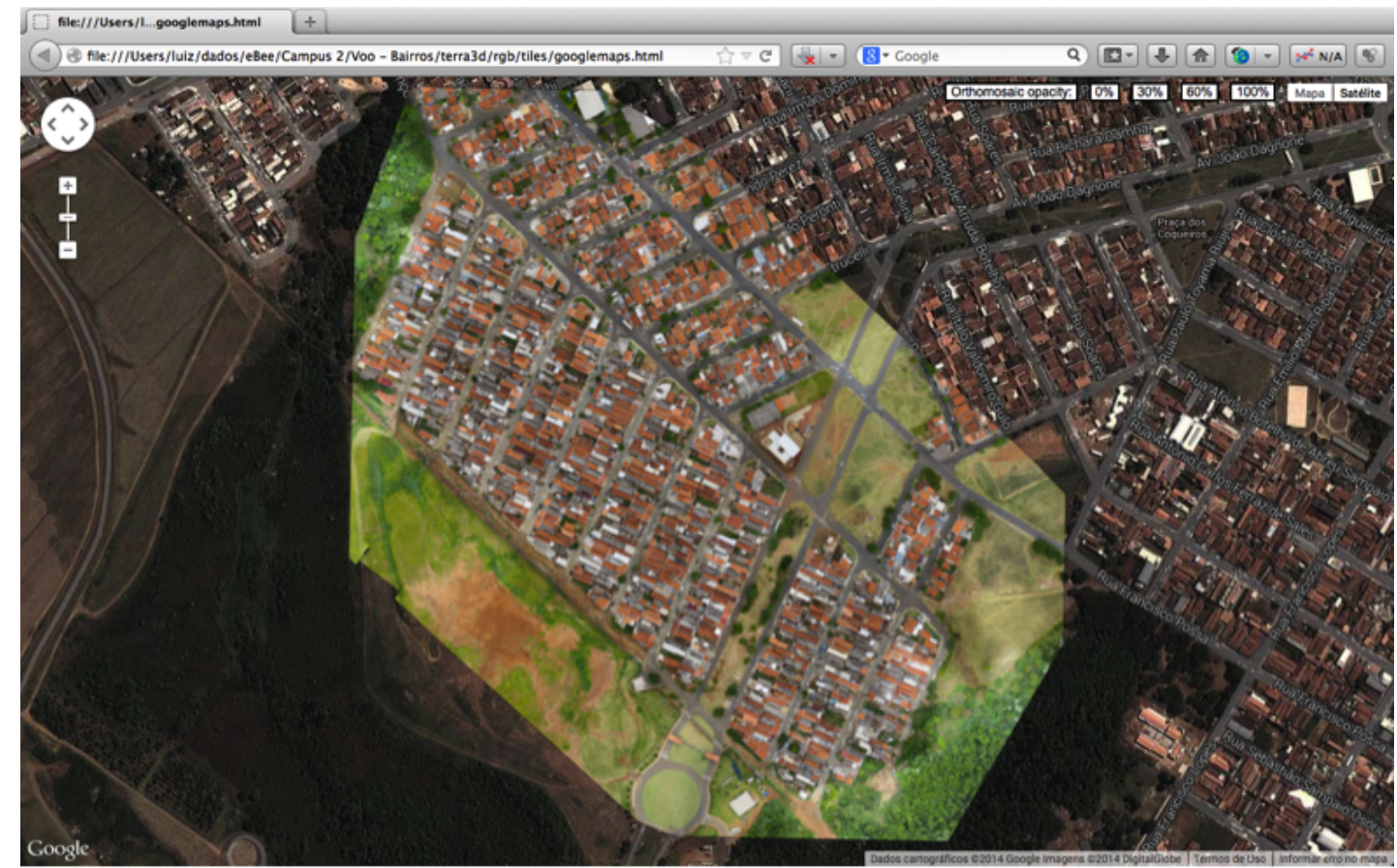

Figura 4.7 - Imagem de uma área urbana com alta densidade populacional. Mosaico com as fotos geradas com o VANT sobreposta a imagem do Google (mosaico georreferenciado).

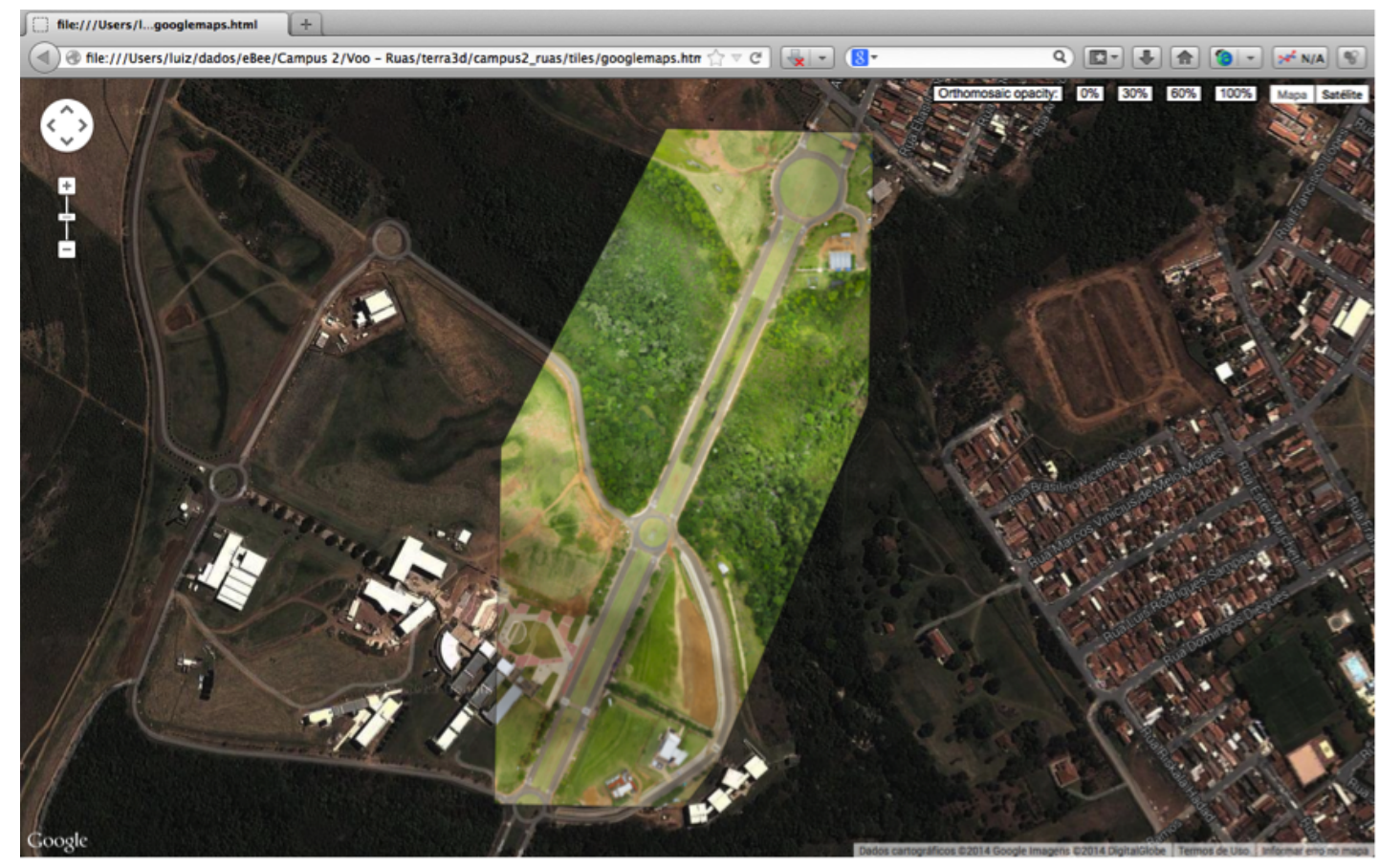

Figura 4.8 - Imagem de uma área urbana com baixa densidade populacional. Mosaico com as fotos geradas com o VANT sobreposta a imagem do Google (mosaico georreferenciado). 
As imagens obtidas, como já mencionado, são de alta resolução espacial, o que permite a obtenção de informações mais precisas. O nível de precisão pode ser notado a partir da observação das imagens ilustradas nas Figuras 4.9 e 4.10 que apresentam o nível de aproximação e detalhes que se pode obter nas imagens.

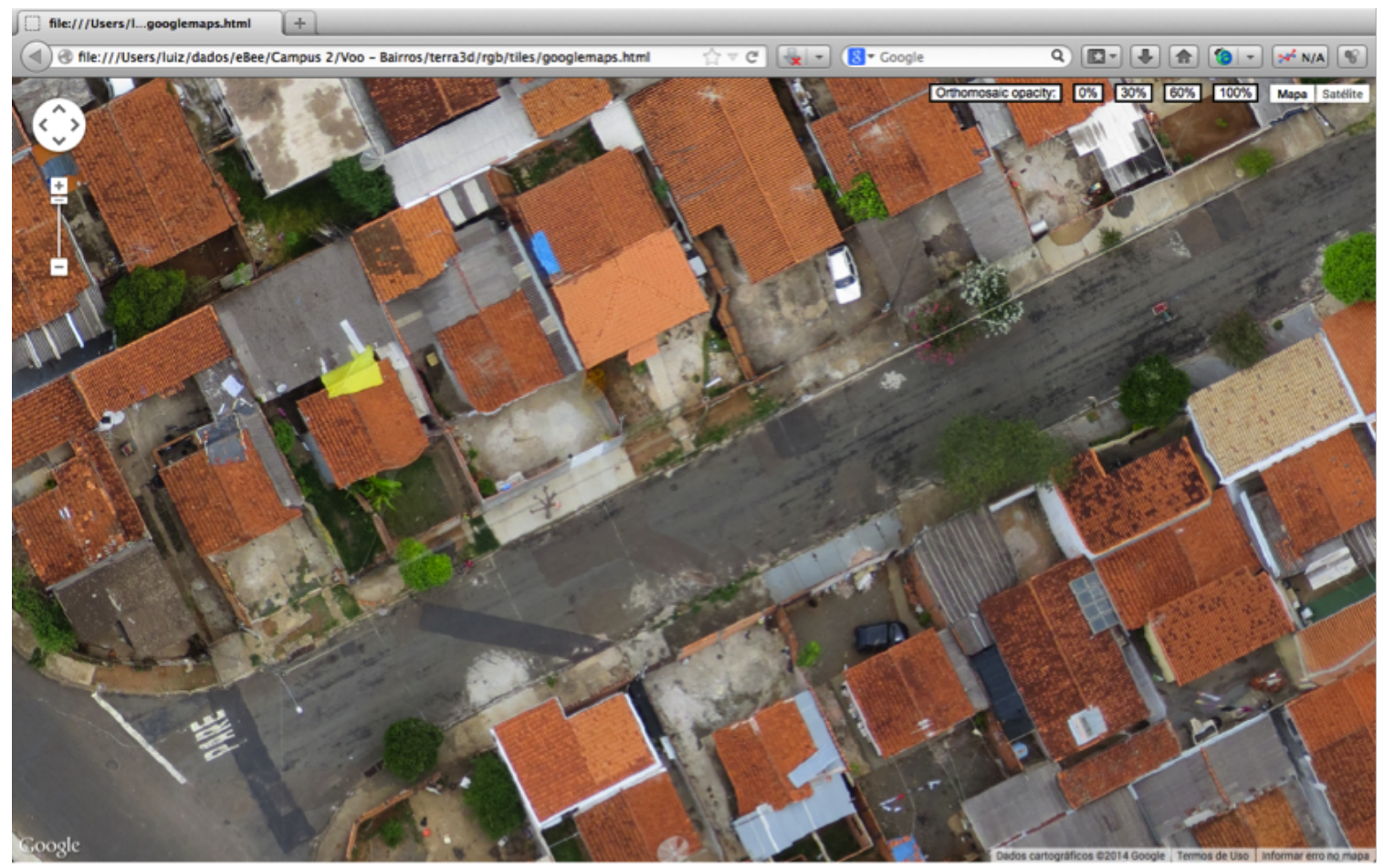

Figura 4.9 - Aproximações e ampliações de regiões com pavimento na região mais povoada.

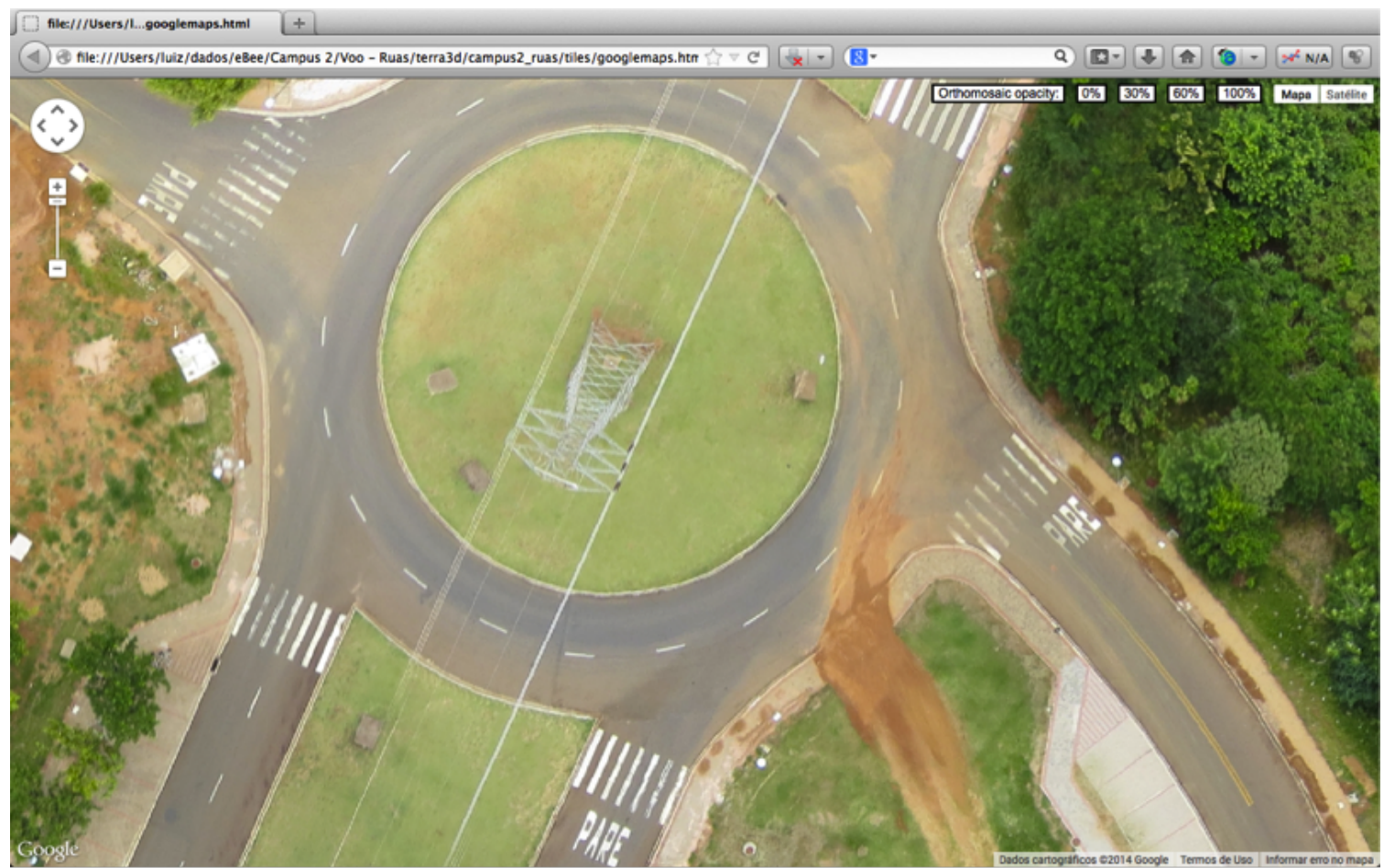

Figura 4.10 - Aproximações e ampliações de regiões com pavimento na região menos povoada. 
Além das missões executadas com a utilização da câmera em RGB, foram realizadas missões com a câmera com filtro NIR. Na Figura 4.11 é ilustrada uma imagem da região densamente povoada com a imagem em NIR. As imagens NIR trazem informações diferentes das imagens RGB, de modo que é possível extrair diferentes informações dos diferentes tipos de imagens.

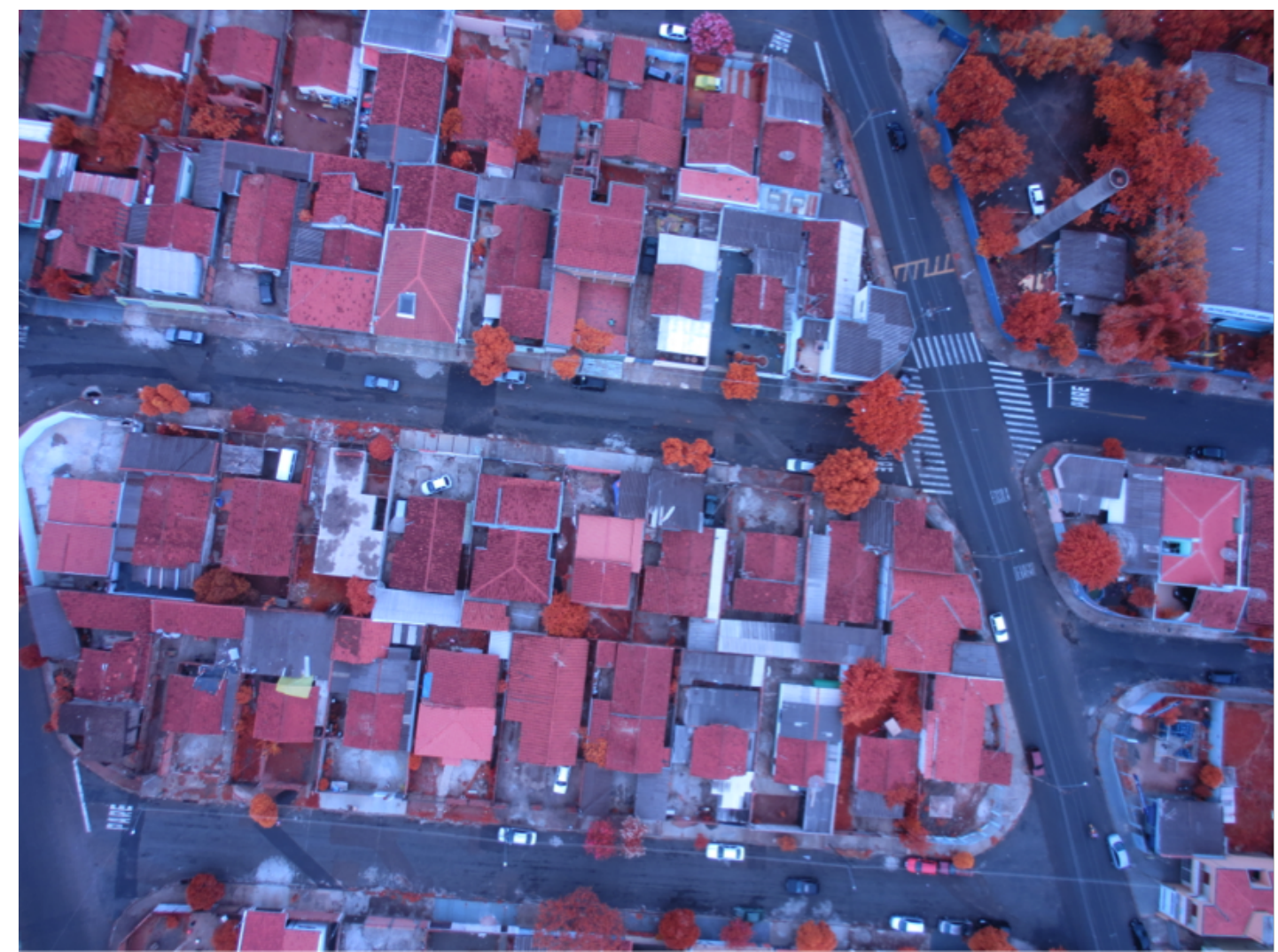

Figura 4.11 - Imagem obtida com a câmera NIR a partir do VANT eBee.

De modo análogo ao RGB, foram gerados mosaicos com as imagens em NIR e também podese aproximar e ampliar a imagem, uma vez que a resolução espacial é a mesma que a das imagens RGB. Pode-se observar que com as informações do NIR outras características podem ser observadas.

A partir desses experimentos realizados em campo foi possível definir qual a forma correta de obtenção das imagens, de modo que pode-se definir recomendações com relação aos parâmetros da missão tais como: a velocidade de cruzeiro, as faixas de recobrimento horizontal e vertical e mais especificamente a resolução da imagem, sendo essas informações importantes para a realização da missão de monitoramento de pavimentos asfálticos, e é uma das contribuições desta tese.

\subsubsection{Pré-Processar imagens}

Após a aquisição das imagens, passando pela especificação das características que devem ter essas imagens com base nas recomendações definidas, as imagens obtidas constituem as entradas para o processo Pré-Processar, que objetiva melhorar a discriminação dos objetos pre- 
sentes na imagem. O processo Pré-Processar imagens é ilustrado na Figura 4.12, e detalhado nesta seção.

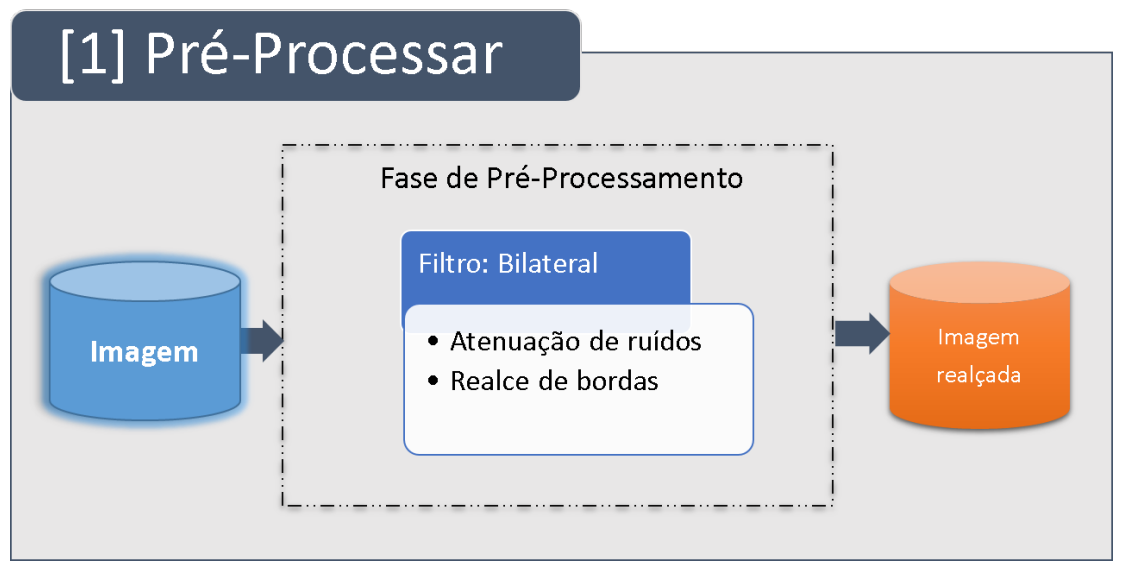

Figura 4.12 - Detalhamento do processo Pré-Processar.

Diversas são as técnicas utilizadas para o realce das imagens de modo a melhorar suas características. Inicialmente foram utilizados os métodos de Equalização do Histograma, o de Dilatação e o de Detecção de bordas, ilustrados na Figura 4.13a, 4.13b, 4.13c respectivamente. Esses testes foram realizados fazendo uso do SPRING versão 5.2.6 SPRING (2006). O SPRING foi escolhido por ser um SIG de código aberto, apresentar todas as características e algoritmos necessários para o almejado nesta tese, além de ser de pleno conhecimento do grupo onde esse trabalho está inserido.

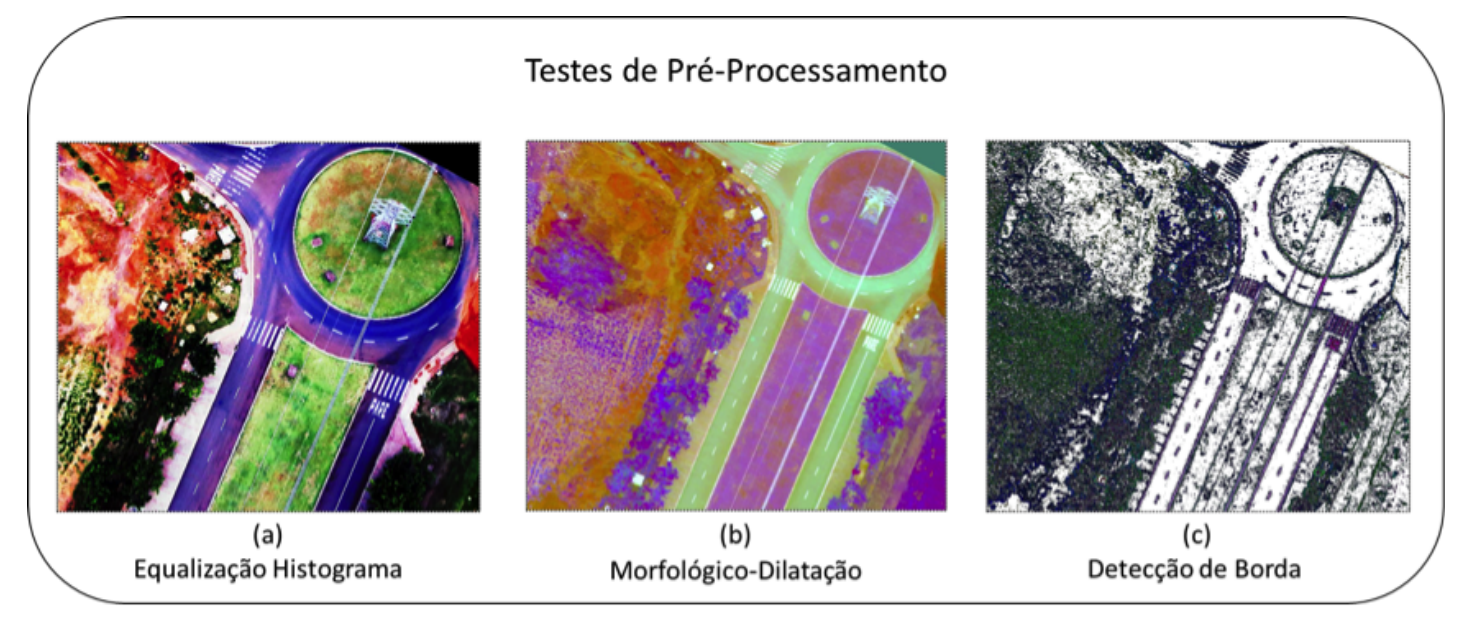

Figura 4.13 - Pré-processamento da imagem para permitir realce das áreas de interesse. (a) Equalização do Histograma; (b) Método morfológico de Dilatação; (c) Método de Detecção de Borda.

Por meio da execução desse processo foi possível detectar, fazendo uso da equalização do histograma, níveis de desgaste no pavimento asfáltico. As áreas mais desgastadas apresentam uma coloração diferenciada da área não desgastada. Isso foi um passo importante no sentido de demonstrar que as técnicas de pré-processamento das imagens contribuem muito para o realce de características do pavimento nas imagens analisadas. Entretanto, os algoritmos de 
suavização, contraste, filtragem e ruído da ferramenta SPRING não mostraram-se suficientes para o processo inicial da metodologia.

Em sendo assim, foram então executados novos testes fazendo uso da linguagem de programação Python versão 2.7.11+ em conjunto com a biblioteca scikit-image versão 0.12.3, uma biblioteca de processamento de imagens. Foram avaliados vários algoritmos, dentre os quais se destacaram a Equalização de Histograma, Gaussiano e Bilateral.

Na Figura 4.14 são ilustradas variações da aplicação da técnica de realce de histograma. É possível observar uma melhora na intensidade das cores, entretanto as bordas e contornos não são bem definidos, o que dificulta a detecção e diferenciação de objetos na cena.

\section{Histogram (pre-processing tests)}

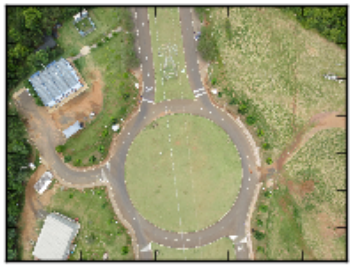

(a) Low contrast image (original)
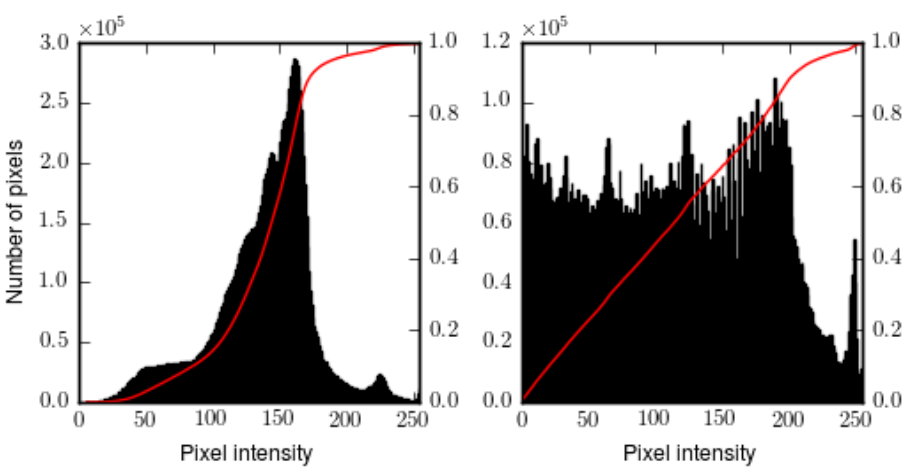

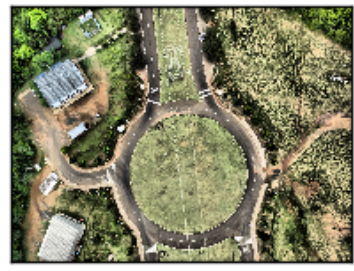

(c) Local equalize

Figura 4.14 - Testes de suavização. a) Imagem original. b) Filtro Gaussiano. c) Filtro Bilateral.

O Guassiano também foi outro filtro avaliado. Este é considerado um dos filtros de suavização mais úteis, mesmo não sendo o mais rápido. Ele é realizado por meio da convolução de cada ponto da matriz de entrada com o kernel Gaussiano e, em seguida, faz-se a adição de todos para geração da matriz de saída. Considerando uma imagem em escala de cinza, pode-se notar que o pixel localizado no meio deve possuir o maior peso. Os pesos dos vizinhos diminuem conforme a distância espacial entre eles e o pixel central aumenta.

O filtro Bilateral diferentemente dos filtros de suavização que além de dissolverem os ruídos também suavizam as bordas, evita que essa suavização de bordas ocorra a partir do realce das mesmas. O filtro Bilateral considera os pixels vizinhos com pesos associados a cada um deles. Esses pesos têm dois componente, o primeiro que é o peso utilizado no filtro Gaussiano (o pixel localizado no meio tem o maior peso e os demais possuem os pesos decrementados de acordo com a distância espacial entre eles). A segunda componente leva em consideração a diferença de intensidade entre os pixels vizinhos e o avaliado. 
Na Figura 4.15 é ilustrado o filtro Bilateral e é possível observar uma melhora na imagem a partir da suavização, remoção de ruídos e realce de borda, o que possibilita uma melhor caracterização dos objetos na imagem.

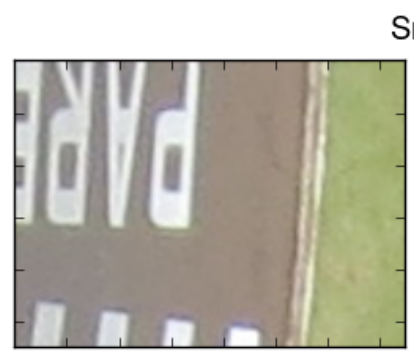

(a) Image (original)

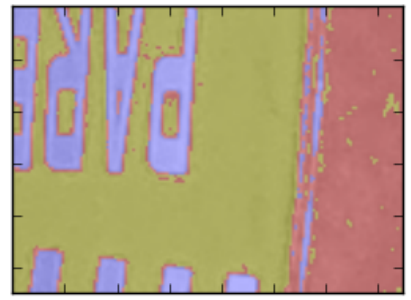

(d) K-means (3 clusters)

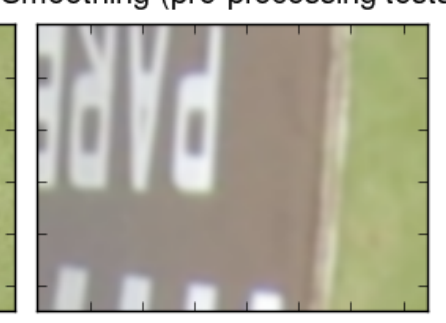

(b) Gaussian

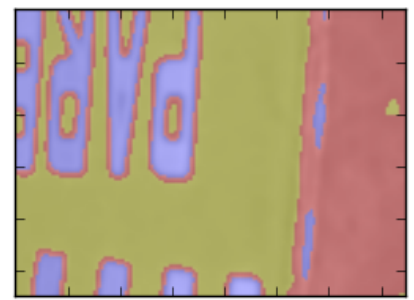

(e) K-means (3 clusters)

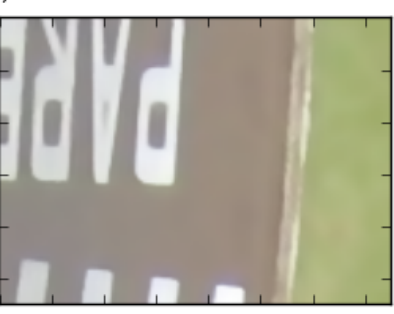

(c) Bilateral

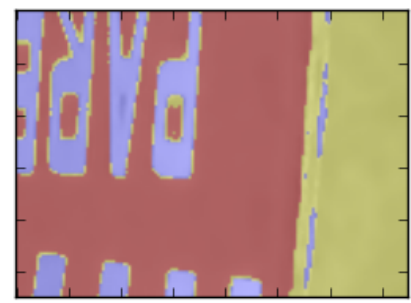

(f) K-means (3 clusters)

Figura 4.15 - Testes de Histograma. a) Imagem original. b) Gaussiano. c) Bilateral. d) K-means (3 clusters) imagem original. e) K-means Gaussiano. f) K-means Bilateral.

Cabe ressaltar que apesar dos diversos testes realizados, e da eficiência de algumas das técnicas avaliadas e aplicadas às imagens, a utilização da técnica Bilateral mostrou-se mais adequada para ser usada em todas as imagens durante o pré-processamento, pois contribuiu bastante no processo de segmentação atenuando os ruídos e suavizando as bordas dos elementos nas imagens.

Além disso, a importância desse processo fica evidente quando vislumbra-se que novas técnicas ou algoritmos podem surgir e podem impor melhorias significativas às imagens. Outro motivo pelo qual esse processo deve ser mantido é quando imagens obtidas possam apresentar baixa qualidade (por exemplo, imagens aéreas oriundas de outras fontes como GoogleMaps). Esses casos podem ocorrer também quando de danos nos sensores visuais (câmeras) de um VANT enquanto uma missão está sendo executada, e houver a real necessidade de se avaliar as imagens obtidas nesta missão (suponha que fez-se uma missão e no momento seguinte começa a chover ou a ventar muito forte inviabilizando a realização de uma nova missão. Entretanto, é extremamente necessária a visualização das imagens para se observar as condições do pavimento frente a perigos ou danos que possam causar caso não sejam informados aos usuários em tempo hábil.). Em casos de baixa qualidade espacial nas imagens (conforme já indicado na Tabela 4.1), fica impossibilitada a detecção de defeitos de forma automática pela MANIAC.

Sendo assim, embora vários filtros tenham sido testados e implementados em outras imagens e missões, o aperfeiçoamento dos processos de detecção das próximas etapas possibilita- 
ram a utilização apenas do filtro Bilateral, como já mencionado anteriormente. Recomenda-se desta forma, que se utilize o filtro Bilateral como o principal ajuste a ser feito nesta fase, que permite a suavização das imagens removendo ruídos e realçando bordas. Dessa forma, esse filtro será automaticamente realizado na execução do processo Pré-Processar.

\subsubsection{Detectar asfalto}

Este processo tem como principal objetivo realçar a malha viária do conjunto de imagens aéreas obtidas pelo VANT, uma vez que é na malha viária que são detectados os defeitos (Figura 4.16).

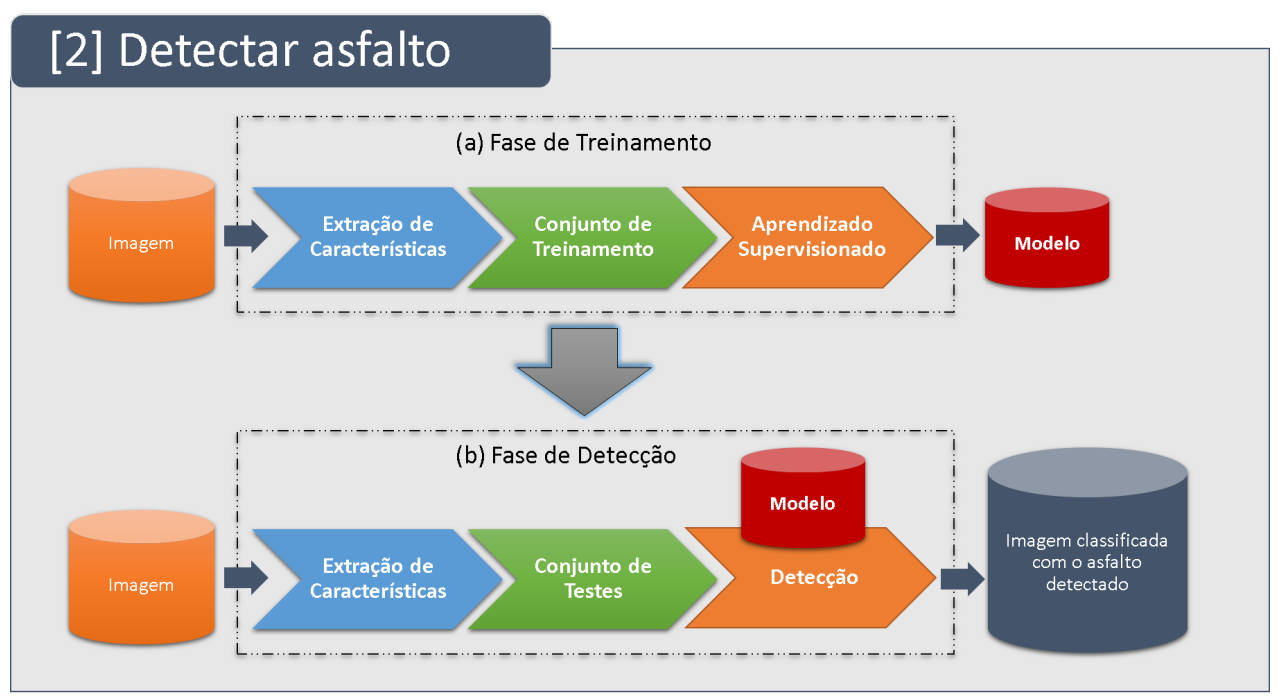

Figura 4.16 - Detalhamento do processo Detectar asfalto.

Os testes iniciais nesta etapa consistiram do uso de SIG que, no caso específico deste trabalho foi o SPRING, como já mencionado anteriormente.

O SIG SPRING apresenta algoritmos para segmentação e classificação, apresentando assim a mesma funcionalidade dos algoritmos de Aprendizado de Máquina. Cabe ressaltar no entanto, que os algoritmos supervisionados e não-supervisionados presentes no SPRING não são genéricos, acabam apenas por conseguir representar o conjunto das imagens que foram apresentadas a ele, sendo necessário a cada nova missão novo treinamento e nova classificação.

Os resultados dos testes fazendo-se uso do SPRING são detalhados na Seção 4.2.3.1.

A técnica de Aprendizado de Máquina permite a criação de um modelo genérico pois, uma vez a partir do modelo treinado diferentes conjuntos de imagens possam ser classificados automaticamente.

Fazendo-se uso de técnicas de aprendizado de máquina, as atividades desta fase subdividemse em duas etapas: Treinamento e Detecção, detalhados na Seção 4.2.3.2. 


\subsubsection{Classificação das imagens para detecção de pavimento asfáltico utilizando SIG}

Foram feitos alguns levantamentos e estudos focados nos SIG SPRING. Após o georreferenciamento, obtido diretamente da missão inserida no VANT, as fotos aéreas passaram pelo processo de segmentação e posteriormente pelo processo de classificação automática, para que fossem testados os métodos de classificação supervisionada e não-supervisionada já existentes no SPRING. Foram realizadas as classificações por pixel e por região.

Antes da realização dos testes de classificação por regiões no SPRING, as imagens aéreas passaram pelo processo de segmentação, que se baseia nas características de descontinuidade e similaridade dos tons de cinza de uma imagem, principalmente quando há mudança abrupta desses valores Gonzalez e Woods (2007). De acordo com os autores de Moigne e Tilton (1995), na segmentação, os pixels da imagem além de serem agrupados a partir dos níveis de cinza, leva-se em consideração o contraste, valores espectrais ou textura e atributos espaciais e de contexto, já detalhado no Capítulo 2 .

Para realizar o processo de segmentação foi necessário definir a similaridade e a área da imagem a ser segmentada. A similaridade é a diferença entre o valor do pixel e a média da região vizinha. Quando o valor de similaridade for maior que o definido pelo usuário, o pixel não pertencerá àquela região. Já a definição da área significa o menor valor de área em pixels, para que uma região seja separada de outra (BARBOSA et al., 2000).

Na Figura 4.17 é ilustrado o número de tentativas, variando-se os limiares, até que se chegasse a uma definição de qual é a combinação ideal entre limiar de similaridade e área mínima, objetivando detectar as regiões de asfalto a partir de imagens aéreas.

\begin{tabular}{|c|c|c|c|c|c|}
\hline 5 & 10 & 15 & 25 & 35 & Similaridade \\
\hline 20 & 20 & 20 & 20 & 20 & \\
\hline 50 & 50 & 50 & 50 & 50 & Área \\
\hline 80 & 80 & 80 & 80 & 80 & \\
\hline
\end{tabular}

Figura 4.17 - Combinações dos pares de limiares.

Na Figura 4.18 são apresentados resultados de testes de segmentação com combinações de diferentes áreas e similaridades.

Os testes realizados levaram em conta os resultados já obtidos na Figura 4.17, que apresentam um conjunto resumido obtido a partir de vários testes realizados e que demonstraram ser as melhores combinações dos pares de limiares. É possível observar que na Figura 4.18a que, fazendo uso do limiar mais baixo que os resultados não são muito bons, pois não é possível conseguir extrair todo o asfalto, ocorre ainda muito ruído e não é possível uma boa extração 


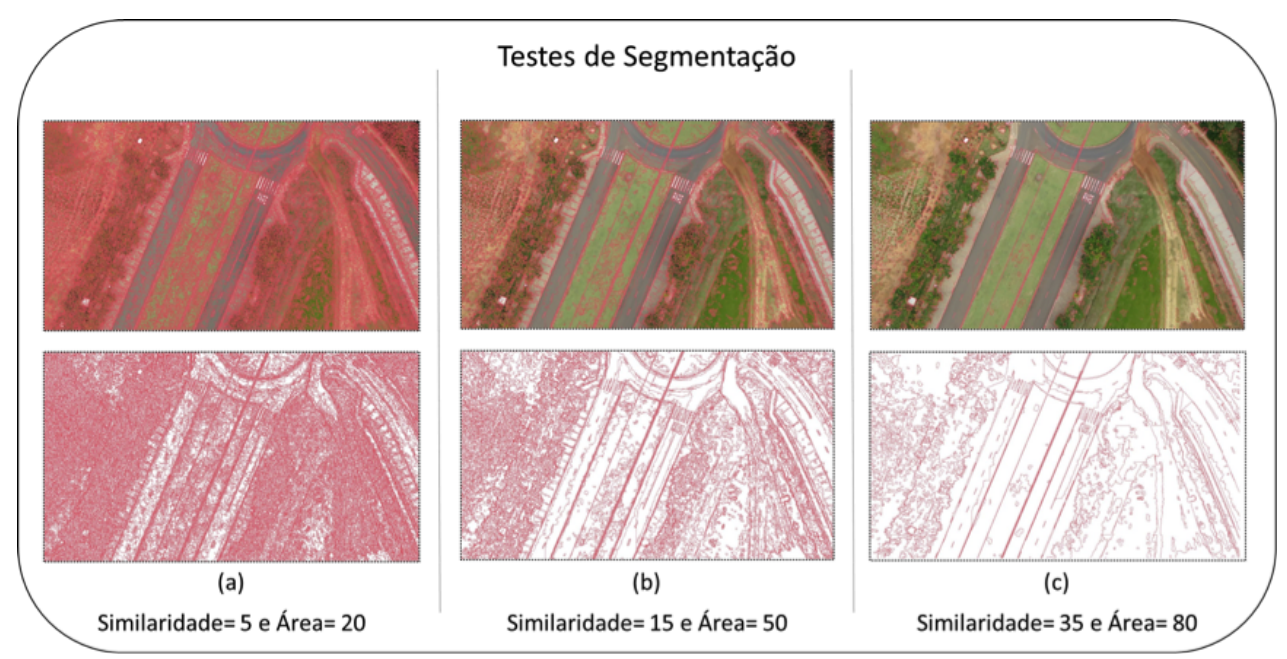

Figura 4.18 - Imagens segmentadas com combinação de pares de limiares: (a) Similaridade = 5 e Área = 20; (b) Similaridade $=15$ e Área $=50 ;$ (c) Similaridade $=35$ e Área $=80$.

da região desejada.

Na Figura 4.18b com um limiar mais fino já se observam melhores resultados quando comparado com a Figura 4.18a. O melhor resultado obtido a partir das melhores combinações de pares de limiares foi o que pode ser observado na Figura 4.18c. Nesta, com a segmentação é possível obter bons resultados e detectar a região onde existe asfalto fazendo uso do par: similaridade 35 e área 80.

Após realizada a segmentação e extraídas as características passa-se ao processo de classificação.

O processo de classificação supervisionada no SPRING foi realizado por meio da criação de classes temáticas.

No processo de classificação não-supervisionada efetuado pixel a pixel no SIG SPRING, a fotografia aérea utilizada foi carregada no formato de coloração monocromática e a classificação foi gerada no menu contraste com operação linear, utilizando fatiamento normal e a quantidade de classes foi escolhida na opção fatias.

Já no processo de classificação supervisionado pixel a pixel no mesmo programa, foram extraídas amostras da superfície asfáltica e posteriormente analisadas para eliminar as confusões geradas durante o treinamento. Em seguida, foi escolhido o algoritmo MAXVER (Máxima Verossimilhança), que classifica a imagem por pixels, analisando-os isoladamente e mapeando-os para uma classe baseada no seu valor.

A comparação entre o método supervisionado e não-supervisionado é ilustrada na Figura 4.19 .

Na classificação por região, ocorreu a geração de um arquivo de contexto de segmentação obtido por crescimento de regiões. Na sequência, para a classificação supervisionada, adotouse o algoritmo Bhattacharya, que de acordo com o INPE (Instituto Nacional de Pesquisas Es- 


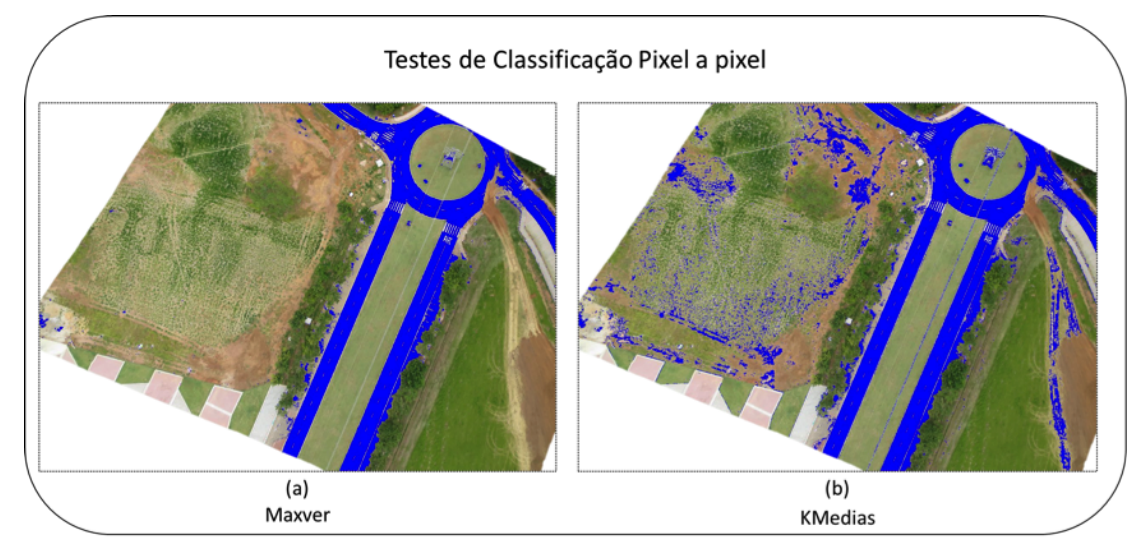

Figura 4.19 - Classificação pixel a pixel. (a) Método MAXVER - classificação supervisionada; (b) KMedias classificação não-supervisionada.

paciais) mede a distância média entre as distribuições e probabilidades de classes espectrais. Para a classificação não supervisionada por região, o algoritmo adotado foi o Isoseg, que determina um conjunto de regiões pelos atributos estatísticos de média, matriz de covariância e área (SPRING, 2006).

A comparação entre o método supervisionado e não-supervisionado é ilustrada na Figura 4.20.

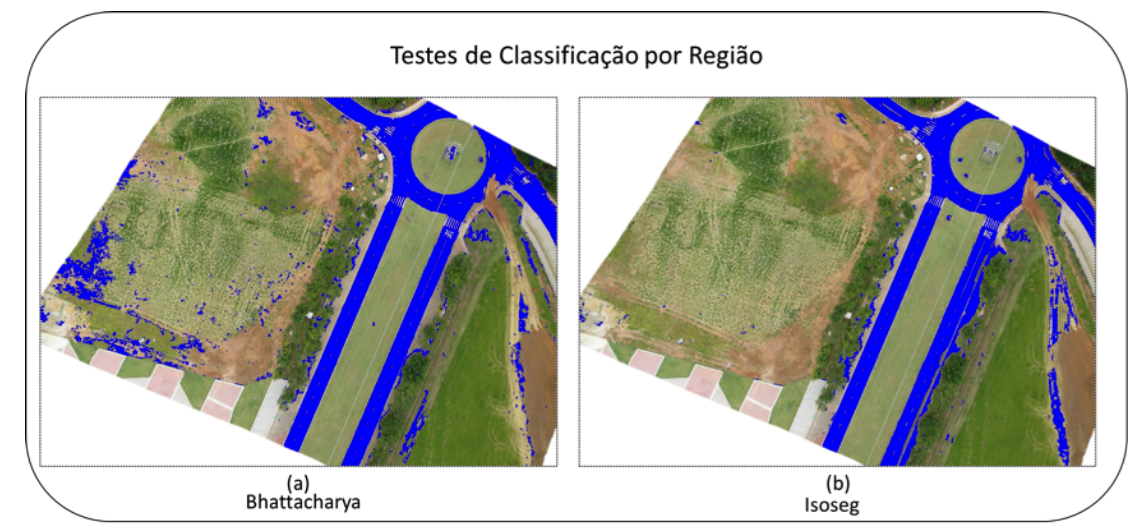

Figura 4.20 - Classificação por região. (a) Método Bhattacharya - classificação supervisionada; (b) Isoseg - classificação não-supervisionada.

De modo análogo aos resultados obtidos com a classificação pixel a pixel é possível observar que o método de classificação supervisionado é mais eficiente quando comparado ao não-supervisionado. Isso permite induzir que neste trabalho serão utilizados métodos de classificação supervisionados para a detecção de asfalto.

Na classificação das fotografias aéreas por fotointerpretação (vetorização sobre a imagem), o ambiente alvo (rodovias e estradas com asfalto) foram previamente identificados nas fotografias aéreas, e sobre esses ambientes (classes) foram gerados polígonos. Após isso, o mosaico de polígonos foi convertido em um mapa de classes apresentando áreas com asfalto e sem, a partir de uma edição realizada na tabela de atributos do arquivo shapefile, onde cada polígono gerado na vetorização recebeu o nome da respectiva classe que pertencia. Posteriormente 
foram atribuídas cores diferentes para representar cada classe, gerando o mapa de estradas pavimentadas.

Apesar de gerar bons resultados, para cada nova missão ou conjunto de imagens novo treinamento deveria ser realizado. Como já mencionado no processo Pré-Processar, o aprendizado de máquina permite essa generalização, sendo então a técnica a ser adotada neste processo.

\subsubsection{Classificação das imagens para detecção de pavimento asfáltico utilizando Apren- dizado de Máquina}

A realização do processo de detectar asfalto na MANIAC foi composto pelas fases de treinamento e detecção tendo sido utilizado o aprendizado supervisionado, que se provou mais eficiente que o não-supervisionado para esse tipo de detecção.

Neste processo fez-se uso da linguagem de programação Python versão 2.7.11+ em conjunto com a biblioteca scikit-learn versão 0.17.1.

Antes de iniciar o processamento de cada fase, deve ser definida a parte do conjunto de imagens a ser utilizada para fazer o treinamento e parte a ser utilizada nos testes/validação. Para essa separação uma amostra de $30 \%$ das imagens foi escolhida aleatoriamente para compor o conjunto de testes/validação, sendo que o restante foi utilizado para treinamento, de modo que se possa verificar a acurácia dos resultados.

Na Figura 4.21 é ilustrado o detalhamento do processo Detectar asfalto.

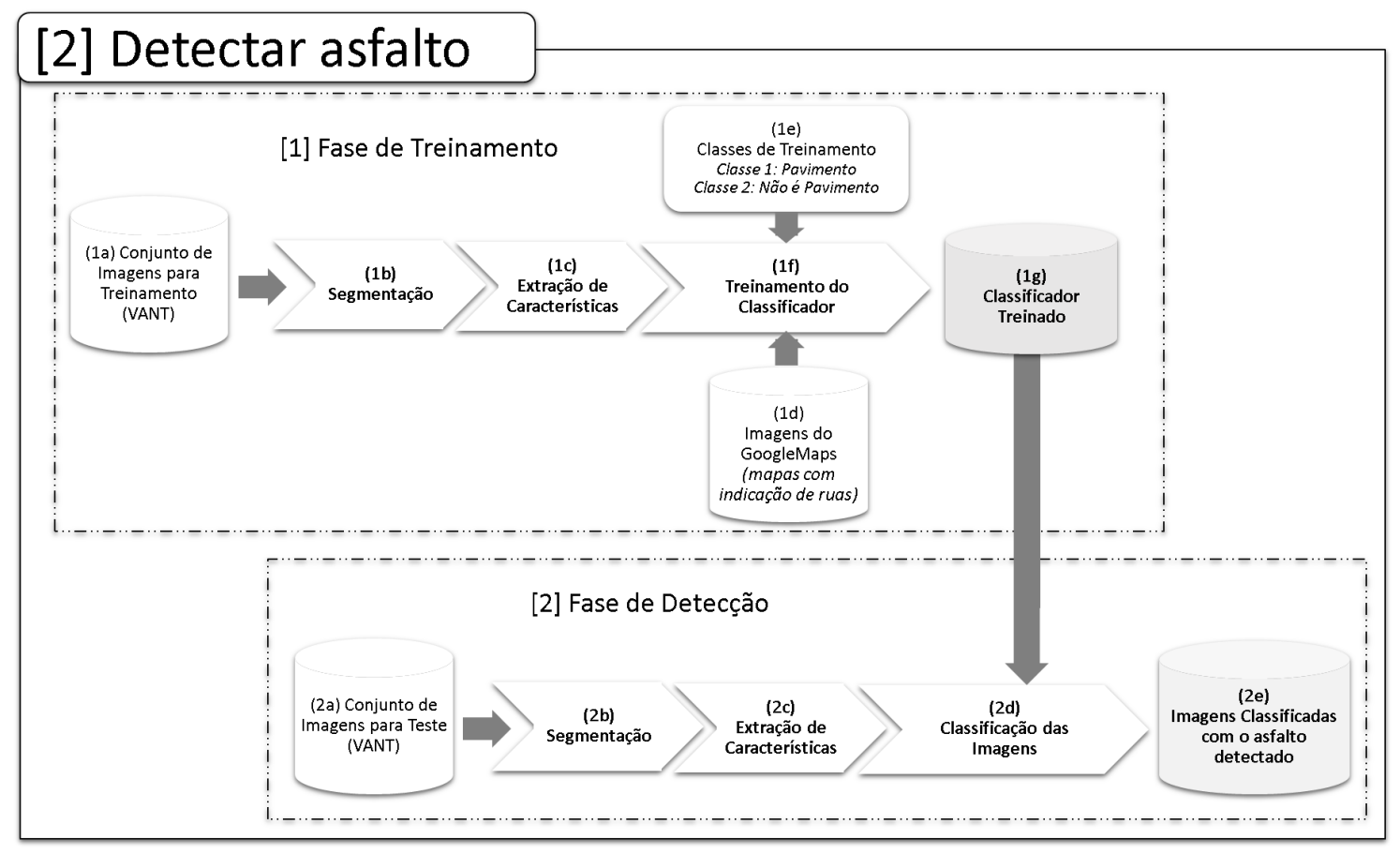

Figura 4.21 - Fluxograma detalhado do processo Detectar asfalto.

Inicialmente foi realizada a segmentação da imagens (Etapa 1b), de modo análogo ao realizado com o SIG, uma vez que esse processo se faz necessário para que possam ser extraídas 
as características que serão utilizadas, posteriormente, para classificação. Essa segmentação foi realizado por meio do algoritmo SLIC (superpixel Radhakrishna et al. (2010)), onde o número total de segmentos é obtido proporcionalmente ao tamanho da imagem para melhorar o desempenho computacional, por exemplo gerou-se 3024 pixels segmentos para uma imagem com tamanho $4608 \times 3456$ conforme ilustrado na Figura 4.22). Para cada segmento gerado (Figura 4.23), extrai-se as propriedades e características (também conhecidas como features) (Etapa 1c), fundamentais para o treinamento e, posteriormente utilizadas para a classificação automática de outras imagens que apresentem regiões com características similares.

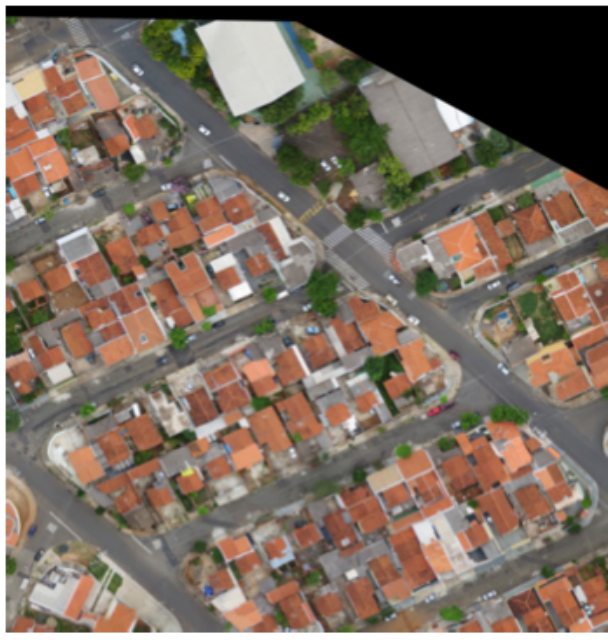

(a)

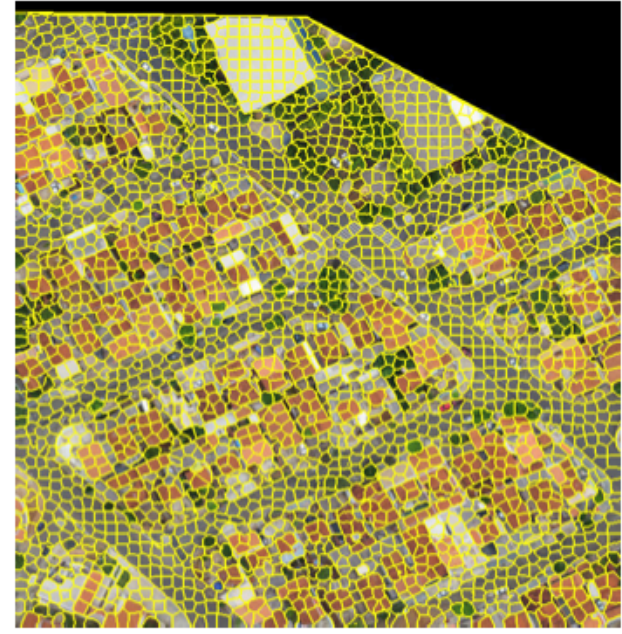

(b)

Figura 4.22 - Aplicação do algoritmo de superpixel na imagem aérea, a) imagem não segmentada. b) imagem segmentada com 3024 segmentos.

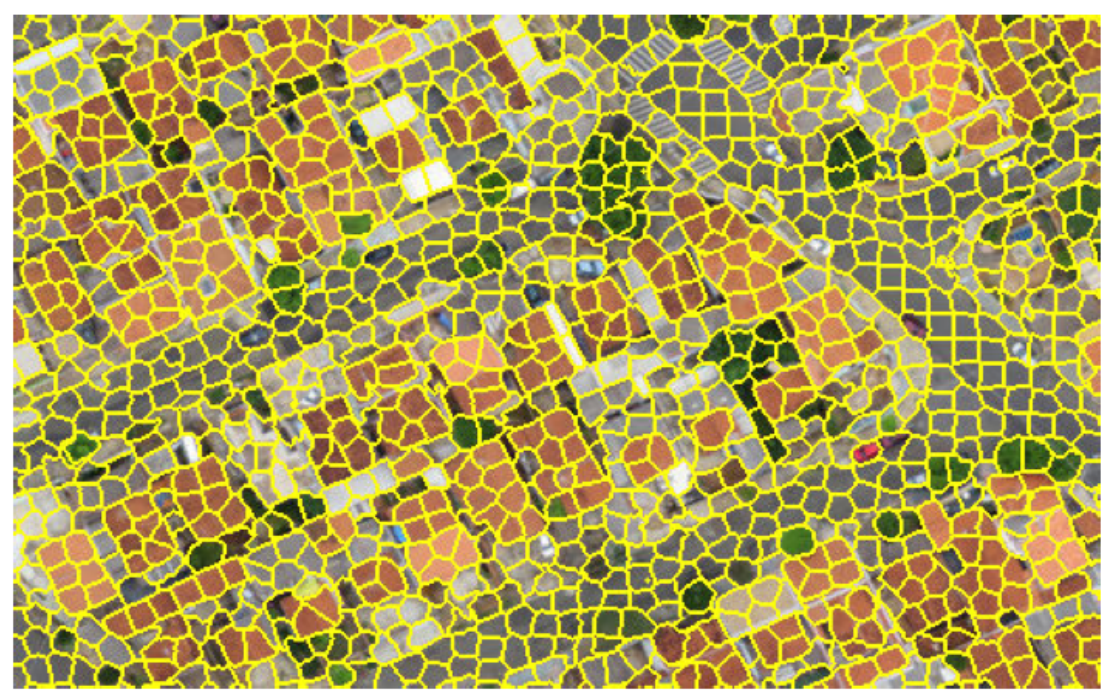

Figura 4.23 - Exemplo de imagem segmentada pelo algoritmo superpixel.

No caso específico do exemplo apresentado as features capturadas para cada segmento foram as seguintes: valores da média e desvio padrão (gradiente descendente, entropia e regional máxima) e histograma colorido HSV com 64 valores. Dessa forma, o número total de features 
obtidas para cada segmento é de 70. Uma parte desses valores, de uma região específica é ilustrada na Figura 4.24.

\begin{abstract}
$5.02612,0.12507,133.13889,10.82475,0.00000,0.00000,2.19722,1.60944,1$ $.09861,0.00000,0.00000,0.00000,0.00000,0.00000,0.69315,1.09861,0.000$ $00,0.00000,0.00000,0.00000,0.00000,0.00000,0.00000,0.00000,0.69315,0$ $.00000,0.00000,0.00000,0.00000,0.00000,0.00000,0.00000,0.00000,0.000$ $00,0.00000,0.00000,0.00000,0.00000,0.00000,0.00000,0.00000,0.00000,0$ $.00000,0.00000,0.00000,0.00000,0.00000,1.09861,0.00000,0.00000,0.000$ $00,0.00000,0.00000,0.00000,0.00000,0.00000,0.00000,0.00000,0.00000,0$ $.00000,0.00000,0.00000,0.00000,0.00000,0.69315,0.00000,0.00000,0.000$ $00,0.00000,0.00000,1$
\end{abstract}

Figura 4.24 - Exemplo de listagem das features para treinamento.

Os seis valores iniciais destacados na Figura 4.24 estão associados às médias e desvios padrão, enquanto que os demais valores não destacados estão associados ao histograma colorido.

O último valor destacado será sempre 1 ou 0 . Ele representa o valor da classificação desse segmento em relação ao mapa de ruas (malha viária) do GoogleMaps que, nesta aplicação é tratada como máscara (ou labels) de ruas. O valor 1 representa que, de acordo com o GoogleMaps, essa região da imagem pertence a uma malha viária, isto é, "é um pavimento", enquanto que o valor 0 quer dizer que "não é pavimento", informando que essa parta da imagem onde as $f e-$ atures foram coletadas referem-se a regiões como residências, árvores, telhados, entre outros. Deste modo, o valor total de features a serem obtidas é de $70+1=71$, para considerar o label da imagem.

Na Figura 4.25 é ilustrada uma sobreposição do mapa de ruas GoogleMaps (labels) com os segmentos gerados da imagem para uma melhor visualização.

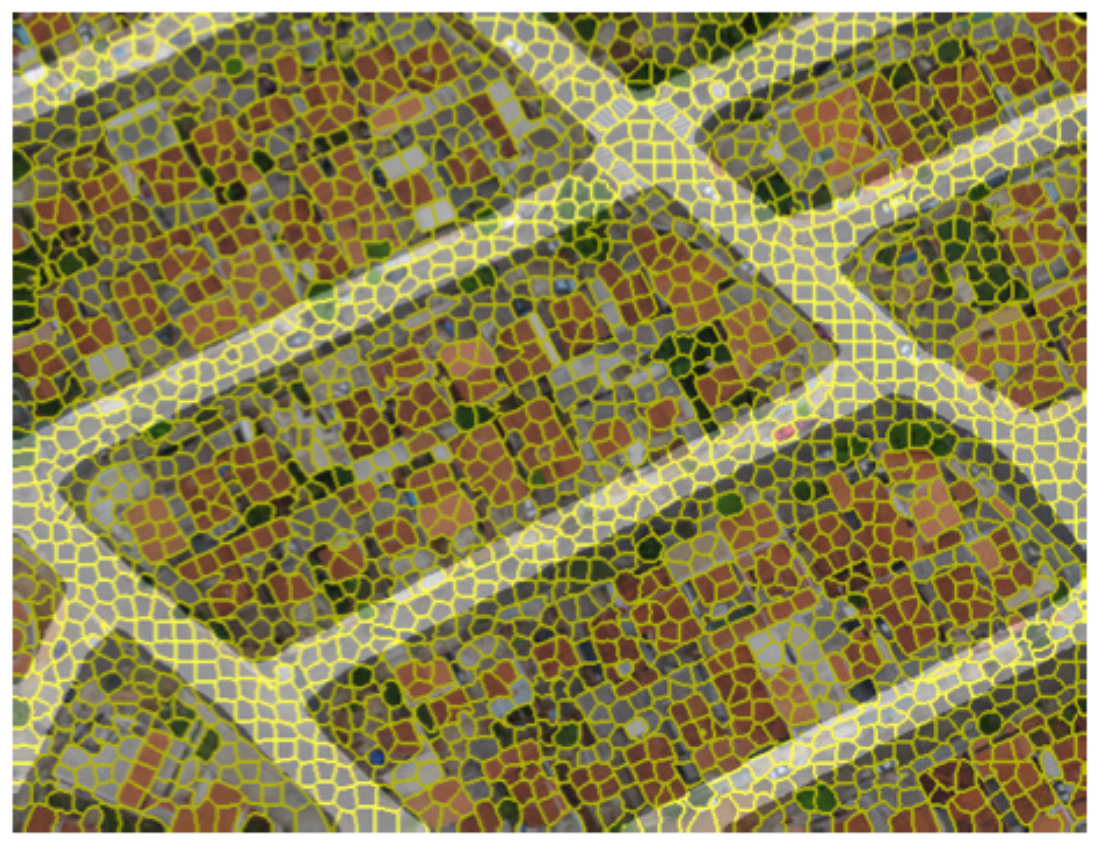

Figura 4.25 - Exemplo de imagem segmentada com o respectivo label. 
Uma vez processadas todos os segmentos do conjunto de imagens para treinamento (neste caso de exemplo $3024 \times 5=15.120$ segmentos) com todas as features tem-se a geração de uma quantidade de informações para o treinamento na ordem de $15.120 \times 71=1.073 .520$. Para exemplificar os cálculos, considerou-se um número total de 5 imagens para treinamento.

A incorporação automática do label de ruas GoogleMaps (Etapa 1d) permite a automatização dos label no aprendizado supervisionado, de modo que não se precisa fazer essa marcação de forma manual, o que levaria muito mais tempo para realizar essa etapa. Esse processo não foi trivial, e o algoritmo de extração desse label é então ilustrado na Figura 4.26.

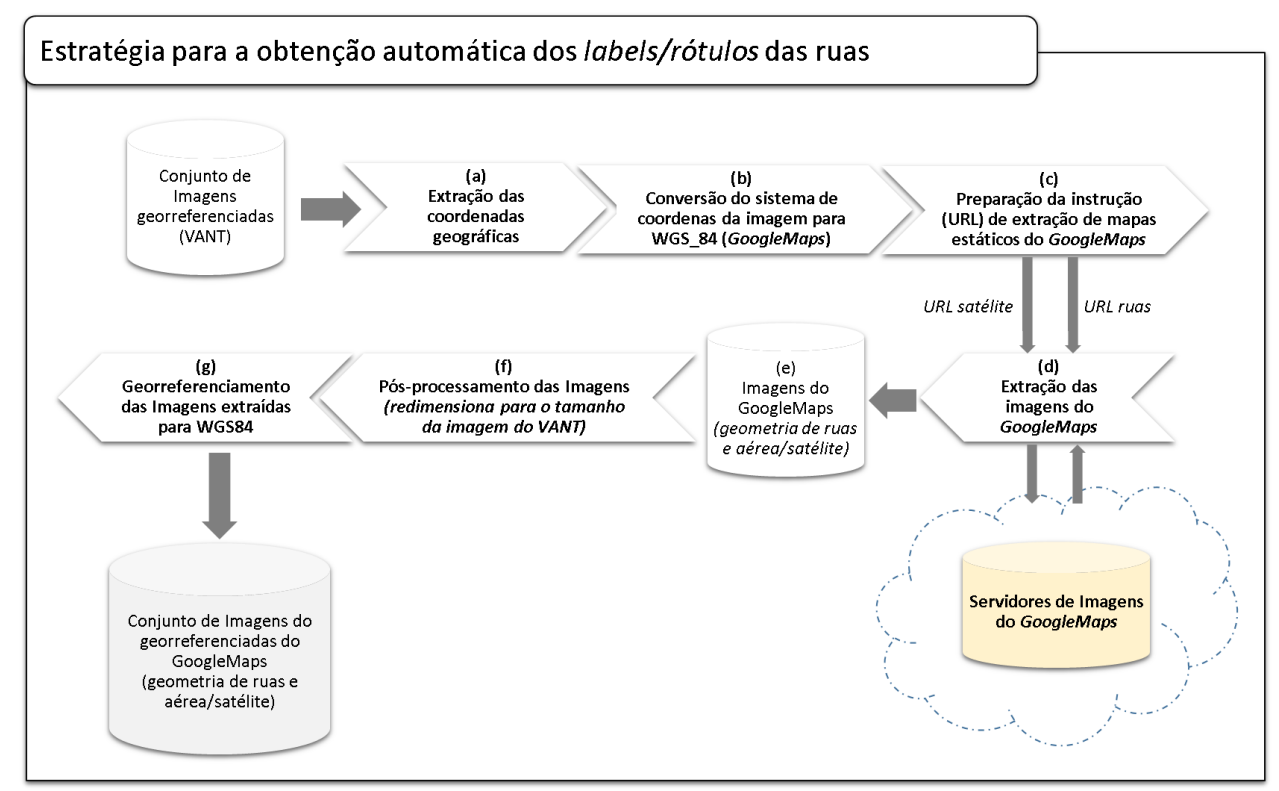

Figura 4.26 - Estratégia para a obtenção automática da geometria de ruas do GoogleMaps.

Cabe ressaltar que esse label GoogleMaps apesar de ter bastante utilidade e facilitar o processo de verificação do GroundTruth, pode apresentar falhas dependendo do local onde a missão foi realizada, uma vez que os mapas do Google podem estar desatualizados, apresentando dessa forma erros e inconsistências sobre a localização correta das ruas para a marcação dos labels, como pode ser observado na Figura 4.27 e na Figura 4.28. Sendo assim, recomenda-se que seja sempre feita uma verificação visual desses labels quando utilizados, pois esses erros de posicionamento são muito fáceis de perceber através de uma rápida avaliação visual.

Com base no algoritmo ilustrado na Figura 4.26 é possível observar que tudo tem início a partir das imagens aéreas obtidas pelo VANT e o pós-processamento das mesmas para geração de um mosaico.

Esse é um exemplo dos valores obtidos para o mosaico gerado para essa missão especificamente. Obviamente, cada missão gerará informações específicas e individuais, entretanto o processo a ser seguido é exatamente o mesmo definido pela MANIAC.

Para que o mosaico fique compatível com o mapa do GoogleMaps, isto é, que permita a extração automática dos mapas de ruas e que se possa fazer o alinhamento automático dos 


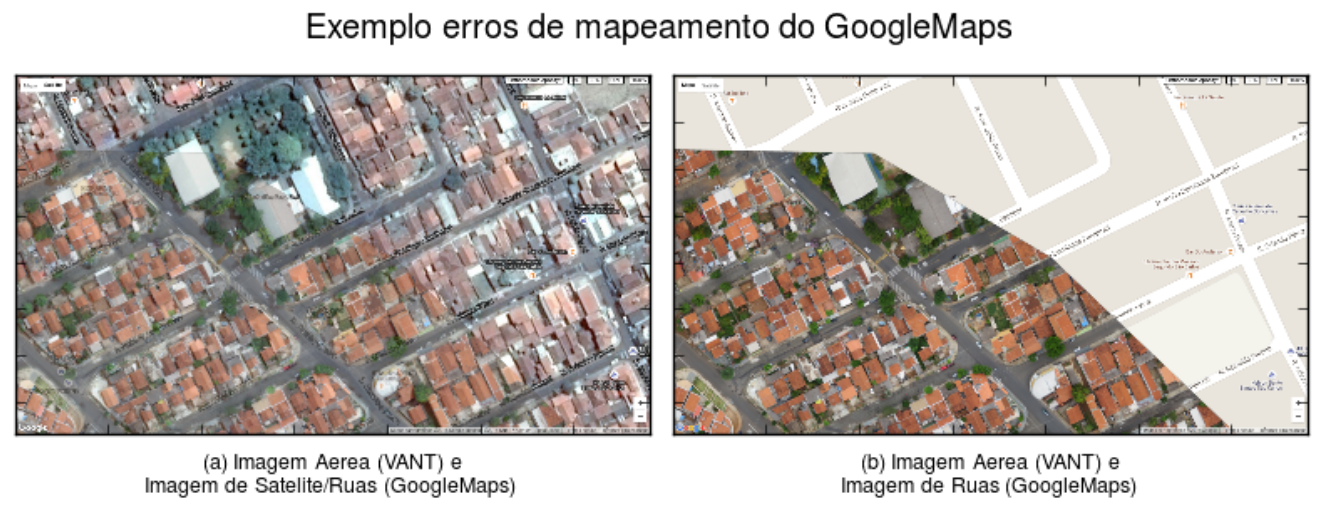

Figura 4.27 - Exemplo de erro do posicionamento do label de ruas do GoogleMaps. a) imagem aérea VANT e imagem de satélite e mapa de ruas do (label GoogleMaps sobrepostas). b) imagem aérea VANT e imagem de ruas do GoogleMaps sobrepostas

\section{Exemplo Segmentacao de Ruas com sobreposicao dos Labels para treinamento}

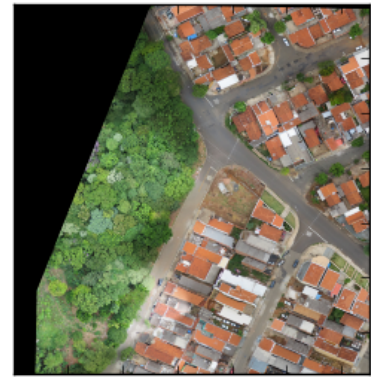

(a) Imagem Aerea (VANT)

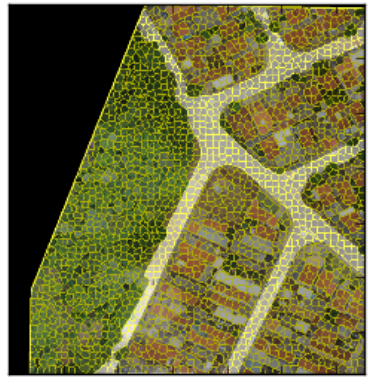

(b) Segmentacao com os Labels indicados)

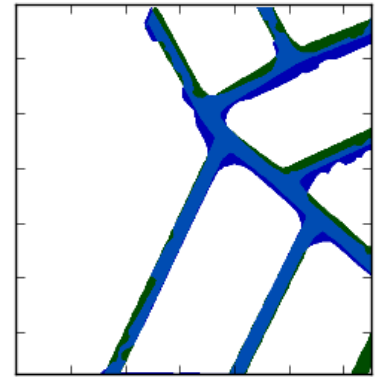

(c) Label automatico do GoogleMaps (cor verde)

Figura 4.28 - Exemplo segmentação de Ruas com sobreposição dos labels para treinamento. a) imagem aérea original. b) segmentação com os labels destacados. c) Label de ruas automáticamente obtido do GoogleMaps (cor verde) e label manual (cor azul)

dois mapas, faz-se necessário que ambos estejam no mesmo sistema de projeções, o que não é o caso, uma vez que o GoogleMaps e o mapa gerado pelo VANT são gerados em projeções diferentes. Sendo assim, foi necessário converter o sistema de coordenadas do mosaico (UTM) para o mesmo sistema do GoogleMaps (LatLong). Esse processo de conversão foi acrescentado e incorporado a MANIAC por meio de um utilitário denominado gdalwarp ${ }^{1}$, que faz parte de um pacote de ferramentas denominadas GDAL (Geospatial Data Abstraction Library) (Figura 4.29) e executados automaticamente a partir do código Python.

A partir das coordenadas do mosaico convertidas em latitude/longitude, foi extraído do GoogleMaps os mapas de ruas para serem utilizados como informações e/ou marcações de localização da malha viária da região mapeada.

Na Figura 4.30 é ilustrado um mapa de ruas extraído do GoogleMaps com a marcação de um polígono em vermelho que representa a região mapeada pelo VANT. Essa marcação serve para que o recorte do mapa possa ser feito de modo a permitir o enquadramento/sobreposição com o mapa do mosaico gerado a partir das imagens aéreas obtidas.

\footnotetext{
${ }^{1}$ http://www.gdal.org/gdalwarp.html
} 


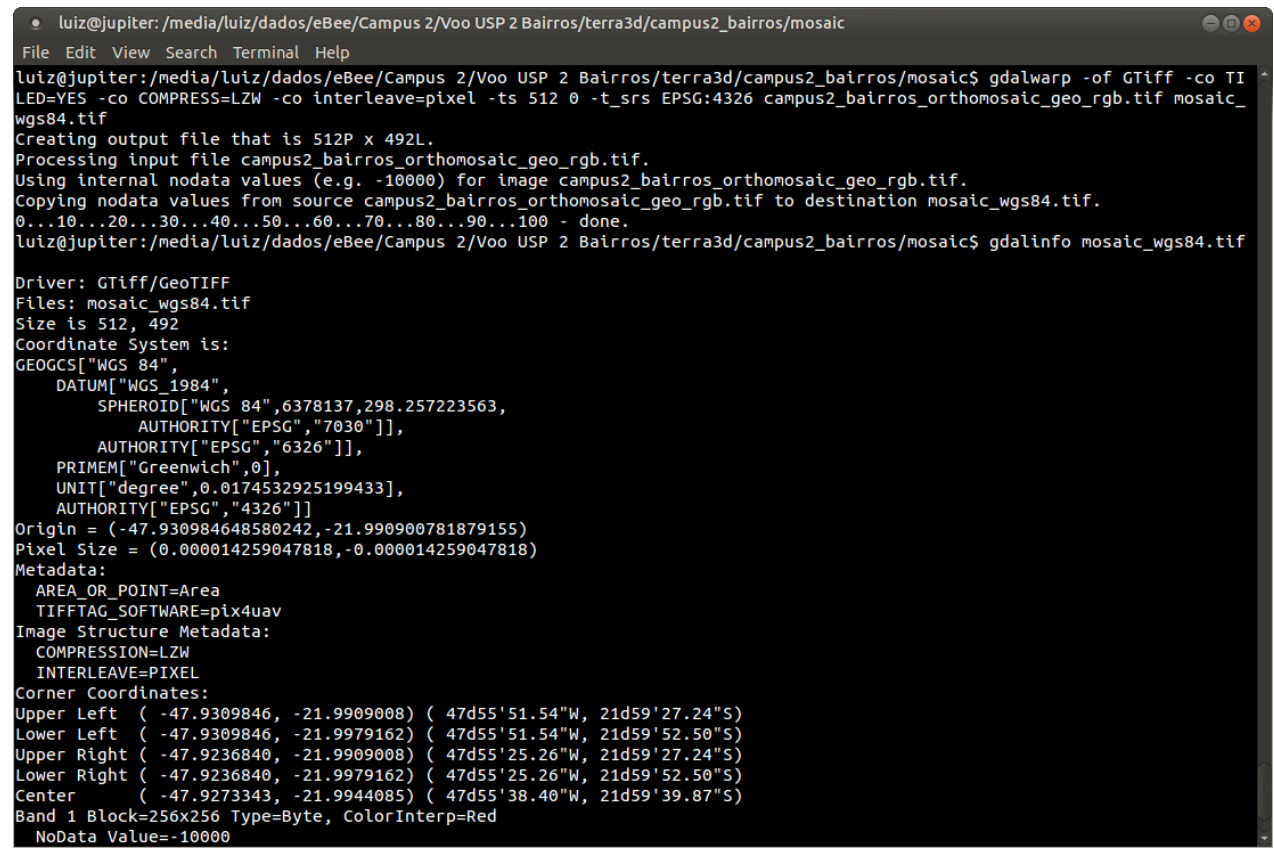

Figura 4.29 - Exemplo do processo de conversão de sistema de coordenadas do Mosaico.

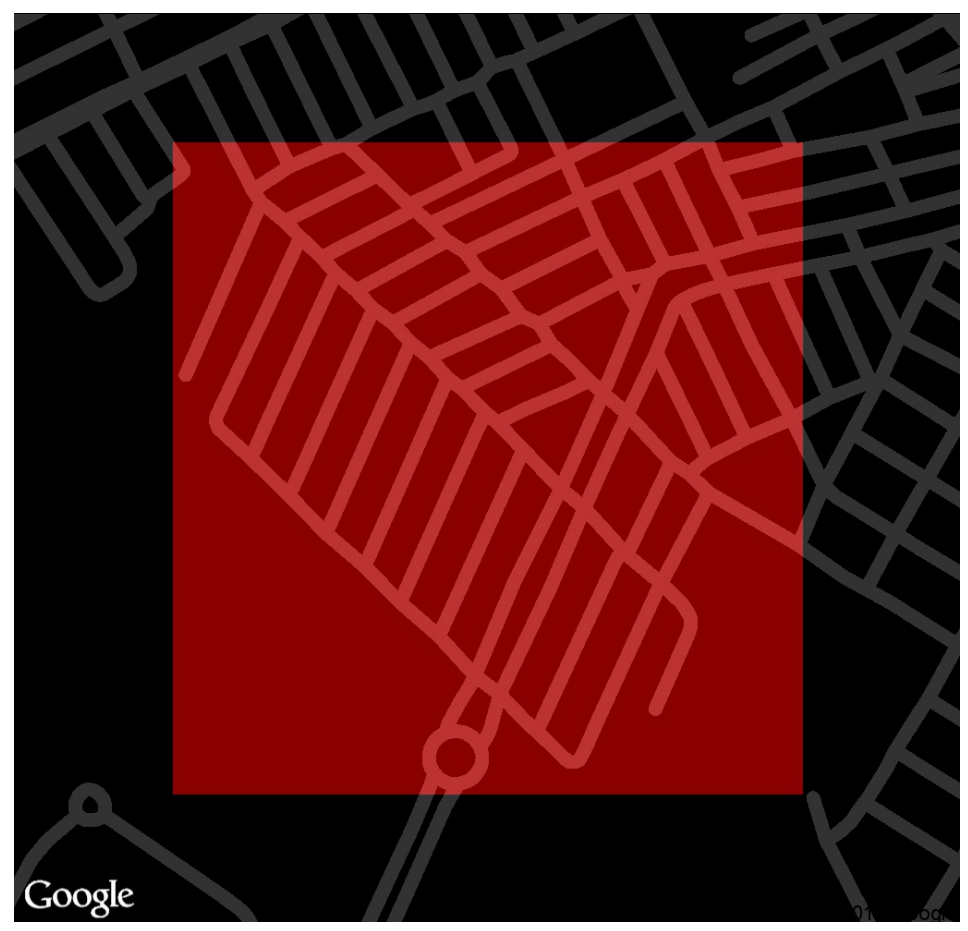

Figura 4.30 - Mapa de ruas extraído do GoogleMaps da região mapeada pelo VANT.

O processo não termina, pois as informações obtidas do GoogleMaps necessitam ser ainda tratadas para que sejam eliminadas informações desnecessárias.

Na Figura 4.31a é ilustrado o mapa de ruas extraído do GoogleMaps em sua formatação padrão. Na Figura 4.31b é ilustrado o mapa de ruas obtido a partir do uso de recursos da API (Application Programming Interface) ${ }^{2}$ do Google com formatação e visualização de ma-

\footnotetext{
${ }^{2}$ https://developers.google.com/maps/documentation/static-maps/intro\#StyledMaps
} 
pas para eliminar todas as informações desnecessárias e de menor importância, normalmente apresentadas na visualização padrão do GoogleMaps. Dessa maneira, é possível destacar as informações importante, que no contexto desta tese referem-se as malhas viárias.

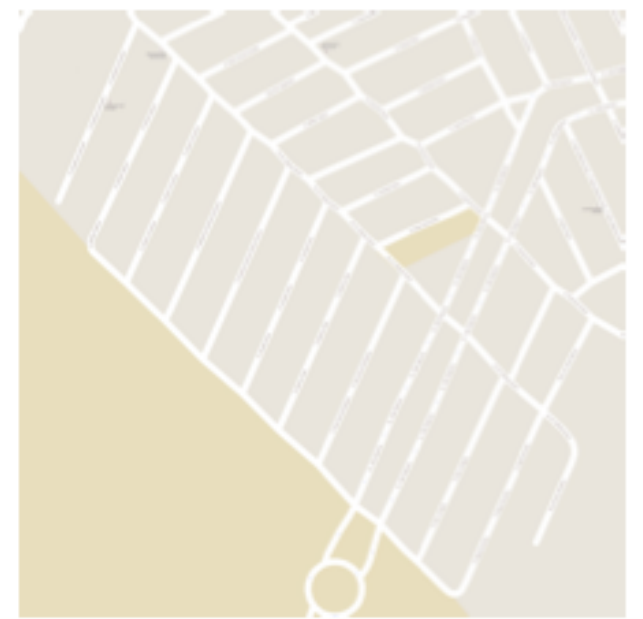

(a)

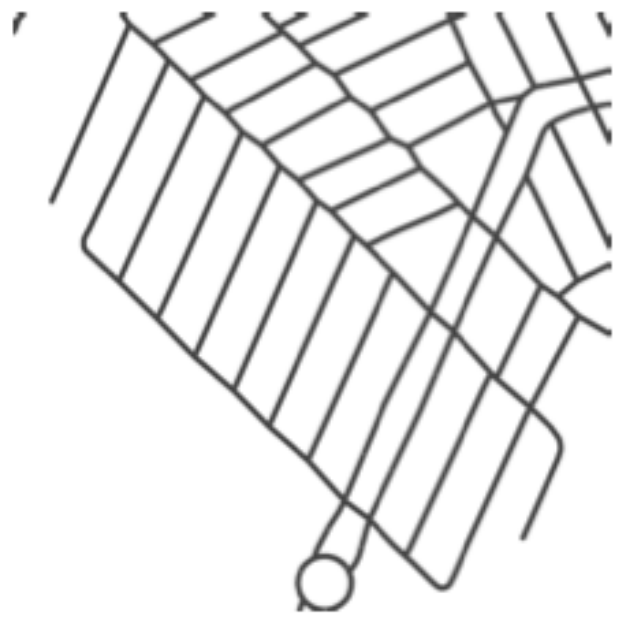

(b)

Figura 4.31 - Mapa de ruas extraído do GoogleMaps. a) Formatação padrão. b) Formatação customizada para destacar a malha viária.

Essa customização foi viabilizada inserindo-se alguns parâmetros na URL (Uniform Resource Locator) padrão de busca de mapas estáticos do GoogleMaps, isto é, a consulta permite obter apenas uma imagem representando mapa por vez, sendo necessário alterar os parâmetros das coordenadas na URL para obter uma nova imagem de mapa referente a uma nova localização. Esse tipo de interação e busca de mapas no GoogleMaps (não interativa) é mais usada por desenvolvedores de aplicações e, consequentemente, as aplicações por eles desenvolvidas.

Como parte do processo, objetivando garantir um baixo índice de consumo computacional de processamento das imagens (devido ao grande tamanho do arquivo digital do mosaico), o arquivo é particionado em arquivos menores (por exemplo, com uma grade de $5 \times 4$ ). Assim, ao invés de processar ou carregar o arquivo inteiro na memória do computador e comprometer o desempenho do processamento de outras funcionalidades, o processamento de pedaços menores do arquivo para o processamento dos dados é altamente recomendável, eficaz e gerenciável.

Desse modo, o novo conjunto de imagens (esse número de imagens pode variar de acordo com o tamanho e duração da missão, que pode gerar mais ou menos imagens que irão compor o mosaico, consequentemente incluindo mais ou menos imagens no conjunto particionado). Apenas para manter uma organização, os nomes dos arquivos foram padronizados para se referirem às coordenadas dos pixesl superior esquerda onde o particionamento da imagem foi aplicado em relação às coordenadas do mosaico inteiro (Figura 4.32). Cabe ressaltar que esses nomes não influenciam, pois o conteúdo do arquivo é o que realmente interessa.

De modo análogo, o mapa de ruas extraído do GoogleMaps também é particionado em 


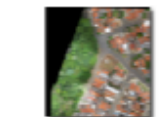

tile_0_0.jpg
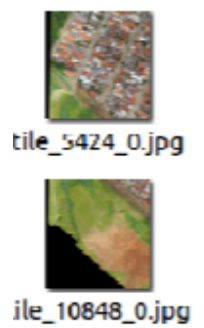

ile_10848_0.jpg

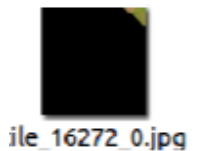

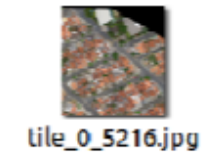
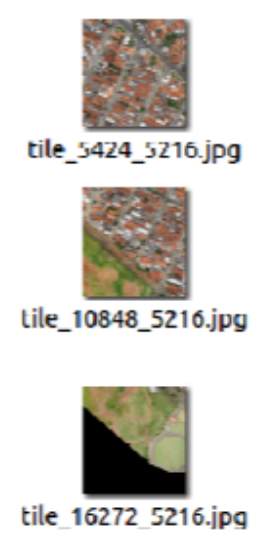
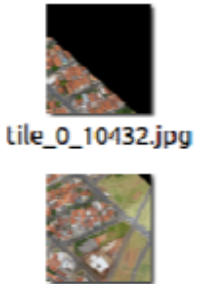

tile_5424_10432.jpg
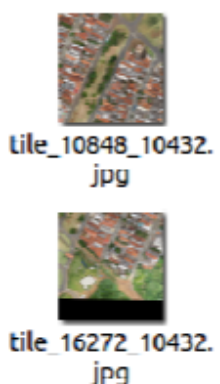
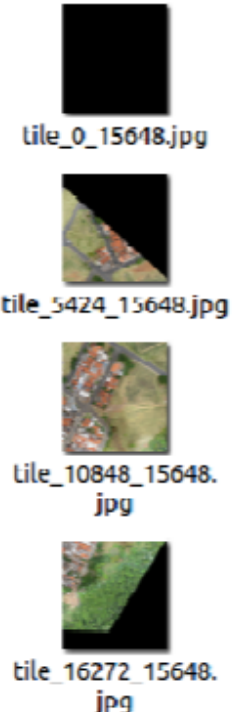

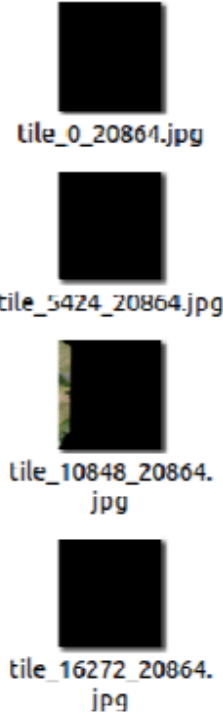

pg

Figura 4.32 - Exemplo de um conjunto de imagens particionadas do mosaico.

mesmo número de partes, preservando assim a sobreposição dos dois mapas, implicando em as imagens do mosaico e do GoogleMaps possuírem as mesmas dimensões.

Uma vez concluída a fase de obtenção das features por meio do processo de segmentação, os demais passos da MANIAC são seguidos.

Na extração das características foram definidas as imagens para o conjunto de treinamento e conjunto de teste a partir da remoção de algumas imagens que não continham informações relevantes para o processamento.

As imagens removidas do processamento foram, na maioria, imagens com nenhuma informação para processar (como por exemplo imagens de borda do mosaico), como é possível observar na Figura 4.32 que ilustra as imagens contidas no arquivo title_020864.jpg.

A técnica de Aprendizado de Máquina supervisionado utilizada foi o Random Forest. Os parâmetros para a execução desse algoritmo podem ser informados manualmente, entretanto, nesta tese, com objetivo de automatizar o processo, foi utilizado o recurso de hiperparameters Bergstra e Bengio (2012), onde é possível submeter todo o conjunto de dados a uma análise prévia para que os melhores parâmetros possam ser obtidos para a execução do algoritmo. Isto é feito informando para o procedimento de hiperparametrização quais parâmetros se deseja analisar e qual o range de valores desejado. O algoritmo de hiperparametrização para esses dados foi implementado utilizando a biblioteca scikit-learn ${ }^{3}$.

Os melhores parâmetros sugeridos e utilizados para esse conjunto de dados foram:

RandomForestClassifier(bootstrap $=$ False, class_weight $=$ None, criterion $=^{\prime}$ entropy ${ }^{\prime}$, max_depth $=$ None, max_features $=10$, max_leaf_nodes $=$

\footnotetext{
${ }^{3} \mathrm{http} / /$ scikit-learn.org/stable/
} 
None, min_samples_leaf $=1$, min_samples_split $=10$, min $_{w}$ eight_fraction_leaf $=$ $0.0, n \_$estimators $=10, n \_j o b s=1, o o b \_s c o r e=F a l s e$, random_state $=$ None, verbose $=$ 0, warm_start $=$ False)

A partir desses parâmetros (best parameters), a fase de treinamento é realizada com o conjunto de imagens de treinamento. Uma vez que os dados foram submetidos ao treinamento supervisionado, como resultado do treinamento foi considerada a criação de duas classes ( $\mathrm{Pa}$ vimento e não_Pavimento) (Etapa 1e).

Para esse conjunto de treinamento (Etapa 1f) obteve-se um modelo de treinamento onde é possível aplicar um novo conjunto de dados e o sistema irá retornar a classificação desses dados. Tem-se então o Classificador Treinado (Etapa 1g).

A próxima etapa consiste na Detecção propriamente dita do pavimento asfáltico, e é feita na Fase de Detecção.

Uma vez definido o Conjunto de imagens para teste, obtido na fase de Treinamento, utilizase esse conjunto de dados (imagens) para serem tratados, ou seja, segmentados (Etapa 2b) para que ocorra a extração de características das mesmas (Etapa 2c), respeitando o mesmo processo efetuado durante a fase de Treinamento. Obtém-se um Conjunto de Testes, no qual é aplicado o Classificador Treinado, realizando-se assim a Classificação das imagens (Etapa 2d) sem a utilização de labels e então é realizado o processo de Detecção gerando as Imagens Classificadas, ou seja, a detecção do pavimento asfáltico (Etapa 2e).

Na Figura 4.33 é ilustrado o resultado do processamento em uma imagem teste.

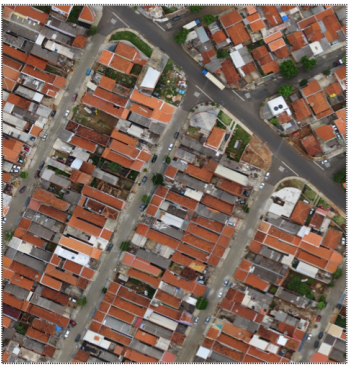

(a)

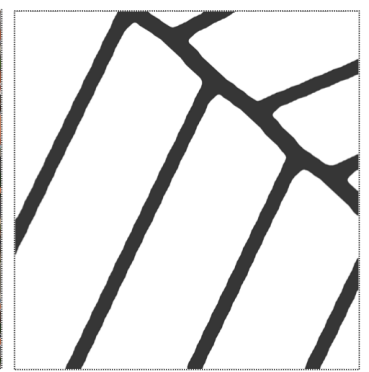

(b)

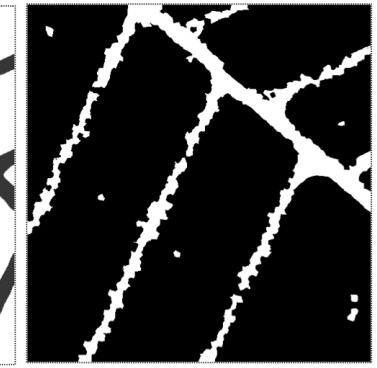

(c)

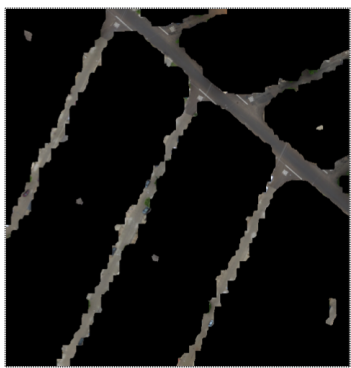

(d)

Figura 4.33 - Resultado do processamento em uma imagem teste. a) imagem original. b) máscara de ruas do GoogleMaps para validação. c) máscara gerada automaticamente com as marcações de malha viária na cor branca. d) imagem final.

Na Figura 4.34 são ilustrados os resultados de uma nova imagem utilizada para testar o modelo de predição/detecção de pavimentos a partir da base de dados de imagens e features que foram extraídas para o treinamento do classificador. 


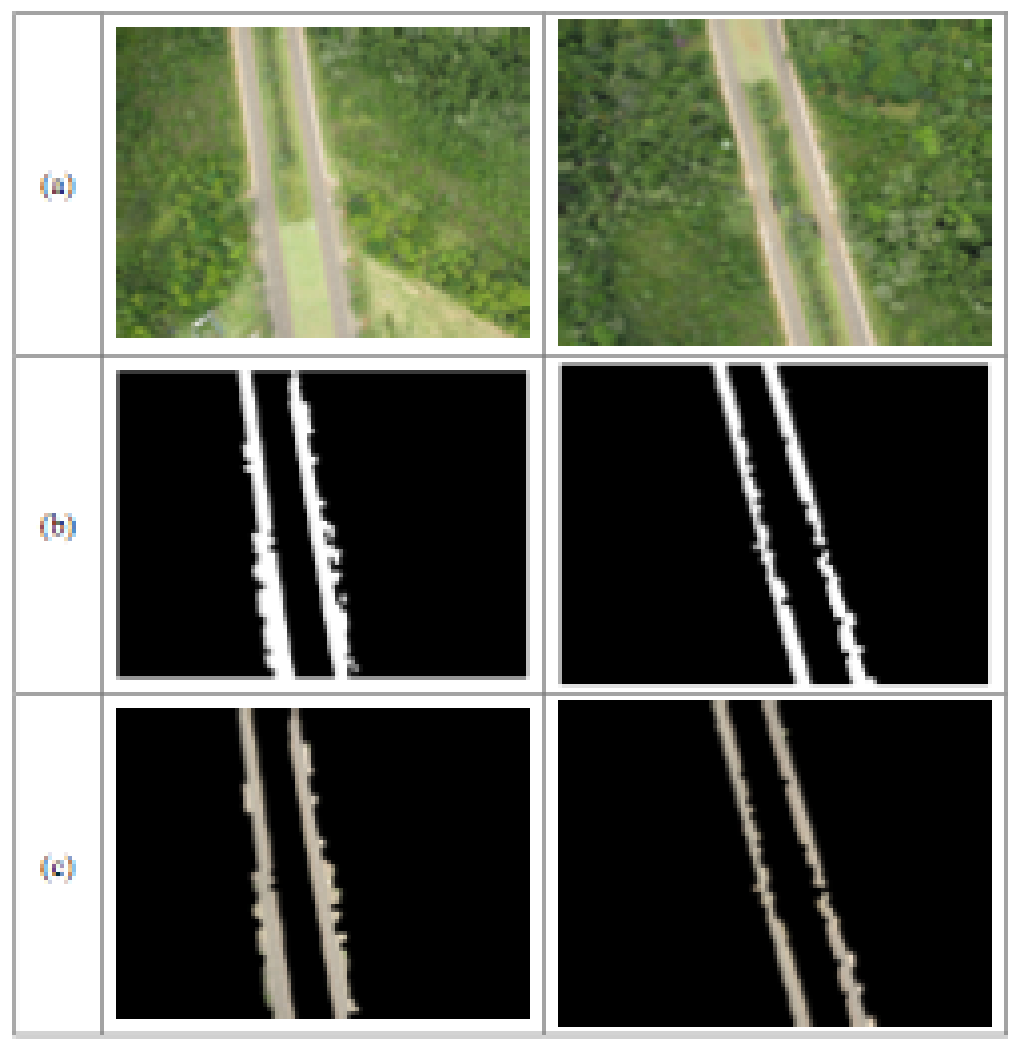

Figura 4.34 - Resultado do teste de processamento em 2 imagens novas. a) imagem original. b) imagem/máscara gerada automaticamente. c) imagem final com a aplicação da máscara de ruas na imagem original para deixar apenas a malha viária.

\subsubsection{Identificar defeitos}

Por último é detalhado o processo Identificar Defeitos (Figura 4.35). Este processo tem como objetivo principal a classificação da malha viária em malha com defeito e malha sem defeito. Com esse diagnóstico, é possível a geração de relatórios que podem facilitar o processo de manutenção da malha viária que possam contribuir/auxiliar no processo de vistorias tradicionais (feitas por profissionais e que costumam ser demoradas e caras).

Neste processo, assim como nos processos anteriores, fez-se uso da linguagem de programação Python versão 2.7.11+ em conjunto com a biblioteca scikit-learn versão 0.17.1.

O processo Identificar defeitos, diferentemente do processo Detectar asfalto, foi implementado por meio do aprendizado não-supervisionado. Uma vez especificado a partir do uso de aprendizado de máquina, esse processo também subdivide-se em duas fases, a Fase de Treinamento e a Fase de Detecção, conforme podem ser observadas na Figura 4.36

De modo análogo ao processo Detectar asfalto, antes de iniciar o processamento de cada fase, deve ser definida a parte do conjunto de imagens a ser utilizada para fazer o treinamento e parte a ser utilizada nos testes/validação. Para essa separação uma amostra de $30 \%$ das imagens foi escolhida aleatoriamente para compor o conjunto de testes/validação, sendo que o restante foi utilizado para treinamento, de modo que se possa verificar a acurácia dos resultados. 


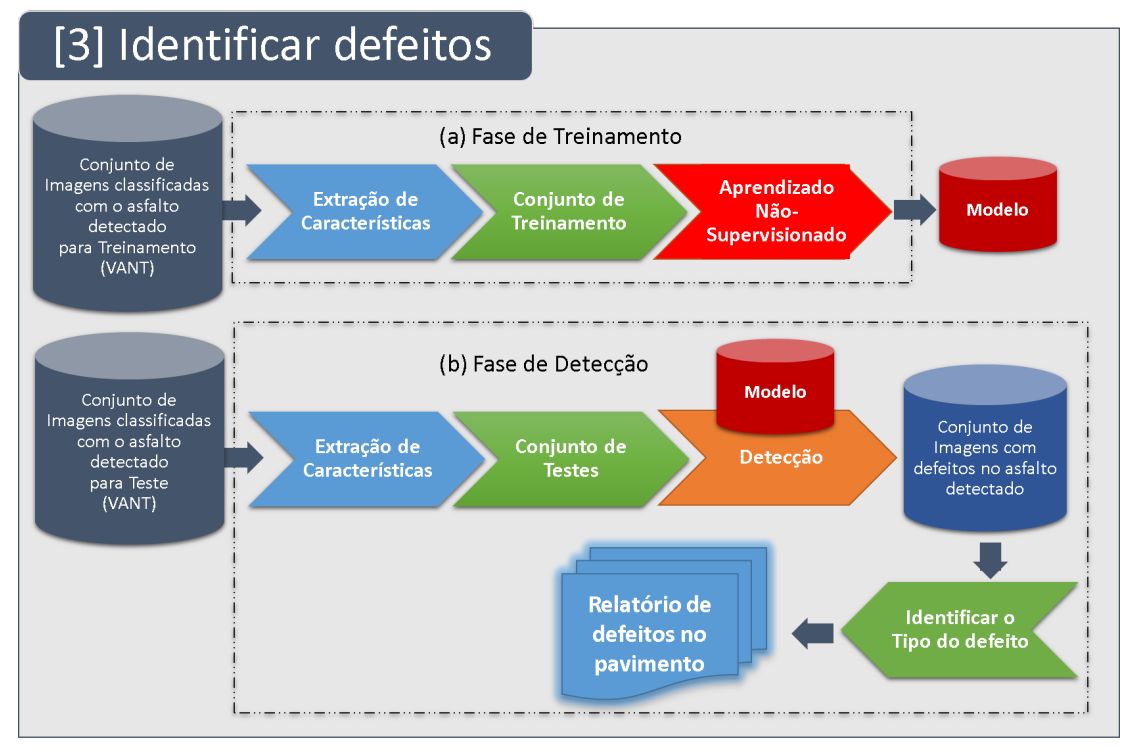

Figura 4.35 - Processo Identificar defeitos.

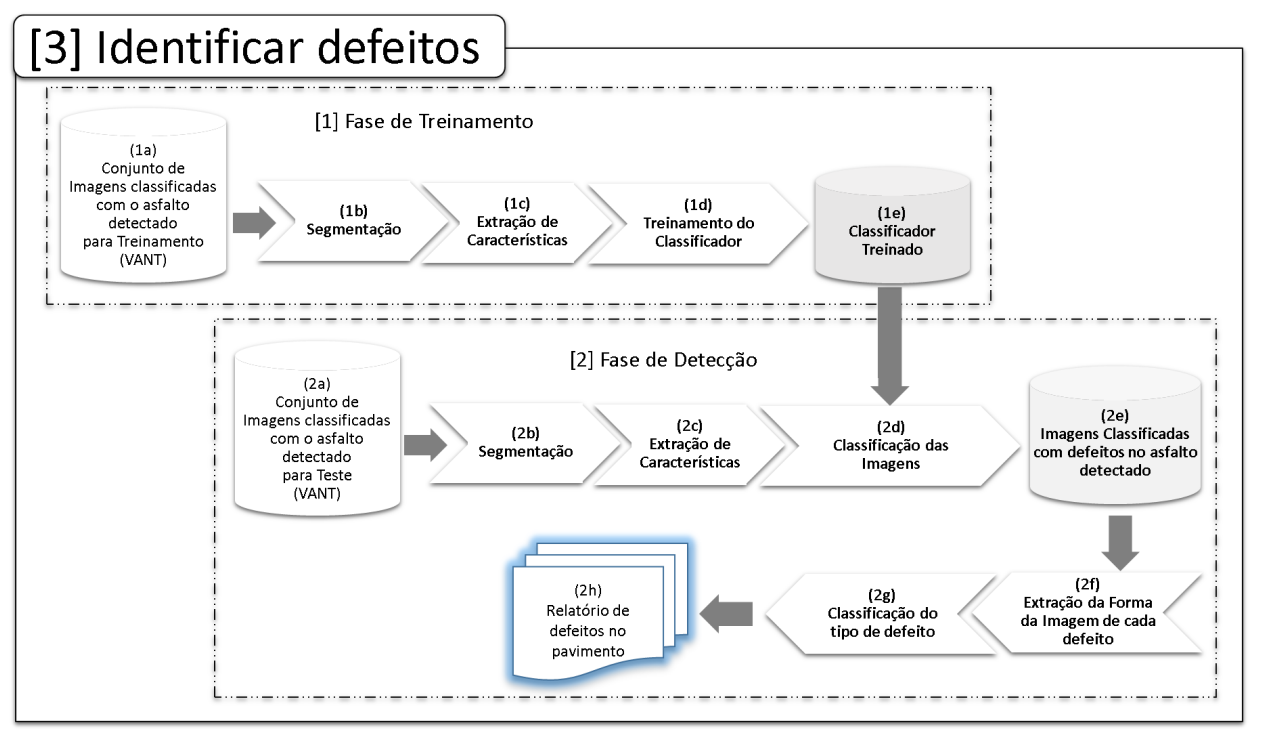

Figura 4.36 - Detalhamento do processo Identificar defeitos.

A Fase de Treinamento utiliza o conjunto de imagens separadas para o treinamento para treinar o classificador e outro conjunto de imagens para ser utilizado na fase de testes do classificador treinado, que classificará as regiões com defeito no pavimento (Etapa 1a).

As imagens de treinamento são submetidas à um processo de segmentação que faz uso do algoritmo de agrupamento ou clustering. Superpixel (SLIC) é ilutrado na Figura 4.37.

Para cada região segmentada da imagem extrai-se as características necessárias para a fase de treinamento do classificador. Nessas regiões, as features mais importantes, normalmente, são selecionadas para serem utilizadas no treinamento.

Considerando-se que serão classificadas pequenas regiões, não se fez necessária a determinação de features mais complexas, sendo assim, deu-se preferência para a escolha de features 


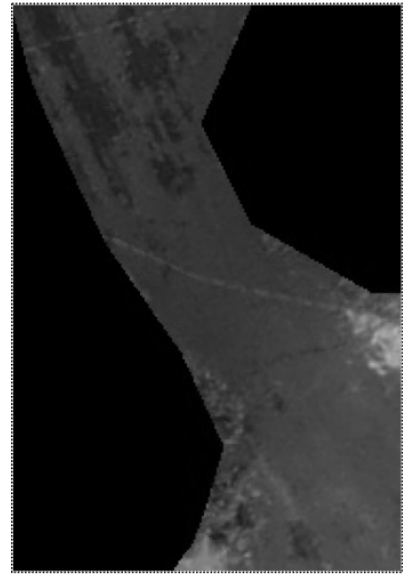

(a)

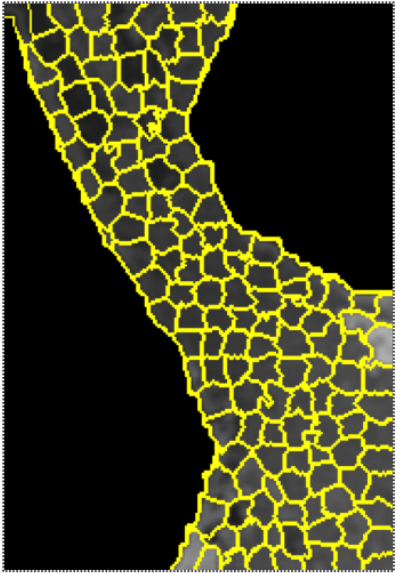

(b)

Figura 4.37 - Aplicação do algorítmo superpixel na imagem. a) imagem não segmentada com o asfalto detectado. b) imagem segmentada.

que possibilitem pouco espaço de armazenamento e processamento computacional rápido, como ilustrado na Tabela 4.2.

Tabela 4.2 - Exemplos de features utilizadas.

\begin{tabular}{|l|l|c|}
\hline \multicolumn{1}{l}{} & \multicolumn{1}{l}{ Feature } & Tamanho \\
\hline Nível de Cinza & Média e desvio padrão & 2 \\
\hline Entropia & Média e desvio padrão & 2 \\
\hline Gradiente & Média e desvio padrão & 2 \\
\hline Regional Máxima & Média e desvio padrão & 2 \\
\hline Histograma do Nível de Cinza & $\begin{array}{l}\text { Histograma do nível de cinza } \\
\text { normalizado }\end{array}$ & 16 \\
\hline & Total & 24 \\
\hline
\end{tabular}

Para avaliar as features mais relevantes ou de maior importância para o treinamento foi utilizada a técnica de seleção de features, também denominada de feature rank Zhang (2009). Essa técnica permite detectar features, por exemplo, que apresentam pouca variação nos dados de modo que não contribuem para o treinamento, pois não indica uma situação de mudança de comportamento na característica que está sendo tratada. Com essa informação, é possível identificar essas features de menor importância para melhorar a etapa de treinamento.

O resultado do processamento de seleção de features é ilustrado na Figura 4.38 e, pode-se observar no gráfico que quantidade ideal de features para treinamento indicada foram de 03 (três) e as que obtiveram maior nível de importância foram: nível de cinza, entropia e gradiente.

Sendo assim, as features escolhidas para o treinamento são ilustradas na Tabela 4.3.

No caso específico do exemplo apresentado, uma parte dos valores das features obtidas de uma região é ilustrado na Tabela 4.4.

$\mathrm{Na}$ fase de treinamento do processo Detectar asfalto foi utilizada uma estratégia de otimização de rotulação automática da Segmentação (Etapa 1b) das imagens por meio do uso do 


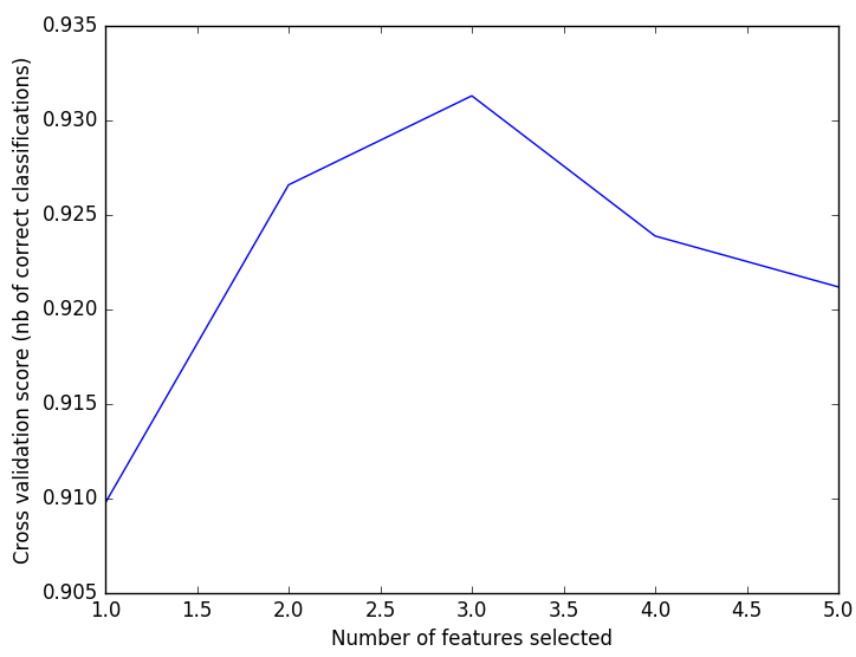

Figura 4.38 - Features mais importantes para o treinamento.

Tabela 4.3 - Features selecionadas para extrair da Imagem.

\begin{tabular}{|l|l|c|}
\hline \multicolumn{1}{ll}{} & \multicolumn{1}{l}{ Feature } & Tamanho \\
\hline Nível de Cinza & Média e desvio padrão & 2 \\
\hline Entropia & Média e desvio padrão & 2 \\
\hline Gradiente & Média e desvio padrão & 2 \\
\hline & Total & 6 \\
\hline
\end{tabular}

Tabela 4.4 - Exemplo de listagem das features para treinamento.

\begin{tabular}{|c|c|c|c|c|c|}
\hline \multicolumn{9}{|c|}{ gray_mean } & gray_std & entropy_mean & entropy_std & gradient_mean & gradient_std \\
\hline 93.94504 & 7.37724 & 1.54578 & 0.53646 & 32.49761 & 38.15305 \\
137.68060 & 29.73298 & 2.25726 & 0.17692 & 185.03846 & 34.66799 \\
101.87962 & 4.08611 & 1.55141 & 0.47817 & 22.32104 & 23.60613 \\
54.15681 & 18.38860 & 2.27660 & 0.14078 & 122.92710 & 42.96394 \\
74.79420 & 7.52305 & 1.93693 & 0.47276 & 86.52174 & 54.57842 \\
3.34583 & 3.05252 & 1.80727 & 0.50060 & 81.38750 & 7.40072 \\
74.18482 & 2.36702 & 1.42512 & 0.51012 & 27.52035 & 23.51394 \\
36.26634 & 18.86762 & 2.11031 & 0.40501 & 72.69249 & 16.01149 \\
60.23633 & 11.64342 & 2.03292 & 0.36274 & 55.12109 & 24.40189 \\
87.56993 & 8.73035 & 1.94104 & 0.42022 & 48.16863 & 23.59149 \\
46.08571 & 15.17587 & 2.28987 & 0.10524 & 81.97143 & 9.07740 \\
80.64497 & 5.97729 & 1.69085 & 0.53452 & 41.12623 & 31.85618 \\
53.60924 & 4.08968 & 1.91801 & 0.37021 & 54.23529 & 16.95233 \\
103.06051 & 1.88953 & 1.33752 & 0.49441 & 12.53395 & 5.90008 \\
4.44011 & 4.66495 & 1.66509 & 0.58087 & 136.49304 & 10.42492 \\
\hline
\end{tabular}

mapa de ruas (labels) do GoogleMaps.

Para a identificação de defeitos, a estratégia adotada para evitar a marcação manual das classes a serem treinadas foi a utilização de uma técnica de treinamento não-supervisionado, como já mencionado anteriormente.

Já está consolidado na literatura a utilização do treinamento supervisionado para a detecção de defeitos no pavimento asfáltico Oliveira e Correia (2008),Li et al. (2009), Koch e Brilakis 
(2011), Salman et al. (2013) mas não para o uso de imagens aéreas. Por outro lado, a utilização de técnicas de aprendizado não-supervisionado na detecção de defeitos no pavimento asfáltico fazendo uso ou não de imagens aéreas constitui ainda uma área de estudo a ser explorada e é a adotada na MANIAC.

Neste processo, o classificador é treinado com uma técnica não-supervisionada utilizando técnicas de detecção de anomalias, que é baseada em todos os dados coletados. A Extração de Características (Etapa 1c), por exemplo, do nível de cinza é feita em cada região do asfalto obtida pela etapa de segmentação das imagens, determinando assim um padrão de variação (range) dos dados coletados. Dessa forma, por meio da determinação de uma faixa ou limite de dados aceitável, a técnica classifica os dados em duas classes principais: dados dentro do padrão ou dados "bons" e dados fora do padrão ou dados "ruins/contaminados".

Analisando apenas a feature nível de cinza, depois de coletados todos os níveis médios de cinza de cada segmento do conjunto de amostra de imagem do pavimento, o classificador, baseado na técnica de detecção de anomalias, procura pelos valores de nível de cinza menos comuns nos dados. Os dados ruins ou menos comuns, neste caso, são os níveis de cinza relacionados aos defeitos, pois, nesse contexto, é mais comum ou normal predominar a quantidade de valores de níveis de cinza necessários sobre asfalto sem defeito do que valores sobre asfalto com defeito. Na sequência, as regiões com valores contaminados (asfalto com defeito) são os dados ruins, fora do padrão, isto é, neste conceito considerados como anomalias.

Foram utilizadas na MANIAC duas técnicas de detecção de anomalias: OneclassSVN e EllipticEnvelope.

Se os dados a serem treinados estiverem puros, sem anomalias ou todos no padrão desejado, é recomendado utilizar o OneClassSVN Schölkopf et al. (2001), caso contrário, a técnica EllipticEnvelope onde os dados a serem treinados possuem ruídos ou estão contaminados, sendo que neste caso é necessário informar um índice de contaminação desses dados.

Para um melhor desempenho computacional no tempo de processamento de dados e maior automatização de todo o processo, o classificador foi treinado utilizando a técnica EllipticEnvelope. Os parâmetros necessários e os respectivos valores padrões para cada um é: EllipticEnvelope(store_precision=True, assume_centered=False, support_fraction=None, contamination $=0.1$, random_state $=$ None)

O valor do parâmetro contamination refere-se ao grau de pureza dos dados a serem treinados, esse valor pode ser determinado manualmente por meio do conhecimento prévio dos dados a serem treinados, por exemplo, o índice de regiões de defeitos na região a ser treinada. Para esse parâmetro, assim como para os demais, os valores foram determinados por meio da técnica de hiperparametrização, e a partir de uma faixa de valores para cada parâmetro buscase os melhores parâmetros para o classificador, isto é, aquela combinação de parâmetros que permite o classificador produzir dados mais confiáveis. Os intervalos de dados dos parâmetros 
utilizados para a hiperparametrização podem ser observados na Tabela 4.5.

Tabela 4.5 - Intervalos utilizados nos parâmetros.

\begin{tabular}{|c|c|}
\hline \multicolumn{1}{c}{ Parâmetro } & Valor \\
\hline support_fraction & {$[0.1,1.0]$, variando 0.1} \\
\hline contamination & {$[0.1,0.5]$, variando 0.05} \\
\hline assume_centered & {$[$ False, True $]$} \\
\hline
\end{tabular}

Uma vez que os dados foram submetidos ao treinamento não-supervisionado para a detecção de anomalias, o Treinamento do Classificador (Etapa 1d) resultou na determinação de um intervalo (range) para a separação dos dados treinados, neste caso, um intervalo de dados que permita separar as amostras de imagens com defeito no asfalto. Dessa forma, o classificador considera duas classes de treinamento: classe 1 para "asfalto sem defeito" e classe 2 para "asfalto com defeito" que são os dados fora do padrão da maioria dos dados para treinamento, também denominados de ruídos. O Classificador Treinado já pode ser utilizado para classificar novas imagens do pavimento para a detecção de defeitos.

Após terminada a fase de treinamento é possível utilizar o classificador treinado para classificar um novo conjunto de imagens (conjunto imagens de teste) a qual fora previamente separada do conjunto para treinamento do classificador. A classificação desse conjunto de imagens de testes é importante, pois o classificador desconhece os dados dessas imagens, portanto é fundamental verificar o seu comportamento diante da classificação desses dados. Dá-se dessa forma início a Fase de Detecção.

Da mesma maneira que as imagens de treinamento, as imagens de teste também passam pelas etapas de Segmentação (Etapa 2b) e Extração de Características (Etapa 2c).

A classificação das imagens é feita com o auxílio do classificador treinado a partir das características extraídas das imagens de teste, sendo assim, identifica-se quais as regiões das imagens que possuem defeitos no pavimento, gerando dessa forma um conjunto de imagens composto por imagens que apresentam presença de defeitos no pavimento (Figura 4.39).

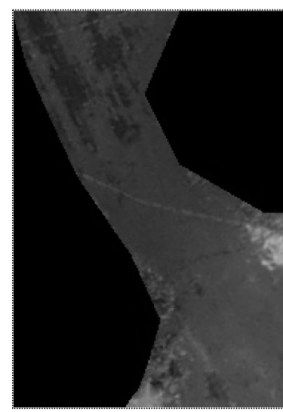

(a)

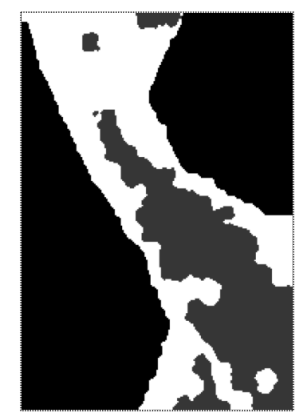

(b)

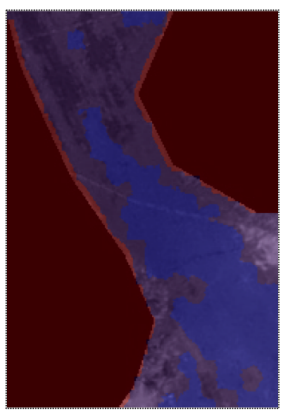

(c)

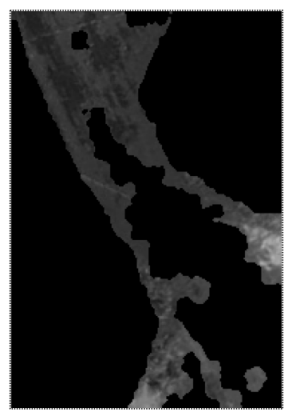

(d)

Figura 4.39 - Resultado do processamento da classificação de defeitos no pavimento. a) imagem original b) máscara gerada automaticamente com os defeitos em branco. c) imagem com sobreposição destacando as áreas sem defeitos em azul. d) imagem final apenas com as regiões com defeitos detectadas. 
Uma vez que as regiões com defeito no asfalto foram identificadas nas imagens, a etapa de Extração da Forma (Etapa 2f) gera informações sobre a morfologia de cada região que foi classificada com defeito com o objetivo de identificar o tipo de cada defeito encontrado. Operações de processamento de imagens de morfologia são utilizadas nesta etapa para a obtenção de informações como: área, perímetro, contorno e polígono aproximado.

Por meio da técnica de Aproximações Poligonais, utilizando, por exemplo, polígonos de perímetro mínimo Gonzalez e Woods (2007), os contornos das regiões com defeitos os defeitos classificados são convertidos para uma forma de um polígono equivalente, ilustrado na Figura 4.40 .

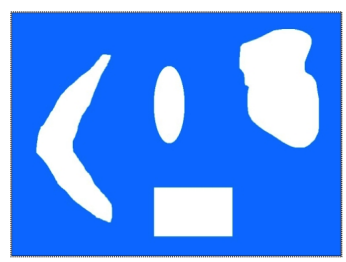

(a)

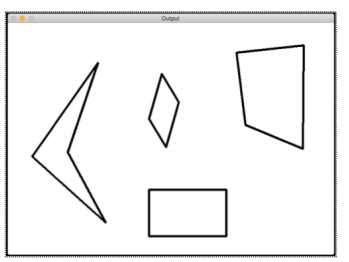

(b)

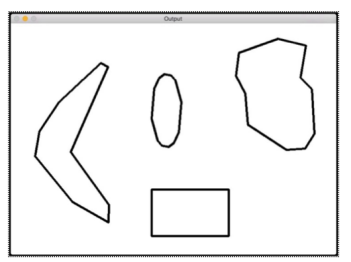

(c)

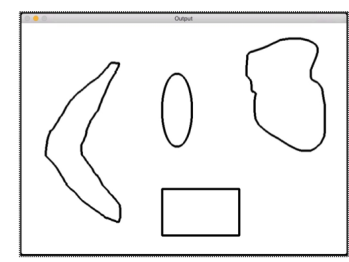

(d)

Figura 4.40 - Exemplo de utilização da técnica de aproximação de polígono. (a) Imagem original. (b) Fator de aprox. $=0.05$. (c) Fator de aprox. $=0.01$ (contorno mais suave). (d) Fator de aprox. $=0.00001$ (muito parecido com a imagem original)

Para a obtenção dos polígonos contornando cada defeito utiliza-se a técnica agrupamento de $K$-means com 03 grupos ou classes (classe 0: para fundo, descarte ou anomalias; classe 1: para regiões sem defeitos; classe 2: regiões com defeitos).

A informação sobre o polígono de cada região da imagem detectada com defeito, como pode ser observado na 4.41, permite que seja feita a Classificação do Tipo de Defeito (Etapa 2g) de acordo com a forma do polígono encontrada pela a técnica da aproximação.

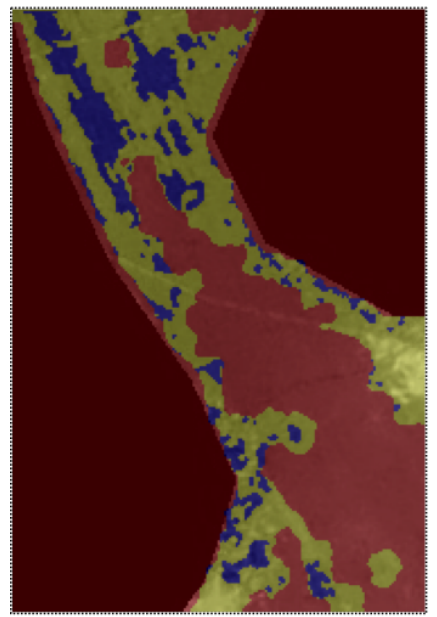

(a)

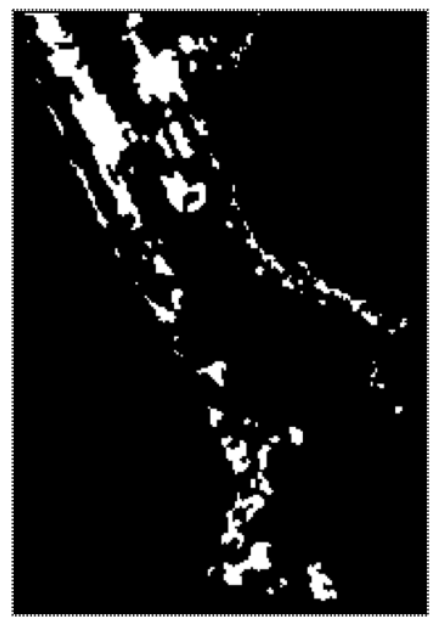

(b)

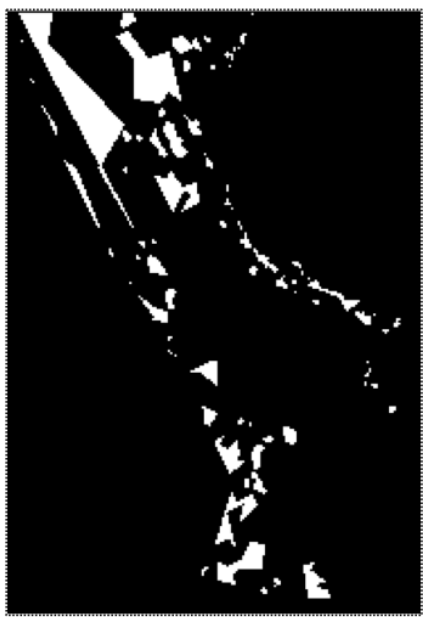

(c)

Figura 4.41 - Exemplo da segmentação e aproximação dos polígonos da região com defeito. a) imagem segmentada. b) imagem com os polígonos dos defeitos da segmentação destacados em branco. c) imagem com os polígonos dos defeitos aproximados. 
Utilizando essa técnica, o critério de classificação dos principais tipos de defeitos que puderam ser detectados de acordo com a forma do polígono equivalente são ilustrados na Tabela 4.6 .

Tabela 4.6 - Critério de classificação dos tipos de defeitos.

\begin{tabular}{|c|c|c|}
\hline \multicolumn{1}{l}{ Tipo de Defeito } & Polígono Equivalente & Número de Vértices \\
\hline Fenda (Trincas) & Linha & $\mathrm{n}=2$ \\
\hline Panela & Círculo & $\mathrm{n}>16$ \\
\hline Remendo & Demais Formas & $2>\mathrm{n}>16$ \\
\hline
\end{tabular}

O resultado do processamento dos tipos de defeitos (das imagens com defeitos) baseado nos critérios de aproximação de polígono da Tabela 4.6 é ilustrado na Figura 4.42.

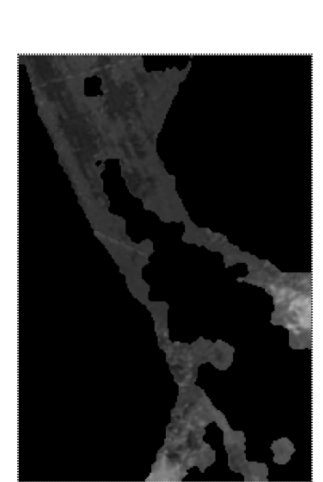

(a)

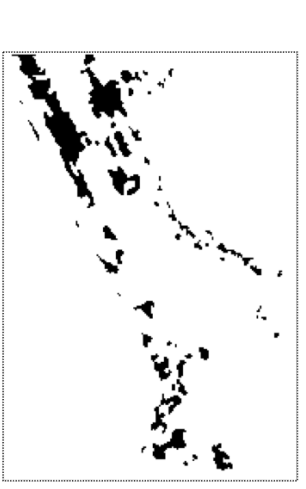

(b)

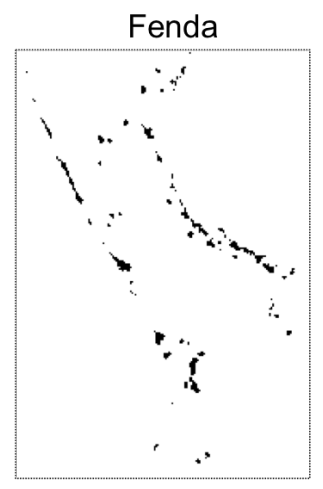

(c)

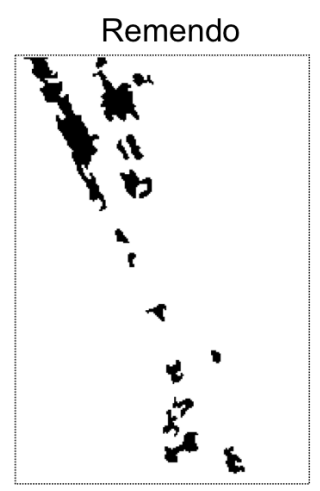

(d)

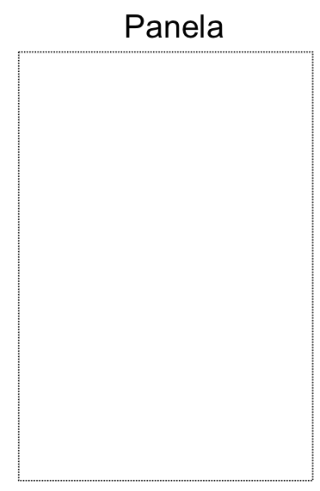

(e)

Figura 4.42 - Processamento dos tipos defeitos no pavimento. a) imagem classificada com os defeitos. b) imagem com os defeitos destacados em preto. c) imagem com os defeitos do tipo Fenda destacados em preto. d) imagem com os defeitos do tipo Remendo destacados em preto. e) defeitos do tipo Panela não foram encontrados nessa imagem.

Para concluir essa fase de identificação de defeitos, a aplicação desse critério de classificação de defeitos no pavimento, possibilita, então, que além de detectar as regiões com defeitos no asfalto, também seja possível a identificação dos principais tipos de defeitos encontrados nas imagens analisadas.

Por fim o Relatório de Defeitos (Etapa 2h) é gerado, listando textualmente os defeitos encontrados em cada imagem analisada. Sendo assim, essas informações serão utilizadas para determinar o tipo do defeito e classificar a imagem de forma automática.

Segundo Resende (2010), é possível calcular um Índice Categoria de Defeito $\left(I_{\text {cat }}\right)$ somandose a área de cada segmento classificado como pertencente ao defeito, dividido pela soma da área dos objetos classificados como asfalto para cada imagem de acordo com a Equação (4.1).

$$
I_{c a t}=\frac{\sum \operatorname{area}\left(O_{c a t}\right)}{\sum \operatorname{area}\left(O_{\text {asfalto }}\right)}
$$

Sendo: 
- $I_{c a t}$ - Índice da categoria de defeitos em análise;

- $O_{c a t}$ - Objetos classificados como sendo da categoria de defeitos em análise;

- $O_{\text {asfalto }}$ - Objetos classificados como asfalto.

Adotando-se a Equação (4.1) para o cálculo do $I_{c a t}$ é possível a obtenção do relatório de tipos de defeitos (Figura 4.43) onde podem ser observados os índices de categorias de defeitos que foram calculados para uma determinada imagem.

Relatório de Tipos de Defeitos: tile_5424_0_seg_ind_69.png

Defeitos (todos) -> area: $0.360005 \mathrm{~m}^{2}$, qtd: 53

Tipo1 (Fenda) -> area: $0.001698 \mathrm{~m}^{2}$, qtd: 22, Icat1: 0.000041

Tipo2 (Remendo) -> area: $0.360571 \mathrm{~m}^{2}$, qtd: 31, Icat2: 0.008801

Tipo3 (Panela) $\rightarrow$ area: $0.000000 \mathrm{~m}^{2}$, qtd: 0, Icat3: 0.000000

Área do segmento (asfalto): $40.968696 \mathrm{~m}^{2}$

Figura 4.43 - Relatório de tipos de defeitos para cada imagem.

A partir da soma ponderada dos valores dos $I_{c a t}$, obtidos por meio das imagens, é gerado um Índice Gravidade Global por imagem $\left(I G G^{\prime}\right)$ e um Índice Gravidade Global Expedito por imagem $\left(I G G E^{\prime}\right)$ da mesma forma que é feito o cálculo do $I G G$ e $I G G E$ pelo método convencional.

Com a geração do Relatório de Defeitos finaliza-se a MANIAC, e os resultados podem então auxiliar a tarefa de monitoramento de pavimento asfáltico. Exemplos parciais desse relatório são ilustrados nas Figuras 4.44 e 4.45.

\begin{tabular}{ccccccccccc}
\hline nome do segmento & Ind. Trinca & Ind. Remendo & Ind. Panela & fp. Trinca & fp Remendo fp Panela & IGI' Trinca & IGI' Remendo IGI' Panela & IGG' \\
\hline tile_5424_0_seg_ind_686.png & 0.000076 & 0.094765 & 0.000000 & 0.8 & 0.6 & 1.0 & 0.000061 & 0.056859 & 0.000000 & 0.056919 \\
\hline tile_5424_0_seg_ind_69.png & 0.000041 & 0.008801 & 0.000000 & 0.8 & 0.6 & 1.0 & 0.000033 & 0.005281 & 0.000000 & 0.005314 \\
tile_5424_0_seg_ind_713.png & 0.000000 & 0.002594 & 0.000000 & 0.8 & 0.6 & 1.0 & 0.000000 & 0.001556 & 0.000000 & 0.001556 \\
\hline tile_5424_0_seg_ind_714.png & 0.000063 & 0.029657 & 0.000000 & 0.8 & 0.6 & 1.0 & 0.000051 & 0.017794 & 0.000000 & 0.017845 \\
tile_5424_0_seg_ind_715.png & 0.000000 & 0.006793 & 0.000000 & 0.8 & 0.6 & 1.0 & 0.000000 & 0.004076 & 0.000000 & 0.004076 \\
tile_5424_0_seg_ind_745.png & 0.000043 & 0.036372 & 0.000000 & 0.8 & 0.6 & 1.0 & 0.000035 & 0.021823 & 0.000000 & 0.021858 \\
$\ldots$ & $\ldots$ & $\ldots$ & $\ldots$ & $\ldots$ & $\ldots$ & $\ldots$ & $\ldots$ & $\ldots$ & $\ldots$ & $\ldots$ \\
\hline
\end{tabular}

Figura 4.44 - Relatório parcial de defeitos com os valores do IGI' e IGG' calculados a partir das imagens analisadas.

\begin{tabular}{cccccccc}
\hline nome do segmento & Ind. Trinca & Ind. Remendo & Ind. Panela & Pt Trinca & Ppr Remendo & Ppr Panela & IGGE' \\
\hline tile_5424_0_seg_ind_686.png & 0.000076 & 0.094765 & 0.000000 & 0.3 & 1.0 & 0.7 & 0.0947870 \\
\hline tile_5424_0_seg_ind_69.png & 0.000041 & 0.008801 & 0.000000 & 0.3 & 1.0 & 0.7 & 0.0088140 \\
tile_5424_0_seg_ind_713.png & 0.000000 & 0.002594 & 0.000000 & 0.3 & 1.0 & 0.7 & 0.0025940 \\
\hline tile_5424_0_seg_ind_714.png & 0.000063 & 0.029657 & 0.000000 & 0.3 & 1.0 & 0.7 & 0.0296760 \\
\hline tile_5424_0_seg_ind_715.png & 0.000000 & 0.006793 & 0.000000 & 0.3 & 1.0 & 0.7 & 0.0067930 \\
\hline tile_5424_0_seg_ind_745.png & 0.000043 & 0.036372 & 0.000000 & 0.3 & 1.0 & 0.7 & 0.0363850 \\
\hline$\ldots$ & $\ldots$ & $\ldots$ & $\ldots$ & $\ldots$ & $\ldots$ & $\ldots$ & $\ldots$ \\
\hline
\end{tabular}

Figura 4.45 - Relatório parcial de defeitos com o valor do IGGE’ calculado a partir das imagens analisadas.

Com base nas informações obtidas pelos índices de avaliação do pavimento, como por exemplo $I G G^{\prime}$ e $I G G E^{\prime}$, pode-se definir de maneira automatizada qual o grau de defeito de cada imagem analisada. 


\subsubsection{Considerações finais}

Neste capítulo foi introduzida a metodologia MANIAC, a qual tem como objetivo a detecção automática de defeitos em pavimentos asfálticos flexíveis. Foi apresentada a visão macroscópica da metodologia, bem como o detalhamento do funcionamento de cada um dos macro processos que compõem a metodologia.

O processo Pré-Processar é o processo mais simples, e é o responsável por melhorar a qualidade das imagens. Os processos Detectar asfalto e Identificar defeitos constituem o coração da metodologia. O processo Detectar asfalto emprega o uso de Aprendizado de Máquina supervisionado, fazendo uso da técnica de Random Forest para permitir a detecção da malha viária dentre as imagens obtidas a partir do VANT. Neste processo, a criação de uma máscara baseada nas informações oriundas do GoogleMaps permite que a avaliação do GroundTruth seja feita de forma automática, característica relevante e inovadora no processo.

O processo Identificar Defeito, por outro lado, faz uso do aprendizado não-supervisionado, utilizando EllipticEnvelope. Neste processo é realizada a detecção de pavimentos com defeito, bem como por meio de Aproximações Poligonais foi possível incorporar à MANIAC a detecção de alguns dos principais tipos de defeito: Fenda, Panelas e Remendos. Por fim a MANIAC gera um relatório apresentando os defeitos nos pavimentos utilizando índices de avaliação do pavimento tradicionalmente utilizados.

No Capítulo 5 são descritos os resultados experimentais que investigam e validam o uso da metodologia MANIAC. 


\section{Capítulo}

\section{Resultados Experimentais}

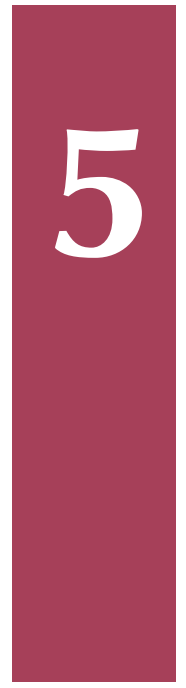

A MANIAC, incluindo todos os processos de que é composta, foi validada por meio de experimentos fazendo uso de dados de missões reais realizadas com o VANT de asa fixa eBee em áreas mais e menos povoada em região urbana, e em rodovias.

Este capítulo está estruturado da seguinte forma: na Seção 5.1 são apresentadas as considerações iniciais. Na Seção 5.2 são apresentados os testes experimentais realizados em áreas de menor densidade populacional. Na Seção 5.3 são apresentados os resultados e a validação da metodologia para área de maior densidade populacional, e na Seção 5.4 são apresentados os resultados para áreas de rodovias. Por fim, o capítulo é finalizado com a Seção 5.6 que apresenta as considerações finais.

\subsection{Considerações iniciais}

Uma vez especificada a MANIAC, fazem-se necessários experimentos que possam validar a acurácia das técnicas e algoritmos que compõem essa metodologia, de modo a validá-la como um todo.

A validação da MANIAC, das técnicas e algoritmos que a compõem foi realizada por meio de experimentos que fizeram uso de dados reais obtidos com o VANT eBee em áreas mais e menos povoadas e em rodovias (o detalhamento de cada uma das missões é apresentado detalhadamente em cada um dos experimentos individualmente). Assim, foram realizados três experimentos que puderam comprovar a acurácia da MANIAC na detecção de defeitos em pavimentos asfálticos flexíveis.

A infraestrutura computacional utilizada nos experimentos executados foi um equipamento 
Intel Core i7, com 8GB de RAM e Disco rígido de 1TB, onde fez-se uso da linguagem de programação Python versão 2.7.11+ em conjunto com a biblioteca scikit-image versão 0.12 .3 e scikit-learn versão 0.17.1.

Na Tabela 5.1 é apresentado o planejamento dos experimentos realizados.

Tabela 5.1 - Projeto dos experimentos realizados.

\begin{tabular}{|c|c|c|c|}
\hline \multicolumn{2}{|c|}{ Experimento } & $\begin{array}{l}\text { Área } \\
\left(m^{2}\right)\end{array}$ & \multirow{2}{*}{$\begin{array}{c}\text { Localização } \\
\text { (Latitude, Longitude) }\end{array}$} \\
\hline E1 & $\begin{array}{l}\text { Detecção de defeitos em pavimentos } \\
\text { localizados em áreas menos povoadas }\end{array}$ & 283.781 & \\
\hline E2 & $\begin{array}{l}\text { Detecção de defeitos em pavimentos } \\
\text { localizados em áreas mais povoadas }\end{array}$ & 587.640 & $\begin{array}{c}(-47.9273343,-21.9944113) \\
\left(47^{\circ} 55^{\prime} 38.40^{\prime \prime} \mathrm{W}, 21^{\circ} 59^{\prime} 39.88^{\prime \prime} \mathrm{S}\right)\end{array}$ \\
\hline E3 & $\begin{array}{l}\text { Detecção de defeitos em pavimentos } \\
\text { localizados em rodovias }\end{array}$ & 1.518 .425 & $\begin{array}{l}\text { (-48.4975731, -23.0192534), } \\
\left(48^{\circ} 29^{\prime} 51.26^{\prime \prime}, 23^{\circ} 1^{\prime} 9.31^{\prime \prime S}\right)\end{array}$ \\
\hline
\end{tabular}

Esses experimentos foram assim planejados pois constituem as diferentes situações em que normalmente o pavimento asfáltico é encontrado. Por meio destes, foi possível obter conclusões a cerca da acurácia da MANIAC mesmo quando da presença de muito, médio e pouco ruído (ou quantidade distintas de objetos) presente nas imagens obtidas.

Cabe ressaltar que para todos os experimentos foram observadas as recomendações dos parâmetros necessários para que a obtenção das imagens fosse feita de forma apropriada. Optouse também por manter a mesma estrutura de descrição dos experimentos para que comparações pudessem ser realizadas.

\subsection{Experimento em área menos povoada}

\subsubsection{A missão - obtenção das imagens}

O primeiro experimento (E1) foi realizado na área localizada no município de São Carlos, perfazendo uma área de $0,28 \mathrm{~km}^{2}$. Na Figura 5.1 é ilustrada a tela da missão.

O voo foi realizado no dia 22 de fevereiro de 2014 com duração da missão de 8 minutos e produzindo 48 imagens. Após o tempo de 3 horas de pós-processamento, o arquivo digital do mosaico gerado possui as seguintes propriedades:

- Tamanho do Arquivo: Largura de 9.390 pixel; Altura de 15.715 pixel (328,9 MB);

- Resolução Espacial (Tamanho do pixel): 4,01 cm/pixel;

- Sistema de Coordenadas/Projeção: WGS 84/UTM zona 23S;

- Coordenadas Geodésicas:

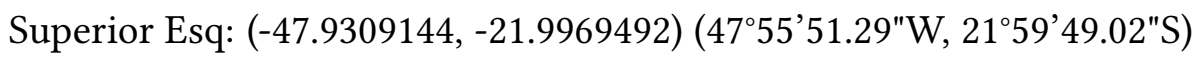




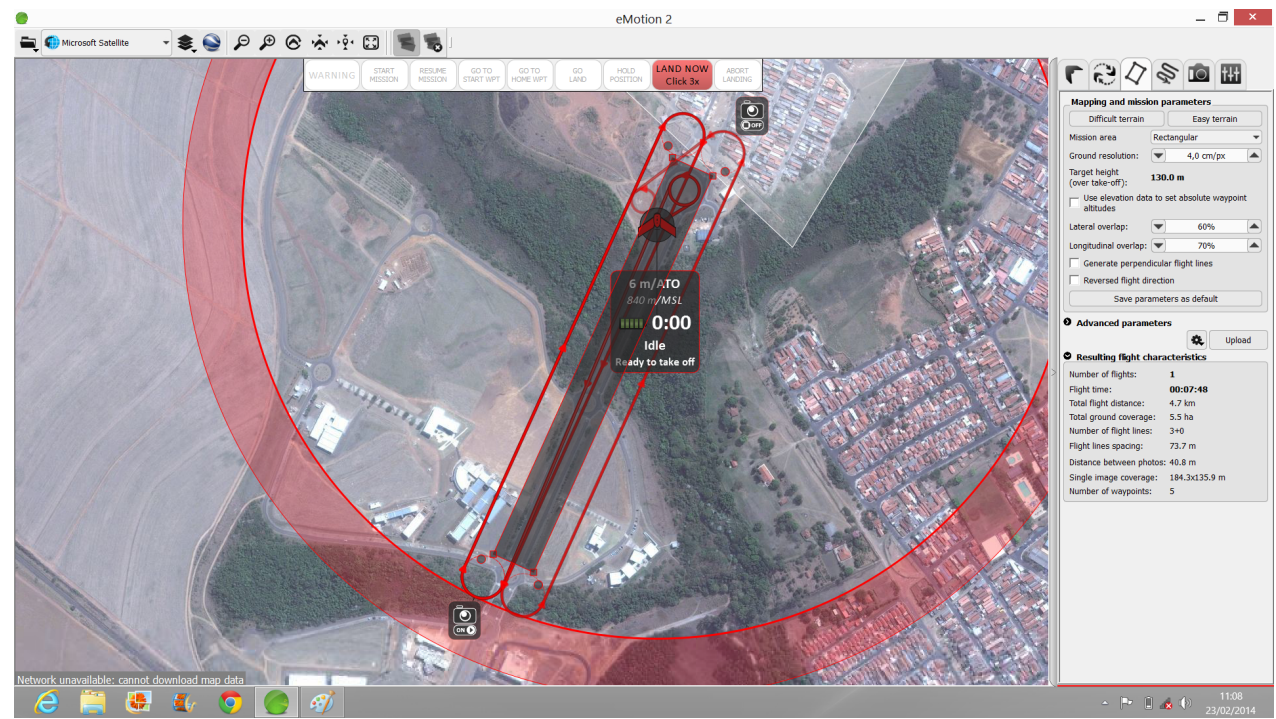

Figura 5.1 - Tela da execução da missão do Experimento 1.

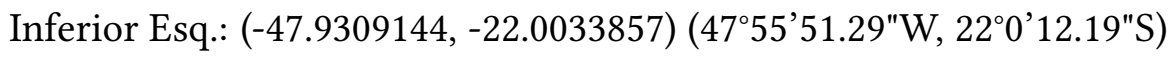

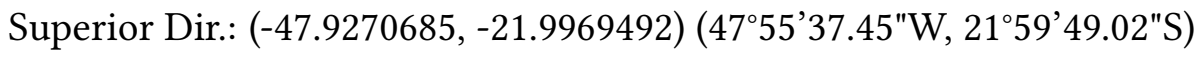

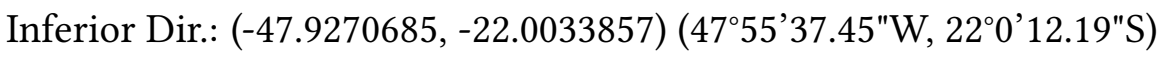

Central: (-47.9289914, -22.0001675$)\left(47^{\circ} 55^{\prime} 44.37^{\prime \prime} \mathrm{W}, 22^{\circ} 0^{\prime} 0.60^{\prime \prime} \mathrm{S}\right)$.

A Figura 5.2 ilustra o mosaico georeferenciado gerado a partir das 48 imagens aéreas obtidas pelo VANT eBee.

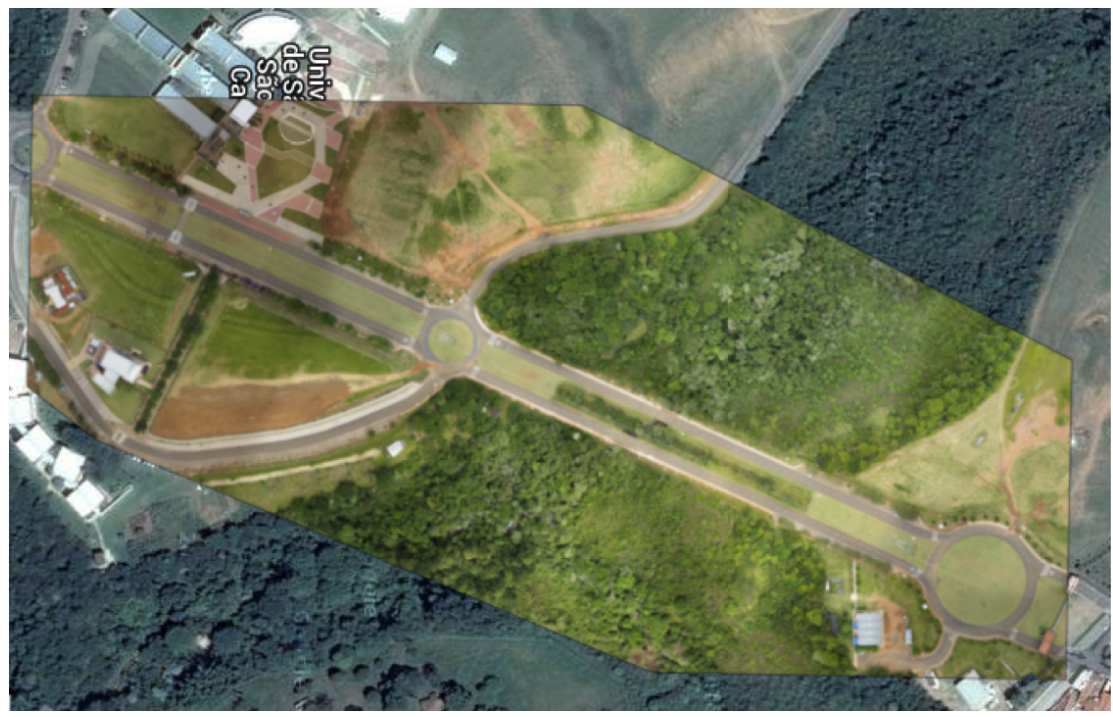

Figura 5.2 - Mosaico gerado a partir da imagens obtidas pelo VANT sobreposto pela imagem de satélite do GoogleMaps - Experimento 1.

É possível observar pelo mosaico apresentado que a área em questão não é densamente povoada, apresentando um conjunto pequeno de construções. Esse tipo de experimento permite validar a efetividade a MANIAC em áreas onde não há presença de muitos objetos característicos de áreas urbanas, apesar de os mesmo existirem. 
A partir da obtenção das imagens inicia-se o processo de detecção de defeitos em pavimentos asfálticos flexíveis por meio da MANIAC.

\subsubsection{Pré-Processar}

A primeira etapa é de pré-processamento das imagens, realizada a partir do conjunto de imagens aéreas obtidas com a execução da missão pelo VANT, a de Pré-Processar. Na Figura 5.3 é ilustrado o processo, sendo que na Figura 5.3a são ilustradas as imagens originais enquanto que na Figura 5.3b são ilustradas as imagens obtidas com a aplicação do filtro bilateral .

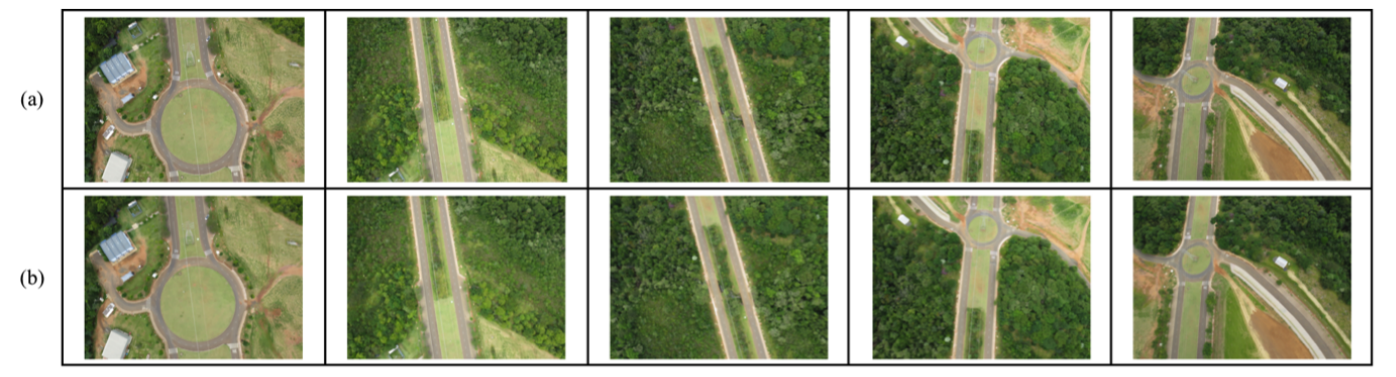

Figura 5.3 - Pré-processamento das imagens obtidos no Experimento 1 (E1). (a) Imagens originais; (b) Imagens pré-processadas com o filtro bilateral.

Foi utilizado o filtro bilateral que permite que os ruídos sejam eliminados e as bordas ressaltadas. As imagens obtidas nesse processo servem de entrada para o próximo processo da metodologia.

\subsubsection{Detectar asfalto}

A etapa Detectar asfalto é realizada por meio da submissão das imagens obtidas e já préprocessadas ao classificador previamente treinado.

Como parte do processo, objetivando melhorar o tempo de processamento da imagem final gerada em cada missão (devido ao grande tamanho do arquivo do mosaico), o arquivo digital com quase $328.9 \mathrm{MB}$ foi particionado em 21 arquivos (com uma grade de 5x4) como ilustrado na Figura 5.4.

O novo conjunto de 21 imagens (no caso deste experimento) é gerado com tamanho de 3928 (largura) por 2347 (altura) pixels, isto é, aproximadamente 4.0MB para cada imagem.

Para essa missão o (E1) o tempo de processamento para a fase de detecção do pavimento para cada imagem foi de 5 minutos utilizando o equipamento já mencionado.

Parte do pavimento asfáltico detectado é ilustrado na Figura 5.5.

A acurácia da detecção do pavimento asfáltico para o E1 é demonstrada por meio da matriz de confusão ilustrada na Figura 5.6. 


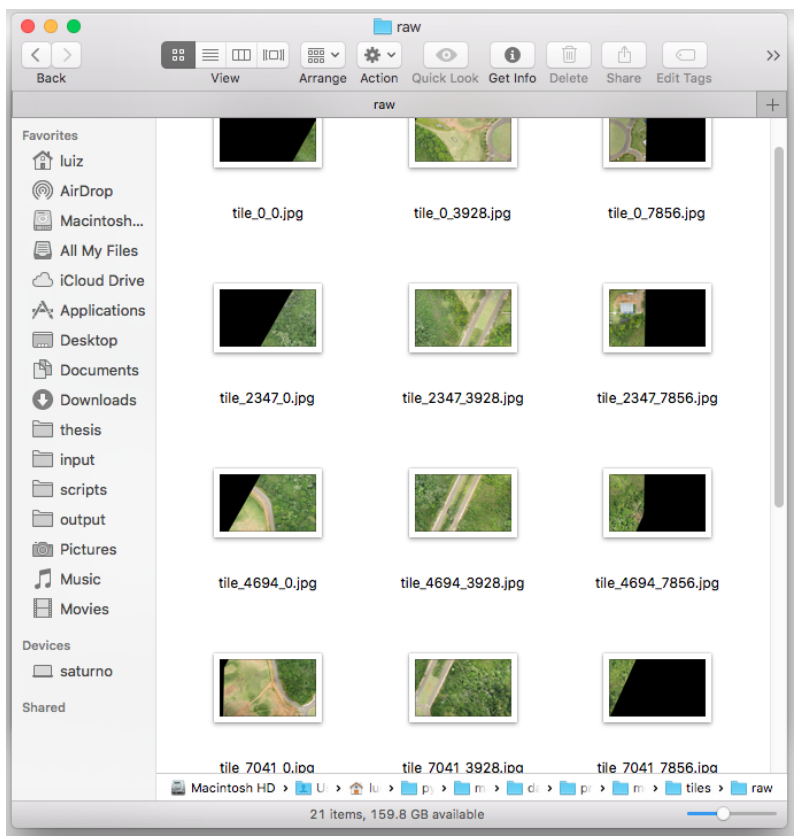

Figura 5.4 - Particionamento do arquivo digital do mosaico do Experimento 1 (E1).

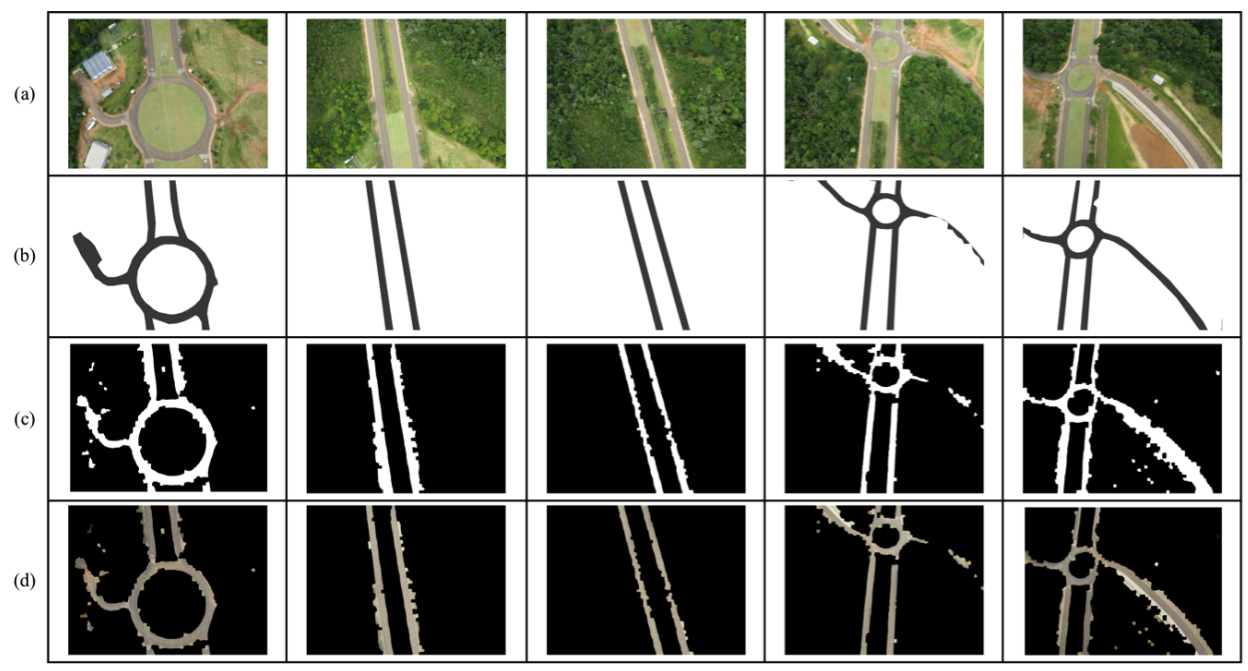

Figura 5.5 - Pavimento asfáltico detectado para o Experimento 1 (E1).

É possível observar por meio da matriz de confusão que no E1 o resultado das métricas de desempenho apresentadas e da F-measure são positivas. Tem-se uma acurácia de $99 \%$ para a detecção do pavimento asfáltico.

\begin{tabular}{|rrrr|}
\hline True Positive & False Negative & Accuracy & Precision \\
3959 & 12 & 0.99 & 0.99 \\
& & & \\
False Positive & True Negative & Recall & F1 Score \\
18 & 337 & 0.99 & 0.99 \\
\hline
\end{tabular}

Figura 5.6 - Matriz de confusão e outras medidas de avaliação do algoritmo de AM aplicado ao Experimento 1 (E1) na detecção de pavimento. 
Por meio dos valores apresentados pelas medidas utilizadas para avaliar os resultados apresentados pelo algoritmo de aprendizado, é possível afirmar que a identificação em áreas menos povoadas (E1) foi bem sucedido.

\subsubsection{Identificar defeitos}

Uma vez detectados e obtidos os pavimentos asfálticos existentes nas imagens, a próxima etapa consiste na identificação do pavimento defeituoso, e posteriormente na identificação dos tipos de defeitos encontrados no mesmo.

Na Figura 5.7a são ilustrados três trechos distintos de pavimentos detectados no E1. Por meio do uso de um classificador treinado é feita a identificação das regiões que apresentam defeitos no pavimento, sendo então gerada pelo classificador uma máscara com os defeitos na cor em branca (Figura 5.7b). Na Figura 5.7c são ilustradas as sobreposições da máscara, permitindo-se assim que os defeitos sejam destacados, e por fim na Figura 5.7d são ilustradas as imagens onde os defeitos são destacados.

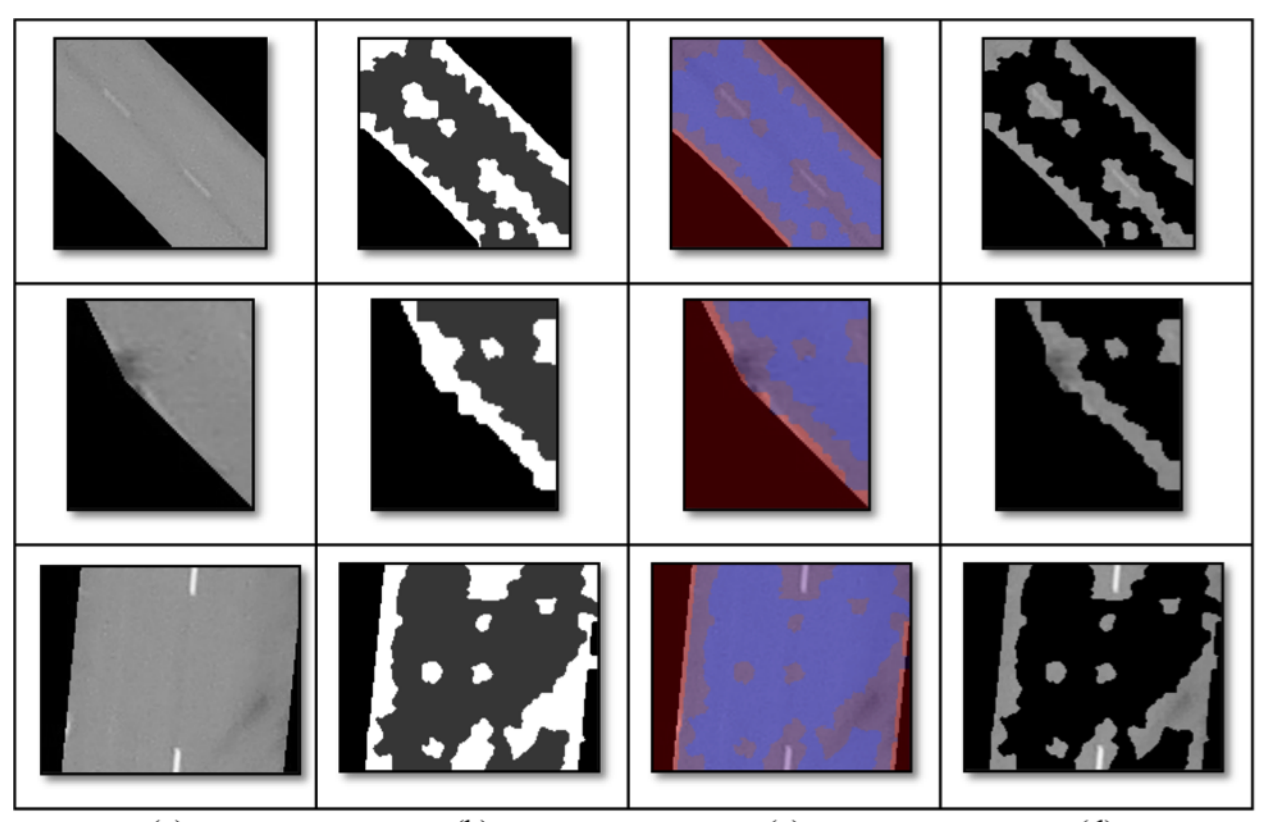

(a) (b) (c) (d)

Figura 5.7 - Resultados do processamento da classificação de defeitos em diferente trechos de pavimentos do E1. a) imagem original b) máscara gerada automaticamente com os defeitos em branco. c) imagem com sobreposição destacando as áreas sem defeitos em azul. d) imagem final apenas com as regiões com defeitos detectadas.

Partindo-se da detecção e da classificação das áreas com defeito no pavimento, é possível realizar a última etapa da MANIAC, a identificação dos tipos de defeitos. Na Figura 5.8a são ilustradas as imagens originais onde os defeitos foram previamente encontrados. Na Figura $5.8 \mathrm{~b}$ os defeitos são destacados para serem identificados. Por meio da identificação dos tipos de defeitos, os mesmo são apresentados nas Figuras 5.8c, 5.8d e 5.8e respectivamente, em que são identificados os defeitos do tipo Fenda para a primeira imagem, Remendo para a segunda e terceira imagens, não sendo encontrado o tipo de defeito Panela para nenhuma das imagens ilustradas. 


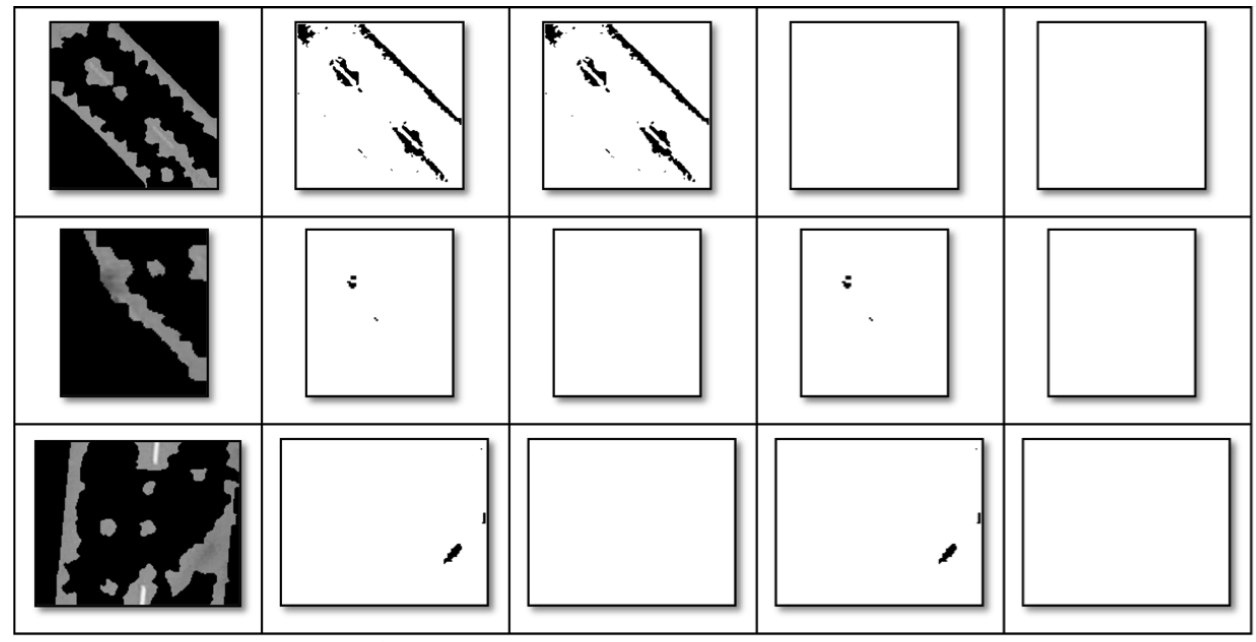

(a)

(b)

(c)

(d)

(e)

Figura 5.8 - Processamento dos tipos defeitos no pavimento das imagens obtidas no E1. a) imagem classificada com os defeitos. b) imagem com os defeitos destacados em preto. c) imagem com os defeitos do tipo Fenda destacados em preto. d) imagem com os defeitos do tipo Remendo destacados em preto. e) defeitos do tipo Panela não foram encontrados nessas imagens.

A acurácia da detecção dos defeitos encontrados no pavimento para o E1 é demonstrada por meio da matriz de confusão ilustrada na Figura 5.9.

É possível observar por meio da matriz de confusão que no E1 que o resultado das métricas de desempenho e da F-measure são positivas. Tem-se uma acurácia de $82 \%$ para a detecção de defeitos e uma precisão de $78 \%$. Resultados apresentados na literatura para a detecção de defeitos oscilam entre $77 \%$ e $80 \%$, sendo o melhor resultado apresentado somente para o tipo de defeito Fenda. Neste experimento obteve-se a ocorrência de dois tipos de defeitos Remendo e Fenda, de modo que pode-se afirmar que a acurácia obtida foi muito boa.

\begin{tabular}{|rrrr|}
\hline True Positive & False Negative & Accuracy & Precision \\
$\mathbf{1 3 6 2}$ & $\mathbf{9 6}$ & $\mathbf{0 . 8 2}$ & $\mathbf{0 . 7 8}$ \\
& & & \\
False Positive & True Negative & Recall & F1 Score \\
$\mathbf{2 0 0}$ & $\mathbf{1 7}$ & $\mathbf{0 . 8 2}$ & $\mathbf{0 . 8 0}$ \\
\hline
\end{tabular}

Figura 5.9 - Matriz de confusão e outras medidas de avaliação do algoritmo de AM aplicado ao Experimento 1 (E1) na detecção de defeito no pavimento.

Partes dos resultados obtidos no Relatório de Defeitos gerado para o experimento 1 (E1) são ilustradas nas Figuras 5.10 e 5.11.

O Índice de Gravidade Global calculado para o experimento 1 (E1) foi de 4,00 correspondente ao conceito "Ótimo"(DNIT 06/2003) ou "Bom"(DNER 08/1994). Isso implica em possuir um pavimento de boas ou ótimas condições, mesmo apresentando alguns defeitos.

O Índice de Gravidade Global Expedito calculado para o experimento 1 (E1) foi de 6,00 variando entre um conceito "Ótimo"e "Bom"dependendo do valor atribuído para o ICPF. De modo 


\begin{tabular}{|c|c|c|c|c|c|c|c|c|c|c|}
\hline nome do segmento & Ind. Trinca & Ind. Remendo & Ind. Panela & fp. Trinca & fp Remendo & fp Panela & IGI' Trinca & IGI' Remendo & IGI' Panela & IGG' $^{\prime}$ \\
\hline IMG_0340_seg_ind_407.png & 0.000039 & 0.000847 & 0.000000 & 0.8 & 0.6 & 1.0 & 0.000031 & 0.000508 & 0.000000 & 0.000539 \\
\hline IMG_0340_seg_ind_411.png & 0.000923 & 0.015615 & 0.000000 & 0.8 & 0.6 & 1.0 & 0.000738 & 0.009369 & 0.000000 & 0.010107 \\
\hline IMG_0340_seg_ind_413.png & 0.000000 & 0.001572 & 0.000000 & 0.8 & 0.6 & 1.0 & 0.000000 & 0.000943 & 0.000000 & 0.000943 \\
\hline IMG_0340_seg_ind_441.png & 0.000789 & 0.001776 & 0.000000 & 0.8 & 0.6 & 1.0 & 0.000631 & 0.001065 & 0.000000 & 0.001697 \\
\hline IMG_0340_seg_ind_446.png & 0.015081 & 0.006549 & 0.000000 & 0.8 & 0.6 & 1.0 & 0.012065 & 0.003929 & 0.000000 & 0.015994 \\
\hline IMG_0340_seg_ind_447.png & 0.019378 & 0.000785 & 0.000000 & 0.8 & 0.6 & 1.0 & 0.015502 & 0.000471 & 0.000000 & 0.015973 \\
\hline IMG_0340_seg_ind_45.png & 0.000426 & 0.012027 & 0.000000 & 0.8 & 0.6 & 1.0 & 0.000341 & 0.007216 & 0.000000 & 0.007557 \\
\hline IMG_0340_seg_ind_470.png & 0.000052 & 0.039820 & 0.000000 & 0.8 & 0.6 & 1.0 & 0.000041 & 0.023892 & 0.000000 & 0.023933 \\
\hline IMG_0340_seg_ind_485.png & 0.022194 & 0.001793 & 0.000000 & 0.8 & 0.6 & 1.0 & 0.017755 & 0.001076 & 0.000000 & 0.018831 \\
\hline
\end{tabular}

Figura 5.10 - Listagem parcial do cálculo do IGI' e do IGG' a partir das imagens obtidas no E1.

\begin{tabular}{cccccccc}
\hline nome do segmento & Ind. Trinca & Ind. Remendo & Ind. Panela & Pt Trinca & Ppr Remendo & Ppr Panela & IGGE' \\
\hline IMG_0340_seg_ind_407.png & 0.000039 & 0.000847 & 0.000000 & 0.3 & 0.8 & 0.7 & 0.0006890 \\
\hline IMG_0340_seg_ind_411.png & 0.000923 & 0.015615 & 0.000000 & 0.3 & 1.0 & 0.7 & 0.0158910 \\
IMG_0340_seg_ind_413.png & 0.000000 & 0.001572 & 0.000000 & 0.3 & 1.0 & 0.7 & 0.0015720 \\
\hline IMG_0340_seg_ind_441.png & 0.000789 & 0.001776 & 0.000000 & 0.3 & 1.0 & 0.7 & 0.0020120 \\
IMG_0340_seg_ind_446.png & 0.015081 & 0.006549 & 0.000000 & 0.3 & 1.0 & 0.7 & 0.0110730 \\
IMG_0340_seg_ind_447.png & 0.019378 & 0.000785 & 0.000000 & 0.3 & 1.0 & 0.7 & 0.0065980 \\
IMG_0340_seg_ind_45.png & 0.000426 & 0.012027 & 0.000000 & 0.3 & 1.0 & 0.7 & 0.0121550 \\
IMG_0340_seg_ind_470.png & 0.000052 & 0.039820 & 0.000000 & 0.3 & 1.0 & 0.7 & 0.0398350 \\
IMG_0340_seg_ind_485.png & 0.022194 & 0.001793 & 0.000000 & 0.3 & 1.0 & 0.7 & 0.0084510 \\
\hline
\end{tabular}

Figura 5.11 - Listagem parcial do cálculo do IGGE’ a partir das imagens obtidas no E1.

análogo ao IGG, o resultado implica na obtenção de um pavimento em boas condições mesmo apresentando uma série de defeitos. Uma das vantagens da metodologia é permitir que o especialista verifique os tipos de defeitos e a localização dos mesmos, fazendo assim um diagnóstico mais eficiente da situação do pavimento monitorado/analisado.

\subsection{Experimento em área povoada}

\subsubsection{A missão - obtenção das imagens}

O segundo experimento (E2) foi realizado na área localizada no município de São Carlos, perfazendo uma área de $0,59 \mathrm{~km}^{2}$. Na Figura 5.12 é ilustrada a tela dessa missão.

O voo foi realizado no dia 22 de fevereiro de 2014. A duração da missão foi de 15 minutos tendo sido obtidas 118 imagens. Na Figura 5.13 é ilustrado um mosaico georeferenciado gerado a partir das 118 imagens aéreas obtidas pelo VANT eBee após o tempo de 8 horas de pósprocessamento.

$\mathrm{O}$ arquivo digital do mosaico gerado possui as seguintes propriedades:

- Tamanho do Arquivo: Largura de 20.256 pixel; Altura de 21.192 pixel (1,36 GB);

- Resolução Espacial (Tamanho do pixel): $3.36 \mathrm{~cm} / \mathrm{pixel}$;

- Sistema de Coordenadas/Projeção: WGS 84/UTM zona 23S;

- Coordenadas Geodésicas:

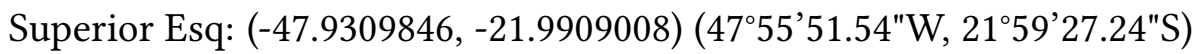




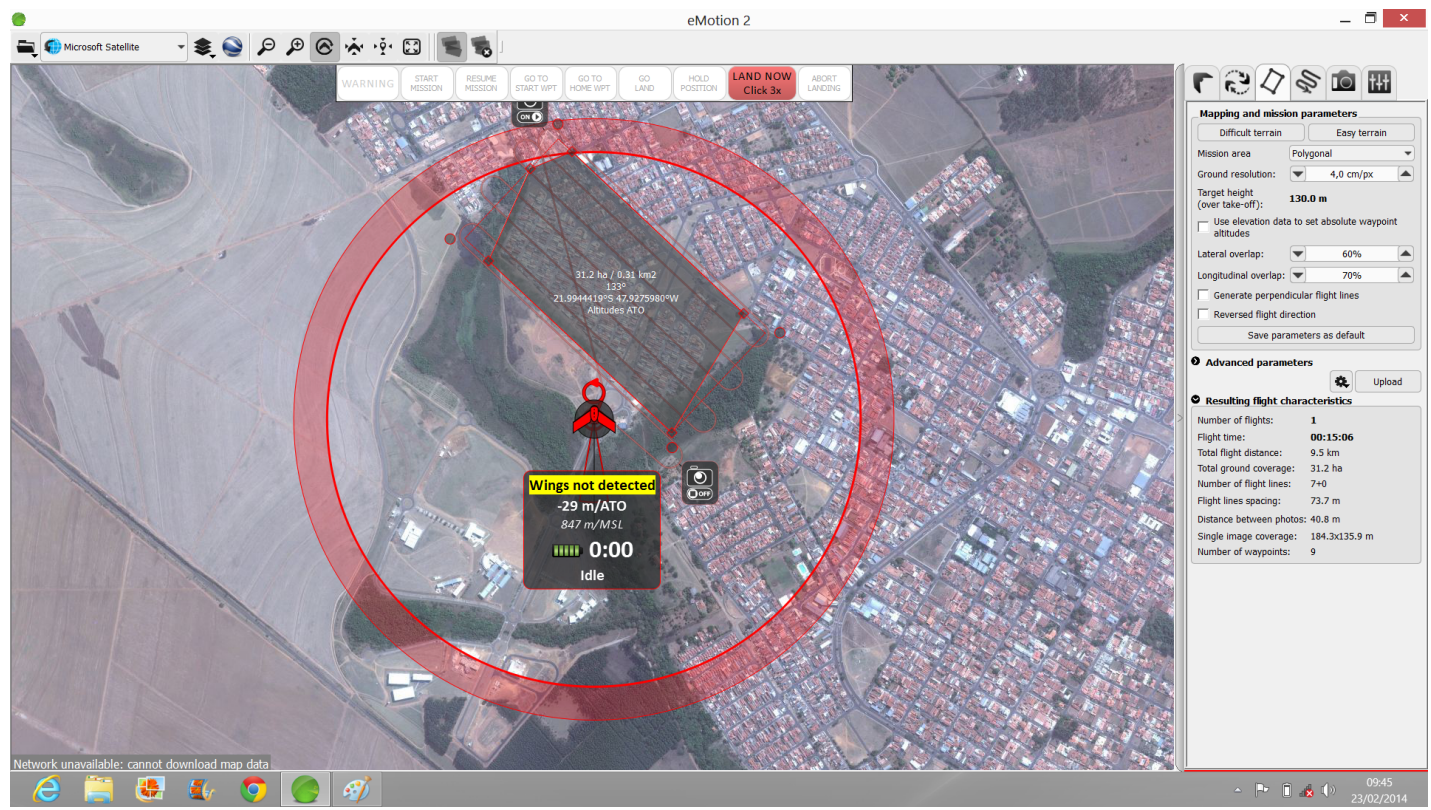

Figura 5.12 - Tela da execução da missão do Experimento 2 (E2).

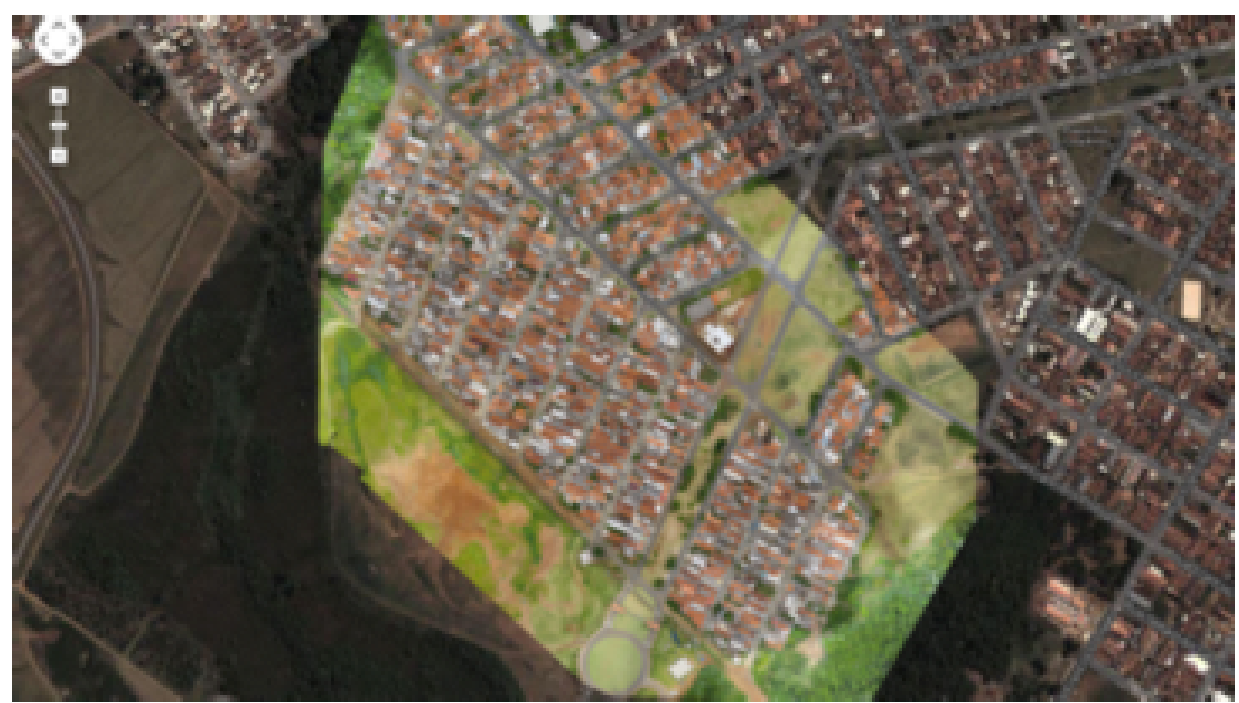

Figura 5.13 - Mosaico gerado a partir da imagens obtidas pelo VANT sobreposto pela imagem de satélite do GoogleMaps - Experimento 2 (E2).

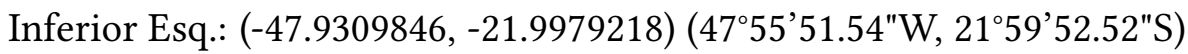

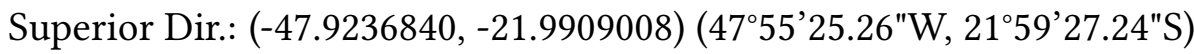

Inferior Dir.: (-47.9236840, -21.9909008) (4755’25.26"W, 2159’27.24"S)

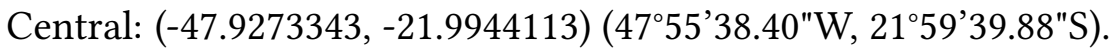

É possível observar pelo mosaico apresentado que a área em questão é densamente povoada, apresentando além do pavimento muitas construções. Esse tipo de experimento permite validar a efetividade a MANIAC em áreas onde há presença de diferentes tipos de objetos, o que caracteriza uma área de maior dificuldade para identificação não só do pavimento mas também dos tipos de defeitos presentes neste pavimento. 
A partir da obtenção das imagens inicia-se o processo de detecção de defeitos em pavimentos asfálticos flexíveis por meio da MANIAC.

\subsubsection{Pré-Processar}

A primeira etapa é a de pré-processamento, realizada a partir da base de imagens obtidas com a execução da missão. Na Figura 5.14 é ilustrado o processo.

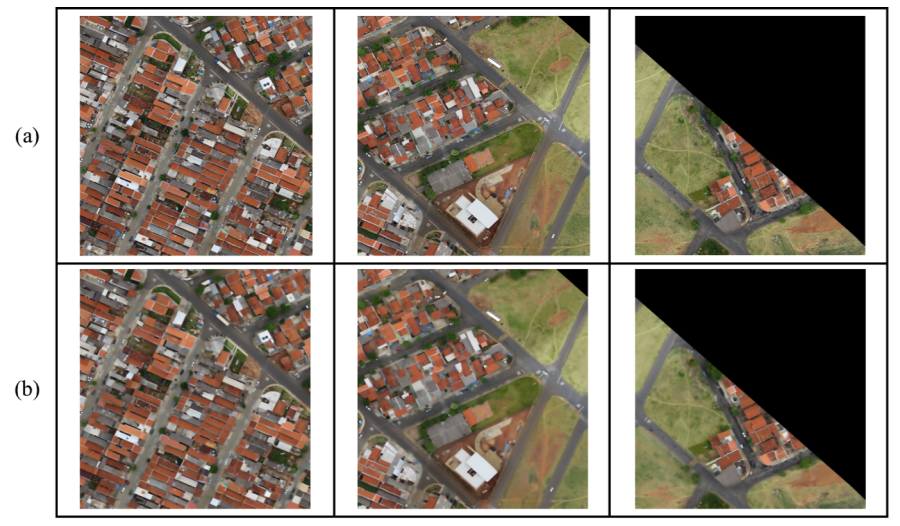

Figura 5.14 - Pré-processamento das imagens obtidas para o Experimento 2 (E2). (a) Imagens originais; (b) Imagens pré-processadas fazendo uso do filtro bilateral.

Na Figura 5.14a são ilustradas as imagens originais, e na Figura 5.14b, como pode ser observado, foi utilizado o filtro Bilateral onde os ruídos são minimizados e as bordas das imagens realçadas. De modo análogo ao primeiro experimento, as imagens obtidas nesse processo servem de entrada para o próximo processo da metodologia.

\subsubsection{Detectar asfalto}

A etapa Detectar asfalto é realizada por meio da submissão as imagens obtidas e já préprocessadas ao classificador previamente treinado.

Como parte do processo, objetivando melhorar o tempo de processamento das imagens (devido ao grande tamanho do arquivo do mosaico), o arquivo digital com aproximadamente 1,36 GB foi particionado em 20 arquivos (com uma grade de 5x4) como ilustrado na Figura 5.15.

O novo conjunto de 20 imagens (no caso deste experimento) é gerado com tamanho de 5216 (largura) por 5424 (altura) pixels, isto é, aproximadamente 9.3MB para cada imagem.

Para essa missão do (E2) o tempo de processamento para a fase de detecção do pavimento para cada imagem foi de 5 minutos de processamento no equipamento já mencionado.

Parte do pavimento asfáltico detectado é ilustrado na Figura 5.16.

A acurácia da detecção do pavimento asfáltico para o E2 é demonstrada por meio da matriz de confusão ilustrada na Figura 5.17. 


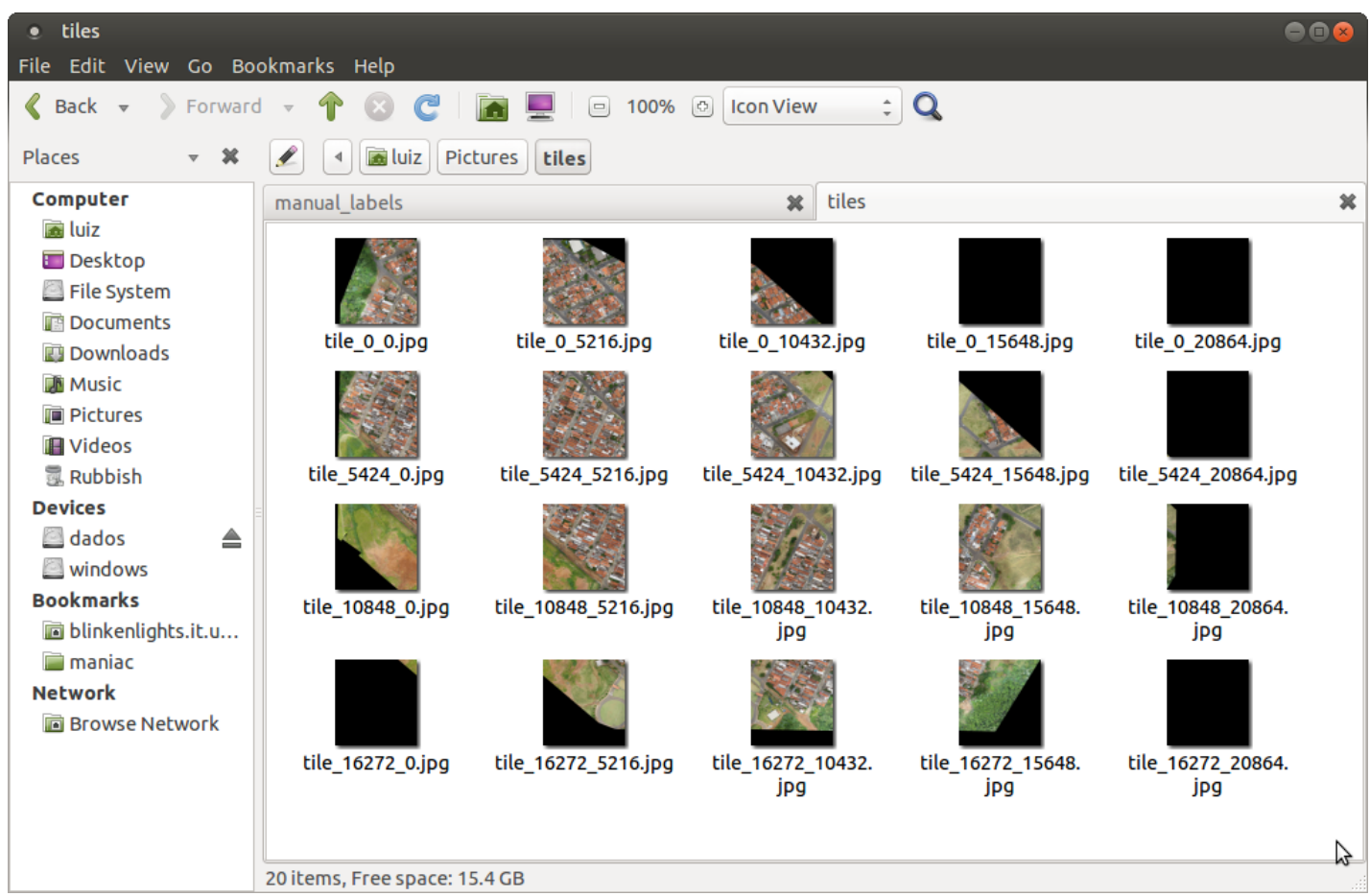

Figura 5.15 - Particionamento do arquivo digital do mosaico do Experimento 2 (E2).

Observa-se por meio da matriz de confusão que no E2 os resultados das métricas de desempenho apresentadas e da $F$-measure são positivos. Tem-se uma acurácia de $97 \%$ para a detecção do pavimento asfáltico.

Apesar de ser menor quando comparada à acurácia do E1, os valores obtidos podem ser considerados muito bons, uma vez que esse experimentos é bastante representativo, pois o pavimento é detectado com esse grau de acurácia mesmo estando rodeado por diferentes tipos de construções e estar localizado em uma área povoada. Sendo assim, é possível afirmar que a identificação em áreas povoadas (E2) fazendo uso dos algoritmos de Aprendizado de Máquina supervisionado foi realizada com êxito.

\subsubsection{Identificar defeitos}

Uma vez detectados e obtidos os pavimentos asfálticos, a próxima etapa consiste na definição do pavimento defeituoso, e posteriormente a identificação dos defeitos existentes no mesmo.

Na Figura 5.18a são ilustrados três trechos distintos de pavimentos detectados no E2. Por meio do uso de um classificador treinado é feita a identificação das regiões que apresentam defeitos no pavimento, sendo então gerada uma máscara com os defeitos em branco (Figura 5.18b). Na Figura 5.18c são ilustradas as sobreposições da máscara, permitindo-se assim que os defeitos sejam destacados, e por fim na Figura 5.18d são ilustradas as imagens onde os defeitos são destacados.

Partindo-se da detecção e da classificação das áreas com defeito no pavimento, é possível realizar a última etapa da MANIAC, a identificação dos tipos de defeitos propriamente ditos. 
(a)

(b)

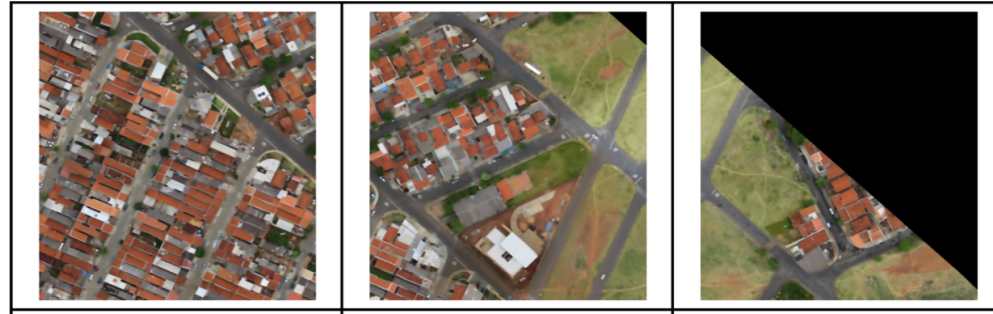

(c)

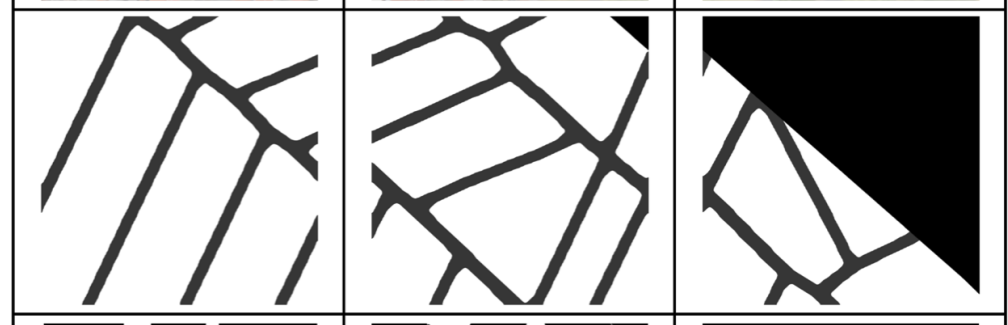

(d)
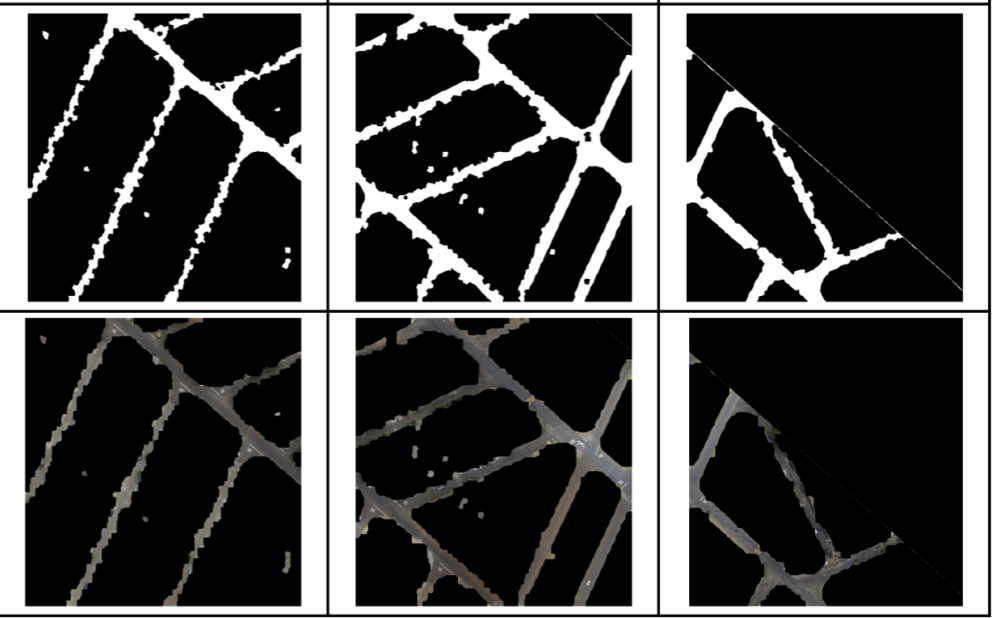

Figura 5.16 - Pavimento asfáltico detectado para diferentes imagens obtidas no Experimento 2 (E2).

\begin{tabular}{|rrrr|}
\hline True Positive & False Negative & Accuracy & Precision \\
6784 & 67 & 0.97 & 0.98 \\
& & & \\
False Positive & True Negative & Recall & F1 Score \\
118 & 1525 & 0.98 & 0.98 \\
\hline
\end{tabular}

Figura 5.17 - Matriz de confusão e acurácia do Experimento 2 (E2) para a detecção de pavimento.

Na Figura 5.19a são ilustradas as imagens originais onde os defeitos foram previamente encontrados. Na Figura 5.19b os defeitos são destacados para serem identificados. Por meio da identificação dos defeitos, os mesmo são apresentados nas Figuras 5.19c, 5.19d e 5.19e respectivamente, em que são identificados os defeitos do tipo Fenda, Remendo e Panela.

A acurácia da detecção dos defeitos no pavimento para o E2 é demonstrada por meio da matriz de confusão ilustrada na Figura 5.20.

É possível observar por meio não só da matriz mas do resultado das métricas de desempenho e da F-measure que os resultados são positivos. Tem-se uma acurácia de $97 \%$ e uma precisão de $98 \%$ para a detecção de defeitos asfáltico. Os defeitos apresentados são do tipo Fenda e 


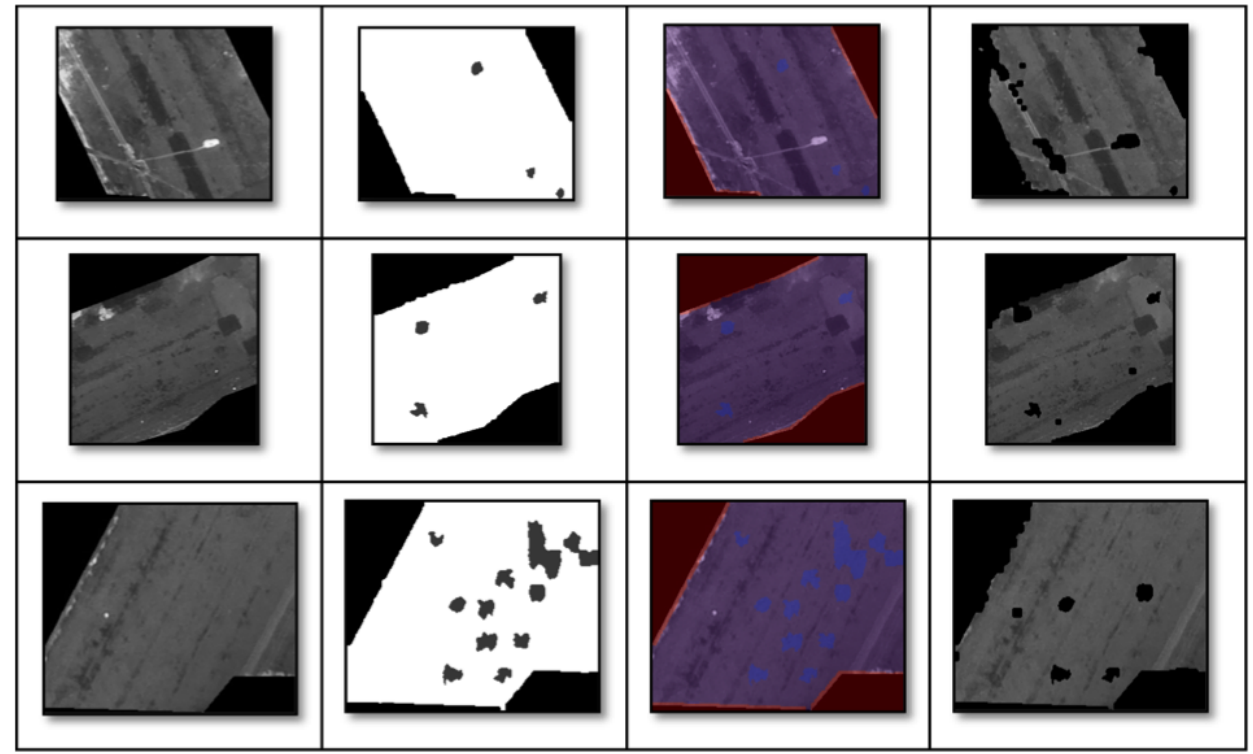

(a)

(b)

(c)

(d)

Figura 5.18 - Resultados do processamento da classificação de defeitos em diferente trechos de pavimentos do E2. a) imagem original b) máscara gerada automaticamente com as partes com defeitos na cor branca. c) imagem com sobreposição destacando as áreas sem defeitos em azul. d) imagem final apenas com as regiões com defeitos detectadas.

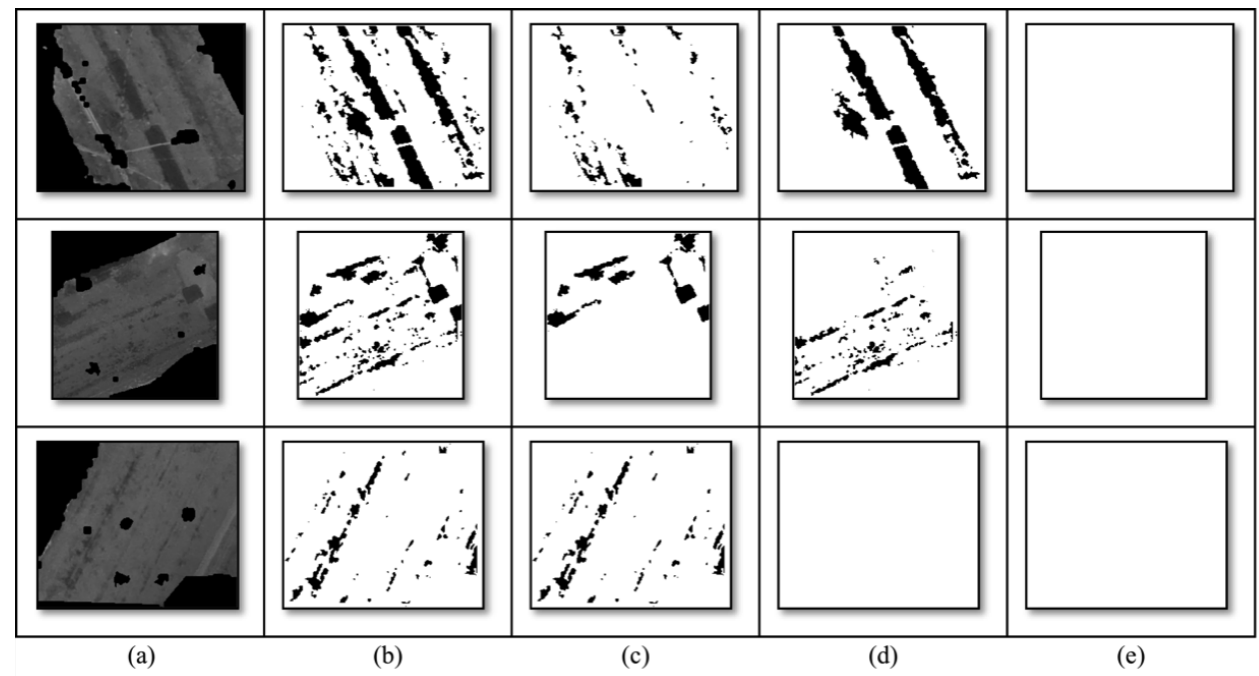

Figura 5.19 - Processamento dos tipos defeitos no pavimento das imagens obtidas no E2. a) imagem classificada com os defeitos. b) imagem com os defeitos destacados em preto. c) imagem com os defeitos do tipo Fenda destacados em preto. d) imagem com os defeitos do tipo Remendo destacados em preto. e) defeitos do tipo Panela não foram encontrados nessas imagens.

\section{Remendo.}

Partes dos resultados obtidos no Relatório de Defeitos que foi gerado para o experimento 2 (E2) são ilustradas nas Figuras 5.21 e 5.22.

O Índice de Gravidade Global calculado para o experimento 2 (E2) foi de 21,00 correspondente ao conceito "Bom"(DNIT 06/2003) ou "Regular"(DNER 08/1994). Isso implica em possuir um pavimento em condições regulares à boa, uma vez que muitos são os defeitos apresentados.

O Índice de Gravidade Global Expedito calculado para o experimento 2 (E2) foi de 34,00 va- 


\begin{tabular}{|rrrr|}
\hline True Positive & False Negative & Accuracy & Precision \\
11 & 43 & 0.92 & 0.91 \\
False Positive & True Negative & Recall & F1 Score \\
12 & $\mathbf{7 1 0}$ & $\mathbf{0 . 9 3}$ & $\mathbf{0 . 9 2}$ \\
\hline
\end{tabular}

Figura 5.20 - Matriz de confusão e outras medidas de avaliação do algoritmo de AM aplicado ao Experimento 2 (E2) na detecção de defeito no pavimento.

\begin{tabular}{|c|c|c|c|c|c|c|c|c|c|c|}
\hline nome do segmento & Ind. Trinca & Ind. Remendo & Ind. Panela & fp. Trinca & fp Remendo & fp Panela & IGI' Trinca & IGI' Remendo & IGI' Panela & IGG' $^{\prime}$ \\
\hline tile_5424_0_seg_ind_684.png & 0.000000 & 0.012234 & 0.000000 & 0.8 & 0.6 & 1.0 & 0.000000 & 0.007340 & 0.000000 & 0.007340 \\
\hline tile 54240 seg ind $685 . \mathrm{png}$ & 0.000000 & 0.009532 & 0.000000 & 0.8 & 0.6 & 1.0 & 0.000000 & 0.005719 & 0.000000 & 0.005719 \\
\hline tile_5424_0_seg_ind_686.png & 0.000076 & 0.094765 & 0.000000 & 0.8 & 0.6 & 1.0 & 0.000061 & 0.056859 & 0.000000 & 0.056919 \\
\hline tile_5424_0_seg_ind_69.png & 0.000041 & 0.008801 & 0.000000 & 0.8 & 0.6 & 1.0 & 0.000033 & 0.005281 & 0.000000 & 0.005314 \\
\hline tile_5424_0_seg_ind_713.png & 0.000000 & 0.002594 & 0.000000 & 0.8 & 0.6 & 1.0 & 0.000000 & 0.001556 & 0.000000 & 0.001556 \\
\hline tile_5424_0_seg_ind_714.png & 0.000063 & 0.029657 & 0.000000 & 0.8 & 0.6 & 1.0 & 0.000051 & 0.017794 & 0.000000 & 0.017845 \\
\hline tile_5424_0_seg_ind_715.png & 0.000000 & 0.006793 & 0.000000 & 0.8 & 0.6 & 1.0 & 0.000000 & 0.004076 & 0.000000 & 0.004076 \\
\hline tile_5424_0_seg_ind_745.png & 0.000043 & 0.036372 & 0.000000 & 0.8 & 0.6 & 1.0 & 0.000035 & 0.021823 & 0.000000 & 0.021858 \\
\hline tile_5424_0_seg_ind_748.png & 0.000013 & 0.009163 & 0.000000 & 0.8 & 0.6 & 1.0 & 0.000010 & 0.005498 & 0.000000 & 0.005508 \\
\hline
\end{tabular}

Figura 5.21 - Listagem parcial do cálculo do IGI' e do IGG' a partir das imagens obtidas no E2.

\begin{tabular}{|c|c|c|c|c|c|c|c|}
\hline nome do segmento & Ind. Trinca & Ind. Remendo & Ind. Panela & Pt Trinca & Ppr Remendo & Ppr Panela & IGGE' \\
\hline tile_5424_0_seg_ind_684.png & 0.000000 & 0.012234 & 0.000000 & 0.3 & 1.0 & 0.7 & 0.0122340 \\
\hline tile_5424_0_seg_ind_685.png & 0.000000 & 0.009532 & 0.000000 & 0.3 & 1.0 & 0.7 & 0.0095320 \\
\hline tile_5424_0_seg_ind_686.png & 0.000076 & 0.094765 & 0.000000 & 0.3 & 1.0 & 0.7 & 0.0947870 \\
\hline tile_5424_0_seg_ind_69.png & 0.000041 & 0.008801 & 0.000000 & 0.3 & 1.0 & 0.7 & 0.0088140 \\
\hline tile_5424_0_seg_ind_713.png & 0.000000 & 0.002594 & 0.000000 & 0.3 & 1.0 & 0.7 & 0.0025940 \\
\hline tile_5424_0_seg_ind_714.png & 0.000063 & 0.029657 & 0.000000 & 0.3 & 1.0 & 0.7 & 0.0296760 \\
\hline tile_5424_0_seg_ind_715.png & 0.000000 & 0.006793 & 0.000000 & 0.3 & 1.0 & 0.7 & 0.0067930 \\
\hline tile_5424_0_seg_ind_745.png & 0.000043 & 0.036372 & 0.000000 & 0.3 & 1.0 & 0.7 & 0.0363850 \\
\hline tile_5424_0_seg_ind_748.png & 0.000013 & 0.009163 & 0.000000 & 0.3 & 1.0 & 0.7 & 0.0091670 \\
\hline
\end{tabular}

Figura 5.22 - Listagem parcial do cálculo do IGGE’ a partir das imagens obtidas no E2.

riando entre um conceito "Bom"e "Regular"dependendo do valor atribuído para o ICPF. Analogamente ao IGG, o resultado obtido implica em possuir um pavimento em condições regulares à boa.

\subsection{Experimento em rodovia}

\subsubsection{A missão - obtenção das imagens}

O terceiro experimento (E3) foi realizado na área localizada no município de Pardinho, perfazendo uma área de $1,52 \mathrm{~km}^{2}$.

O voo foi realizado em 18 de outubro de 2014. A duração da missão foi de 16 minutos tendo sido obtidas 113 imagens. Após o tempo de 6 horas de pós-processamento o arquivo digital do mosaico foi gerado contendo as seguintes propriedades:

- Tamanho do Arquivo: Largura de 14.844 pixel; Altura de 12.461 pixel (384,9 MB);

- Resolução Espacial (Tamanho do pixel): 8,49 cm/pixel; 
- Sistema de Coordenadas/Projeção: WGS 84/UTM zona 23S;

\section{- Coordenadas Geodésicas:}

Superior Esq: (-48.5038768, -23.0139617) (48³0’13.96"W, 230’50.26"S)

Inferior Esq.: (-48.5038768, -23.0245452) (48³0’13.96"W, 231'ㄹ.36"S)

Superior Dir.: (-48.4912693, -23.0139617) (48²9’28.57"W, 23050.26"S)

Inferior Dir.: (-48.4912693, -23.0245452) (48²9'28.57"W, 23¹'28.36"S)

Central: (-48.4975731, -23.0192534) (48²9’51.26"W, 231'9.31"S).

Na Figura 5.23 é ilustrado o mosaico georeferenciado gerado a partir de todas as imagens aéreas obtidas pelo VANT eBee.

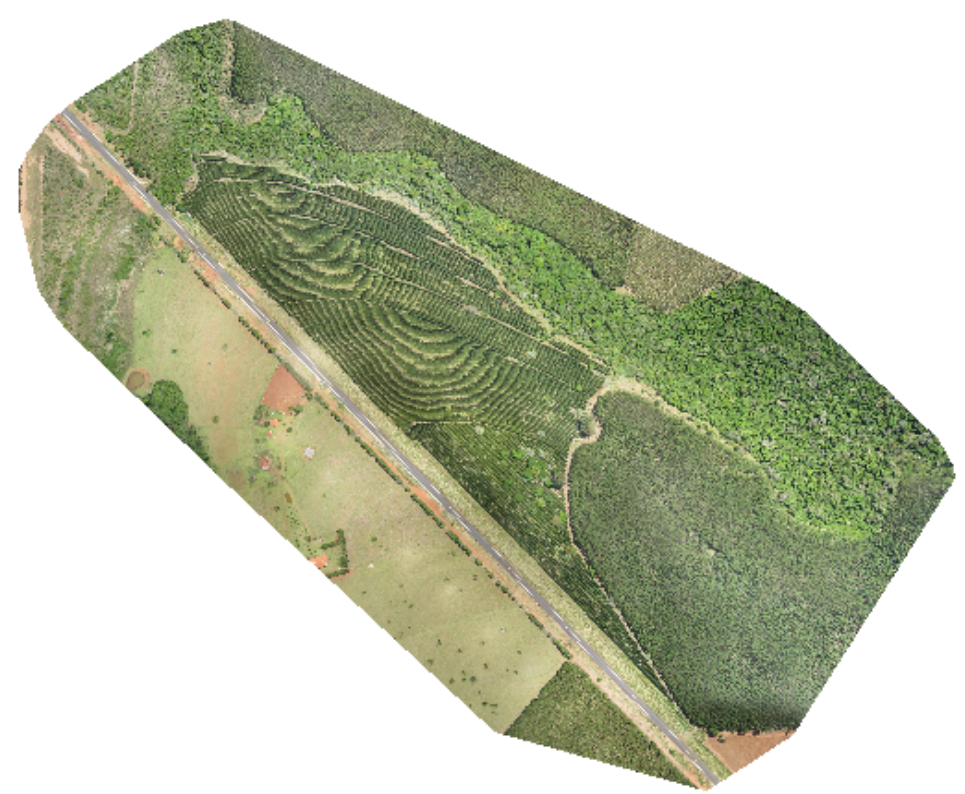

Figura 5.23 - Mosaico gerado a partir da imagens obtidas pelo VANT - Experimento 3 (E3).

É possível observar pelo mosaico apresentado que a área em questão não é densamente povoada, apresentando apenas a rodovia margeada por área rural. Esse experimento permite validar a efetividade a MANIAC nos mais diferentes tipos de ambientes nos quais o pavimento asfáltico está presente.

A partir da obtenção das imagens inicia-se o processo de detecção de defeitos em pavimentos asfálticos flexíveis por meio da MANIAC.

\subsubsection{Pré-Processar}

De modo análogo aos experimentos E1 e E2, primeira etapa da metodologia consiste no processo Pré-Processar que realiza o pré-processamento das imagens obtidas com a execução da missão. Na Figura 5.24 é ilustrado o processo.

Na Figura 5.24a são ilustradas as imagens originais, enquanto na Figura 5.24b, como pode ser observado, são ilustradas as imagens a partir da aplicação do filtro Bilateral onde os ruídos são 


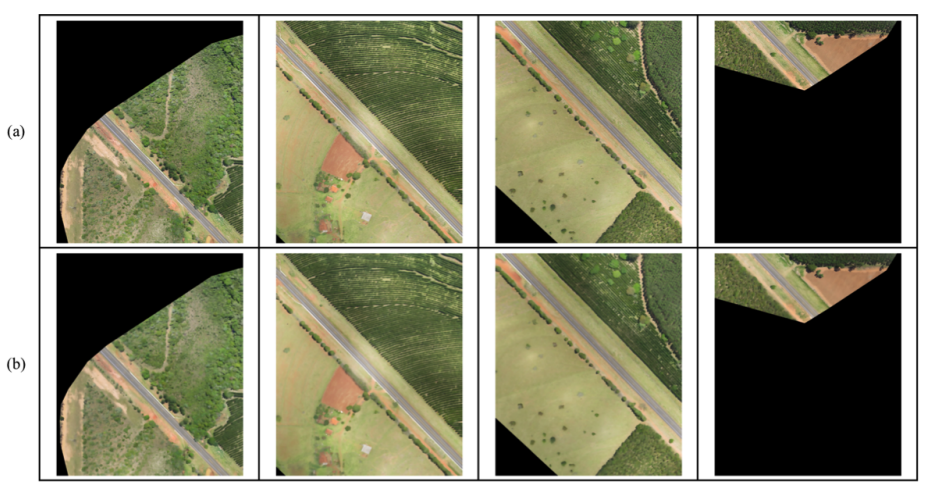

Figura 5.24 - Pré-processamento das imagens obtidas para o Experimento 3 (E3).

minimizados e as bordas das imagens realçadas. De modo análogo aos demais experimentos (E1 e E2), as imagens obtidas nesse processo servem de entrada para o próximo processo da metodologia.

\subsubsection{Detectar asfalto}

A etapa Detectar asfalto é realizada por meio da submissão as imagens obtidas e já préprocessadas ao classificador previamente treinado.

Como parte do processo, objetivando melhorar o tempo de processamento das imagens (devido ao grande tamanho do arquivo do mosaico), o arquivo digital com aproximadamente 385 MB foi particionado em 20 arquivos (com uma grade de 5x4) como ilustrado na Figura 5.25.

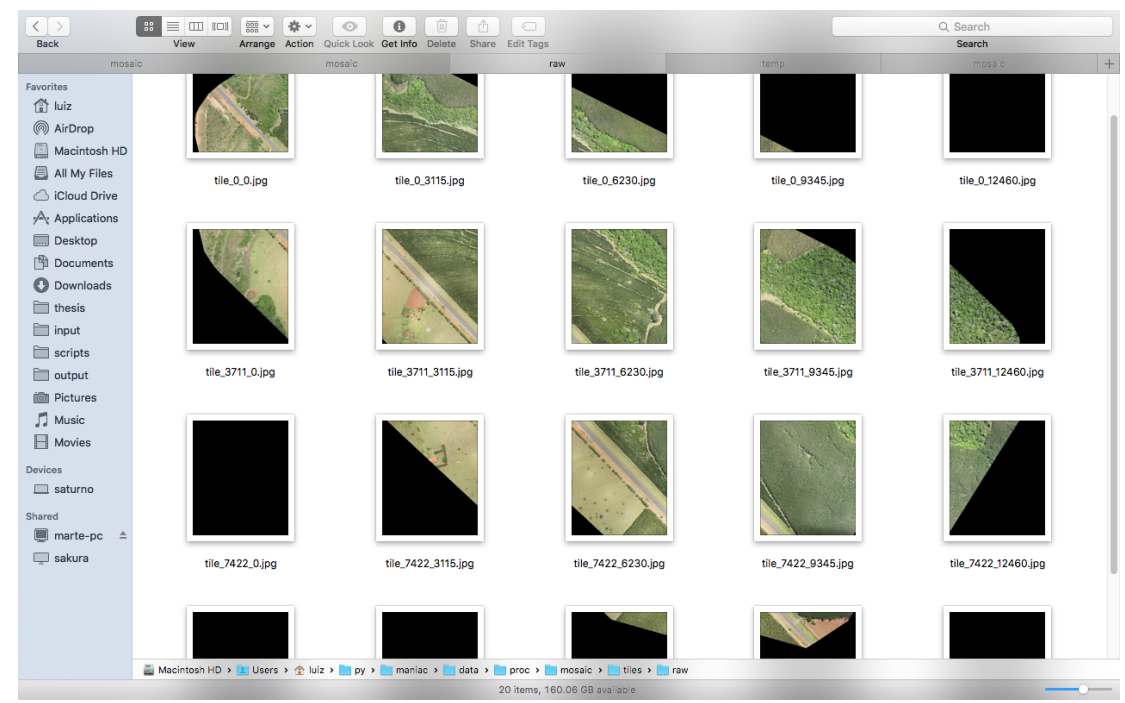

Figura 5.25 - Particionamento do arquivo digital do mosaico do Experimento 3 (E3).

O novo conjunto de 20 imagens (no caso deste experimento) é gerado com tamanho de 3115 (largura) por 3711 (altura) pixels, isto é, aproximadamente 5.7MB para cada imagem.

Para essa missão do (E3) o tempo de processamento para a fase de detecção do pavimento para cada imagem foi de 3 minutos de processamento no equipamento previamente mencio- 
nado.

Parte do pavimento asfáltico detectado é ilustrado na Figura 5.26.

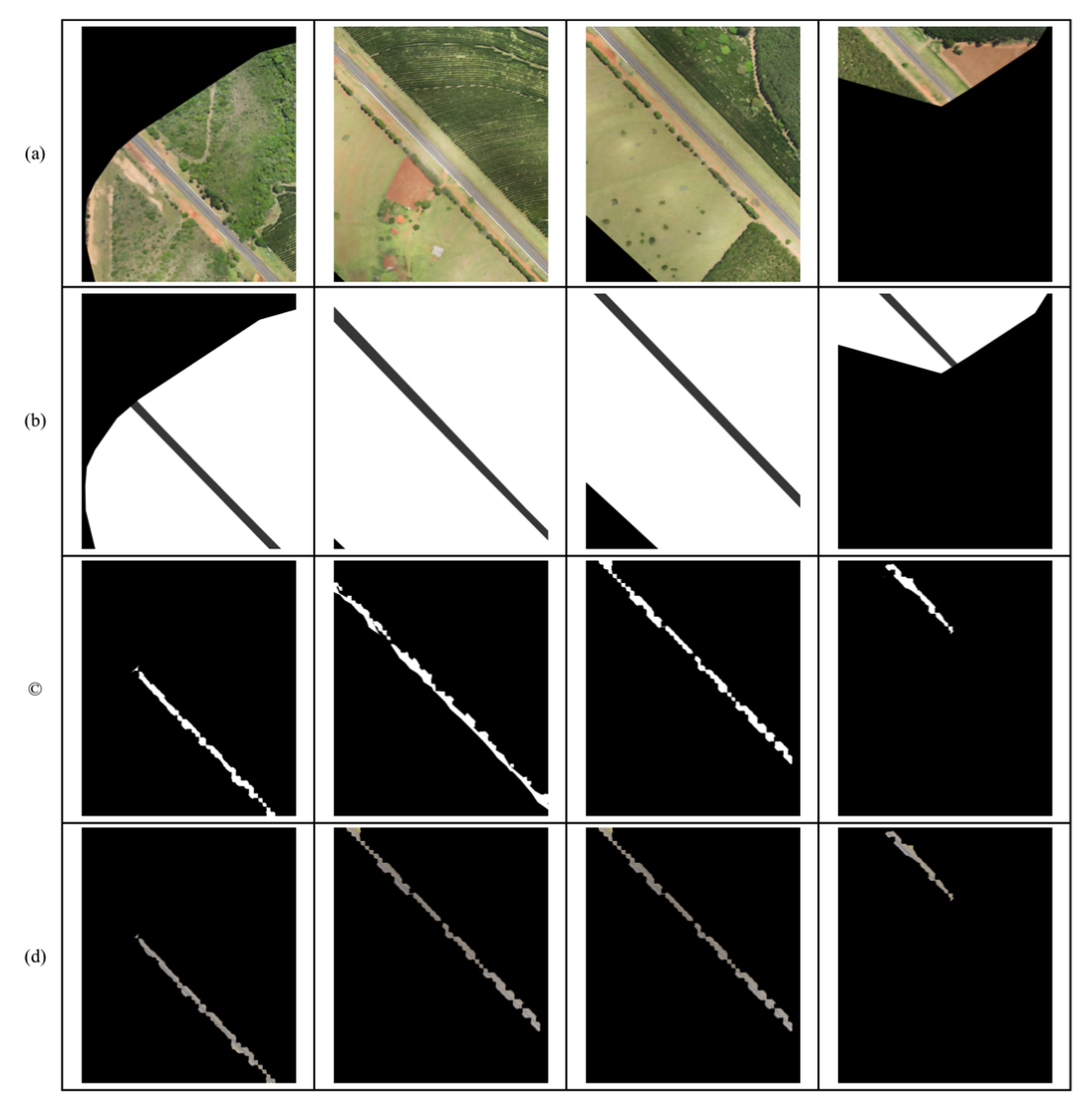

Figura 5.26 - Pavimento asfáltico detectado para o Experimento 3 (E3).

A acurácia da detecção do pavimento asfáltico é demonstrada por meio da matriz de confusão ilustrada na Figura 5.27.

\begin{tabular}{|rrrr|}
\hline True Positive & False Negative & Accuracy & Precision \\
$\mathbf{5 4 6 7}$ & $\mathbf{5}$ & $\mathbf{0 . 9 9}$ & $\mathbf{0 . 9 9}$ \\
& & & \\
False Positive & True Negative & Recall & F1 Score \\
$\mathbf{2 9}$ & $\mathbf{1 7 6}$ & $\mathbf{0 . 9 9}$ & $\mathbf{0 . 9 9}$ \\
\hline
\end{tabular}

Figura 5.27 - Matriz de confusão e acurácia do Experimento 3 (E3) para a detecção de pavimento.

É possível verificar por meio da matriz de confusão que no E3 os resultado das métricas de desempenho apresentadas e da F-measure são positivos. Tem-se uma acurácia ainda melhor que as apresentadas no E1 e E2. Isso se deve ao fato do asfalto a ser detectado encontrarse em uma região com elementos mais homogêneos (áea rural ou com apenas vegetação), demonstrando que a técnica utilizada é efetiva. A acurácia foi de $99 \%$. 


\subsubsection{Identificar defeitos}

Uma vez detectados e obtidos os pavimentos asfálticos, a próxima etapa consiste na definição do pavimento defeituoso, e posteriormente a identificação do tipo de defeito do mesmo.

Na Figura 5.28a são ilustrados três trechos distintos de pavimentos detectados no E3. Por meio do uso de um classificador treinado é feita a identificação das regiões que apresentam defeitos no pavimento, sendo então gerada uma máscara com os defeitos em branco (Figura 5.28b). Na Figura 5.28c são ilustradas as sobreposições da máscara, permitindo-se assim que os defeitos sejam destacados, e por fim na Figura 5.28d são ilustradas as imagens onde os defeitos são destacados.

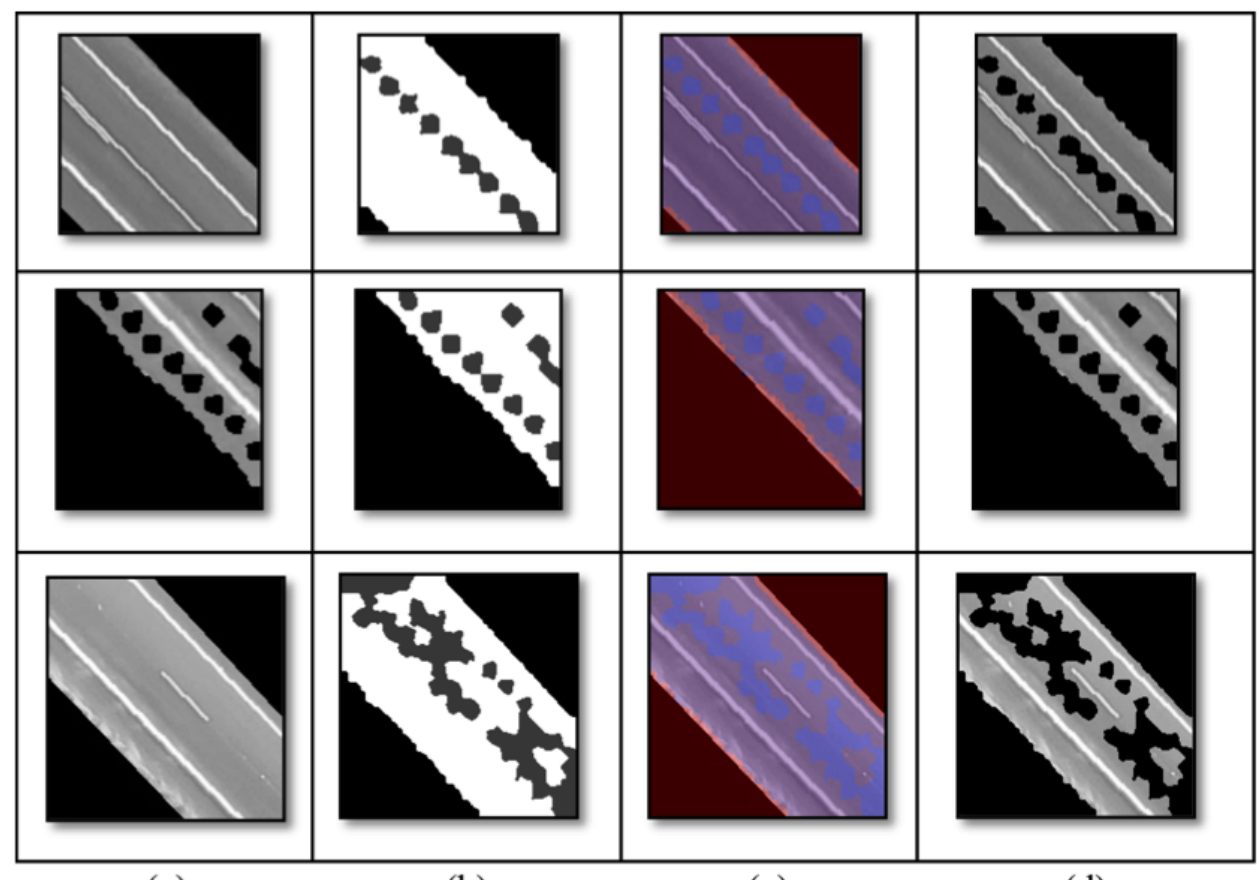

(a)

(b)

(c)

(d)

Figura 5.28 - Resultados do processamento da classificação de defeitos em diferente trechos de pavimentos do E3. a) imagem original b) máscara gerada automaticamente com os defeitos em branco. c) imagem com sobreposição destacando as áreas sem defeitos em azul. d) imagem final apenas com as regiões com defeitos detectadas.

Partindo-se da detecção e da classificação das áreas com defeito no pavimento, é possível realizar a última etapa da MANIAC, a identificação dos tipos dos defeitos propriamente ditos. $\mathrm{Na}$ Figura 5.29a são ilustradas as imagens originais onde os defeitos foram previamente encontrados. Na Figura 5.29b os defeitos são destacados para serem identificados. Por meio da identificação dos defeitos, os mesmo são apresentados nas Figuras 5.29c, 5.29d e 5.29e respectivamente, em que são identificados os defeitos do tipo Fenda, Remendo e Panela.

A acurácia da detecção dos defeitos para o E3 é demonstrada por meio da matriz de confusão ilustrada na Figura 5.30.

É possível observar por meio da matriz de confusão que no E3 o resultado das métricas de desempenho apresentadas e da F-measure são positivas. Tem-se uma acurácia de $96 \%$ e uma 


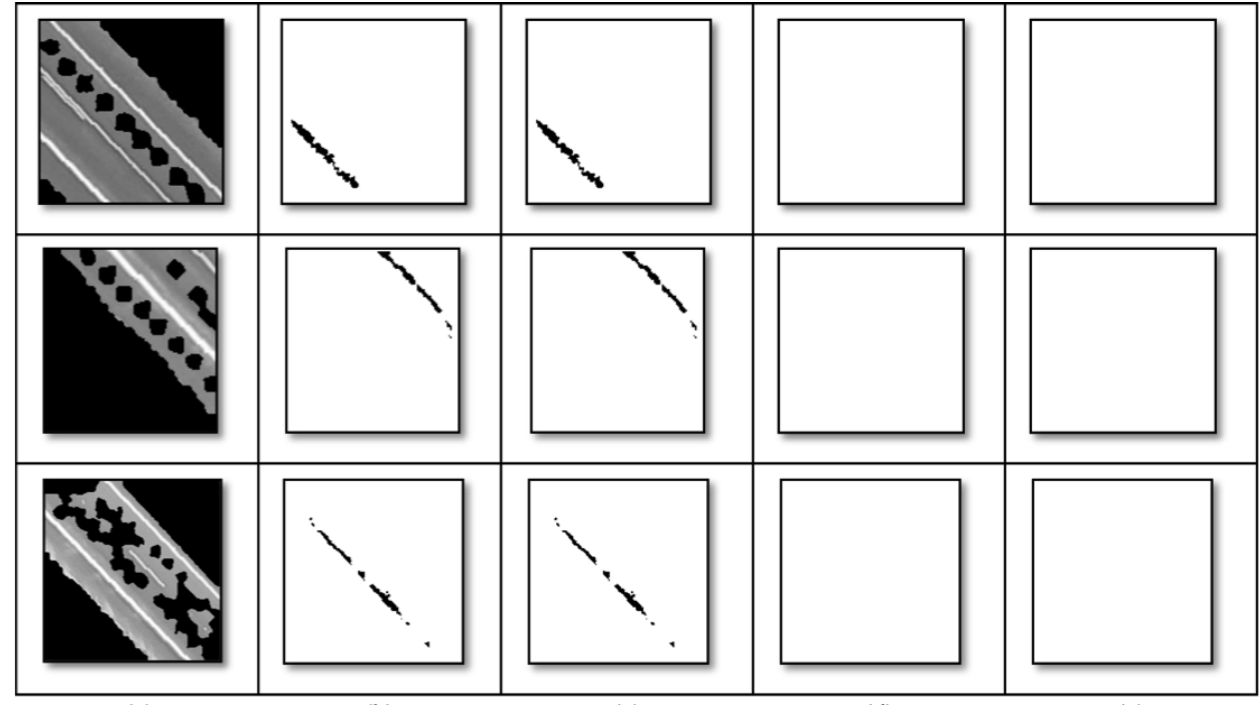

(a) (b)

(c)

(d)

(e)

Figura 5.29 - Processamento dos tipos defeitos no pavimento das imagens obtidas no E3. a) imagem classificada com os defeitos. b) imagem com os defeitos destacados em preto. c) imagem com os defeitos do tipo Fenda destacados em preto. d) imagem com os defeitos do tipo Remendo não foram encontrados em nenhuma das imagens. e) defeitos do tipo Panela não foram encontrados em nenhuma das das imagens.

\begin{tabular}{|rrrr|}
\hline True Positive & False Negative & Accuracy & Precision \\
2 & 24 & 0.96 & $\mathbf{0 . 9 6}$ \\
False Positive & True Negative & Recall & F1 Score \\
5 & 927 & $\mathbf{0 . 9 7}$ & $\mathbf{0 . 9 6}$ \\
\hline
\end{tabular}

Figura 5.30 - Matriz de confusão e outras medidas de avaliação do algoritmo de AM aplicado ao Experimento 3 (E3) na detecção de defeito no pavimento.

precisão de $96 \%$ para, no caso deste experimento, o tipo de defeito Fenda. Mais uma vez a acurácia obtida é melhor do que a encontrada na literatura, já mencionada anteriormente.

Os resultados obtidos com o Relatório de Defeitos que foi gerado para o experimento 3 (E3) são ilustrados nas Figuras 5.31 e 5.32 .

\begin{tabular}{|c|c|c|c|c|c|c|c|c|c|c|}
\hline nome do segmento & Ind. Trinca & Ind. Remendo & Ind. Panela & fp. Trinca & fp Remendo & fp Panela & IGI' Trinca & IGI' Remendo & IGI' Panela & IGG' \\
\hline tile_7422_6230_seg_ind_290.png & 0.005052 & 0.014331 & 0.000000 & 0.8 & 0.6 & 1.0 & 0.004042 & 0.008599 & 0.000000 & 0.012640 \\
\hline tile_7422_6230_seg_ind_291.png & 0.050151 & 0.041662 & 0.000000 & 0.8 & 0.6 & 1.0 & 0.040121 & 0.024997 & 0.000000 & 0.065118 \\
\hline tile_7422_6230_seg_ind_30.png & 0.008624 & 0.011744 & 0.000000 & 0.8 & 0.6 & 1.0 & 0.006899 & 0.007046 & 0.000000 & 0.013945 \\
\hline tile_7422_6230_seg_ind_31.png & 0.020609 & 0.013420 & 0.000000 & 0.8 & 0.6 & 1.0 & 0.016487 & 0.008052 & 0.000000 & 0.024539 \\
\hline tile_7422_6230_seg_ind_318.png & 0.076023 & 0.008469 & 0.000000 & 0.8 & 0.6 & 1.0 & 0.060819 & 0.005082 & 0.000000 & 0.065900 \\
\hline tile_7422_6230_seg_ind_319.png & 0.036076 & 0.006540 & 0.000000 & 0.8 & 0.6 & 1.0 & 0.028861 & 0.003924 & 0.000000 & 0.032785 \\
\hline tile_7422_6230_seg_ind_32.png & 0.005538 & 0.011367 & 0.000000 & 0.8 & 0.6 & 1.0 & 0.004430 & 0.006820 & 0.000000 & 0.011250 \\
\hline tile_7422_6230_seg_ind_347.png & 0.004569 & 0.074119 & 0.000000 & 0.8 & 0.6 & 1.0 & 0.003655 & 0.044472 & 0.000000 & 0.048127 \\
\hline tile_7422_6230_seg_ind_350.png & 0.022947 & 0.017783 & 0.000000 & 0.8 & 0.6 & 1.0 & 0.018358 & 0.010670 & 0.000000 & 0.029027 \\
\hline
\end{tabular}

Figura 5.31 - Listagem parcial do cálculo do IGI' e do IGG’ a partir das imagens obtidas no E3.

O Índice de Gravidade Global calculado para o experimento 3 (E3) foi de 2,00 correspondente ao conceito "Ótimo"(DNIT 06/2003) ou "Bom"(DNER 08/1994). Esse experimento, assim como o E1, apresentou resultados que implicam na obtenção de um pavimento bom ou ótimo. 


\begin{tabular}{|cccccccc}
\hline nome do segmento & Ind. Trinca & Ind. Remendo & Ind. Panela & Pt Trinca & Ppr Remendo & Ppr Panela & IGGE' \\
\hline tile_7422_6230_seg_ind_290.png & 0.005052 & 0.014331 & 0.000000 & 0.3 & 1.0 & 0.7 & 0.0158470 \\
\hline tile_7422_6230_seg_ind_291.png & 0.050151 & 0.041662 & 0.000000 & 0.3 & 1.0 & 0.7 & 0.0567070 \\
\hline tile_7422_6230_seg_ind_30.png & 0.008624 & 0.011744 & 0.000000 & 0.3 & 1.0 & 0.7 & 0.0143310 \\
\hline tile_7422_6230_seg_ind_31.png & 0.020609 & 0.013420 & 0.000000 & 0.3 & 1.0 & 0.7 & 0.0196030 \\
\hline tile_7422_6230_seg_ind_318.png & 0.076023 & 0.008469 & 0.000000 & 0.3 & 1.0 & 0.7 & 0.0312760 \\
\hline tile_7422_6230_seg_ind_319.png & 0.036076 & 0.006540 & 0.000000 & 0.3 & 1.0 & 0.7 & 0.0173630 \\
\hline tile_7422_6230_seg_ind_32.png & 0.005538 & 0.011367 & 0.000000 & 0.3 & 1.0 & 0.7 & 0.0130280 \\
\hline tile_7422_6230_seg_ind_347.png & 0.004569 & 0.074119 & 0.000000 & 0.3 & 1.0 & 0.7 & 0.0754900 \\
tile_7422_6230_seg_ind_350.png & 0.022947 & 0.017783 & 0.000000 & 0.3 & 1.0 & 0.7 & 0.0246670 \\
\hline
\end{tabular}

Figura 5.32 - Listagem parcial do cálculo do IGGE’ a partir das imagens obtidas no E3.

O Índice de Gravidade Global Expedito calculado para o experimento 3 (E3) foi de 2,00 variando entre um conceito "Ótimo"e "Bom"dependendo do valor atribuído para o ICPF.

\subsection{Discussões}

A tarefa de conservação de pavimentos, na maioria das vezes, apresenta uma ampla variabilidade e diversificação de modalidades de serviços a serem executados nas mais diversas condições, incluindo-se entre elas: quantitativos elevadíssimos, demandas por execuções simultâneas e a quilometragem grande e afastada. Desse modo, demandam expressivos recursos de materiais, humanos e financeiros.

A MANIAC é uma metodologia que tem por objetivo a detecção automática de defeitos em pavimentos, e desse modo permite contribuir para esse tipo de trabalho facilitando a obtenção das informações necessárias para a visualização das características e situação do pavimento.

Além disso, a MANIAC permite também uma redução nos custos e uma otimização em partes das tarefas de conservação (mais especificamente na conservação rotineira da componente pavimento), uma vez que em algumas horas de processamento é possível obter resultados que poderiam levar dias para serem levantados, constituindo-se assim, em um instrumento agregador e que permite redução de custo e tempo no processo geral de Conservação Rodoviária (IPR, 2003a).

Para validar a MANIAC e demonstrar sua efetividade, foram realizados os experimentos (E1, E2 e E3) de forma a enfocar a eficácia, eficiência e aplicabilidade da mesma na detecção de pavimentos asfálticos flexíveis.

O E1 foi realizado em uma região menos povoada, ou seja, que não apresenta um grande número de casas ou outros elementos que podem prejudicar a identificação do pavimento. De modo análogo, o E3 também é realizado em uma área não povoada, que permite a melhor caracterização do pavimento. Já o E2 foi realizado em uma área densamente povoada.

Nos três experimentos realizados a acurácia e a precisão apresentam bons resultados. Esses resultados validam também a utilização do label obtido a partir do mapa de ruas do GoogleMaps, uma vez que foi uma das features utilizadas no treinamento supervisionado. A vantagem da 
extração automática dessa feature é que ela já existe para a maior parte dos pavimentos asfálticos hoje existentes, devido à grande popularidade e, principalmente, a possibilidade depoder obter esse tipo de informação sobre qualquer lugar do mundo.

Para avaliar os resultados obtidos com a detecção do pavimento foram computadas várias medidas, destacando-se entre elas a matriz de confusão, a acurácia, a precisão, o recall e o $F$ Measure, comparando os resultados obtidos com o Ground-Truth. Para as medições não foram considerados limitantes (thresholds), de modo que a avaliação foi feita sem considerar nenhuma margem de diferenças de pixels.

Com a realização desses experimentos foi possível validar a MANIAC, pois mesmo no caso mais complexo (E2), ou pior caso, obteve-se uma acurácia de $\mathbf{9 7 \%}$ e uma precisão de $\mathbf{9 8 \%}$, que podem ser consideradas muito boas quando comparadas ao que se encontra na literatura (que apresenta uma acurácia entre $90 \%$ e $93 \%$ ).

Os resultados obtidos nas medidas de acurácia e precisão na detecção dos tipos de defeitos propriamente ditos, também apresentaram bons resultados frente aos encontrados na literatura (cerca de $77 \%$ a $80 \%$ ) e que representam a acurácia quando da detecção de defeitos isoladamente e na maioria dos casos encontrados na literatura o tipo de defeito abordado é a Fenda.

Obteve-se resultados bons onde há ocorrência de mais de um tipo de defeito no pavimento (Fenda e Remendo), como é o caso do E1 e do E2 (obtendo-se uma acurácia de $82 \%$ a 92\%) e, obteve-se resultado ainda melhor na detecção de tipos de defeitos isolados, como é o caso do E3 onde somente o tipo de defeito Fenda foi detectado (acurácia de 96\%).

Não se teve ocorrência do tipo de defeito Panela nos experimentos realizados. Novos voos em regiões onde essa instância ocorra seriam necessários para que se pudesse validar o algoritmo também para esse tipo de defeito. Entretanto, o algoritmo implementado já contempla tal defeito (é possível observar pelos resultados obtidos que nenhum tipo de defeito Panela foi encontrado, de modo que o algoritmo de detecção de defeito foi capaz de detectar a não presença dessa instância).

O Relatório de Defeitos gerado como elemento final da MANIAC, é uma das vantagens da metodologia pois permite que o especialista verifique os tipos de defeitos e a localizações dos mesmos, de maneira que o diagnóstico seja mais eficiente, tanto na monitoração quanto na análise do pavimento.

Cabe ressaltar que esses resultados são ainda mais relevantes e importante uma vez que as imagens forma obtidas por meio de VANTs e não por aparelhos próprios e mais próximos do solo, mas por outro lado por meio de imagens dotadas de alta resolução espacial.

Sendo assim, a MANIAC se apresenta como uma metodologia de fácil utilização e aplicabilidade, flexível, robusta, extensível e apropriada para o monitoramento e inspeção de pavimentos asfálticos flexíveis. 
A partir de imagens obtidas por meio do Sensoriamento Remoto semi-orbital, fazendo uso de VANTs, é possível obter um relatório detalhado no qual obtém-se informações sobre o tipo do defeito, a extensão e a localização do mesmo. Esse monitoramento pode ser executado de forma mais rápida que a tradicional, pois o VANT é capaz de imagear uma região mais ampla em menos tempo (no caso do VANT utilizado para realização dos experimentos realizados nesta tese, é possível imagear 56 hectares em 20 minutos de voo), o que permite uma economia bastante significativa em termos de tempo e custo financeiro (imaginando-se aqui a hora/atividade de um profissional capacitado para tal atividade). O profissional pode ser utilizado para aprimorar o sistema e dispensar tempo em tarefas mais desafiadoras. É uma metodologia que permite o monitoramento do pavimento de forma não-destrutiva, complementando assim as formas tradicionais de monitoramento hoje existentes, tornando-se ainda mais atrativa para organizações que tem como premissa a gerência de extensas áreas pavimentadas, como é o caso de países como o Brasil.

\subsection{Considerações finais}

Neste capítulo foram apresentados os resultados obtidos com a utilização da MANIAC, bem como sua validação por meio da apresentação de várias medidas como a matriz de confusão, acurácia, precisão e F-measure obtidas.

Foram detectados não só o pavimento asfáltico das imagens obtidas pelos VANTs, mas também os defeitos existentes nesses pavimentos. Não apenas foram detectados pavimentos defeituosos mas também foram destacados e apresentados os tipos de defeitos e ainda gerados os índices de qualidade do pavimento.

Três diferentes experimentos foram realizados e os resultados dos mesmos apresentados para que a flexibilidade e generalidade da MANIAC pudesse ser avaliada e validada. Foi possível observar que a metodologia é eficiente para os mais diferentes tipos de cenários: áreas menos povoadas, áreas densamente povoadas e áreas de rodovias, circundadas prioritariamente por vegetação e terra.

Os resultados apresentados neste capítulo corroboram com a hipótese levantada nesta tese de que é possível realizar o monitoramento das condições do pavimento fazendo uso de imagens obtidas por VANTs. Esse monitoramento com a geração de um relatório do tipo de defeitos (bem como a sua localização), deve permitir que a realização dos procedimentos de conservação e restauração das rodovias seja feito de forma mais eficiente quando utilizado na prática.

No próximo capítulo são apresentadas as principais contribuições desta tese, as conclusões, as limitações da metodologia, as dificuldades encontradas e os trabalhos futuros. 


\section{Capítulo}

\section{Conclusões}

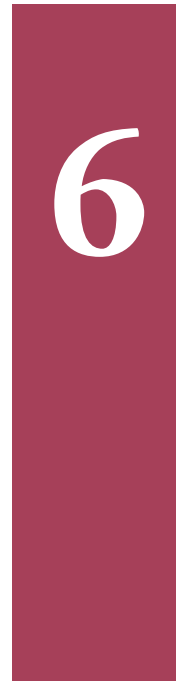

Esta pesquisa de doutorado investigou o problema de detecção de defeitos em pavimentos asfálticos flexíveis fazendo uso de imagens aéreas obtidas a partir de veículos aéreos não tripulados de pequeno porte.

A tarefa de detecção automática não é trivial, uma vez que requer conhecimento de diferentes áreas, caracterizando-se assim como uma tarefa interdisciplinar. Para que fosse possível sua realização fez-se necessário o estudo de diferentes áreas e disciplinas com intuito de extrair das mesmas uma estratégia integrada que permitisse que a detecção fosse realizada com efetividade.

O Sensoriamento Remoto foi uma das áreas pesquisadas, e a partir de estudos realizados optou-se pelo uso de VANTs em detrimento ao uso de satélites para a obtenção das imagens uma vez que, o custo desses veículos de pequeno porque é baixo, eles fornecem imagens de alta resolução e voam abaixo das nuvens, o que permite uma melhor visibilidade do objeto de estudo.

Posteriormente buscou-se aprender sobre as condições do pavimento asfáltico flexível. Essa área por si só apresenta diversos desafios, como a manutenção preventiva, o estudo dos materiais componentes, o desgaste, o monitoramento, entre outros. A necessidade de vias com boas condições de rolamento, além do monitoramento preventivo para minimizar os gastos com reparos e reabilitações do pavimento, motivou o uso e a aplicação dos VANTs como ferramenta para detecção dos defeitos nesse tipo de pavimento.

Por meio da investigação aqui realizada foi possível identificar na literatura a existência de diversos trabalhos que têm como objetivo a classificação dos diferentes tipos de defeitos presentes nesse tipo de pavimento, bem como a utilização de diferentes técnicas para realizar 
essa classificação. Apesar de existirem diversas pesquisas que demonstram a necessidade de metodologias e métodos que viabilizem a detecção automática de defeitos em pavimentos asfálticos, essas metodologias fazem uso apenas de imagens específicas dos defeitos buscando classificá-los, usando imagens obtidas em solo com o uso de câmeras ou equipamentos específicos para isso e que requerem a presença de um especialista para obtenção das mesmas e as técnicas utilizadas, na maioria das vezes, só classificam os defeitos no pavimento se as imagens tiverem em condições específicas.

Neste trabalho constata-se que é possível a existência de uma metodologia realmente automática que permite a entrada de imagens obtidas por meio de VANTs e a geração automática de relatórios de defeitos de pavimentos asfálticos. Essa metodologia é denominada MANIAC.

Essa metodologia apresenta recomendações que vão desde os ajustes dos parâmetros necessários para a execução da missão de monitoramento do pavimento (especificações de altitude, qualidade da imagem, velocidade de voo, entre outros), necessários para que as imagens de entrada sejam suficientes para que se obtenha um bom diagnóstico, até a geração do relatório de defeitos, classificando-os.

A MANIAC incorpora técnicas modernas de aprendizado de máquina, tanto supervisionado quando não-supervisionado, que permitem a realização de um aprendizado e, posteriormente, que o modelo gerado possa ser utilizado para classificar e diagnosticar corretamente as novas imagens. A metodologia permite ainda que novos e diferentes algoritmos sejam acrescentados, sendo assim flexível e, apesar de ter sido concebida para pavimentos asfálticos a metodologia pode facilmente ser estendida para outros tipos de pavimentos, sendo assim extensível. Além disso, os resultados apresentados com o uso da metodologia apresentam alto grau de acurácia, sendo que a metodologia pode ser considerada robusta e, uma vez que novas técnicas, algoritmos e tecnologias podem ser integradas e adaptadas, a MANIAC pode ainda ser considerada atemporal.

Para a realização do aprendizado supervisionado é necessário a utilização de rótulos e, sendo assim, obteve-se uma inovação, fazendo uso da estratégia de obtenção automática de rótulos da malha viária a partir do GoogleMaps para a detecção do asfalto. Isso permitiu uma melhora no aprendizado e facilitou a geração automática do GroundTruth.

A detecção do asfalto foi realizada com uma acurácia de $\mathbf{9 7 , 0 \%}$ no pior caso e $\mathbf{9 9 , 0 \%}$ no melhor caso, frente a acurácia existente na literatura que é de 90,0\% no melhor caso.

A identificação de defeitos foi realizada para os principais tipos de defeitos (Remendo, Fendas e Panelas), apresentando assim uma prova de conceito de que a metodologia concebida permite a identificação de defeitos com uma acurácia de 96,0\%, mas sabendo-se que é possível melhorar o uso de técnicas, e até mesmo definir técnicas específicas para cada tipo de defeito, conforme pode ser observado pelos artigos existentes na literatura e apresentado na Seção 3.

O relatório de defeitos finaliza a metodologia permitindo a especialistas a observação de da- 
dos que auxiliam no monitoramento e análise do pavimento. Os resultados obtidos por meio dos relatórios vêm ao encontro do que se esperava frente as observações realizadas. Neste relatório são apresentados dois índices, o IGG e o IGGE escolhidos apenas para demonstrar o potencial da ferramenta, cujos resultados são semelhantes em termos do diagnóstico da qualidade do pavimento para os três casos avaliados. Cabe salientar que esses índices podem ser substituídos por outros índices que possam representar mais fielmente determinado caso, demonstrando mais uma vez a flexibilidade e extensibilidade da MANIAC. Como já mencionado anteriormente, os índices obtidos correspondem aos índices das tabelas que permitem o julgamento da qualidade do pavimento. Os resultados obtidos apresentam pavimentos bons a ótimos para os experimentos 1 e 3 e resultado de bom a regular para o experimento 2 .

Desta forma, fica evidente, por meio dos resultados experimentais apresentados e discutidos na Seção 5 a eficiência da MANIAC, corroborando com a hipótese dessa tese de que é possível a detecção de defeitos de forma automática por meio de veículos aéreos não tripulados de baixo custo, e que esta detecção provê ganhos em termos de tempo e de custo, evitando que o trabalho de inspeção seja executado por humanos, o que muitas vezes pode implicar em colocar em risco suas vidas.

\subsection{Principais resultados e contribuições}

- Definição de parâmetros - recomendações sobre parâmetros para execução de missões de monitoramento para detecção de defeitos em pavimentos asfálticos fazendo uso de VANTs de pequeno porte;

- Detecção automática de Desgastes de Pavimentos - detecção automática de desgastes de pavimentos flexíveis asfálticos por meio do uso de equalização de histograma, permitindo assim que medidas preventivas possam ser tomadas para que não ocorra maiores danos ocasionando maiores gastos com consertos nas áreas detectadas;

- Geração automática de label de ruas - a obtenção automática do label ruas a partir do mapa de ruas do GoogleMaps contibuiu no processo de verificação automática do GroundTruth permitindo assim que o tempo e o custo sejam minimizados;

- MANIAC - especificação e desenvolvimento de uma Metodologia para Monitoramento de Pavimentos Asfálticos com uso de VANTs para Detecção Automática de Defeitos. Essa metodologia permite que ocorra uma diminuição no tempo e custo no diagnóstico de tarefas de conservação de rodovias pavimentadas, além de permitir que medidas preventivas possam também ser tomadas (BRANCO; SEGANTINE, 2015);

- Novas aplicaçãoes da técnica de detecção de anomalias - através dos bons resultados de classificação dos defeitos no pavimento utilizando a técnica de detecção de anomalias, 
pode-se dizer que essa técnica também pode utilizada para em aplicaçoes de detecção de defeitos no pavimento.

\subsection{Limitações da abordagem}

Como toda pesquisa, a aqui realizada também apresenta limitações. Uma vez que o trabalho realizado possui um prazo para ser finalizado não é possível que todas as possibilidades sejam abordadas e tratadas, fazendo-se assim necessário delimitar o escopo do trabalho.

- Uma vez que são utilizados Veículos Aéreos Não Tripulados para a obtenção das imagens, faz-se necessário definir que o mesmo (com a tecnologia utilizada quando do desenvolvimento desta pesquisa) só podem voar em dias não chuvosos e com pouco vento, portanto depente de boas condições climáticas para a realização da missão;

- Os pavimentos tratados foram os pavimentos asfálticos flexíveis, o que outros tipos de pavimentos (estradas de terra, pavimentos de concreto, entre outros) no qual,não puderam ser tratados da forma com que se espera e novos algoritmos podem ser incluídos para contemplá-los;

- As imagens consideradas pela metodologia devem respeitar os parâmetros necessários (recomendados pela metodologia), caso contrário a mesma não funcionará corretamente, isto é, precisam de alta resolução espacial para gerar o relatório de defeitos com os devidos índices de qualidade do pavimento;

- A existência de elementos, como carros, caminhões, árvores, entre outros, podem e vão obstruir a visão das imagens obtidas, sendo que não será possível a detecção ou identificação de pavimento localizado na região onde o veículo se encontra, esteja ele com defeito ou não. Dessa forma, a sombra desses elementos também pode afetar a detecção de defeitos caso a missão seja executada logo pela manhã ou ao final da tarde.

\subsection{Dificuldades encontradas}

Como mencionado, essa pesquisa envolveu conhecimentos multidisciplinares, o que permitiu gerar resultados inovadores mas também deparar com diversas dificuldades, não só tecnológicas mas científicas aqui elencadas:

- Pulverização dos conceitos - uma vez que a pesquisa é interdisciplinar, os conceitos encontravam-se pulverizados na literatura e buscavam atender somente a área em questão. Esse trabalho permitiu a integração de diferentes conceitos para a realização e obtenção de uma pesquisa sólida e com resultados que demonstram a eficiência da agregação de áreas; 
- A obtenção das imagens - realizar voos com um VANT não é algo complicado quando se tem uma boa tecnologia em mãos. Entretanto, a regulamentação do uso desses veículos ainda é algo novo. O voo em regiões povoadas não é autorizado. A realização do voo demandou diversos esforços para que o mesmo acontecesse;

- Diferentes técnicas de Aprendizado de Máquina - o uso de diferentes técnicas de Aprendizado de Máquina permitiu maior conhecimento da área, entretanto, diversas foram as implementações realizadas para que se pudesse escolher os melhores algoritmos para os diferentes casos (detecção de pavimento e identificação de defeitos). Muitas das técnicas que apresentavam-se como candidatas a prover bons resultados não resultaram em informações compatíveis com o esperado. Sendo assim, a manipulação das imagens e a obtenção das técnicas e algoritmos a serem utilizados na MANIAC para que a mesma pudesse fornecer os resultados esperados demandaram grande esforço e horas de processamento e ajustes de códigos;

- Integração das tecnologias e abordagens - a integração das diferentes áreas, vista por meio da metodologia apresentada, aparenta ser trivial. No entanto, a definição da metodologia, bem como a ordem das etapas e a real necessidade de cada uma dessas etapas demandou muito tempo, além de todo o processo de implementação e validação, trabalhoso e desafiador, que apesar de ser tecnológico é necessário para demonstrar e apresentar a prova de conceito da validade da MANIAC.

\subsection{Trabalhos futuros}

O objetivo da MANIAC, na sua presente versão, é realizar de forma automática a detecção de defeitos pavimentos asfálticos flexíveis. Entretanto, ela pode ser estendida e novas funcionalidades podem ser incorporadas. Sendo assim, sugerem-se os seguintes trabalhos a serem realizados que permitem dar continuidade à MANIAC:

1. Integrar a MANIAC com o Sistema de Informações Geográficas que permitem a chamada de rotinas em Phyton da MANIAC de modo que o usuário pode fazer uso das funcionalidades necessárias do SIG e também gerar os relatório de defeitos de uma maneira mais simplificada para o usuário final;

2. Execução em paralelo do particionamento das imagens na etapa de segmentação, de modo a permitir uma maior velocidade e agilidade no processamento das imagens. Uma possibilidade é o uso de CUDA (Compute Unified Device Architecture) ou mesmo máquinas paralelas virtuais que permitam essa otimização;

3. Comparação dos diferentes algoritmos existentes na literatura para detecção de defeitos - a partir da existência da MANIAC é possível integrar vários outros algoritmos de processamento de imagem, e uma vez que a malha viária é identificada automaticamente, 
é possível efetuar uma gama de comparações com diferentes algoritmos já existente na literatura;

4. Estender o número de tipos de defeitos que podem ser identificados pela MANIAC a partir da utilização de diferentes algoritmos que não o baseado em polígonos;

5. Definir junto a órgãos oficiais (como o DNIT) modelos e informações necessárias que possam auxiliar na conservação e no monitoramento de vias pavimentadas;

6. Estender a MANIAC para que a detecção de pavimentos possa ser realizada para diferentes tipos de pavimentos que não só os asfálticos flexíveis;

7. Geração de índices de qualidade baseados em outras normas nacionais e internacionais;

8. Efetuar melhorias no relatório de defeitos, padronizá-lo de acordo com as normas estabelecidas pelas entidades responsáveis pelo monitoramento de manutenção de vias como o DNIT;

9. Efetuar ajustes para detectar defeitos no pavimento em imagens obtidas por meio do Street View da Google. 


\section{Referências}

ALDRIDGE, E.; STENBIT, J. P. Unmanned aerial vehicles roadmap 2002-2027. Office of the Sectary of Defense, Department of Defense USA, Washington, Tech. Rep, 2002. 2002.

ARMOUSH, A.; BECKSCHULZE, E.; KOWALEWSKI, S. Safety assessment of design patterns for safety-critical embedded systems. In: IEEE. Software Engineering and Advanced Applications, 2009. SEAA'09. 35th Euromicro Conference on. [S.1.], 2009. p. 523-527.

ARMY, U. Unmanned aircraft systems roadmap 2010-2035. US Army UAS Center of Excellence, Fort Rucker, Alabama, USA, 2010. v. 10, p. 205, 2010.

ARONOFF, S. Geographic information systems: a management perspective. 1989. Taylor \& Francis, 1989.

ASSIDIQ, A. A. et al. Real time lane detection for autonomous vehicles. In: IEEE. Computer and Communication Engineering, 2008. ICCCE 2008. International Conference on. [S.1.], 2008. p. $82-88$.

AUSTIN, R. Unmanned aircraft systems: UAVS design, development and deployment. [S.1.]: John Wiley \& Sons, 2011.

AUTHORITY, U. C. A. Unmanned Aircraft System Operations in UK Airspace-Guidance. [S.l.]: CAP722, 2012.

BAATZ, M.; SCHÄPE, A. Multiresolution segmentation: an optimization approach for high quality multi-scale image segmentation. [S.l.]: Herbert Wichmann Verlag: Berlin, Germany, 2000. $12-23$ p.

BAMNETT, V.; LEWIS, T. Outliers in statistical data. 1994. JSTOR, 1994.

BARBOSA, C. et al. Mapping amazon wetlands through region growing segmentation and segmented-based classification jers-1 data.(cd rom). Simpósio Latino Americano de Sensoriamento Remoto, Puerto Iguazu, Argentina. Anais, 2000. 2000. 
BARR, M. Programming embedded systems in $C$ and $C++$. [S.l.]: "O’Reilly Media, Inc.", 1999.

BEKMEZCI, I.; SAHINGOZ, O. K.; TEMEL, Ş. Flying ad-hoc networks (fanets): A survey. Ad Hoc Networks, 2013. Elsevier, v. 11, n. 3, p. 1254-1270, 2013.

BERGER, A. S. Embedded systems design: an introduction to processes, tools and techniques. 2001. CMP books, 2001.

BERGSTRA, J.; BENGIO, Y. Random search for hyper-parameter optimization. The fournal of Machine Learning Research, 2012. JMLR. org, v. 13, n. 1, p. 281-305, 2012.

BIOLCHINI, J. et al. Systematic review in software engineering. System Engineering and Computer Science Department COPPE/UFRF, Technical Report ES, 2005. v. 679, n. 05, p. 45, 2005.

BIOLCHINI, J. C. de A. et al. Scientific research ontology to support systematic review in software engineering. Advanced Engineering Informatics, 2007. Elsevier, v. 21, n. 2, p. 133-151, 2007.

BIRDAL, T.; ERÇIL, A. Real-time automated road, lane and car detection for autonomous driving. 2007. Sabancı University, 2007.

BLOOMFIELD, R. et al. Validation, verification and certification of embedded systems. 2005. 2005.

BLYENBURGH, P. van. Uav systems: global review. In: Conference, Amsterdam, The Netherlands. [S.l.: s.n.], 2006.

BRANCO, K. R. L. J. C. Contribuições na área de Sistemas Distribuídos e Redes de Computadores e suas aplicações em Sistemas Embarcados Críticos. Tese (Doutorado) - Universidade de São Paulo, 2012.

BRANCO, L. H. C.; SEGANTINE, P. C. L. Maniac-uav-a methodology for automatic pavement defects detection using images obtained by unmanned aerial vehicles. In: IOP PUBLISHING. Journal of Physics: Conference Series. [S.1.], 2015. v. 633, n. 1, p. 012122.

BRECHER, A.; NORONHA, V.; HEROLD, M. Uav2003-a roadmap for deploying unmanned aerial vehicles (uavs) in transportation. In: US DOT/RSPA: Volpe Center and NCRST Infrastructure, Specialist Workshop, Santa Barbara, December.(http://www. ncgia. ucsb. edu/ncrst/meetings/20031202SBAUAV2003/Findings/UAV2003-Findings-Final. pdf).(Accessed May, 2008). [S.l.: s.n.], 2003.

BREIMAN, L. Random forests. Machine learning, 2001. Springer, v. 45, n. 1, p. 5-32, 2001.

BURROUGH, P. A. Principles of geographical information systems for land resources assessment. 1986. Taylor \& Francis, 1986.

BUZA, E.; OMANOVIC, S.; HUSEINOVIC, A. Pothole detection with image processing and spectral clustering. In: Proceedings of the 2nd International Conference on Information Technology and Computer Networks, Antalya, Turkey. [S.l.: s.n.], 2013. v. 810, p. 4853.

CAMPOVERDE, M. L. M.; COBOS, M. I. P. Catálogo de deterioros en pavimientos. 2002. 2002.

CHAO, H.; CAO, Y.; CHEN, Y. Autopilots for small unmanned aerial vehicles: a survey. International fournal of Control, Automation and Systems, 2010. Springer, v. 8, n. 1, p. 36-44, 2010. 
CHENG, H. et al. Novel approach to pavement cracking detection based on fuzzy set theory. Journal of Computing in Civil Engineering, 1999. American Society of Civil Engineers, v. 13, n. 4, p. 270-280, 1999.

CHENG, H.-D.; MIYOJIM, M. Automatic pavement distress detection system. Information Sciences, 1998. Elsevier, v. 108, n. 1, p. 219-240, 1998.

CHOU, J.; O’NEILL, W. A.; CHENG, H. Pavement distress classification using neural networks. In: IEEE. Systems, Man, and Cybernetics, 1994. Humans, Information and Technology., 1994 IEEE International Conference on. [S.1.], 1994. v. 1, p. 397-401.

CLAPPER, J. et al. Unmanned Systems Integrated Roadmap 2009-2034.

CODELLA, N. C. et al. Towards large scale land-cover recognition of satellite images. In: IEEE. Information, Communications and Signal Processing (ICICS) 2011 8th International Conference on. [S.1.], 2011. p. 1-5.

COOPER, J.; GOODRICH, M. A. Towards combining uav and sensor operator roles in uav-enabled visual search. In: IEEE. Human-Robot Interaction (HRI), 2008 3rd ACM/IEEE International Conference on. [S.1.], 2008. p. 351-358.

COWEN, D. J. Gis versus cad versus dbms: What are the differences?. Photogramm. Eng. Remote Sens., 1988. v. 54, n. 11, p. 1551-1555, 1988.

DOD, U. Unmanned systems integrated roadmap: Fy2013-2038. Washington, DC, USA, 2013. 2013.

DOUGHERTY, E. R.; LOTUFO, R. A.; SPIE, T. I. S. for O. E. Hands-on morphological image processing. [S.1.]: SPIE Optical Engineering Press Washington, 2003.

DUNN, W. R. Designing safety-critical computer systems. Computer, 2003. IEEE, v. 36, n. 11, p. 40-46, 2003.

ENTERPRISE, E. C. D.-G. for et al. Roadmap for the integration of civil Remotely-Piloted Aircraft Systems into the European Aviation System. [S.1.]: OIB, 2013.

FARRADINE, P. Use of unmanned aerial vehicles in traffic surveillance and traffic management. [S.1.], 2005.

FERNANDO, S. et al. Real-time lane detection on suburban streets using visual cue integration. International fournal of Advanced Robotic Systems, 2014. InTech, v. 11, 2014.

FISCHER, W. A.; HEMPHILL, W.; KOVER, A. Progress in remote sensing (1972-1976). Photogrammetria, 1976. Elsevier, v. 32, n. 2, p. 33-72, 1976.

FLORENZANO, T. G. Imagens de satélite para estudos ambientais. [S.l.]: Oficina de textos, 2002.

FUKUHARA, T. et al. Automatic pavement-distress-survey system. fournal of Transportation Engineering, 1990. American Society of Civil Engineers, v. 116, n. 3, p. 280-286, 1990.

FURTADO, V. H. et al. Aspectos de segurança na integração de veículos aéreos não tripulados (vant) no espaço aéreo brasileiro. Anais do VII Simpósio de Transporte aéreo-Sitraer7, 2008. p. 506-517, 2008. 
GEORGE, J.; SUJIT, P.; SOUSA, J. B. Search strategies for multiple uav search and destroy missions. Fournal of Intelligent \& Robotic Systems, 2011. Springer, v. 61, n. 1-4, p. 355-367, 2011.

GEORGOPOUlOS, A.; LOIZOS, A.; FLOUDA, A. Digital image processing as a tool for pavement distress evaluation. ISPRS fournal of Photogrammetry and Remote Sensing, 1995. Elsevier, v. 50, n. 1, p. 23-33, 1995.

GONZALEZ, R.; WOODS, R. E. Processamento de Imagens Digitais. [S.1.]: Editora Blutcher:São Paulo, 2007.

GONZALEZ, R.; WOODS, R. E.; EDDIND, S. Digital Image Processing Using MATLAB. [S.1.]: Third New Jersey: Prentice Hall, 2004.

GOODCHILD, M. F. Geographical data modeling. Computers \& Geosciences, 1992. Elsevier, v. 18, n. 4, p. 401-408, 1992.

GRIFFITHS, D. J. Introduction to electrodynamics. [S.1.]: Prentice-Hall, 1999.

HARDIN, P. J.; HARDIN, T. J. Small-scale remotely piloted vehicles in environmental research. Geography Compass, 2010. Wiley Online Library, v. 4, n. 9, p. 1297-1311, 2010.

HERNANDES, E. et al. Using gqm and tam to evaluate start-a tool that supports systematic review. CLEI Electronic fournal, 2012. Centro Latinoamericano de Estudios en Informática, v. 15, n. 1, p. 3-3, 2012.

HEROLD, M.; ROBERTS, D. Spectral characteristics of asphalt road aging and deterioration: implications for remote-sensing applications. Applied Optics, 2005. Optical Society of America, v. 44, n. 20, p. 4327-4334, 2005.

HEROLD, M. et al. Imaging spectrometry and asphalt road surveys. Transportation Research Part C: Emerging Technologies, 2008. Elsevier, v. 16, n. 2, p. 153-166, 2008.

HEROLD, M. et al. Road condition mapping with hyperspectral remote sensing. In: Proceedings of the 2004 AVIRIS workshop, March. [S.l.: s.n.], 2004.

HEROLD, M.; ROBERTS, D. A. Mapping asphalt road conditions with hyperspectral remote sensing. In: 5th International Symposium Remote Sensing of Urban Areas (URS 2005), Tempe, AZ, USA. [S.l.: s.n.], 2005.

IPR, D. de Planejamento e P. . Manual de Conservação Rodoviária. [S.1.], 2003.

IPR, D. de Planejamento e P. . NORMA DNIT 005/2003 - TER - Defeitos nos pavimentos flexíveis e semi-rígidos Terminologia. [S.1.], 2003.

IPR, D. de Planejamento e P. . NORMA DNIT 006/2003PRO - Avaliação objetiva da superfície de pavimentos flexíveis e semi-rígidos - Procedimento. [S.l.], 2003.

IPR, D. de Planejamento e P. . NORMA DNIT 008/2003PRO - Levantamento visual contínuo para avaliação da superfície de pavimentos flexíveis e semi-rígidos Procedimento. [S.l.], 2003.

ISHIKAWA, A.; SILVA, E. Detection of highways in high resolution images using mathematical morphology techniques. In: Proceedings, 32nd International Symposium on Remote Sensing of Environment: Sustainable Development Through Global Earth Observations. [S.l.: s.n.], 2007. 
JACQUES, D. R. Unmanned aerial vehicles: modeling considerations for wide area search munition effectiveness analysis. In: WINTER SIMULATION CONFERENCE. Proceedings of the 34th conference on Winter simulation: exploring new frontiers. [S.1.], 2002. p. 878-886.

JAIN, A. K.; FARROKHNIA, F. Unsupervised texture segmentation using gabor filters. In: IEEE. Systems, Man and Cybernetics, 1990. Conference Proceedings., IEEE International Conference on. [S.1.], 1990. p. 14-19.

JANUZAJ, V. et al. New challenges in the development of critical embedded systems-an "aeromotive" perspective. In: Leveraging Applications of Formal Methods, Verification, and Validation. [S.1.]: Springer, 2010. p. 1-2.

JAVIDI, B. et al. Pilot for automated detection and classification of road surface degradation features. [S.1.], 2003.

JR, O. T. et al. A mission planner and navigation system for the arara project. In: ICAS-23rd International Congress of Aeronautical Sciences, Toronto. [S.l.: s.n.], 2002.

JR, O. T. et al. Uma metodologia para desenvolvimento de sistemas embarcados críticos com vistas a certificação. IX Simpósio de Automação Inteligente-IX SBAI, 2009. p. 1-6, 2009.

JR, W. C.; IRICK, P. The pavement serviceability-performance concept. Highway Research Board Bulletin, 1960. n. 250, 1960.

KASEKO, M. S.; LO, Z.-P.; RITCHIE, S. G. Comparison of traditional and neural classifiers for pavement-crack detection. Journal of transportation engineering, 1994. American Society of Civil Engineers, v. 120, n. 4, p. 552-569, 1994.

KASEKO, M. S.; RITCHIE, S. G. A neural network-based methodology for pavement crack detection and classification. Transportation Research Part C: Emerging Technologies, 1993. Elsevier, v. 1, n. 4, p. 275-291, 1993.

KEELE, S. Guidelines for performing systematic literature reviews in software engineering. In: Technical report, Ver. 2.3 EBSE Technical Report. EBSE. [S.l.: s.n.], 2007.

KIM, H. et al. Evaluation of asphalt pavement crack sealing performance using image processing technique. In: International Symposium on Automation and Robotics in Construction (ISARC2006). [S.l.: s.n.], 2006. p. 341-345.

KITCHENHAM, B. Procedures for performing systematic reviews. Keele, UK, Keele University, 2004. v. 33, n. 2004, p. 1-26, 2004.

KNIGHT, J. C. Safety critical systems: challenges and directions. In: IEEE. Software Engineering, 2002. ICSE 2002. Proceedings of the 24rd International Conference on. [S.1.], 2002. p. 547-550.

$\mathrm{KOCH}, \mathrm{C}$.; BRILAKIS, I. Pothole detection in asphalt pavement images. Advanced Engineering Informatics, 2011. Elsevier, v. 25, n. 3, p. 507-515, 2011.

KOUTSOPOULOS, H.; DOWNEY, A. Primitive-based classification of pavement cracking images. Fournal of Transportation Engineering, 1993. American Society of Civil Engineers, v. 119, n. 3, p. 402-418, 1993. 
KOUTSOPOULOS, H. N.; KAPOTIS, V. I.; DOWNEY, A. B. Improved methods for classification of pavement distress images. Transportation Research Part C: Emerging Technologies, 1994. Elsevier, v. 2, n. 1, p. 19-33, 1994.

KOUTSOPOULOS, H. N.; SANHOURI, I. E. Methods and algorithms for automated analysis of pavement images. [S.1.: s.n.], 1991.

LEE, B. J. Development of an integrated digital pavement imaging and neural network system. [S.1.]: The University of Iowa, 2001.

LEE, H.; OSHIMA, H. New crack-imaging procedure using spatial autocorrelation function. fournal of Transportation Engineering, 1994. American Society of Civil Engineers, v. 120, n. 2, p. 206-228, 1994.

LEONARDI, F. et al. Avaliação comparativa entre classificação supervisionada por regiões e orientada a objeto para imagens de alta resolução espacial: Cbers 2b-hrc e quickbird. SIMPÓSIO BRASILEIRO DE SENSORIAMENTO REMOTO, 2009. v. 14, p. 981-988, 2009.

LI, L. et al. Flexible pavement distress evaluation using image analysis. In: ASCE. Applications of Advanced Technologies in Transportation Engineering (1991). [S.1.], 1991. p. 473-477.

LI, L. et al. Automatic pavement crack recognition based on bp neural network. PROMETTraffic\&Transportation, 2014. Fakultet prometnih znanosti Sveučilišta u Zagrebu, v. 26, n. 1, p. 11-22, 2014.

LI, N. et al. Automation recognition of pavement surface distress based on support vector machine. In: IEEE. Intelligent Networks and Intelligent Systems, 2009. ICINIS'09. Second International Conference on. [S.1.], 2009. p. 346-349.

LIEDI, B. et al. Pavimentação asfáltica: formação básica para engenheiros. Rio de faneiro: PETROBRAS: ABEDA, 2008. 2008.

LILLESAND, T.; KIEFER, R. W.; CHIPMAN, J. Remote sensing and image interpretation. [S.1.]: John Wiley \& Sons, 2014.

LIU, S.-W. et al. Detection of cracks using neural networks and computational mechanics. Computer methods in applied mechanics and engineering, 2002. Elsevier, v. 191, n. 25, p. 2831-2845, 2002.

MASER, K. Computational techniques for automating visual inspection. Massachusetts Institute of Technology, Report, Cambridge, MA, 1987. 1987.

MATHAVAN, S.; RAHMAN, M.; KAMAL, K. Application of texture analysis and kohonen map for region segmentation of pavement images for crack detection. Transportation Research Record: Journal of the Transportation Research Board, 2012. Transportation Research Board of the National Academies, n. 2304, p. 150-157, 2012.

MCCORMACK, E.; STIMBERIS, J. Small unmanned aircraft evaluated for avalanche control. Transportation Research Record: fournal of the Transportation Research Board, 2010. Transportation Research Board of the National Academies, n. 2169, p. 168-173, 2010.

MEDIKONDA, B. S.; PANCHUMARTHY, S. R. A framework for software safety in safetycritical systems. ACM SIGSOFT Software Engineering Notes, 2009. ACM, v. 34, n. 2, p. 1-9, 2009. 
MEIGNEN, D.; BERNADET, M.; BRIAND, H. One application of neural networks for detection of defects using video data bases: identification of road distresses. In: IEEE. Database and Expert Systems Applications, 1997. Proceedings., Eighth International Workshop on. [S.1.], 1997. p. $459-464$.

MERINO, L. et al. A cooperative perception system for multiple uavs: Application to automatic detection of forest fires. Fournal of Field Robotics, 2006. Wiley Online Library, v. 23, n. 3-4, p. 165-184, 2006.

MICA, J.; COSTELLO, J. Unmanned aircraft systems: Federal actions needed to ensure safety and expand their potential uses within the national airspace system. [S.1.]: Report, 2008.

MILLER, J. S.; BELLINGER, W. Y. Distress identification manual for the long-term pavement performance program. [S.1.], 2014.

MOIGNE, J. L.; TILTON, J. C. Refining image segmentation by integration of edge and region data. Geoscience and Remote Sensing, IEEE Transactions on, 1995. IEEE, v. 33, n. 3, p. 605-615, 1995.

MURPHY, K. P. Machine learning: a probabilistic perspective. [S.l.]: MIT press, 2012.

NEJAD, F. M.; ZAKERI, H. An expert system based on wavelet transform and radon neural network for pavement distress classification. Expert Systems with Applications, 2011. Elsevier, v. 38, n. 6, p. 7088-7101, 2011.

OLIVEIRA, C. P. d. Análise dos modelos para cálculo de níveis de segurança relacionados à operação de veículos aéreos não tripulados. Tese (Doutorado) - Universidade de São Paulo, 2009.

OLIVEIRA, H.; CORREIA, P. L. Identifying and retrieving distress images from road pavement surveys. In: IEEE. Image Processing, 2008. ICIP 2008. 15th IEEE International Conference on. [S.1.], 2008. p. 57-60.

OLIVEIRA, H.; CORREIA, P. L. Automatic road crack segmentation using entropy and image dynamic thresholding. In: IEEE. Signal Processing Conference, 2009 17th European. [S.l.], 2009. p. 622-626.

PAQUIS, S.; LEGEAY, V.; KONIK, H. Road surface textures classification using opening-based image processing. INTERNATIONAL ARCHIVES OF PHOTOGRAMMETRY AND REMOTE SENSING, 2000. INTERNATIONAL SOCIETY FOR PHOTOGRAMMETRY \& REMOTE, v. 33, n. B3/2; PART 3, p. 685-691, 2000.

PASTOR, E.; LÓPEZ, J.; ROYO, P. An embedded architecture for mission control of unmanned aerial vehicles. In: IEEE. Digital System Design: Architectures, Methods and Tools, 2006. DSD 2006. 9th EUROMICRO Conference on. [S.1.], 2006. p. 554-560.

PASTOR, E.; LOPEZ, J.; ROYO, P. Uav payload and mission control hardware/software architecture. Aerospace and Electronic Systems Magazine, IEEE, 2007. IEEE, v. 22, n. 6, p. 3-8, 2007.

PITRE, R. R.; LI, X. R.; DELBALZO, D. A new performance metric for search and track missions 2: Design and application to uav search. In: 2009 12th International Conference on Information Fusion. [S.l.: s.n.], 2009. 
PURI, A. A survey of unmanned aerial vehicles (uav) for traffic surveillance. Department of computer science and engineering, University of South Florida, 2005. 2005.

QINGWU, H.; HAIYING, W. A framework for traffic accident scene investigation with gps vrs, road database and stereo vision integration. In: IEEE. Multi-Platform/Multi-Sensor Remote Sensing and Mapping (M2RSM), 2011 International Workshop on. [S.1.], 2011. p. 1-5.

RADHAKRISHNA, A. et al. Slic superpixels. Dept. School Comput. Commun. Sci., EPFL, Lausanne, Switzerland, Tech. Rep, 2010. v. 149300, 2010.

RASCHKA, S. Python machine learning. 2015. Packt Publishing, 2015.

RATHINAM, S.; KIM, Z.; SENGUPTA, R. Vision-based following of structures using an unmanned aerial vehicle (uav). Institute of Transportation Studies, 2006. 2006.

RESENDE, M. R. Investigação do uso de imagens de sensor de sensoriamento remoto hiperespectral e com alta resolução espacial no monitoramento da condição de uso de pavimentos rodoviários. Dissertação (Mestrado) - Escola Politécnica da Universidade de São Paulo, 2010.

RESENDE, M. R. et al. Classificação híbrida: pixel a pixel e baseada em objetos para o monitoramento da condição da superfície dos pavimentos rodoviários. Bol. Ciênc. Geod., sec. Artigos, 2012. v. 18, n. 3, p. 397-420, 2012.

RICHARDS, A. Alien vision: exploring the electromagnetic spectrum with imaging technology. 2001. SPIE Press, 2001.

RUSSELL, S. J.; NORVIG, P. Artificial intelligence: a modern approach (international edition). 2002. \{Pearson US Imports \& PHIPEs\}, 2002.

SALARI, E. et al. Transportation Informatics: Advanced Image Processing Techniques for Automated Pavement Distress Evaluation. [S.1.], 2010.

SALMAN, M. et al. Pavement crack detection using the gabor filter. In: IEEE. Intelligent Transportation Systems-(ITSC), 2013 16th International IEEE Conference on. [S.1.], 2013. p. 2039-2044.

SCHÖLKOPF, B. et al. Estimating the support of a high-dimensional distribution. Neural computation, 2001. MIT Press, v. 13, n. 7, p. 1443-1471, 2001.

SEGANTINE, P. C. L. Estudo do Sinergismo entre os Sistemas de Informação Geográfica e o de Posicionamento Global. Tese (Doutorado) - Universidade de São Paulo, 2001.

SERRA, J. Image Analysis and Mathematical Morphology. [S.l.]: Academic Press, INC., 1982.

SHORT, N. The remote sensing tutorial. 2010. 2010.

SIFFERT, M. et al. Catalogue de dégradations de surface des chaussées. [S.1.]: Méthode d'essai des LPC, 1998.

SKIDMORE, A. Environmental modelling with GIS and remote sensing. [S.l.]: CRC Press, 2003.

SMITH, T. et al. Kbgis-ii a knowledge-based geographical information system. International fournal of Geographical Information System, 1987. Taylor \& Francis, v. 1, n. 2, p. 149-172, 1987. 
SPRING, I. Sistema de processamento de informações georreferenciadas. Manual de ajuda, 2006. 2006.

TRINDADE, O. et al. A layered approach to design autopilots. In: IEEE. Industrial Technology (ICIT), 2010 IEEE International Conference on. [S.1.], 2010. p. 1415-1420.

WANG, K. C.; GONG, W. Automated pavement distress survey: a review and a new direction. In: Pavement Evaluation Conference. [S.l.: s.n.], 2002. p. 21-25.

WEISER, C. Drone research looks at traffic applications. Cincinnati Enquirer, Mar, 2003. v. 26, 2003.

WILLIGEN, W. H. van et al. Online adaptation of path formation in UAV search-and-identify missions. [S.l.]: Springer, 2011.

WITTEN, I.; FRANK, E.; HALL, M. Data mining: practical machine learning tools and techniques 3 edition morgan kaufmann. San Francisco, CA, 2011. 2011.

XIANG, H.; TIAN, L. Method for automatic georeferencing aerial remote sensing (rs) images from an unmanned aerial vehicle (uav) platform. Biosystems Engineering, 2011. Elsevier, v. 108, n. 2, p. 104-113, 2011.

XU, B.; HUANG, Y. Development of an automatic pavement surface distress inspection system. [S.l.], 2003.

YEARBOOK, U. Unmanned aircraft systems-the global perspective 2011/2012. Blyenburg \& Co, June, 2011. p. 1967-1709, 2011.

YENIKAYA, S.; YENIKAYA, G.; DÜVEN, E. Keeping the vehicle on the road: A survey on on-road lane detection systems. ACM Computing Surveys (CSUR), 2013. ACM, v. 46, n. 1, p. 2, 2013.

YI, Z.; CAI, W.; YUE, W. Adaptive safety critical middleware for distributed and embedded safety critical system. In: IEEE. Networked Computing and Advanced Information Management, 2008. NCM'08. Fourth International Conference on. [S.1.], 2008. v. 1, p. 162-166.

YINKA, A. O. et al. Performance of drivable path detection system of autonomous robots in rain and snow scenario. In: IEEE. Signal Processing and Integrated Networks (SPIN), 2014 International Conference on. [S.1.], 2014. p. 679-684.

ZHANG, C.; KOVACS, J. M. The application of small unmanned aerial systems for precision agriculture: a review. Precision agriculture, 2012. Springer, v. 13, n. 6, p. 693-712, 2012.

ZHANG, T. On the consistency of feature selection using greedy least squares regression. In: Journal of Machine Learning Research. [S.l.: s.n.], 2009. p. 555-568.

ZHOU, J. Automated pavement inspection based on wavelet analysis. [S.l.: s.n.], 2004.

ZHOU, J.; HUANG, P.; CHIANG, F.-P. Wavelet-based pavement distress classification. Transportation Research Record: Journal of the Transportation Research Board, 2005. Transportation Research Board of the National Academies, n. 1940, p. 89-98, 2005.

ZHOU, J.; HUANG, P. S.; CHIANG, F.-P. Wavelet-based pavement distress detection and evaluation. Optical Engineering, 2006. International Society for Optics and Photonics, v. 45, n. 2, p. 027007-027007, 2006. 
ZIMMERMAN, K. A.; PIERCE, L. M.; KRSTULOVICH, J. Pavement management roadmap. [S.1.], 2010. 
Anexos 


\section{Revisão Sistemática}

\section{ANEXO}

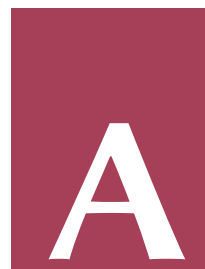

A revisão sistemática é uma forma de identificar, avaliar e interpretar as pesquisas relevantes de uma área em torno de uma questão científica. Por meio dessa técnica é viável resumir possíveis evidências de uma tecnologia, identificar lacunas para sugerir áreas que devem ser investigadas, esclarecer o estado da arte para o posicionamento de novas pesquisas e examinar resultados empíricos que comprovem ou contradizem uma determinada hipótese teórica ou que auxiliem na criação de novas hipóteses (KEELE, 2007).

O processo de revisão sistemática foi realizado com o auxílio da ferramenta State of the Art through Systematic Review (StArt), desenvolvida pelo laboratório de Pesquisa em Engenharia de Software da UFSCAR Hernandes et al. (2012). A ferramenta oferece todo o suporte necessário para a aplicação do protocolo de revisão sistemática de uma maneira formal por meio de etapas bem definidas, proporcionando assim, a aplicação das recomendações presentes na literatura (KEELE, 2007), (BIOLCHINI et al., 2005).

O planejamento da revisão sistemática é apresentado na Seção A.1. A Seção A.2 é relatado o modo como foi realizada a execução da revisão sistemática, com a seleção dos artigos. A Seção A.3 trata do resumo dos resultados obtidos. Entre os artigos encontrados, foram selecionados os artigos que melhor se relacionam com o doutorado e formam os trabalhos relacionados descrito na tese.

\section{A.1 Planejamento}

A primeira etapa da revisão sistemática é o planejamento, no qual são definidos os objetivos, as questões, as fontes da pesquisa e os critérios de seleção. Essas definições possibilitam seguir 
um protocolo pré-determinado para que o investigador não seja tendencioso.

\section{A.1.1 Objetivos}

Os principais objetivos motivadores da revisão sistemática são:

- Identificar as ferramentas utilizadas para monitorar as condições dos pavimentos em rodovias;

- Identificar as técnicas utilizadas para o monitoramento das condições dos pavimentos em rodovias;

- Identificar os custos para o levantamento das condições de pavimentos em rodovias;

- Identificar os processos e metodologias existentes para o monitoramento das condições dos pavimentos em rodovias de modo a averiguar a possibilidade de se efetuar isso de modo automático.

\section{A.1.2 Questões}

Durante o planejamento, a atividade mais importante é a formulação das questões, pois as mesmas estabelecem o foco de interesse da pesquisa Kitchenham (2004). As respostas dessas questões ajudam a realizar uma análise específica e fazer uma conclusão sobre o foco da pesquisa. Com base nos conceitos relacionados ao doutorado foram derivadas duas questões que devem nortear a pesquisa:

- Questão 1 - Quais são as técnicas e ferramentas utilizadas para o monitoramento das condições dos pavimentos em rodovias?;

- Questão 2 - Existem metodologias e os processos que possam ser utilizados para o monitoramento automático das condições dos pavimentos em rodovias?

Para as questões construídas, as seguintes especificidades devem ser consideradas (BIOLCHINI et al., 2007):

- População: Serão observados projetos que envolvam esforços em apresentar técnicas, ferramentas, processos e metodologias que realizem monitoramento das condições de pavimentação de rodovias;

- Intervenção: No contexto da revisão sistemática serão analisadas técnicas, metodologias e processos que levem em conta o monitoramento das rodovias fazendo uso de sensoriamento remoto e o uso de aeronaves, sejam elas tripuladas ou não tripuladas; 
- Comparação: Avaliar e analisar diversas técnicas, ferramentas, metodologias e processos para o monitoramento das condições de pavimentação de rodovias;

- Resultado: Identificação dos processos, ferramentas, metodologias e técnicas para monitoramento das condições de pavimentação de rodovias, inclusive técnicas convencionais, que façam uso de aeronaves, satélites e/ou radares.

\section{A.1.3 Seleção das fontes}

Outro elemento importante na revisão sistemática são as fontes que permitiram obter os trabalhos relevantes na área. Sendo assim, foi selecionado o método de consulta a bases de dados indexadas online, por permitirem fácil acesso aos trabalhos.

Para definir as fontes de busca da revisão sistemática foram observados alguns critérios sobre as mesmas: Cobertura, Conteúdo Atualizado e Disponibilidade. Sobre a Cobertura, somente serão consideradas fontes de busca que retornem um número considerável de trabalhos. Mesmo retornando um grande número de trabalhos só serão considerados os que retornam trabalhos recentes sobre o tema (Conteúdo Atualizado). E por último, serão utilizadas apenas fontes que permitam o acesso de forma íntegra (Disponibilidade). Com base nos critérios foram escolhidas as seguintes bases de busca eletrônica:

- IEEEXplore Digital Library;

- ACM Digital Lybrary;

- Scopus;

- Springer;

- Transportation Research Board - TRB

Além das fontes é preciso estabelecer alguns critérios relacionados às consultas, como os idiomas que serão considerados. Nessa revisão sistemática serão considerados artigos em inglês, por ser a língua adotada internacionalmente para a escrita de trabalhos científicos, e o português, para incluir trabalhos brasileiros, o que permite valorizar o trabalho desenvolvido no país.

Já as palavras-chaves são escolhidas de modo a contemplar os trabalhos que respondam às questões da revisão. Além dos principais termos, também são considerados os seus possíveis sinônimos, listados da seguinte maneira:

- Veículos Aéreos Não Tripulados: unmanned aerial vehicles, UAV, unmanned aerial systems, UAS;

- Pavimentação de rodovias: road maintenance; pavements maintenance; 
- Conservação de rodovias: highway maintenance;

- Pavimentos asfálticos: paving, asphalt pavements;

- Sensoriamento Remoto: remote sensing, detecção remota.

\section{A.1.4 Seleção dos estudos}

De acordo com o protocolo, no planejamento também é necessário definir os critérios de seleção e os procedimentos de análise dos estudos, sendo esta a última etapa do planejamento.

Nesta etapa são definidos os critérios de inclusão e exclusão e os procedimentos para selecionar os estudos. Esses critérios são necessários para dar maior credibilidade à revisão sistemática e garantir que o foco seja mantido até o final da mesma. Já o procedimento para selecionar os estudos define como a etapa de seleção de trabalhos e de análise de resultados será efetuada.

Os critérios de inclusão (CIs) definidos para responder às questões levantadas foram:

- CI1 - estudos que apresentem técnicas e ferramentas para monitoramento de condições de monitoramento de pavimentos de rodovias, seja por meios convencionais ou por meio do uso de aeronaves, satélites e veículos não tripulados;

- CI2 - estudos que apresentem metodologias e processos para monitoramento de condições de monitoramento de pavimentos de rodovias, seja por meios convencionais ou de modo automatizado.

Tendo como base os objetivos da pesquisa, os seguintes critérios de exclusão (CEs) de trabalhos foram definidos:

- CE1 - estudos que não apresentem técnicas para o monitoramento e sim para a conservação ou a recuperação de pavimentos em rodovias;

- CE2 - estudos em que não seja possível o acesso na íntegra do artigo;

- CE3 - estudos que estejam em idiomas diferentes do inglês ou do português;

- CE4 - estudos que não sejam completos (resumos).

O processo de execução da revisão sistemática pode ser separado em quatro etapas. A primeira etapa é a criação de strings de busca com base nas palavras-chave definidas anteriormente e com o uso dos operadores "AND", utilizado para relacionar termos diferentes, e "OR", utilizado para agrupar termos sinônimos ou que representem técnicas diferentes. Essas strings de busca criadas foram aplicadas nas máquinas de busca selecionadas pelo processo de revisão. 
A segunda etapa trata da seleção preliminar dos artigos por meio da leitura dos títulos e resumos. Nessa etapa devem ser identificados os estudos duplicados e a seleção é baseada nos critérios de inclusão e exclusão. Os estudos identificados como repetidos, ou seja, duplicados, não foram verificados em relação aos critérios de inclusão e exclusão. Os estudos analisados que se enquadraram em algum dos critérios de exclusão estabelecidos na revisão foram colocados em uma lista de estudos excluídos. Por fim, os estudos que se enquadraram em algum critério de inclusão foram inseridos em uma lista com o seu respectivo critério de inclusão. Esses estudos foram analisados de maneira mais detalhada e lidos por completo.

Posteriormente foi realizada a terceira etapa do processo de seleção final com a leitura completa dos artigos não-excluídos e a extração inicial das principais informações por meio da elaboração de um resumo.

A quarta e última etapa trata da extração dos dados que abrangem técnicas, ferramentas, metodologias e processos para o monitoramento das condições da pavimentação de rodovias e suas características.

\section{A.2 Execução}

O processo de revisão sistemática descrito neste capítulo foi conduzido no período de 15/09/2015 e 20/11/2015. Para o gerenciamento das referências bibliográficas encontradas durante o processo de revisão utilizou-se as ferramentas Mendeley ${ }^{1}$ e StArt. Cabe ressaltar ainda que os resultados de busca foram obtidos quando realizados na rede da Universidade de São Paulo (USP), de modo que buscas fora da USP podem ocasionar resultados diferentes.

\section{A.2.1 Construção da string de busca}

A primeira etapa de criação de strings de busca foi realizada respeitando-se as especificações de cada base de dados, utilizando os operadores "AND" entre termos diferentes e "OR" para agrupar os sinônimos. Também restringiu-se as buscas dos termos no título e no resumo dos artigos, para garantir a relevância dos estudos com o objetivo da revisão. Apenas a base de dados da Springer Link não permitiu o uso dessa restrição devido a falta da opção de busca em títulos e resumos. As strings de busca criadas com os termos em inglês foram:

- IEEEXplore Digital Library - (((“Document title”:UAS OR “Document title”: Unmanned aerial system OR "Document title":UAV OR "Document title":Unmanned aerial vehicles) AND ("Document title":road maintenance OR "Document title":pavements maintenance OR "Document title":paving OR "Document title":asphalt pavements OR "Document title":highway maintenance OR "Document title":asphalt road OR "Document title”:pavements condition OR "Document title":road pavements) AND ("Document ti-

\footnotetext{
${ }^{1}$ Maiores informações a respeito da ferramenta Mendeley podem ser encontradas em www.mendeley.com
} 
tle":remote sensing OR "Document title":remote-sensing) AND ("Document title": Geographic Information System OR "Document title":GIS)) OR (("Abstract":UAS OR "Abstract”: Unmanned aerial system OR “Abstract”:UAV OR "Abstract”:Unmanned aerial vehicles) AND (“Abstract”:pavements maintenance OR "Abstract”:road maintenance OR “Abstract”:paving OR “Abstract”: asphalt pavements OR "Abstract": asphalt road OR "Abstract”: pavements condition OR “Abstract”: road pavements) AND (“Abstract”:Remote Sensing OR “Abstract": remote- sensing)));

- ACM Digital Library - Title:(UAS OR "Unmanned aerial system" OR UAV OR "Unmanned aerial vehicles") AND ("road maintenance" OR "pavements maintenance" OR paving OR "asphalt pavements" OR "highway maintenance" OR "asphalt road" OR "pavements condition" OR "road pavements") AND ("remote sensing” OR "remote-sensing") AND ("Geographic Information System" OR GIS) OR Abstract: (UAS OR "Unmanned aerial system" OR UAV OR "Unmanned aerial vehicles") AND ("pavements maintenance” OR "road maintenance" OR paving OR "asphalt pavements" OR "asphalt road" OR "pavements condition" OR “road pavements") AND (“Remote Sensing” OR ”remote-sensing”);

- Springer Link - (uas OR "unmanned aerial system" OR uav OR "unmanned aerial vehicles") AND ("road maintenance" OR "pavements maintenance" OR paving OR "asphalt pavements" OR "highway maintenance" OR "asphalt road" OR "pavements condition" OR "road pavements") AND ("remote sensing” OR "remote-sensing”);

- Scopus - TITLE-ABS-KEY((uas OR "unmanned aerial system” OR uav OR "unmanned aerial vehicles") AND ("road maintenance" OR "pavements maintenance" OR paving OR "asphalt pavements" OR "highway maintenance" OR "asphalt road" OR "pavements condition" OR "road pavements") AND ("remote sensing” OR "remote-sensing”));

- TRB - ((uas OR "unmanned aerial system" OR uav OR "unmanned aerial vehicles”) AND ("road maintenance" OR "pavements maintenance" OR paving OR "asphalt pavements" OR "highway maintenance" OR "asphalt road" OR "pavements condition" OR "road pavements") AND (“remote sensing” OR “remote-sensing”));

Já as strings de busca criadas com os termos em português foram:

- IEEEXplore Digital Library - ((“Document title”:SANT OR “Document title”:Sistema de aeronaves não tripuladas OR "Document title":VANT OR "Document title":Veículo aéreo não tripulado) AND ("Document title":pavimentação de rodovias OR "Document title":manutenção de rodovias OR "Document title":manutenção de pavimentos OR "Document title":conservação de rodovias OR "Document title":conservação de pavimentos OR "Document title":pavimentos asfálticos OR "Document title": pavimentos) AND (“Document title”:Sensoriamento Remoto OR "Document title”:Detecção Remota) OR 
(“Abstract”:SANT OR “Abstract”: Sistema de aeronaves não tripuladas OR "Abstract”: VANT OR “Abstract”: Veículo aéreo não tripulado tripulado) AND (“Abstract”:pavimentação de rodovias OR "Abstract”:manutenção de rodovias OR "Abstract”:manutenção de pavimentos OR "Abstract”: conservação de rodovias OR "Abstract”: conservação de pavimentos OR “Abstract”:pavimentos asfálticos OR “Abstract”:pavimentos) AND (“Abstract”:sensoriamento remote OR “Abstract”: detecção remota));

- ACM Digital Library - Title:(SANT OR "Sistema de aeronaves não tripuladas" OR VANT OR "Veículo aéreo não tripulado") AND ("pavimentação de rodovias" OR "manutenção de rodovias" OR "manutenção de pavimentos" OR “conservação de rodovias" OR "conservação de pavimentos" OR "pavimentos asfálticos” OR pavimentos) AND ("Sensoriamento Remoto" OR "Detecção Remota”) OR Abstract:(SANT OR "Sistema de aeronaves não tripuladas" OR VANT OR "Veículo aéreo não tripulado tripulado") AND ("pavimentação de rodovias" OR "manutenção de rodovias" OR "manutenção de pavimentos" OR “conservação de rodovias” OR “conservação de pavimentos” OR "pavimentos asfálticos" OR pavimentos) AND ("sensoriamento remote" OR "detecção remota");

- Springer Link - (SANT OR "Sistema de aeronaves não tripuladas" OR VANT OR "Veículo aéreo não tripulado") AND ("pavimentação de rodovias” OR "manutenção de rodovias" OR "manutenção de pavimentos" OR "conservação de rodovias" OR "conservação de pavimentos" OR "pavimentos asfálticos" OR pavimentos) AND ("Sensoriamento Remoto" OR “Detecção Remota”);

- Scopus - TITLE-ABS-KEY((SANT OR "Sistema de aeronaves não tripuladas" OR VANT OR "Veículo aéreo não tripulado") AND ("pavimentação de rodovias" OR "manutenção de rodovias" OR "manutenção de pavimentos" OR "conservação de rodovias" OR "conservação de pavimentos" OR "pavimentos asfálticos” OR pavimentos) AND (“Sensoriamento Remoto” OR “Detecção Remota”));

- TRB - TITLE-ABS-KEY((SANT OR "Sistema de aeronaves não tripuladas" OR VANT OR "Veículo aéreo não tripulado") AND ("pavimentação de rodovias" OR "manutenção de rodovias" OR “manutenção de pavimentos" OR “conservação de rodovias” OR "conservação de pavimentos" OR "pavimentos asfálticos" OR pavimentos) AND (“Sensoriamento Remoto” OR “Detecção Remota”)).

\section{A.3 Seleção de estudos}

As buscas efetuadas com os termos em português não retornaram nenhum resultado. Os resultados das buscas com os respectivos resumos dos artigos encontrados foram salvos no formato bibtex e importados na ferramenta StArt. Após a remoção dos artigos duplicados identificados pela ferramenta StArt, restaram um total de 74 artigos para a primeira seleção. A proporção de artigos encontrada em cada base de dados pode ser observada na Figura A.1. 


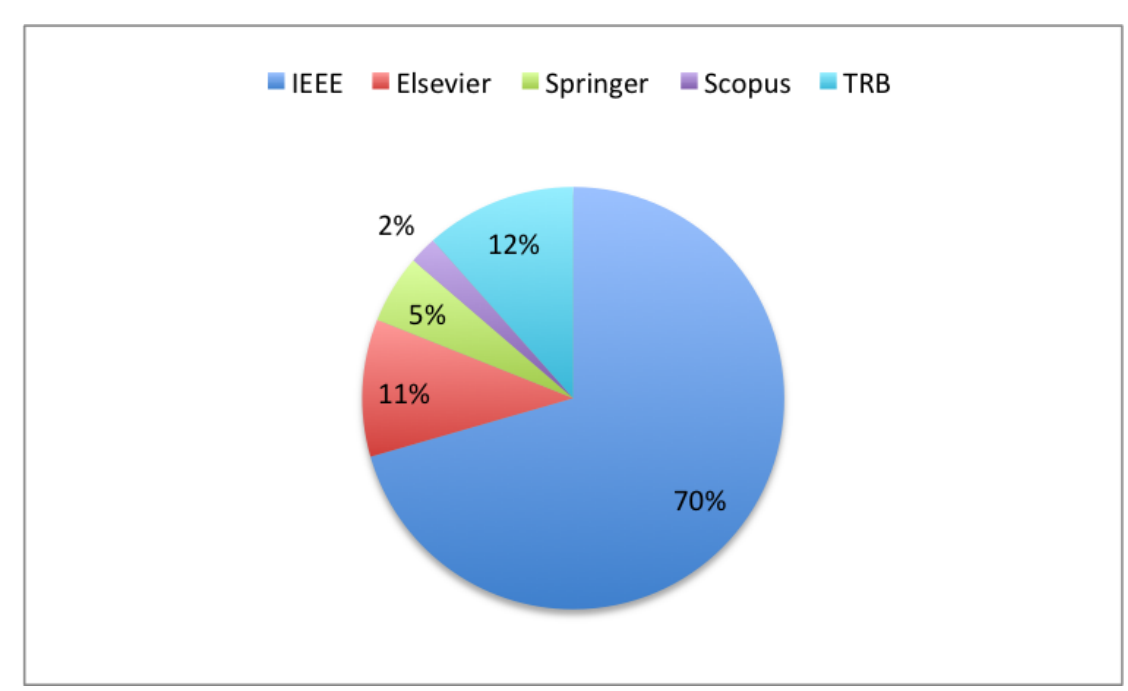

Figura A.1 - Quantidade de artigos encontrados nas bases de dados para a primeira seleção.

A primeira seleção foi realizada com a leitura dos títulos e dos resumos dos artigos, identificandose os critérios de inclusão ou exclusão para cada artigo. Os artigos aceitos foram aqueles que obedeceram ao menos um dos dois critérios de inclusão, enquanto os artigos rejeitados foram aqueles que obedeceram pelo menos um critério de exclusão. O número de artigos rejeitados e aceitos nessa fase podem ser observados no gráfico da Figura A.2.

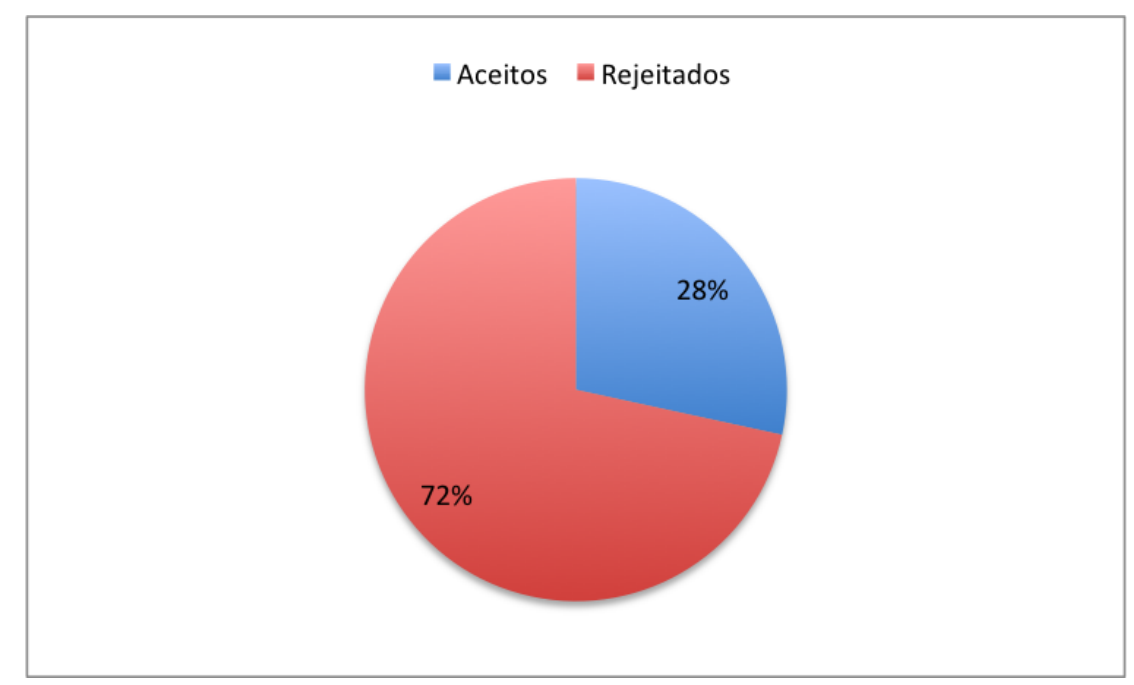

Figura A.2 - Quantidade de artigos aceitos e rejeitados durante a primeira seleção.

Já a segunda seleção foi realizada após a leitura dos artigos completos entre os aceitos na primeira seleção. Essa seleção foi realizada com base nos mesmos critérios da primeira seleção. Durante a leitura completa do artigo também foi produzido um resumo como resultado contendo as principais informações sobre a publicação. Após a seleção, foram classificados como aceitos um total de 27 artigos, e a proporção resultante em relação a cada base de dados pode ser observada na Figura A.3.

Na última etapa da revisão sistemática foi produzida uma síntese discursiva para relatar 


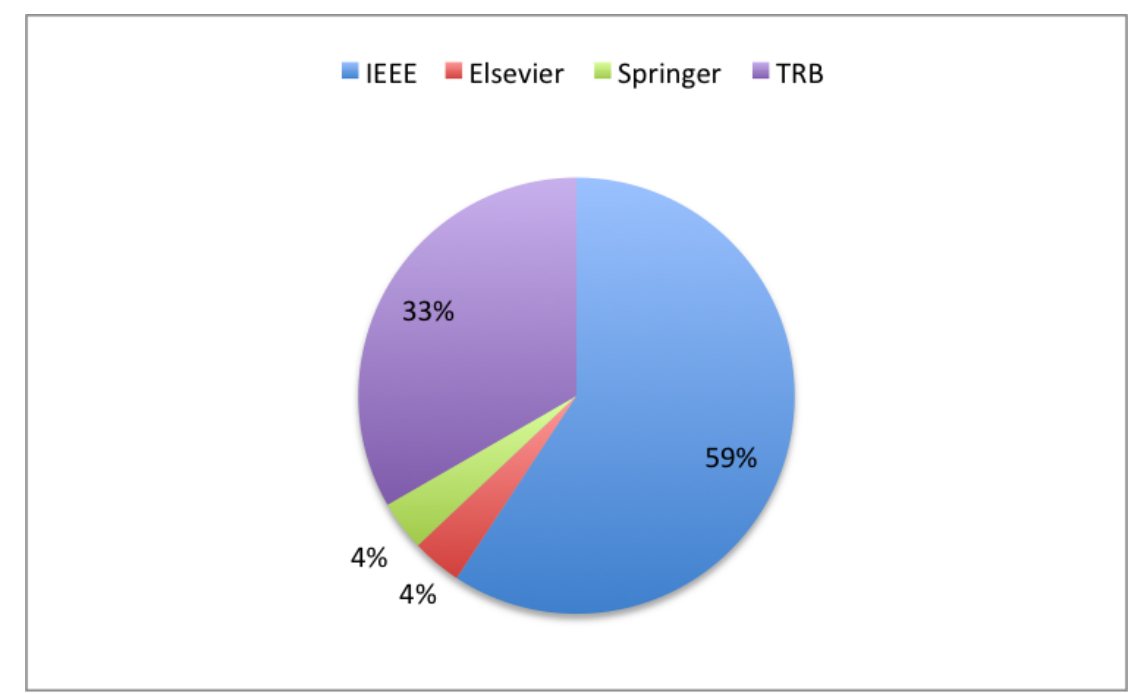

Figura A.3 - Quantidade de artigos aceitos em cada base de dados após a leitura completa dos trabalhos.

as técnicas encontradas e as informações dos projetos, que foi apresentada em detalhes no Capítulo 3. 